\title{
Consenso mexicano sobre diagnóstico y tratamiento del cáncer mamario
}

\section{Introducción}

El primer Consenso Nacional sobre Diagnóstico y Tratamiento del Cáncer Mamario se llevó a cabo en septiembre de 1994, en Colima; sus conclusiones se difundieron ampliamente ${ }^{1}$ y han sido útiles como guía para oncólogos y otros médicos generales y de especialidades afines. Desde entonces se han realizado nueve reuniones periódicas de revisión, en las que se actualizaron los conocimientos y la información disponibles, y se ampliaron las participaciones de otras subespecialidades y disciplinas relacionadas con el diagnóstico y tratamiento de esta enfermedad. Las conclusiones se presentaron en revistas especializadas ${ }^{2-9}$ y están disponibles por vía electrónica en la página del consenso (www.consensocancermamario. com) y en las de otras instituciones y sociedades de oncología.

Debido a que dichas publicaciones han tenido gran difusión y a que se han actualizado de manera constante, prácticamente todos los oncólogos del país están al tanto de las conclusiones del consenso y las utilizan como una herramienta de apoyo para la toma de decisiones en su práctica oncológica diaria. Forman parte, además, de las guías de varias instituciones oncológicas nacionales y de la documentación en la cual se basa la Norma Oficial Mexicana en la materia. ${ }^{10}$

En esta ocasión nos reunimos, ahora de manera virtual, 29 y 30 de enero del 2021, con el fin de revisar los avances recientes en el campo de la prevención, el diagnóstico y el tratamiento del cáncer mamario. Fueron convocados cerca de 105 médicos reconocidos a nivel nacional de todas las instituciones y especialidades relacionadas con esta enfermedad, quienes en grupos de trabajo analizaron la información actualizada de cada área, con objeto de presentarla al pleno para su aprobación. En esta ocasión se agregó el tema "COVID y cáncer de mama» debido a la pandemia por esta enfermedad y el impacto que ha tenido en la atención de las pacientes.

Cabe mencionar que se inscribieron para presenciar el consenso vía electrónica 1,570 participantes, de los que el $25 \%$ eran residentes, el $60 \%$ de provincia y más de 200 inscritos originarios de Centro y Sudamérica.

Esperamos que las conclusiones de esta novena revisión contribuyan como guía a la comunidad médica en general y a los oncólogos en particular, con el fin de que ofrezcan a los pacientes con esta enfermedad un diagnóstico preciso y un tratamiento óptimo y actualizado.

\section{Epidemiología del cáncer mamario en México}

\section{Introducción}

El cáncer de mama es el tumor maligno más frecuente en las mujeres en el mundo y la primera causa de muerte por cáncer. Se estiman alrededor de 1.7 millones de casos nuevos cada año y fallecen 522,000 mujeres por esa enfermedad. El $45 \%$ de los casos se presentan en países de bajos o de medianos recursos $(765,000)$ y el $55 \%$ del total de muertes por cáncer de mama ocurren en dichos países $(287,100)$. La tasa de mortalidad global es de $13.2 \times 100.000$ con rango de
Correspondencia:

Jesús Cárdenas Sánchez

E-mail: jescardenas@ @otmail.com
Fecha de recepción: 15-06-2021

Fecha de aceptación: 08-07-2021 DOI: 10.24875/j.gamo.M21000213
Disponible en internet: 30-09-2021 Gac Mex Oncol. 2021;20(Suppl 2):1-105 www.gamo-smeo.com 2565-005X/@ 2021 Sociedad Mexicana de Oncología. Publicado por Permanyer. Este es un artículo open access bajo la licencia CC BY-NC-ND (http://creativecommons.org/licenses/by-nc-nd/4.0/). 


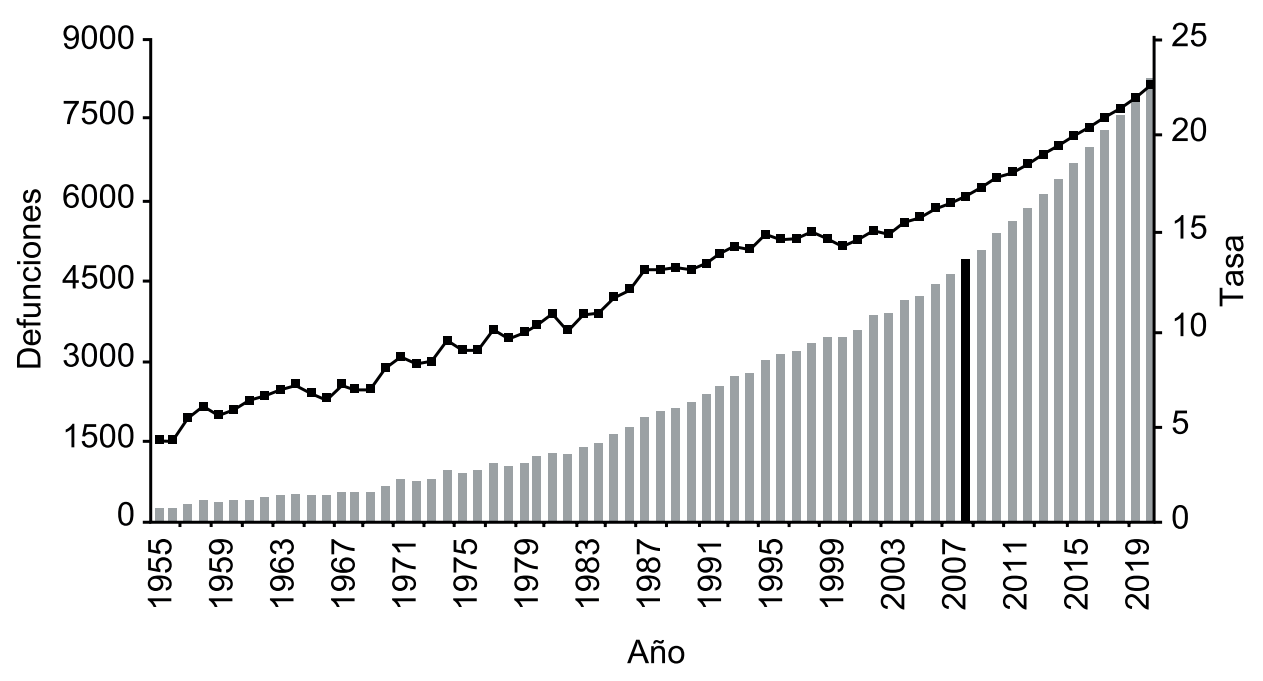

Figura 1. Tendencia de la mortalidad y números de casos por cáncer de mama en México, 1955-2007 y proyección 2008-2020.

*Tasa cruda por 100,000 mujeres de 25 años y más.

Fuente: Bases de Datos OMS, INEGI, SSA. 1955-2007.

8.8 en Asia hasta 19.7 en Europa occidental. ${ }^{1}$ En América Latina, desde el año 2000 la Organización Mundial de la Salud (OMS) reportó que la principal tendencia era el incremento del cáncer de mama. En el 2008, la Organización Panamericana de la Salud (OPS) informó que se diagnosticaron en esta área 320,000 , casos y se estimó para 2030 un incremento del $60 \% .^{2,3}$

En México el cáncer de mama ha tenido un incremento constante, tanto en su incidencia como en su mortalidad, en las últimas tres décadas. De acuerdo con el informe del Departamento de Epidemiología de la Secretaría de Salud, la incidencia se incrementó entre 2000 y 2013, llegando de 10.76 casos por 100,000 habitantes a 26.1 por cada 100,000 mujeres mayores de 25 años, estimando 23,873 nuevos casos en $2013 .{ }^{4}$ Es evidente el incremento, pero obviamente debió existir un subregistro que explique una diferencia tan sustancial (Figura 1). En ello han influido factores como el envejecimiento poblacional, la «occidentalización» del estilo de vida, la educación e información deficientes relativas a la enfermedad, la carencia de un programa nacional de detección oportuna, la dilación en la atención en las instituciones públicas, así como la insuficiencia de recursos humanos, materiales y técnicos para el tratamiento, conjuntamente con la carencia de unidades mamarias especializadas.

En México ha habido un incremento constante en la esperanza de vida desde la década de 1970, llegando a tener las mujeres una media de edad de 77 años y los hombres de 75 años. Esto ha ocasionado un envejecimiento poblacional, incorporando cada año un número importante de mujeres a la edad de riesgo (> 40 años), calculando que en 2020 haya alrededor de 30 millones de mujeres en ese grupo ${ }^{5}$ (Figura 2).

No obstante que el cáncer de mama en México se diagnostique a una media de edad de 52.5 años, una década inferior a la población de América del Norte y Europa occidental, $, 7,7$ la incidencia aumenta proporcionalmente al incremento en la edad, lo que nos hace prever que solamente por el envejecimiento de la población, habrá también un aumento sustancial en el número de casos de cáncer de mama en los próximos años. Además, en nuestra población el cáncer de mama en mujeres menores de 40 años es más frecuente $(13.3 \%)$ que en la población norteamericana o europea. ${ }^{6}$

\section{Impacto económico de la enfermedad}

No solo está dado por el alto costo de los procedimientos diagnósticos y los tratamientos, sino porque afecta a las mujeres en etapas productivas de la vida. El costo del tratamiento es mucho más alto en las etapas localmente avanzadas y metastásicas, que son las que predominan en nuestro país. ${ }^{1}$ El Instituto Nacional de Salud Pública calculó que cada mujer que muere por cáncer de mama equivale a 21 años de vida saludable perdida (AVISAP), lo que representa un costo 


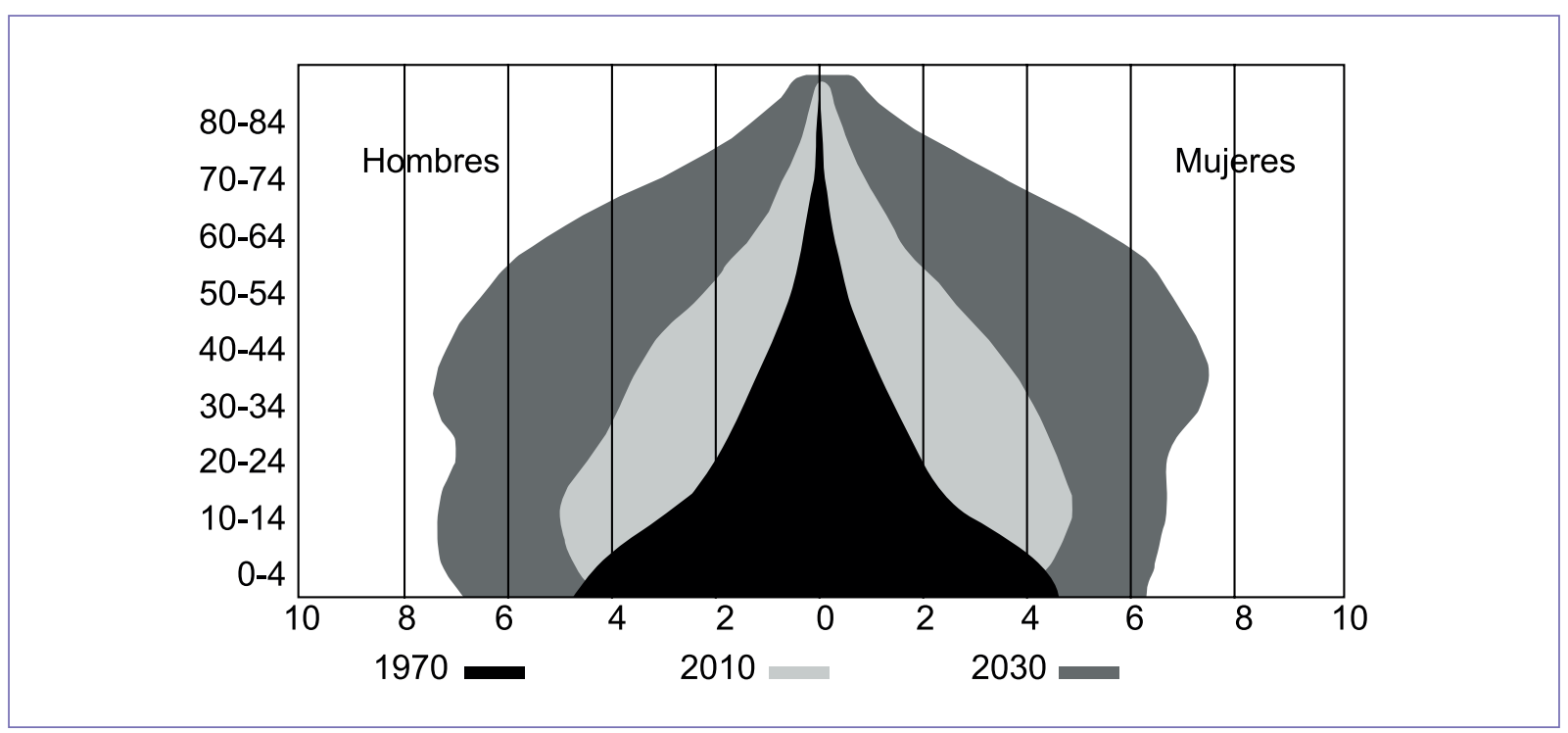

Figura 2. Pirámide de población 1970-2030.

económico tremendo para el país, además del impacto familiar y social de la falta de una madre, con hijos habitualmente adolescentes o jóvenes. ${ }^{8}$

Existen diferencias importantes en la incidencia y mortalidad de la enfermedad entre los Estados del norte y centro de la República Mexicana y los Estados del sureste, con mayor porcentaje de población indígena.

Esto se debe, entre otras razones, al cambio del estilo de vida de la población, que ha adoptado el modelo occidental, donde las mujeres en general tienen un nivel de escolaridad más alto y trabajan fuera del hogar, con mayor ingesta de grasas animales, tabaco y alcohol, sedentarismo y sobrepeso, retraso en el inicio de la reproducción, con primer embarazo tardío (> de 30 años) y ausencia de lactancias, además de uso de agentes hormonales en la menopausia. Esto ocasiona que el cáncer de mama incremente su incidencia en las zonas donde las mujeres tengan esas características, mientras que en los Estados menos desarrollados, donde las mujeres siguen con los trabajos habituales de casa, donde no tienen recursos para comer grasas animales y trabajan físicamente en el campo, tienen hijos a temprana edad y los amamantan por periodos prolongados, la enfermedad es menos frecuente, pero, paradójicamente, cuando se presenta, la baja educación, la carencia de recursos económicos y de cobertura de servicios de salud, ocasiona que la mortalidad sea más elevada (Figura 3).

A partir del 2007, el extinto Seguro Popular incorporó al cáncer de mama al programa de «Gastos
Catastróficos", lo que garantizó el acceso gratuito al tratamiento integral de esa enfermedad a los pacientes no derechohabientes de seguridad social. No obstante, en nuestro país se diagnostica la enfermedad en etapas localmente avanzadas (IIb-III) en el $55.9 \%$ y el $10.5 \%$ en etapa metastásica (IV) (Figura 4) concluyendo que, si bien el acceso universal al tratamiento es eficiente, todavía no hemos logrado mejorar la detección temprana. A ese respecto, recientemente el Instituto Mexicano del Seguro Social (IMSS) ha creado varios centros de diagnóstico de cáncer de mama y la Secretaría de Salud ha implementado unidades denominadas DEDICAM en varios Estados de la república, sin conocer aún el impacto de estas. Debemos orientar el mayor esfuerzo a tratar de detectar el cáncer de mama en la etapa más temprana de la enfermedad. ${ }^{8-10}$

Coahuila Colima Sonora Jalisco CDMX Nuevo León Aguascalientes Chihuahua Sinaloa Baja California Morelos Baja California Sur Durango Tamaulipas Zacatecas Michoacán Querétaro Veracruz Guanajuato Nayarit San Luis Potosí México Hidalgo Puebla Tlaxcala Yucatán Tabasco Chiapas Guerrero Quintana Roo Campeche Oaxaca

\section{Información y factores de riesgo}

\section{Introducción}

La incidencia de cáncer de mama varía alrededor del mundo, y existen diversos factores de riesgo que deben ser abordados desde la prevención y promoción 


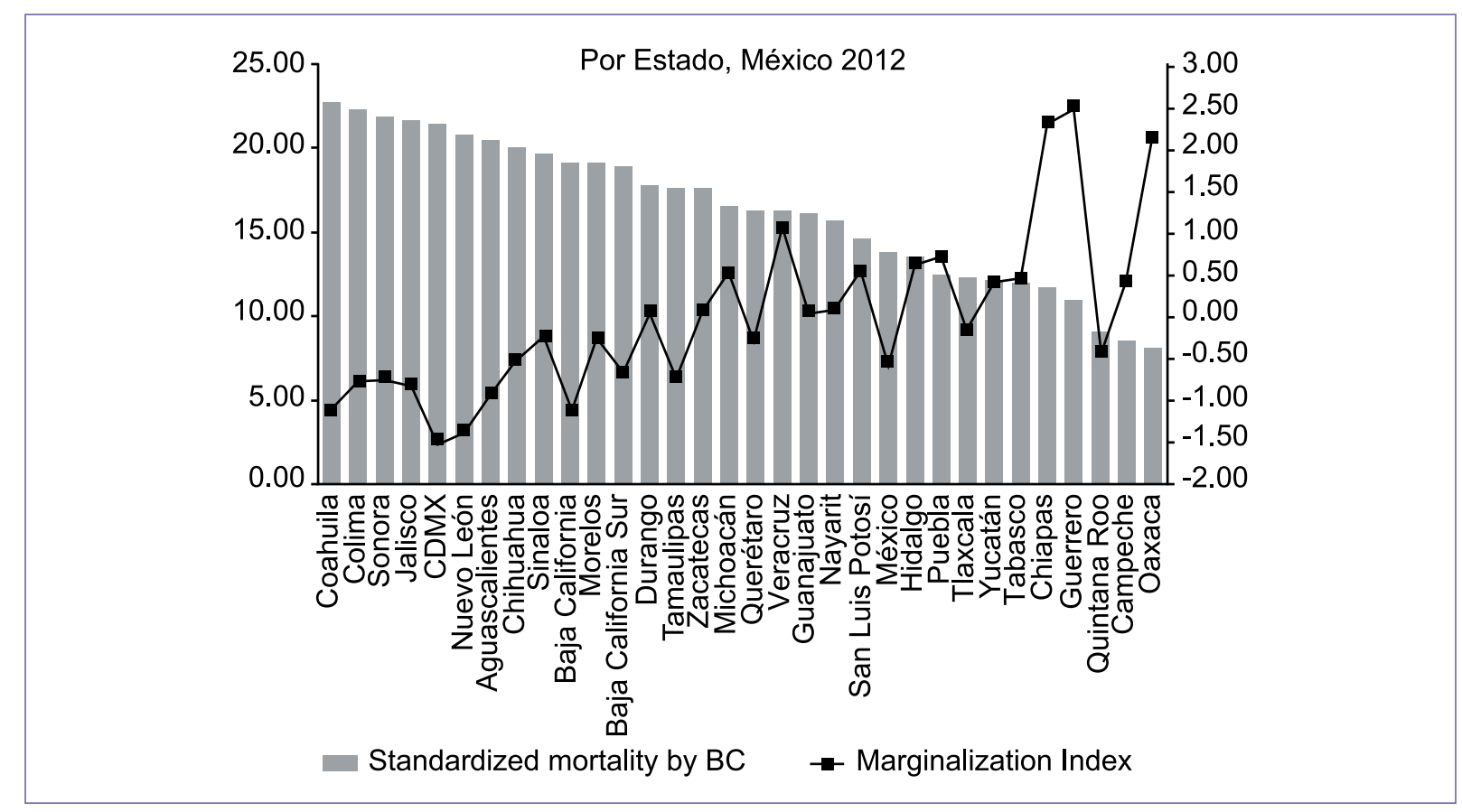

Figura 3. Cáncer de mama. Mortalidad e índice de marginalización en mujeres de 25 años o mayores, por Estado Federativo. México 2004-2012.

Standardized mortality by BC Marginalization Index.

Fuente: Ventura-Alfaro CE. Salud Pública de México. 2016;58(2):194.

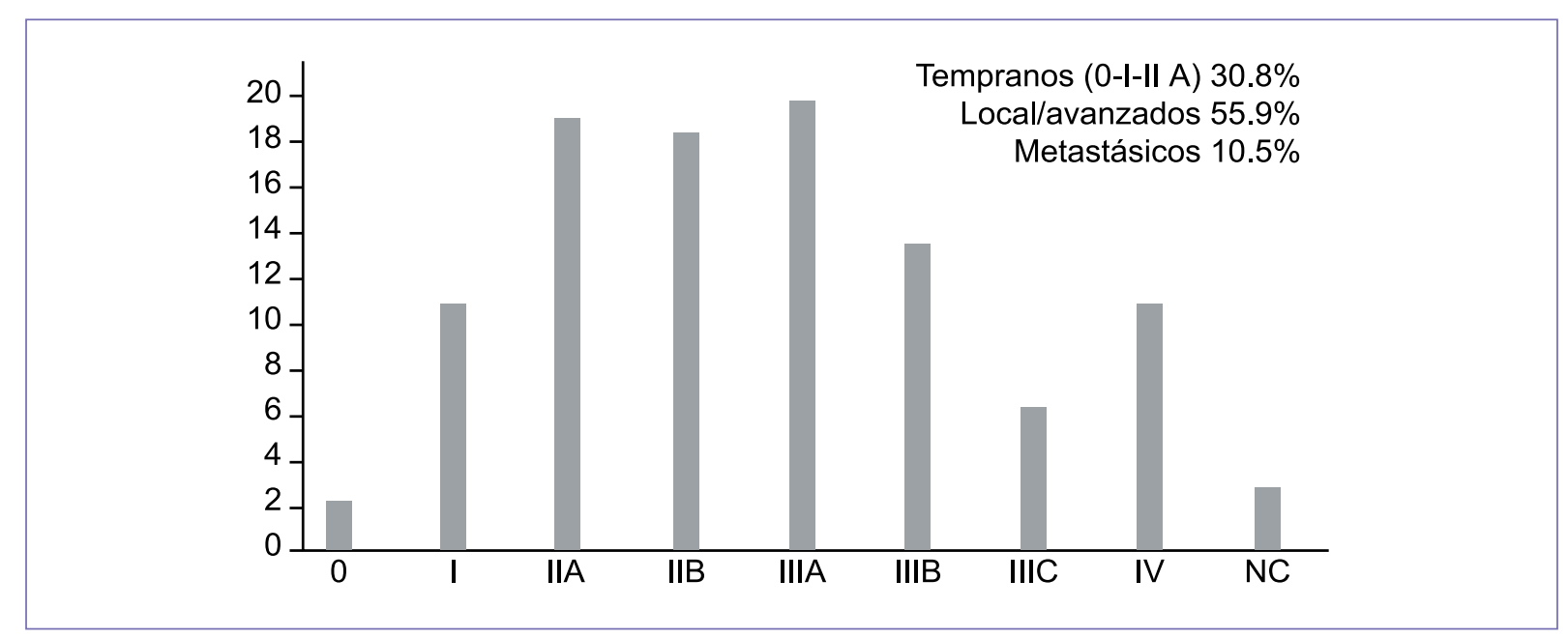

Figura 4. Etapas al diagnóstico en el Seguro Popular 2015.

Fuente: Secretaría de Salud México. Seguro Popular. Informe sobre cáncer de mama, 2015.

de la salud. ${ }^{1}$ Los objetivos internacionales del desarrollo sostenible, propuestos por la Organización Mundial de la Salud (OMS), apuntan a garantizar una vida sana mediante la promoción del bienestar para todas las personas de todas las edades, con igualdad de género. ${ }^{2}$ En el tema específico de cáncer de mama, se ha establecido que las intervenciones comunitarias dirigidas a personas adultas, pueden impactar sobre la detección temprana y la prevención primaria. ${ }^{3}$

Las actividades de prevención incluyen comunicación educativa, para que se reconozcan los factores de riesgo y promoción de estilos de vida sanos, ya que la falta de actividad física y la obesidad aumentan la posibilidad de desarrollar, de forma esporádica, cáncer 
de mama. Recomendamos que la educación sobre el cáncer de mama se dirija a sensibilizar a las mujeres para conocer las características normales de sus mamas, buscar atención médica oportuna si descubren alguna anormalidad y acudir periódicamente al médico para revisiones clínicas y radiológicas (ver Capítulo V. Estudios de tamizaje). ${ }^{4,5}$

Adicionalmente, para fomentar la prevención primaria y la detección oportuna es fundamental la inclusión de líderes comunitarios (gobernantes, maestros) en los programas, así como la capacitación de los médicos de primer contacto. Las intervenciones educativas pueden implementarse en contextos comunitarios, incluyendo los lugares de trabajo, las clínicas de atención primaria y las escuelas. ${ }^{5,6}$ Asimismo, se sugiere incluir la materia de oncología en los programas de las facultades de medicina, y capacitar a médicos en formación sobre la detección oportuna del cáncer de mama.

Las desigualdades en el acceso a la atención médica para el cáncer de mama se reflejan en las estadísticas de años de vida perdidos, por muerte prematura y pérdida en la calidad de vida por discapacidad, por lo que se deben implementar acciones específicas y sistematizadas para la identificación de factores de riesgo, la detección, el diagnóstico temprano y la referencia oportuna. ${ }^{7}$

\section{Factores de riesgo}

Los factores de riesgo conocidos para el desarrollo del cáncer de mama se enumeran a continuación. 3,7,8

\subsection{BıLLóGICOS}

- Mujer.

- Edad avanzada.

- Historia personal o familiar de cáncer de mama (en familiares de primer grado).

- Antecedentes de hiperplasia ductal atípica, imagen radial o estrellada y carcinoma lobulillar in situ.

- Vida menstrual mayor de 40 años (menarquia antes de los 12 años y menopausia después de los 52 años).

- Densidad mamaria.

- Ser portador/a de mutaciones en genes de susceptibilidad a cáncer de mama.

\subsection{Asociados al tRATAMIENTO DE ENFERMEDADES PREVIAS}

- Exposición a radiación ionizante terapéutica torácica, principalmente durante el desarrollo o el crecimiento.

\subsection{REPROdUCTIVOS}

- Nuligesta.

- No lactar.

- Primer embarazo a término después de los 30 años de edad.

- Terapia hormonal con estrógeno y progesterona combinados, en la perimenopausia o posmenopausia por más de cinco años.

\subsection{Relacionados con el estilo de Vida}

- Obesidad.

- Sedentarismo.

- Consumo de alcohol.

- Tabaquismo.9-11

El factor de riesgo más importante relacionado con el estilo de vida es la obesidad y, dado que en México esta condición se encuentra presente en un porcentaje muy elevado de la población, representa un serio problema de salud pública con alto impacto en la sociedad. Las mujeres obesas posmenopáusicas poseen un riesgo mayor de padecer cáncer de mama, en comparación con las no obesas, lo cual parece deberse a niveles altos de estrógenos circulantes. Adicionalmente, las supervivientes de cáncer de mama que desarrollan obesidad tienen un mayor riesgo de recurrencia 0 de segundos primarios. ${ }^{12-15}$

Una circunferencia de cintura mayor de 80 centímetros se asocia con un aumento del riesgo de cáncer de mama; por otro lado, una edad de menarquia temprana asociada a estados de obesidad mórbida es otro de los factores de importancia en la génesis de esta patología. La atención de la paciente con obesidad debe incluir modificaciones dietéticas, promoción de actividad física, componentes de cambio de comportamiento y seguimiento a largo plazo. ${ }^{15}$

\section{Recomendaciones generales de actividad física}

Los Centers for Disease Control and Prevention (CDC) de Estados Unidos indican:

- Realizar 150 minutos semanales de ejercicio aeróbi$\mathrm{co}$, de intensidad moderada (caminata o ciclismo).

- Efectuar 75 minutos por semana, de actividad aeróbica de intensidad vigorosa (correr, trotar, saltar, nadar).

La motivación es fundamental para lograr una adecuada adherencia al tratamiento y para mantener sus efectos a largo plazo. La inclusión de actividades físicas en la comunidad ayuda a prevenir las enfermedades 
crónicas en general, y tales actividades son protectoras para cáncer de mama, por lo que su importancia debe difundirse por los medios masivos (incluyendo las redes sociales) a toda la población, con particular énfasis en poblaciones de alto riesgo.

\section{Prevención primaria del cáncer mamario}

\section{Terapia reductora de riesgo}

Los criterios aplicados en los estudios para considerar a mujeres en alto riesgo como candidatas a quimioprevención incluyen: ${ }^{1}$

- Edad > 60 años.

- Edad de 35 a 59 años con riesgo en el modelo de Gail de cáncer de mama $\geq 1.66 \%$ en 5 años.

- Edad $\geq 35$ años con antecedentes de carcinoma lobulillar o ductal in situ, hiperplasia atípica ductal o lobulillar.

- Portadoras de mutaciones BRCA-1, BRCA-2 sin mastectomía profiláctica. ${ }^{2}$

\section{Intervención farmacológica}

En mujeres en alto riesgo ${ }^{1,2}$ se recomienda el empleo de los siguientes agentes:

- Tamoxifeno a dosis de $20 \mathrm{mg}$ por día en premenopáusicas y posmenopáusicas o raloxifeno a dosis de $60 \mathrm{mg}$ por día en posmenopáusicas por un tiempo de 5 años, con base en los estudios P-1 (NSABP), RUTH 4, MORE 4, CORE, STAR 2, IBIS-I. Su uso mostró reducción del riesgo de carcinoma ductal invasor y fueron aprobados para este fin., ${ }^{1,-10}$ No hay estudios aleatorizados para pacientes menores de 35 años.

- Dosis bajas de tamoxifeno (5 mg cada 24 horas por 3 años) en pacientes sintomáticas con la dosis estándar de $20 \mathrm{mg}$, puede ser una opción. ${ }^{11}$

- Inhibidores de aromatasa (IA) en pacientes posmenopáusicas. El exemestano (estudio MAP-33) y el anastrozol (IBIS-II6) mostraron reducción del riesgo de cáncer de mama invasor. ${ }^{12,13}$ Estos agentes aún no han sido aprobados por agencias regulatorias para esta indicación.

Para decidir el uso de medicamentos reductores de riesgo deben tomarse en cuenta otros factores que pudieran contraindicarlos; en el caso del tamoxifeno, la historia de eventos tromboembólicos 0 de hiperplasia atípica de endometrio, y para el de un IA, osteopenia importante u osteoporosis.
Intervención quirúrgica: ver el Capítulo X. Mastectomía reductora de riesgo.

\section{Diagnóstico temprano. Evaluación de la mama por imagen}

\section{Estudios de tamizaje}

Recomendaciones generales:

- Autoexamen mamario mensual a partir de los 18 años (7 días después de terminada la menstruación).

- Examen clínico mamario anual a partir de los 25 años.

- Mastografía anual de tamizaje en mujer asintomática a partir de los 40 años.

- El ultrasonido (US) mamario es el estudio de elección inicial en mujeres menores de 35 años con patología mamaria.

- El uso de mastografía de detección en mujeres con mama densa aunada a US aumenta la sensibilidad al $87 \% .^{2}$

\section{Estudios de imagen}

El uso de los estudios de imagen como la mastografía, el US, la resonancia magnética (RM) y más recientemente los moleculares permiten detectar, caracterizar, evaluar la extensión de la enfermedad y dar seguimiento a las lesiones mamarias.

El estándar de referencia para el diagnóstico del cáncer de mama es el estudio histopatológico. Las biopsias percutáneas con aguja de corte y los sistemas de aspiración con guía estereotáxica o por US son los métodos de elección en lesiones no palpables y palpables con sospecha de malignad. En los casos donde las lesiones son visibles únicamente por RM o estudios moleculares, la biopsia se efectuará por medio de estos métodos.

\subsection{Mastografía}

La mastografía es el único método de imagen que ha demostrado disminución en la mortalidad por cáncer de mama en un $21 \%$; en países con ingresos altos se ha observado que el tamizaje organizado, de base poblacional, reduce la mortalidad en cifras superiores al $30 \%{ }^{3}$

La mastografía tiene una sensibilidad diagnóstica del 77 al $95 \%$ y especificidad del 94 al $97 \%$, siendo dependientes de la densidad mamaria. ${ }^{4}$ 
Aunque estos datos son significativos, la decisión de iniciar y/o mantener un programa de cáncer de mama requiere una evaluación de la relación costo-efectividad del tamizaje; la mastografía favorece el diagnóstico temprano y el uso de terapias efectivas contra el cáncer mamario mejora la supervivencia global de las pacientes y reduce el impacto económico por años de vida perdidos.

Es importante considerar que la mastografía de tamizaje puede ocasionar sobrediagnóstico y tratamientos innecesarios (20\%), ansiedad en las mujeres y cáncer inducido por radiación (uno en mil mujeres tamizadas). ${ }^{5}$

A la fecha hay diferentes técnicas de adquisición en mastografía:

- Adquisición convencional. El mastógrafo es analógico y la adquisición de las imágenes se realiza con el sistema pantalla-película, lo que además necesita un equipo dedicado de revelado automático.

- Adquisición digital. Por medio de detectores integrados al propio mastógrafo (digital) o detectores externos (digitalizada, computed radiography [CR]); la impresión del estudio se realiza con un equipo láser de alta resolución.

\subsubsection{Mastografía digital}

Emplea un detector digital. La adquisición, el procesamiento y la visualización de la imagen se manejan de forma independiente, lo cual representa una mayor ventaja en relación con el sistema analógico, asimismo se reduce el porcentaje de repeticiones debido al constante control de calidad de la imagen, lo cual reditúa en una mayor productividad y menor dosis de radiación ionizante.

La mastografía digital, desde el punto de vista clínico, incrementa la detección del cáncer de mama en paciente con mamas densas, las cuales son un factor de riesgo reconocido para cáncer de mama y puede mejorar la visualización de microcalcificaciones. ${ }^{6}$

La mastografía digital tiene capacidad para aplicaciones avanzadas tales como:

- Telemastografía. Es una herramienta que permite el envío de las imágenes para su interpretación o consulta a distancia.

- Mastografía con tomosíntesis o tridimensional (3D). Se obtienen múltiples imágenes desde diferentes ángulos. Mejora la detección de cáncer de mama en un $27 \%$ y disminuye el número de rellamadas en programas de tamizaje en un $17.2 \% .7,8$

- Mastografía sintetizada. Es una técnica que consiste en obtener imágenes tridimensionales y a partir de ellas las bidimensionales, por lo cual se reduce la dosis de radiación en un 39\%. Una de las ventajas de la mastografía sintetizada es que mejora la visibilidad de las distorsiones de la arquitectura, masas y microcalcificaciones. ${ }^{9}$

- Biopsia por estereotaxia con tomosíntesis. Cuando se encuentra una distorsión de la arquitectura, sin traducción en US, la biopsia debe guiarse con sistema corte-aspirado y estereotaxia integrada con tomosíntesis, ya que generalmente se trata de carcinomas invasores.

- Sistema de detección asistida por computadora (CAD). En general, son sistemas que orientan en la detección de tumores en una imagen médica, al funcionar como un segundo lector. En mastografía se han diseñado diversos métodos de segmentación o extracción de las características de los tumores mamarios. La evaluación del rendimiento de los sistemas CAD en mastografía indica que su sensibilidad es alta, pero también el número de falsos positivos, lo que reduce su especificidad. ${ }^{10}$

- Mastografía contrastada. Estudio funcional que combina la mastografía convencional con administración intravenosa de medio de contraste. Existen dos modalidades temporal y dual. Su finalidad es detectar tumores de pequeño tamaño, lo cual permite la visualización de hallazgos con captación del medio de contraste sobre el tejido glandular normal que no presenta realce, siendo de gran utilidad en mamas densas y en pacientes con contraindicación o alternativa a la RM con resultados similares. ${ }^{11}$

Sin importar el tipo de técnica de mastografía empleada, debe existir un programa de garantía de calidad que involucra el área física, el equipamiento y al personal. La toma de los estudios de mama deberá realizarse por personal técnico radiólogo entrenado y la interpretación por médicos radiólogos certificados y con experiencia en esta área.

La mastografía deberá ser interpretada y la conclusión emitida en sistema BI-RADS (breast imaging reporting and data system) (Tabla 1) ${ }^{9,12}$

\subsubsection{Mastografía diagnóstica}

Se efectúa en caso de una mastografía de detección anormal y en las siguientes situaciones: ${ }^{14}$

- Mama densa.

- Lesiones mamarias detectadas con otra modalidad de imagen y en las que clínicamente se requiera este estudio.

- Masa o tumor palpable. 
Tabla 1. Sistema BI-RADS ${ }^{13}$

\begin{tabular}{|c|c|c|}
\hline Categoría & & Recomendaciones \\
\hline 0 & $\begin{array}{l}\text { Insuficiente para diagnóstico } \\
\text { Existe un } 13 \% \text { de posibilidad } \\
\text { de malignidad }\end{array}$ & $\begin{array}{l}\text { Se requiere evaluación con imágenes mastográficas adicionales u } \\
\text { otros estudios (US), así como la comparación con estudios previos } \\
\text { Esta categoría no debe de ser utilizada como indicación para } \\
\text { realización de RM }\end{array}$ \\
\hline 1 & $\begin{array}{l}\text { Negativo } \\
\text { Ningún hallazgo que reportar }\end{array}$ & Mastografía anual en mujeres a partir de los 40 años \\
\hline 2 & Hallazgos benignos & Mastografía anual en mujeres a partir de los 40 años \\
\hline 3 & $\begin{array}{l}\text { Hallazgos probablemente benignos. Menos del } 2 \% \\
\text { de probabilidad de malignidad }\end{array}$ & $\begin{array}{l}\text { Requiere seguimiento por imagen, unilateral del lado con hallazgos } \\
\text { dudosos a los } 6 \text { meses y posteriormente anual bilateral por } 2 \text { años, } \\
\text { esta categoría solo se recomienda en mastografía diagnóstica }\end{array}$ \\
\hline 4 & $\begin{array}{l}\text { Hallazgos de sospecha } \\
\text { de malignidad. Se subdivide en: } \\
\text { 4a - Baja sospecha de malignidad } \\
\text { 4b - Moderada sospecha para malignidad } \\
\text { 4c - Alta sospecha para malignidad }\end{array}$ & $\begin{array}{l}4(>2 \mathrm{a}<95 \%) \\
4 \mathrm{a}(>2 \mathrm{a} \leq 10 \%) \\
4 \mathrm{~b}(>10 \mathrm{a} \leq 50 \%) \\
4 \mathrm{c}(>50 \% \mathrm{a} \leq 95 \%) \\
\text { Requiere biopsia }\end{array}$ \\
\hline 5 & Altamente sugestivo de malignidad & Requiere biopsia. VPP > 95\% \\
\hline 6 & Con diagnóstico histológico de malignidad & $\begin{array}{l}\text { En espera de tratamiento definitivo } \\
\text { o valoración de respuesta a tratamiento }\end{array}$ \\
\hline
\end{tabular}

BI-RADS: breast imaging reporting and data system; US: ultrasonido; RM: resonancia magnética; VPP: valor predictivo positivo.

Fuente: American College of Radiology, 2013.

- Secreción sanguinolenta por el pezón.

- Cambios en la piel del pezón o la areola.

- Dolor focal persistente.

- Seguimiento de BI-RADS 3.

\subsubsection{Indicaciones especiales de mastografía}

- Mujer joven con sospecha clínica de cáncer mamario, independientemente de su edad.

- Historia familiar de cáncer en edades tempranas, se indicará la mastografía anual a partir de los 30 años o 10 años antes de la edad del familiar más joven con cáncer (no antes de los 25 años), deberá considerarse la RM contrastada anual alternando con la mastografía.

- Antecedentes de biopsia mamaria con reporte histológico de lesiones de alto riesgo. ${ }^{15}$

\subsection{ULtRASONIDO MAMARIO}

EI US es una valiosa herramienta complementaria de la mastografía diagnóstica. Se requieren equipos de alta resolución, además de experiencia y conocimiento de la anatomía, la patología de la glándula mamaria y su evaluación por US; debe realizarse con transductor lineal de alta frecuencia, banda ancha y zona focal variable (ideal entre 10 y $23 \mathrm{MHz}$ ). ${ }^{16}$
EI US dirigido es complemento de la mastografía diagnóstica por su utilidad para diferenciar nódulos quísticos de sólidos y, de estos, los benignos de los malignos, el estatus de la vascularidad y elasticidad de un tumor; es de utilidad en la etapificación inicial del cáncer mamario, debido a que evalúa multifinalidad, multicentricidad, extensión o componente intraductal, estado ganglionar tanto de axila como región supraclavicular e infraclavicular y paraesternal, lo que puede condicionar modificaciones en el tratamiento hasta en un $28 \% .^{17}$

EI US de tamizaje está indicado en pacientes con mama densa y mastografía negativa. ${ }^{17,18}$

Indicaciones clínicas del US mamario:

- Evaluación de anormalidades palpables y aquellas detectadas en mastografía y RM.

- Evaluación de implantes mamarios.

- Guía de procedimientos intervencionistas.

- Planeación del tratamiento de radioterapia.

- Evaluación de ganglios axilares.

En mujeres con tejido mamario denso, el US de tamizaje puede detectar carcinomas mastográficamente ocultos ( 1.9 a 4.2 cánceres adicionales por cada 1,000 mujeres examinadas). ${ }^{19,20}$ Numerosos estudios han comprobado que en estos casos el US demuestra adicionalmente de dos a cinco carcinomas ocultos por 1,000 mujeres. Usualmente los tumores ocultos en las 
mastografías y detectados en US son invasivos y con ganglios negativos. La densidad mamaria es un factor importante en la detección y diagnóstico del carcinoma mamario, ya que disminuye su sensibilidad; además, representa un aumento significativo del riesgo para desarrollar dicha patología (4.7 veces mayor que en las mujeres con mamas grasas). Algunas lesiones detectadas en RM son mastográficamente ocultas, pero pueden encontrarse mediante US dirigido (segunda revisión intencionada), esta recomendación también es válida para los estudios moleculares.

La modalidad de visión extendida del US mamario es útil para medir lesiones de gran tamaño y valorar multifocalidad.

El papel del radiólogo en la etapificación del cáncer de mama es demostrar antes de un procedimiento quirúrgico la presencia de metástasis axilares con un valor predictivo positivo, que sea lo suficientemente alto para permitir al cirujano decidir cuándo realizar disección axilar. La presencia de metástasis axilares y el tamaño del tumor primario son dos factores pronósticos para evaluar a los pacientes con cáncer de mama invasor y determinan el uso de quimioterapia sistémica y radioterapia. A las pacientes con ganglios negativos T1 y T2 se les efectúa ganglio centinela. ${ }^{21}$

EI US es la herramienta básica para evaluar ganglios axilares; tiene una sensibilidad moderada, pero puede ser sumamente específico, en especial cuando los criterios morfológicos están afectados.

Hallazgos como la pérdida del hilio graso y vascularidad periférica son criterios más importantes que el tamaño del ganglio para identificar metástasis. El engrosamiento cortical focal o difuso se considera el signo más temprano para identificarlas, pero es un criterio difícil de aplicar y con un valor predictivo bajo porque no es específico. Se puede evaluar de forma subjetiva o específica midiendo el espesor de la corteza, la cual debe ser menor a $3 \mathrm{~mm} .{ }^{22}$

Los ganglios linfáticos con morfología sospechosa por imagen se someten a biopsia por aspiración con aguja fina (BAAF) o biopsia con aguja de corte para evitar riesgo anestésico, tiempo quirúrgico y mayor costo. En el diagnóstico, la BAAF ha reportado una sensibilidad del 25 al $87 \%$; la biopsia con aguja de corte, del 90 al $94 \% .{ }^{23}$

\subsection{RESONANCIA MAGNÉTICA}

Método complementario a la mastografía y el US. No utiliza radiación ionizante y proporciona información morfológica y funcional por medio de la administración endovenosa de medio de contraste paramagnético (gadolinio); es necesario contar con un resonador de por lo menos 1.5 teslas y antena dedicada a la glándula mamaria

La RM tiene una sensibilidad del $90 \%$ y especificidad del $89 \%$.

Se debe efectuar evaluación multiparamétrica: que incluye: curvas de perfusión, espectroscopia y difusión, lo cual aumenta la especificidad del método. ${ }^{24}$

La evaluación cinética (curvas de perfusión) de las lesiones observadas mide la captación del contraste, dentro de la lesión, en un periodo de tiempo. La señal de la intensidad se incrementa luego de la administración del contraste; se mide en relación con el nivel precontraste, al relacionar el tiempo y la intensidad de la señal, se generan curvas que proveen información acerca de las propiedades vasculares de la lesión. Generando tres tipos de curvas que constan de dos etapas: la inicial, que puede ser lenta, moderada 0 rápida, y la etapa retardada, que puede ser continua (tipo I), considerada en más del $90 \%$ de lesiones benignas, en meseta (tipo II), considerada indeterminada, o de lavado (tipo III), que es la más frecuente en lesiones malignas. ${ }^{15}$

La RM tiene mayor número de falsos negativos en tumores menores de $3 \mathrm{~mm}$, así como en el carcinoma in situ de bajo grado y en el lobulillar, por lo que para un diagnóstico certero es fundamental la integración de las características morfológicas y funcionales aunadas a los hallazgos de la mastografía y el US.

La especificidad de este método se incrementa con la técnica de espectroscopia (biopsia virtual), que permite la cuantificación de colina, marcador tisular de proliferación celular que brinda información bioquímica del tejido. Otra técnica es la difusión, la cual se basa en el movimiento de las moléculas de agua en los tejidos y es útil en la diferenciación de lesiones benignas y malignas. Se contraindica el uso de gadolinio en mujer embarazada.

La conclusión y las recomendaciones deben efectuarse con el sistema BI-RADS. Indicaciones de la RM contrastada:

- Etapificación en cáncer mamario.

- Valoración de márgenes después de escisión de tumor primario.

- Recurrencia local (con intervalo de 6 meses posterior a manejo quirúrgico y un año tras radioterapia). Respuesta al tratamiento.

- Búsqueda de primario oculto con metástasis axilares. 
- Tamizaje en paciente con alto riesgo y mama densa, alternando con mastografía y US. Este estudio también está indicado en pacientes con riesgo genético de cáncer mamario hereditario, ya que la sensibilidad y especificidad para este grupo es del 91 y $97 \%$ respectivamente. Se recomienda protocolo abreviado, que disminuye costos y tiempo de adquisición, con un alto valor predictivo positivo.

- Guía de biopsias en caso de lesiones visibles solo por medio de este método y no corroboradas en la segunda revisión intencionada por US.

- No se recomienda el uso sistemático preoperatorio de la RM de mama para evaluar la extensión de la enfermedad, porque no ha demostrado mejorar la supervivencia global o disminución de las tasas de rescisión, ni reducción de costos.

- La RM no contrastada está indicada en la valoración de la integridad de los implantes mamarios, particularmente con sospecha de ruptura intracapsular $u$ otras complicaciones. ${ }^{25,26}$

\subsection{Estudios MOLECULARES DE LA MAMA (PET y PEM)}

La tomografía por emisión de positrones (PET) y la mastografía por emisión de positrones (PEM) son estudios de imagen, no solo morfológicos, sino funcionales, que evalúan la actividad molecular de los tumores malignos, al inyectar mediante vía endovenosa un radiotrazador, generalmente 18-fluorodesoxiglucosa, aunque cada vez existen más en el mercado, con aumento en la especificidad.

La PET-CT combina tomografía computarizada y medicina nuclear, con la localización precisa del tumor primario, así como de las metástasis a distancia, evaluación de respuesta a tratamiento, seguimiento y reetapificación; tiene una resolución espacial de $1.7 \mathrm{~mm}$ y las unidades de captación semicuantitativa se refieren como SUV y no deben exceder de 2.5; también se efectúa comparación cualitativa, al comparar la captación con otros órganos.

La PEM es un equipo compacto, donde los detectores están arriba y abajo de la glándula mamaria, por lo cual tiene una gran resolución espacial, que permite detectar lesiones con un tamaño hasta de $1.2 \mathrm{~mm}$; proporciona imágenes en proyecciones similares a la mastografía, previa inyección endovenosa de la mitad de la dosis del radiotrazador que la utilizada en la PETCT. Tiene una sensibilidad similar a la RM contrastada, pero mayor especificidad; su principal indicación es la etapificación locorregional del cáncer mamario, si se planea cirugía conservadora, valoración de axila, respuesta a tratamiento, así como recurrencias y es de utilidad en mamoplastia de aumento y sospecha de cáncer; este método de imagen no se ve afectado por la densidad mamaria y no está limitado por cambios posquirúrgicos recientes.

Puede haber falsas negativas en carcinomas pequeños, con pobre actividad metabólica, bajo grado nuclear, cáncer in situ y cáncer lobulillar infiltrante, similar a la RM.

Es posible efectuar simultáneamente ambos estudios (PET y PEM) con la dosis del PET-CT; es de gran utilidad en tumores endocrinos como de endometrio, tiroides, colon y ovario, donde pueden asociarse con cáncer mamario (doble primario). ${ }^{27,28}$

\section{Procedimientos de intervención guiados por imagen (mama y cadenas ganglionares)}

\section{Introducción}

Hasta hace algunos años, la biopsia escisional, previo marcaje con aguja percutánea, era la única herramienta de diagnóstico en lesiones clínicamente no palpables. Actualmente, la biopsia con aguja de corte se ha convertido en una herramienta de evaluación diagnóstica en lesiones no palpables de la mama, que evita biopsias escisionales en los casos benignos, abate costos y reduce riesgos para la paciente, con mínimos cambios del tejido mamario que puedan alterar el seguimiento en mastografías posteriores.

En los casos de neoplasias malignas permite al cirujano planear en conjunto, con la paciente, las alternativas terapéuticas. Debe elegirse el método guía en el cual la lesión se visualice mejor: microcalcificaciones mediante mastografía con sistema de estereotaxia y recientemente con tomosíntesis, de gran utilidad en distorsiones de la arquitectura; la masa o nódulo principalmente mediante guía por ultrasonido (US) y menos frecuente en los casos en que las lesiones de sospecha sean únicamente visualizadas en resonancia magnética o mastografía por emisión de positrones. La biopsia guiada por imagen aumenta la precisión diagnóstica, incluidos los casos de tumor palpable. ${ }^{1}$

\section{Indicaciones de biopsia}

Lesiones de sospecha categorizadas como BI-RADS (breast imaging reporting and data system) 4 y 5 : - Microcalcificaciones de sospecha. 
- Asimetría focal.

- Asimetría en desarrollo o cambios en una lesión ya existente detectada en el seguimiento mastográfico.

- Distorsión arquitectónica, signo radiológico mejor caracterizado mediante tomosíntesis y que representa en la mayoría de los casos cáncer invasor.

Se recomienda colocar un marcador en el sitio de la biopsia.

La corroboración de la extracción de las microcalcificaciones se lleva a cabo con control mastográfico de los fragmentos, antes de ser enviada al estudio histopatológico.

\subsection{BIOPSIA POR ASPIRACIÓN (CITOLOGÍA)}

Se realiza con un muestreo percutáneo de lesiones sospechosas, con aguja fina de calibre 22 a $25 \mathrm{G}$ para diagnóstico citológico; es de bajo costo, además de poseer sensibilidad y especificidad adecuadas, tiene como limitante la necesidad de contar con la experiencia tanto del radiólogo que la realiza como del citólogo que la interpreta. Actualmente el uso de la citología, principalmente en evaluación de ganglios axilares con cambios en su morfología, contribuye a la toma de decisiones de manejo multidisciplinario de las pacientes.

La sensibilidad de la biopsia por aspiración con aguja fina para las metástasis de los ganglios axilares varía según la sospecha previa al procedimiento:

- Del $11 \%$ para los ganglios morfológicamente normales (corteza uniforme $<3 \mathrm{~mm}$ ).

- Del $44 \%$ en ganglios indeterminados (corteza uniforme $>3 \mathrm{~mm} 0<3$ con engrosamiento focal).

- Del $93 \%$ para ganglios sospechosos (engrosamiento focal y corteza $>3 \mathrm{~mm}$ y/o pérdida de hilio graso).

- La sensibilidad global oscila del 25 al $86.4 \%$, especificidad del 81 al 100\%, índice de falsos negativos del 3.7 al $19 \%$ y falsos positivos del $0.68 \%$. Valor predictivo positivo del 64 al $100 \%$ y valor predictivo negativo del 59 al $80 \%$.

- El marcaje de los ganglios reportados citológicamente metastásicos proporciona una mejor evaluación de la respuesta patológica posterior a la quimioterapia neoadyuvante, para determinar si existe enfermedad residual.

\subsection{BIOPSIA CON AGUJA DE CORTE (HISTOLÓGICA)}

Es el método ideal de diagnóstico de lesiones no palpables; se realiza bajo anestesia local y es un procedimiento bien tolerado, ambulatorio y con mínimas complicaciones.

En las lesiones categorizadas BI-RADS 4 y 5, sean nódulos o microcalcificaciones, existe la alternativa de biopsia guiada por US o estereotaxia con sistemas de corte asistido por vacío; este último es indispensable en microcalcificaciones.

La corroboración de la extracción de las microcalcificaciones se lleva a cabo con el control mastográfico de los fragmentos, antes del estudio histopatológico.

Se requiere biopsia quirúrgica con fines diagnósticos y terapéuticos cuando en el resultado histopatológico de la biopsia con aguja de corte y/o sistema de corte aspiración no exista correlación entre imagen y patología o el estudio histopatológico considere la escisión.

Es necesario efectuar un control radiológico de la mama intervenida en un lapso de seis meses.

En todos los casos, la correlación entre la imagen y los resultados de patología debe ser la pauta para el tratamiento; los grupos multidisciplinarios de manejo del cáncer mamario deberán tener un método de trabajo sistemático que permita la correlación del clínico, el radiólogo y el patólogo.

Se recomienda colocar marcador en el sitio de la biopsia, al finalizar el procedimiento.

El uso de la quimioterapia neoadyuvante en cáncer de mama con ganglios positivos (N1) diagnosticados por biopsia percutánea reduce la enfermedad axilar en un $55 \%$, por lo que se recomienda dejar un marcador en el ganglio. ${ }^{2,3}$

\section{Estudio histopatológico}

\section{Recomendaciones para trabajo y reporte de espécimen de cirugía conservadora}

\subsection{INDICACIONES DE TRANSOPERATORIO}

- Estatus de los bordes quirúrgicos.

- Ganglio centinela.

\subsection{Manejo del esPÉCIMEN}

- El espécimen debe ser referido con estudio radiológico.

- Bordes referidos (6) con sedas, cuentas o entintado (idealmente teñidas por el cirujano).

- La pieza quirúrgica debe recibirse intacta (sin ningún tipo de manipulación o corte). 
Tabla 2. Criterios para la elección del tipo de biopsia

\begin{tabular}{|c|c|c|}
\hline $\begin{array}{l}\text { Tipo de } \\
\text { biopsia }\end{array}$ & Tipo de lesión & Calibre de aguja \\
\hline BAAF & $\begin{array}{l}\text { - Quistes } \\
\text { - Ganglios axilares } \\
\text { - No se recomienda en tumor primario de mama }\end{array}$ & $-22-25 \mathrm{G}$ \\
\hline Aguja de corte & - Lesiones sólidas & - 11 y $14 \mathrm{G}$ son las más utilizadas \\
\hline $\begin{array}{l}\text { Corte aspiración } \\
\text { automático con guía } \\
\text { por estereotaxia } 0 \\
\text { por ecografía }\end{array}$ & $\begin{array}{l}\text { - Calcificaciones sospechosas biopsia por estereotaxia } \\
\text { - Asimetrías focales y distorsiones de la arquitectura } \\
\text { solo visibles en tomosíntesis con US negativo se } \\
\text { sugiere biopsia con estereotaxia y tomosíntesis } \\
\text { integrada } \\
\text { - Nódulo complejo guía ecográfica }\end{array}$ & $\begin{array}{l}\text { - } 8 \text { a } 14 \text { G } \\
\text { - Mínimo } 8 \text { muestras; dicho número dependerá del } \\
\text { tipo y tamaño de la lesión }\end{array}$ \\
\hline $\begin{array}{l}\text { Biopsia } \\
\text { quirúrgica }\end{array}$ & $\begin{array}{l}\text { - Lesiones que no pueden ser biopsiadas de manera } \\
\text { percutánea (limitación técnica), biopsias previas con } \\
\text { aguja de corte no concordantes }\end{array}$ & \\
\hline
\end{tabular}

BAAF: biopsia por aspiración con aguja fina; US: ultrasonido.

- El espécimen debe ser seccionado únicamente por el médico patólogo (Tabla 2).

- Cortes perpendiculares de los bordes quirúrgicos (se considera borde quirúrgico negativo, para carcinoma ductal in situ, cuando este dista $\geq 2 \mathrm{~mm}$ ). ${ }^{1} \mathrm{Si}$ es menor a esta medida deberá especificarse en el reporte.

- Cortes seriados del espécimen con grosor de 3 a $5 \mathrm{~mm}$.

- Incluir los cortes en forma seriada y ordenada. Si la pieza cuenta con arpón, referir el número de cápsulas donde se encuentra la lesión marcada.

- Se recomienda incluir la totalidad del tejido marcado con el arpón y $1 \mathrm{~cm}$ en su periferia, además de representativos del tejido restante.

- Indicar la relación de cortes en la descripción macroscópica.

\section{Recomendaciones para el informe histopatológico del carcinoma mamario infiltrante}

Este consenso recomienda el protocolo del American Joint Committee on Cancer (AJCC) 2018 (octava edición) para el examen de especímenes de pacientes con cáncer de mama. ${ }^{2} \mathrm{~A}$ continuación se mencionan los parámetros del diagnóstico que consideramos imprescindibles en el informe histopatológico.

\subsection{TIPO DE ESPÉCIMEN Y LOCALIZACIÓN ANATÓMICA}

\subsubsection{Parámetros macroscópicos}

- Peso y tamaño del espécimen.

- Tamaño del tumor en sus tres dimensiones.

- Tipo de bordes: infiltrantes y no infiltrantes.

- Distancia del tumor con los bordes y el lecho quirúrgico (los bordes deben ser referidos por el cirujano de preferencia con tintas de colores). ${ }^{3}$

\subsubsection{Parámetros microscópicos}

\subsubsection{Tipo histológico}

El diagnóstico del tipo histológico debe apegarse a los criterios de la $5 .^{\text {a }}$ edición de la Clasificación de los Tumores de la Mama, según la Organización Mundial de la Salud. ${ }^{4}$

En caso de observar diferentes patrones, especificar el porcentaje de cada uno de ellos.

Dejan de ser variantes histológicas, convirtiéndose en patrones morfológicos de carcinoma invasor de tipo no especial, el carcinoma medular, oncocítico, rico en lípidos, rico en glucógeno, células claras, diferenciación sebácea, diferenciación neuroendocrina, carcinoma con células gigantes de tipo osteoclasto, pleomórfico, con diferenciación acoriocarcinoma y con patrón melanocítico. $^{4}$ 
Se agregan dos subtipos: cistadenocarcinoma mucinoso y carcinoma de células altas de polaridad reversa. ${ }^{4}$

Las neoplasias neuroendocrinas se dividen en tumores neuroendocrinos y carcinomas neuroendocrinos. ${ }^{4}$

\subsubsection{Grado histológico}

Las variantes deberán graduarse con el esquema de Scarff-Bloom-Richardson, descrito a continuación:

- Formación de túbulos:

- Calificación de 1: el 75\% o más del tumor compuesto por túbulos.

- Calificación de 2: del 10 al 75\% del tumor compuesto por túbulos.

- Calificación de 3: menos de 10\% del tumor compuesto por túbulos.

- Grado nuclear:

- Calificación de 1: núcleo pequeño, uniforme, cromatina densa.

- Calificación de 2: núcleo con moderada variación en tamaño y forma; puede observarse nucléolo poco aparente.

- Calificación de 3: núcleo con marcado incremento en tamaño, forma y contornos irregulares, dos o más nucléolos prominentes, cromatina gruesa.

- Número de mitosis:

- Calificación de 1: $\leq 12$ mitosis en 10 Campos Gran Aumento (CGA).

- Calificación de 2: 13 a 24 mitosis en 10 CGA.

- Calificación de 3: $\geq 25$ mitosis en 10 CGA.

El parámetro de mitosis aquí referido está dado para

un diámetro de campo de 0.65 a 40X en 10 campos, para otro diámetro, consultar tabla de conversión de objetivo en referencia. ${ }^{4}$

Se deberán reportar por separado los tres parámetros mencionados y el puntaje final para determinar el grado histológico, el cual será como sigue:

- Grado I: 3 a 5 puntos.

- Grado II: 6 a 7 puntos.

- Grado III: 8 a 9 puntos.

Ante la presencia de carcinoma canalicular in situ o carcinoma lobulillar in situ, mencionar el tipo y porcentaje.

La permeación linfovascular se valora en el tejido peritumoral.

Infiltración a piel, pezón y areola (dermis papilar, reticular, ulcerada) y músculo.

La evaluación del infiltrado linfocítico tumoral (TIL, tumor infiltrating lymphocytes) se realizará siguiendo las recomendaciones del International TILs Working
Group 2014. 5,6 Este parámetro es obligatorio reportarlo en el carcinoma triple negativo y grupo HER2 (receptor de factor de crecimiento epidérmico humano) neu, debido a que se considera actualmente un fuerte factor pronóstico y predictivo. $^{7}$

\subsection{Definiciones y conceptos Generales}

Es bien conocido que las neoplasias malignas son antigénicas y pueden ocasionar una respuesta inmunitaria, debido a los productos proteicos alterados que producen y que pueden ser reconocidos por nuestro sistema inmunitario como elementos extraños. Los elementos que se liberan debido a la respuesta inmunitaria tienen un papel pronóstico y predictivo en muchas neoplasias sólidas.

Los TIL han ganado gran importancia como biomarcadores que pueden indicar el uso de tratamientos de inmunoterapia en el cáncer. Por lo anterior, se aconseja utilizarlos de manera sistemática en determinadas neoplasias.

En la actualidad, se encuentran disponibles varias guías o lineamientos para la evaluación correcta de los TIL, que serán descritos en este consenso ${ }^{8}$.

\subsection{RESPUESTA INMUNITARIA DEL HUÉSPED}

Los productos proteicos generados por las células cancerosas, debido a las mutaciones genéticas que sufren, funcionan como neoantígenos y se convierten en células «extrañas». Además, el microambiente hipóxico y necrótico de las neoplasias mandan señales de daño al sistema inmunitario.

Las células inmunitarias que infiltran las neoplasias pueden fomentar su crecimiento y progresión, pero también crear un ambiente inmunosupresor en el cual la neoplasia se desarrolla. Los linfocitos T citotóxicos $\mathrm{CD} 8+$, los linfocitos T-cooperadores que producen interferón $\gamma$ y las células asesinas naturales se asocian, por lo general, con respuestas inmunitarias antitumorales favorables, junto con macrófagos con fenotipo M1 y células dendríticas (Tabla 3).

\subsection{EVALUACIÓN DE INFILTRADO LINFOCÍTICO TUMORAL EN CARCINOMA INVASOR DE LA GLÁNDULA MAMARIA}

La mayoría de los carcinomas mamarios muestran alguna cantidad de infiltrado linfoide, incluso existen carcinomas ricos en dicho infiltrado, que son neoplasias ocupadas por TIL en un área $>50$ o 60\%. Los carcinomas mamarios que por lo general muestran la 
Tabla 3. Células inmunitarias presentes en el microambiente tumoral

\begin{tabular}{|l|l|}
\hline Supresión tumoral & Progresión tumoral \\
\hline M1 & Célula T reguladora \\
\hline Célula NK & M2 \\
\hline Célula NKT & Célula dendrítica-2 \\
\hline Célula N1 & Célula N2 \\
\hline LT CD8+ & Célula Th2 \\
\hline Células dendríticas-1 & Célula mieloide \\
\hline Célula Th1 & \\
\hline Célula Tfh & \\
\hline
\end{tabular}

NK: natural killer, NKT: natural killer T; LT: linfocito; Th: T helper; Tfh: Follicular helper $T$.

característica señalada, corresponden al grupo de los triples negativos (20\%) y los carcinomas HER2+ (16\%). Solo el $6 \%$ de los carcinomas luminales muestran esta característica.

Varios metaanálisis han confirmado que los altos niveles de TIL se asocian con una mejor supervivencia libre de enfermedad y supervivencia global, solo en los subtipos triple negativo y HER2+.

\subsection{INTERPRETACIÓN DE LOS INFILTRADOS LINFOCÍTICOS TUMORALES PRESENTES EN EL CARCINOMA MAMARIO}

Para evaluar los TIL debemos conocer algunos conceptos:

Los TIL o linfocitos que infiltran a los carcinomas se localizan en el área que separa a los bordes del tumor del tejido del huésped, en una extensión de $1 \mathrm{~mm}$. De esta forma, contamos con dos compartimentos: la porción central del tumor y el margen de invasión.

Los lineamientos que se tomarán en cuenta para la interpretación de los TIL, en el carcinoma invasor, se encuentran en la tabla 4.

\subsection{EVALUACIÓN DE LINFOCITOS INTRATUMORALES EN EL CARCINOMA INTRADUCTAL}

En comparación con el carcinoma invasor, se cuenta con menor cantidad de información respecto al infiltrado linfoide asociado al carcinoma intraductal (CID). Algunos estudios sugieren que los TIL asociados con CID se relacionan con ciertas características clínico-patológicas y progresión de la enfermedad, pero no tienen
Tabla 4. Guía para la evaluación de TIL en cáncer invasor de mama

Se deben evaluar los TIL del compartimento estromal, en forma separada del compartimiento tumoral y reportarse cada rubro por su parte

Excluir los TIL que se encuentren fuera del margen de invasión (estroma adyacente, estroma perilobular, etc.)

No tomar en cuenta las áreas que muestren artefactos, necrosis o zonas de regresión tumoral (áreas hialinas)

El conteo debe tomar en cuenta linfocitos y células plasmáticas, pero no los polimorfonucleares

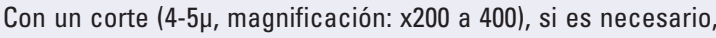
se pueden evaluar varios cortes, por ejemplo, en los casos de heterogeneidad intratumoral

Se prefieren cortes del tumor, en lugar de biopsias con aguja de corte

Evaluar toda el área tumoral (central y márgenes infiltrantes), evitar los sitios en donde se concentra una mayor cantidad de linfocitos (hot spot)

Los TIL deben evaluarse como una variable continua, ello proporciona información biológica más relevante (\%)

Para evaluar los porcentajes de los linfocitos, su patrón de crecimiento en forma separada o pequeños grupos se deberá tomar en cuenta que el porcentaje de los TIL estromales es un parámetro semicuantitativo, por ejemplo, un $80 \%$ de TIL estromales significa que el $80 \%$ del área estromal muestra un infiltrado mononuclear denso.

TIL: linfocitos intratumorales.

significadio pronóstico. Pruneri, et ai. ${ }^{3}$ reportaron en una serie con numerosos casos la asociación entre los TIL estromales con el grado del carcinoma intraductal, la edad del paciente y la presencia de comedo-necrosis. Las características ya señaladas se observaron con mayor frecuencia en los carcinomas intraductales HER2+. No se observó relación con el porcentaje de recurrencia. En este estudio, el método utilizado fue similar al ya descrito para el carcinoma invasor, con modificaciones específicas para el carcinoma intraductal.

La metodología usada por algunos autores es la siguiente:

- Touching TILs: se toma en cuenta el espesor de un linfocito que está en relación con la membrana basal del conducto, se cuentan 20 conductos y se dividen en los siguientes grupos: negativo $(<5$ linfocitos por conducto), escaso (6 a 20 linfocitos por conducto) y denso (> 20 linfocitos por conducto).

- TIL estromales: área estromal periductal alrededor del conducto en dos campos a mayor aumento y a partir del borde. Bajo: < 5 TIL y alto: $>5$ TIL. 
- Circunferencial o casi circunferencial (>75\% de circunferencia): conductos rodeados por linfocitos y células plasmáticas, al menos tres capas en espesor. Calificación: presentes o ausentes.

\subsection{LIGAS PARA TUTORIALES}

- TILs and Breast Cancer. International Immuno-Oncology Working Group

- Suplemental Digital Content 1, http://links.Iww.com/ PAP/A13

- Suplemental Digital Content 2, http://links.Iww.com/ PAP/A14

- Suplemental Digital Content 3, http://links.Iww.com/ PAP/A15

- Suplemental Digital Content 4, http://links.Iww.com/ PAP/A16

\subsection{Microcalcificaciones}

Reportar la presencia de microcalcificaciones y entidad a la que están asociadas en biopsias con aguja de corte, biopsias por estereotaxia y productos de cirugías conservadoras.

\subsection{Otras entidades asociadas}

Hiperplasia, células columnares, adenosis microglandular, etc.

\subsection{DISECCIÓN AXILAR}

- Especificar el total de ganglios disecados.

- Número de ganglios con metástasis.

- Tamaño de los ganglios disecados.

- Ruptura capsular e infiltración por células neoplásicas en los tejidos blandos periganglionares.

\section{Recomendaciones para el reporte de especímenes postratamiento}

Para realizar una evaluación completa y guiar el muestreo de los especímenes postratamiento, el patólogo debe tener la información que se muestra en la tabla $5 .{ }^{10,11}$

Los hallazgos microscópicos que se pueden observar en el tejido mamario y ganglios linfáticos se resumen en la tabla 6.

\section{Reporte histopatológico de lesiones precursoras de alto grado y carcinoma mamario in situ}

\subsection{ReCOMENDACIONES}

Para el informe histopatológico de carcinoma papilar intraquístico y neoplasias papilares relacionadas se debe tomar en cuenta: ${ }^{12}$

- Los criterios de diagnóstico (Tabla 7).

- Cuando existan focos de invasión en el carcinoma papilar intraquístico se debe reportar únicamente el tamaño del componente infiltrante para fines de etapificación.

- Está contraindicado hacer diagnósticos definitivos de neoplasias papilares en transoperatorio, biopsia con aguja de corte y biopsia por aspiración.

\subsection{Carcinoma lobulillar in situ}

Se puede asociar con carcinoma tubular, carcinoma lobulillar infiltrante y lesiones de células columnares, por lo general, atipia epitelial plana (tríada de Rosen). ${ }^{13}$

El diagnóstico de células columnares como lesión precursora se puede realizar siguiendo el diagrama de flujo expresado en la figura $5 .^{1,14}$

\subsection{Carcinoma tRiple negativo y asociación CON ADENOSIS MICROGLANDULAR}

La adenosis microglandular (AMG) se considera una proliferación ductal benigna, pero en el $27 \%$ de los casos existe un riesgo significativo para el desarrollo de carcinoma invasor o in situ de tipo basal (triple negativo). Por lo anterior, la detección y el diagnóstico de certeza de AMG son importantes e incluyen el siguiente panel de inmunohistoquímica (IHQ): S-100 positivo, RE negativo y p63 negativo, colágena tipo IV para visualizar la membrana basal. ${ }^{15,16}$

\subsection{Recomendaciones para el REPORTE DE CARCINOMA DUCTAL IN SITU}

- Correlación anatomo-radiológica:

- Mastografía del espécimen (microcalcificaciones, alteración en la densidad).

- Tamaño del tumor.

- Multiplicar el número de laminillas con tumor por $4 \mathrm{~mm}$ (grosor del corte para la inclusión). 
Tabla 5. Manejo de pieza quirúrgica con neoadyuvancia

\begin{tabular}{|c|c|c|c|}
\hline & $\begin{array}{l}\text { Productos de cirugías } \\
\text { conservadoras }<5 \mathrm{~cm} 0 \\
<30 \mathrm{~g}\end{array}$ & \multicolumn{2}{|c|}{$\begin{array}{l}\text { Productos de cirugías } \\
\text { conservadoras }>5 \mathrm{~cm} 0 \\
>30 \text { g y mastectomías }\end{array}$} \\
\hline & \multicolumn{3}{|c|}{$\begin{array}{l}\text { Especificar si se ha recibido tratamiento neoadyuvante, esquema utilizado y duración } \\
\text { Estadificación inicial TNM con enfásis en el tamaño clínico o radiológico, especificar multifocalidad }\end{array}$} \\
\hline $\begin{array}{l}\text { Datos clínicos } \\
\text { en la solicitud }\end{array}$ & \multicolumn{3}{|c|}{$\begin{array}{l}\text { Datos del reporte de la biopsia inicial (grado histológico, subtipo, perfil molecular, celularidad) } \\
\text { Especificar si existe marcaje o no en sitio de biopsia previo y localización } \\
\text { Sospecha clínica o radiológica de respuesta patológica completa } \\
\text { Se recomienda al radiólogo y al cirujano colocar clip metálico antes del tratamiento, con el fin de asegurar la } \\
\text { identificación del lecho tumoral }\end{array}$} \\
\hline Fijación & \multicolumn{3}{|c|}{ Habitual, de preferencia recibir en fresco para efectuar, cortes, formalina al 10\% amortiguada. Máxima 24 horas } \\
\hline Cortes & $\begin{array}{l}\text { Previo entintado de bordes, en sentido } \\
\text { medio lateral efectuar cortes } \\
\text { secuenciales de } 3 \mathrm{~mm} \text { de grosor }\end{array}$ & \multicolumn{2}{|c|}{$\begin{array}{l}\text { Previo entintado de márgenes, realizar cortes secuenciales en sentido } \\
\text { medio-lateral de } 1 \mathrm{~cm} \text { de grosor }\end{array}$} \\
\hline Esquematización & \multicolumn{3}{|c|}{ Relación de cortes especificados mediante macrofotografía, dibujo, fotocopia, placa radiográfica } \\
\hline Cortes & $\begin{array}{l}\text { Técnica quirúrgica de } \\
\text { ampliación de bordes en segundo } \\
\text { tiempo }\end{array}$ & $\begin{array}{l}\text { Incluir } \\
\text { representativos de } \\
\text { bordes en sentido } \\
\text { perpendicular } \\
\text { Incluir bordes en } \\
\text { sentido } \\
\text { perpendicular } \\
\text { Valorar si se } \\
\text { incluyen } \\
\text { representativos o de } \\
\text { manera integra }\end{array}$ & $\begin{array}{l}\text { Inclusión de los bordes en forma habitual, en } \\
\text { sentido perpendicular }\end{array}$ \\
\hline \multirow[t]{2}{*}{$\begin{array}{l}\text { Inclusión } \\
\text { de cortes }\end{array}$} & Con tumor macroscópico visible & $\begin{array}{l}\text { Incluir íntegramente } \\
\text { con énfasis de } \\
\text { tumor residual }\end{array}$ & $\begin{array}{l}\text { Incluir la neoplasia residual al menos } 5 \text { bloques } \\
\text { y el resto en cortes alternados ( } 2 \text { por cada } \\
\text { sección) con un máximo de } 25 \text { bloques }\end{array}$ \\
\hline & $\begin{array}{l}\text { Sin tumor macroscópico } \\
\text { visible }\end{array}$ & Incluir íntegramente & $\begin{array}{l}\text { Incluir } 2 \text { bloques por cada sección, en forma } \\
\text { alineada con énfasis en zonas de hemorragia y } \\
\text { fibrosis, con un máximo de } 25 \text { bloques }\end{array}$ \\
\hline $\begin{array}{l}\text { En caso de } \\
\text { sospecha } \\
\text { clínica/o } \\
\text { radiológica de } \\
\text { respuesta } \\
\text { patológica } \\
\text { completa }\end{array}$ & Inclusión total & \multicolumn{2}{|c|}{$\begin{array}{l}\text { Incluir dos cortes por cada sección en forma alternada, hasta un } \\
\text { máximo de } 25 \text { bloques e individualizar si se requiere la inclusión total }\end{array}$} \\
\hline
\end{tabular}

- Medir el diámetro mayor en laminilla, cuando es foco único.

- Se tomará como tamaño del tumor, la medida que resulte mayor de las dos anteriores. ${ }^{17,18}$

- Grado.

- Grado nuclear

- Grado 1

- Núcleos monótonos.

- De 1.5 a 2 veces el tamaño de un eritrocito o el núcleo de una célula epitelial.
- Cromatina difusa.

- Nucléolos y mitosis ocasionales.

- Polarización celular.

- Grado 2

- Pleomorfismo moderado.

- De 2 a 2.5 veces el tamaño de un eritrocito o el núcleo de una célula epitelial.

- Cromatina fina a gruesa.

- Nucléolo evidente y mitosis escasas.

- Grado 3 
Tabla 6. Hallazgos histológicos en tejido mamario y ganglios linfáticos posquimioterapia

\section{Hallazgos histopatológicos}

Cambios estromales: obliteración parcial de la arquitectura,

fibrosis e infiltrado histiocítico

Cambios nucleares: nucleomegalia, irregularidad nuclear, multinucleación, vacuolización de la cromatina, ocasionalmente disminución del grado nuclear

Cambios citoplasmáticos: citoplasmas abundantes, vacuolados, eosinofílicos o gris azulados

El tumor residual puede observarse como: células tumorales aisladas, grupos tumorales o como pequeñas glándulas bien definidas con núcleos sin atipia

\section{Reporte recomendado}

Número total de ganglios. Número de ganglios con cambios relacionados a tratamiento sin carcinoma viable

Número de ganglios con metástasis

Diámetro mayor del foco metastásico (no se debe usar la clasificación de micro, macro o grupo aislado de células)

Extensión extracapsular: presente (diámetro mayor), ausente, indeterminada

Respuesta completa: ausencia de células de carcinoma viable, fibrosis y acúmulos de macrófagos espumosos

En algunos casos es recomendable el uso de inmunohistoquímica para identificar células neoplásicas residuales
Tabla 7. Recomendaciones para el informe histopatológico de neoplasias papilares

\begin{tabular}{|c|c|}
\hline & CK 5/6 \\
\hline $\begin{array}{l}\text { Carcinoma papilar } \\
\text { Encapsulado } 0 \\
\text { intraquístico }\end{array}$ & Negativa \\
\hline $\begin{array}{l}\text { Carcinoma papilar sólido } \\
\text { - In situ } \\
\text { - Invasor }\end{array}$ & Negativa \\
\hline $\begin{array}{l}\text { Papiloma intraductal } \\
\text { - Atípico (área de atipia } \\
\leq 3 \mathrm{~mm} \text {, foco } \geq 3 \mathrm{~mm} \text { se } \\
\text { considera papiloma } \\
\text { asociado a CDIS) } \\
\text { - Con CDIS } \\
\text { - Con CLIS }\end{array}$ & $\begin{array}{l}\text { Positiva (patrón en mosaico) } \\
\text { Negativa en áreas de carcinoma }\end{array}$ \\
\hline RE & p63, AML o calponina \\
\hline Positivo intenso & $\begin{array}{l}\text { Ausentes en la periferia y al } \\
\text { centro del tumor }\end{array}$ \\
\hline Positivo intenso & $\begin{array}{l}\text { Ausentes en la periferia y en el } \\
\text { centro del tumor } \\
\text { Presente en la periferia y en el } \\
\text { centro de la lesión }\end{array}$ \\
\hline Positivo débil y focal & $\begin{array}{l}\text { Presente en la periferia y en el } \\
\text { centro de la lesión } \\
\text { Negativo en áreas de carcinoma }\end{array}$ \\
\hline
\end{tabular}

CDIS: carcinoma ductal in situ; CLIS: carcinoma lobulillar in situ; RE: receptores de estrógeno; AML: actina de músculo liso.

- Marcado pleomorfismo.

- Más de 2.5 veces el tamaño de un eritrocito o el núcleo de una célula epitelial.

- Nucléolos prominentes.
- Abundantes mitosis.

- Necrosis ausente o presente.

- Patrones arquitecturales:

- Comedo.

- Cribiforme.

- Papilar.

- Micropapilar.

- Sólido.

- Variantes poco frecuentes:

- Células apocrinas.

- Quístico hipersecretor.

- Tipo mucocele.

- Células en anillo de sello.

- Células pequeñas.

- Tipo escamoso.

- Células fusiformes.

- Lesiones papilares:

- Papiloma complejo o atípico.

- Papiloma complicado con carcinoma in situ.

- Márgenes quirúrgicos:

- Especificar la distancia entre el foco más próximo de carcinoma ductal in situ (CDIS) y el margen entintado. En caso de ser positivos, reportar si son focales o difusos (se considera borde quirúrgico negativo para carcinoma ductal in situ cuando este dista $>2 \mathrm{~mm}$ ). ${ }^{1}$

- Microcalcificaciones.

- Asociadas a carcinoma in situ.

- Adyacentes al área de carcinoma in situ.

- Otros parámetros:

- Determinación de receptores hormonales con reporte que debe incluir porcentaje de células neoplásicas positivas. En el consenso no se consideró relevante la determinación de HER2 neu para 


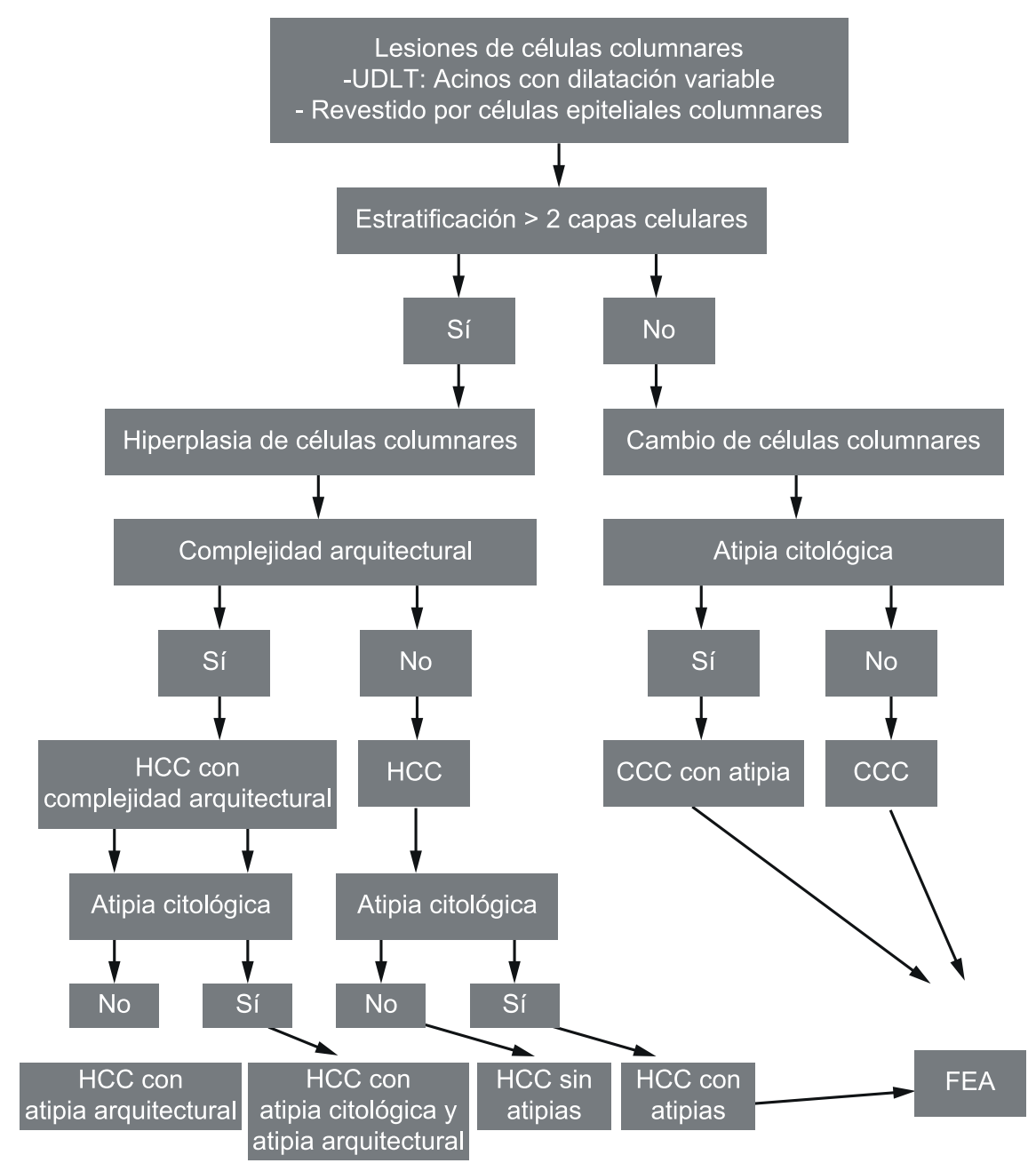

Figura 5. Algoritmo para diagnóstico de lesiones de células columnares papilares.

HCC: hiperplasia de células columnares; CCC: cambio de células columnares; FEA: atipia epitelial plana.

carcinoma ductal in situ, sin embargo, se puede realizar con fines de investigación.

- Carcinoma microinvasor.

- El término "carcinoma microinvasor» se refiere a la presencia de CDIS en el cual existe ruptura de la membrana basal, en uno o varios focos, de hasta $1 \mathrm{~mm}$. Se asocia, por lo general, a un carcinoma intraductal de alto grado y con mucha menor frecuencia a carcinoma lobulillar in situ.

\section{Recomendaciones para el reporte histopatológico del ganglio centinela}

La evaluación del ganglio centinela incluye:

- Procedimiento en el transoperatorio:19,20
- Cortes seriados longitudinales del ganglio con un espesor de $2 \mathrm{~mm}$.

- Evaluación citológica por aposición o impronta de cada cara.

Diez cortes definitivos en parafina, seriados, con intervalo de 200 micras $^{21}$ e IHQ (citoqueratinas AE1/ $A E 3)$, en el corte número 5 , solo en casos seleccionados o con carcinoma lobulillar.

- Informe histopatológico

- Ganglio negativo a metástasis por hematoxilina-eosina (H-E) y por IHQ.

- Ganglio positivo con macrometástasis (metástasis mayores de $2 \mathrm{~mm}$ ).

- Ganglio positivo con micrometástasis de $0.2 \mathrm{~mm}$ hasta $2 \mathrm{~mm}$ de dimensión mayor. Consignar si 
fueron detectadas por H-E o IHQ. En caso de ser varios focos metastásicos tomar en cuenta el de mayor tamaño.

- Ganglio positivo con células tumorales aisladas (células solas o pequeños nidos no mayores de $0.2 \mathrm{~mm}$ ). Consignar si fueron detectadas por $\mathrm{H}-\mathrm{E}$ o IHQ. ${ }^{22}$

- Informar ruptura capsular y el tamaño de la extensión al tejido adiposo. ${ }^{22}$

- Se consideran centinela hasta seis ganglios disecados.

\section{Recomendaciones para el reporte de biopsia por aspiración con aguja fina de tumor mamario}

El consenso no recomienda tomar decisiones terapéuticas basadas en el diagnóstico citopatológico del tumor primario.

\section{Recomendaciones para el reporte de biopsia por aspiración con aguja fina de ganglio axilar con posible metástasis}

- Positivo para metástasis.

- Negativo para metástasis.

- Insuficiente para diagnóstico.

\section{Recomendaciones para reporte de factores pronóstico-predictivos por inmunohistoquímica}

Los receptores hormonales (de estrógenos y progesterona) y la sobreexpresión de la oncoproteína HER2 y el ki67 son factores pronósticos y predictivos indispensables en cáncer de mama, por lo que estos marcadores deben realizarse en todas las pacientes con este diagnóstico. ${ }^{23}$

\subsection{Manejo del tejido}

Se debe utilizar como fijador el formol amortiguado a 10\% (Tabla 8).

El tejido debe colocarse lo más rápido posible en el fijador, máximo 15 minutos después de obtenerlo.

El tejido debe estar seccionado en cortes de 2 a $5 \mathrm{~mm}$ de espesor para la inclusión y en el caso de biopsia con aguja de corte se recomienda incluir dos cilindros por cápsula debido a la reconocida heterogeneidad del cáncer de mama.
Tabla 8. Fórmula de formol buffer (pH 6.8)

\begin{tabular}{|l|c|}
\hline Formol puro & 1 litro \\
\hline Agua destilada & 9 litros \\
\hline Fosfato de sodio monobásico & 40 gramos \\
\hline Fosfato de sodio dibásico & 65 gramos \\
\hline
\end{tabular}

La relación entre el volumen de la muestra y el fijador debe ser de 20 a 1.

Se recomienda la fijación mínima de 6 horas y máxima de 48 horas. Para evitar la fijación prolongada, es deseable que antes de alcanzar las 48 horas se cambie a solución amortiguadora.

No se recomienda acelerar la técnica de procesamiento histológico, mediante calor (estufa, horno de microondas, etc.).

La heterogeneidad intratumoral está relacionada con inestabilidad genética tumoral y el desarrollo de diferentes clonas dentro del tumor ${ }^{24}$, es por ello que se debe de repetir el estudio de IHQ en las siguientes situaciones:

- En caso de que el tejido de la biopsia inicial sea escaso.

- Carcinomas con variación en el grado histológico y/o disparidad morfológica de la biopsia inicial, a la pieza quirúrgica.

- En caso de multicentricidad/multifocalidad con diferente histología.

- Carcinomas de alto grado histológico.

- Tumores bilaterales, con histología diferente.

- En las metástasis y recurrencias.

- En tumores de mastectomías con neoadyuvancia que mostraron respuesta nula, evolución no esperada o que fueron triple negativo de inicio.

- Cuando la evaluación del HER2 no es posible en la biopsia inicial por artificios de mala fijación se deberá repetir en la pieza quirúrgica.

- Cuando la tinción en la biopsia de corte es heterogénea y muestra focos de positividad fuerte en < $10 \%$ del área del carcinoma invasor.

De preferencia se debe de valorar nuevamente el resultado de la biopsia inicial junto con la mastectomía, para comparar expresión de inmunomarcaje y reportarse en el diagnóstico.

\subsection{Criterios de interpretación}

Los siguientes lineamientos disminuyen la probabilidad de interpretaciones equivocadas: ${ }^{25}$ 
- Se deben emplear clonas de anticuerpos validadas.

- Clonas para receptores de estrógeno: 1D5, 6F11, SP1, 1D5+ER. 2.123.

- Clonas para receptores de progesterona: 1A6, 1294, 312.

- Clonas para HER2: 4D5, CB11, A085. ${ }^{25}$

- Siempre se deben revisar controles positivos y negativos. No debe haber tinción inespecífica en el control, ni en el caso problema (p. ej., tejido sano positivo para HER2 neu).

- Cotejar control interno positivo y negativo.

- Interpretar cada tinción solo en muestras que tengan más del $60 \%$ de tejido bien conservado.

- Los receptores de estrógeno (RE) y progesterona (RP) son positivos cuando se expresan como tinción nuclear. Se sugieren los sistemas H-score y Allred $^{23,24}$ especificando porcentaje de células positivas.

- Sistema H-score.

- Porcentaje de células positivas $\times 3$ (tinción nuclear intensa), más

- Porcentaje de células positivas $\times 2$ (tinción nuclear moderada), más

- Porcentaje de células positivas $\times 1$ (tinción nuclear débil).

El resultado es el índice $\mathrm{H}$-score, que va de 0 a 300.

- Sistema Allred

Área positiva con más intensidad de la tinción calculada de la siguiente manera:

- 0 : sin células positivas.

- $1:<1 \%$ de células positivas.

- 2: 1 a $10 \%$ de células positivas

- 3: 11 a $33 \%$ de células positivas.

- 4: 34 a $66 \%$ de células positivas.

- 5: $67 \%$ o más de células positivas.

Intensidad de la tinción: 1 = débil, 2 = moderada y

$3=$ intensa. El resultado es el índice Allred, que va de

0 a 8.

Actualmente es válido solo reportar el porcentaje de células positivas tanto para RE como para RP. Se consideran positivos tanto RE como RP con un porcentaje del $1 \%$ de células neoplásicas positivas. ${ }^{25}$

- Sobreexpresión de HER226,27

- Positivo (3+): tinción de membrana intensa y uniforme en $>10 \%$ de células neoplásicas.

- Indeterminado (2+): tinción de membrana completa y débil en $>10 \%$ de células neoplásicas.
- Negativo (0-1+): no se identifica tinción o esta es débil e incompleta en al menos el $10 \%$ de las células neoplásicas.

En HER2 la clasificación solo aplica para carcinoma invasor, no para carcinoma in situ. Los casos que presenten positividad de HER2 en conductos y lobulillos normales no son valorables y deben repetirse.

- Las recomendaciones para reportar Ki67 son las siguientes:28-30

- Preanalítico

- El índice de Ki-67 se puede realizar en biopsias tru-cut y/o tumores completos en escisiones amplias.

- El índice de Ki-67 en microarreglos de tejido solo debe usarse en estudios clínicos o epidemiológicos.

- Analítico

- En las laminillas electrocargadas se deben incluir controles positivos y negativos conocidos.

- La tinción nuclear solo se considera positiva.

- El anticuerpo MIB-1 es el aceptado actualmente.

- Interpretación

- En la vista panorámica del tumor, se deben elegir cuando menos tres campos de gran aumento (400X) que representen el espectro de tinción de todo el tumor. La evaluación se realiza en cuando menos 500 células neoplásicas y lo más recomendable son 1,000 células.

- En estudios para valorar el pronóstico, se recomienda evaluar el borde invasivo del tumor.

- En estudios de farmacocinética que comparan biopsias tru-cut y escisiones amplias se recomienda evaluar todo el tumor.

- Hot spot se define como el área donde la tinción es particularmente más alta, en relación con otras áreas adyacentes. Si hay varios hot spots se debe elegir el de rango más alto.

Es recomendable utilizar dos métodos:

- Promedio. Consiste en contar manualmente el número de células positivas en los tres campos seleccionados con anterioridad y calcular el promedio.

- Hot spot. Consiste en contar manualmente el número de células positivas en el hot spot de más alto rango, y calcular el promedio.

- Informe

- El índice de Ki67 que se reporta es el porcentaje de células neoplásicas positivas entre el total de células contadas. 


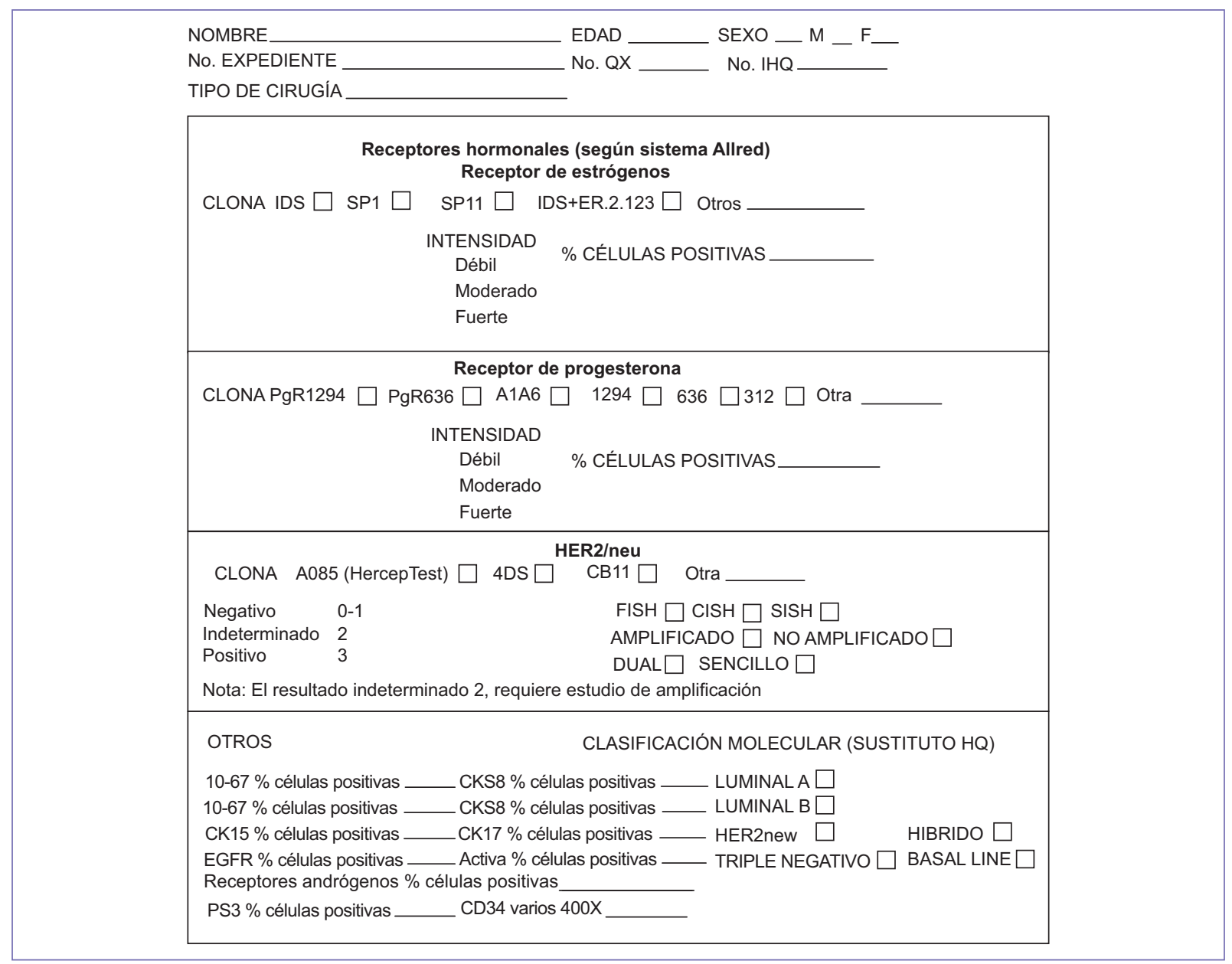

Figura 6. Reporte de patología. Marcadores pronósticos y predictivos de mama.

- Recomendamos reportar el índice obtenido por los dos métodos arriba descritos: hot spot y promedio.

- El punto de corte recomendado por este consenso es del $20 \%$.

\subsection{FORMATO DE INFORME}

El reporte de IHQ debe vincularse al informe principal de patología, para asegurar que los resultados se incorporen al diagnóstico final.

Para garantizar que los resultados sean reproducibles, el informe debe incluir la clona y marca del anticuerpo, el estatus (positivo o negativo), así como los criterios y sistema utilizados. Este consenso recomienda el siguiente formato para el informe de dichos marcadores (Fig. 6).

\subsection{Control de calidad sistemático}

El control de calidad sistemático es esencial para el éxito de la reacción de IHQ.

Se deben incluir controles positivo y negativo en la misma laminilla, donde se analice el tejido problema. Si estos controles están en una laminilla separada, debe asegurarse que sean sometidos a procedimientos simultáneos e idénticos a la muestra problema.

Los controles deben ser fijados y procesados de manera idéntica al tejido estudiado, y sometidos al mismo protocolo de recuperación antigénica e inmunotinción.

Para obtener una tinción adecuada, es necesario el uso de controles que tengan tres niveles de tinción (negativa, débil/moderada, intensa).

Los cortes histológicos para realizar la IHQ deben estar en un cuarto a temperatura ambiente por un periodo no mayor de 14 días, después los resultados son cuestionables. ${ }^{31}$ 


\subsection{Control de calidad externo}

Los laboratorios de patología que realizan pruebas de IHQ deben participar en un programa de control de calidad externo.

Se considera que para tener adecuado control de calidad en IHQ es necesario que el laboratorio procese como mínimo las muestras de 200 casos por año. ${ }^{28,32}$

\section{Recomendaciones para biología molecular}

\subsection{AmpLIFICACIÓN DE HER2}

En la actualidad existen diferentes técnicas para identificar la amplificación del gen HER2. La hibridación in situ fluorescente (FISH) se considera el estándar de oro. Otras variantes de la técnica son la hibridación in situ cromogénica $(\mathrm{CISH})$ y la hibridación in situ con plata (SISH), que pueden ser sencillas (basándose solamente en la detección de HER2) o duales (basándose en la relación de HER2 y el centrómero del cromosoma 17). ${ }^{32}$

Se debe buscar la amplificación de HER2 en los casos que resulten indeterminados (positivo 2+) por $I H Q$.

Se pueden emplear las técnicas de CISH o SISH siempre y cuando se haya realizado un proceso de validación de estas en paralelo con la técnica de FISH y se haya demostrado una concordancia de al menos el $95 \%$ entre la FISH y otra metodología.

\subsection{Criterios de interpretación de LAS REACCIONES DE HIBRIDACIÓN PARA HER2}

Los siguientes lineamientos disminuyen la probabilidad de errores en la interpretación:

- En el corte del tumor con H-E se debe seleccionar la zona de carcinoma invasor, el estudio no se realizará en áreas de carcinoma in situ.

- Inicialmente se evalúa el control; si no es adecuado, debe repetirse la prueba.

- Debe hacerse una evaluación global del caso y contar un mínimo de 20 células neoplásicas para SISH o $\mathrm{CISH}$ y 40 para FISH, en por lo menos dos campos diferentes de carcinoma invasor. En caso de haber áreas con y sin amplificación, han de contarse por separado. Se debe informar como amplificado con una nota que especifique que hay zonas sin amplificacion. ${ }^{26,27}$

\subsection{Puntos de corte para FISH y SISH dual}

- Positivo. Razón HER2/CEP 17 > 2.

- HER2/CEP $17<2$, pero con una cuenta absoluta de HER2 por núcleo $>6$.

- Indeterminado. Razón HER2/CEP $17<2$ y con una cuenta absoluta de HER2 por núcleo $\geq 4$ y $<6$.

- Negativo. Razón HER2/CEP $17<2$ y una cuenta absoluta $<4$.

\subsection{Puntos de corte para CISH sencilla}

- Positivo: > 6 copias/núcleo.

- Indeterminado: de 4 a 6 copias/núcleo (en dos conteos).

- Negativo: < 4 copias/núcleo.

Se recomienda usar preferentemente sistemas duales. En las siguientes situaciones poco habituales, se recomienda: 28

- En reacciones de sonda sencilla, si el conteo de señales es $>4$ pero $<6$, repetir el estudio con sondas duales

- En reacciones de sondas duales, en las situaciones que se enlistan a continuación, se sugiere realizar IHQ en ese mismo tejido. Si el laboratorio que realiza la hibridación no fue el mismo que realizó la IHQ, con base en la repetición de la IHQ, se informa el estatus positivo ( $3+$ ), o negativo ( $0 \circ 1+$ ) del caso; pero si confirma ser $2+$, se realiza una nueva interpretación, bajo ciego, por otro observador. Está también justificado realizar IHQ o hibridación en bloques adicionales del caso. Si la nueva evaluación arroja nuevamente alguna de estas situaciones poco habituales, se informa de la siguiente manera:

- Relación HER2/>CHR $17<2.0$, pero el promedio de señales de HER2 $\geq 6$ : positivo.

- Relación HER2/>CHR $17<2.0$, pero el promedio de señales de HER2 $\geq 4$ y $<6$ : negativo.

- Relación HER2/>CHR $17 \geq 2.0$, pero el promedio de señales de HER2 < 4: negativo.

En todos los casos, se realiza un comentario de la escasa evidencia en este tipo de situaciones.

\subsection{Clasificación molecular del carcinoma MAMARIO Y SU APROXIMACIÓN CON INMUNOHISTOQUÍMICA}

El trabajo de medicina traslacional sobre los cuatro fenotipos moleculares del cáncer de mama (luminal, con sobrexpresión de HER2, fenotipo basal y el similar a mama normal) definidos inicialmente mediante 
Tabla 9. Subtipos moleculares de cáncer de mama y su aproximación por inmunohistoquímica (IHO) según este consenso

\begin{tabular}{|c|c|}
\hline $\begin{array}{l}\text { Subtipo de acuerdo con el } \\
\text { consenso de Colima } 2021\end{array}$ & Aproximación por IHO \\
\hline Luminal A & $\begin{array}{l}\mathrm{RE}+, \mathrm{RP}>20 \% \text {, Ki } 67<20 \% \text { GH } 1 \\
\text { o } 2 \text { y HER2 - }\end{array}$ \\
\hline \multirow[t]{2}{*}{ Luminal B } & $\begin{array}{l}\text { (HER2 -) } \\
\text { RE +, HER } 2-\text {, RP }<20 \% \text { o Ki } 67> \\
20 \% \text { GH } 3\end{array}$ \\
\hline & $\begin{array}{l}\text { (HER2 +) } \\
\text { RE }+ \text {, HER2 +, RP y Ki } 67 \text { cualquier } \\
\text { valor }\end{array}$ \\
\hline HER2 & HER2 +, RE - y RP - \\
\hline Triple negativo & $\mathrm{RE}-, \mathrm{RP}-\mathrm{y} \mathrm{HER} 2-$ \\
\hline
\end{tabular}

GH: grado histológico.

genómica ${ }^{34}$ ha permitido aproximarse a esta clasificación mediante metodologías más accesibles como la IHQ, empleando marcadores como RE, RP y HER2. ${ }^{35-38}$

En población mexicana, la frecuencia promedio de subgrupos definidos por estos marcadores es la siguiente: receptores hormonales positivos $60 \%$, HER2 positivos $20.4 \%$ y triples negativos $23.1 \%{ }^{39,40}$

En la tabla 9 se muestran los subtipos moleculares de cáncer de mama y su aproximación por IHQ, según este consenso. ${ }^{41-43}$

\subsection{CÁNCER DE MAMA TRIPLE NEGATIVO}

El cáncer de mama triple negativo (CMTN) y el fenotipo basal no deben considerarse sinónimos, ya que solo del 49 al $71 \%$ de los CMTN son fenotipo basal y el $77 \%$ de los fenotipo basal son triples negativos. ${ }^{44,45}$ Los CMTN se han subclasificado por expresión génica de diferentes maneras: a) HER2 neu enriquecido, fenotipo basal y bajos en claudina, ${ }^{40}$ b) basal 1 , basal 2 (BL1 y BL2), mesenquimal (M) y tipo mesenquimal células madres (MSL), inmunomodulador (IM) y tipo luminal asociado a andrógenos (LAR). ${ }^{46,47}$

Se recomienda el siguiente panel de IHQ para CMTN, a fin de favorecer la identificación de biomarcadores y subgrupos de pacientes:

- Citoqueratinas basales (ck5/6, ck14 y ck17).

- EGFR.

- P53.

- Receptores de andrógenos.

- PDL-1 (solo en tumores metastásicos triple negativo).

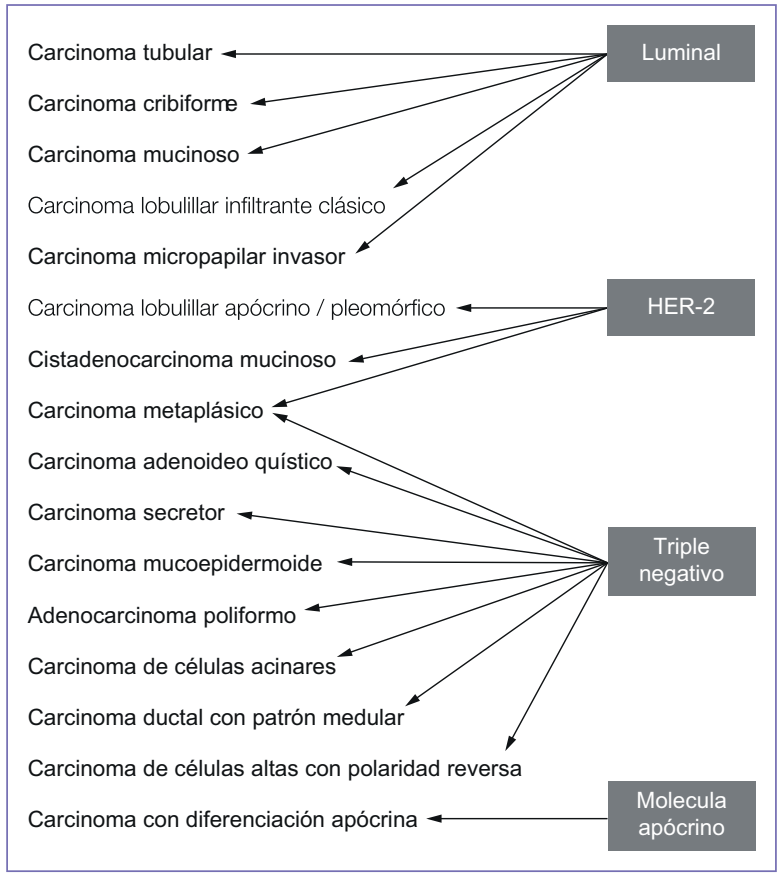

Figura 7. Tipos especiales y subtipos moleculares.

\subsubsection{Clasificación de los tumores triple negativos}

- Grado histológico bajo:

- Carcinoma adenoideo quístico.

- Carcinoma secretor.

- Carcinoma metaplásico tipo fibromatosis.

- Carcinoma mucoepidermoide.

- Grado histológico intermedio:

- Carcinoma de células acinares.

- Grado histológico alto:

- Carcinoma metaplásico variante de células escamosas (epidermoide).

- Carcinoma metaplásico variante de células fusiformes.

- Carcinoma metaplásico con componente heterólogos.

- Carcinoma mucoepidermoide.

- Carcinoma con patrón medular.

\subsection{TIPOS ESPECIALES}

Grupo de carcinomas con características morfológicas, conducta biológica y evolución clínica diferentes al carcinoma ductal infiltrante sin patrón específico (SPE), que además representa el $25 \%$ de todos los carcinomas de mama. ${ }^{47,48}$ En la figura 7 y la tabla 10 se muestran los tipos especiales en correlación con el subtipo 
Tabla 10. Características de los subtipos moleculares y asignación de los tipos histológicos especiales de cáncer de mama

\begin{tabular}{|c|c|c|}
\hline $\begin{array}{l}\text { Subtipo } \\
\text { molecular }\end{array}$ & ER, PR, HER2 & Marcador adicional \\
\hline Fenotipo basal & $\begin{array}{l}\text { ER - } \\
\text { PR - } \\
\text { HER2 - }\end{array}$ & $\begin{array}{l}\text { CK5/6 + } \\
\text { EGFR + }\end{array}$ \\
\hline HER/ER & $\begin{array}{l}\text { ER - } \\
\text { PR - } \\
\text { HER2 - }\end{array}$ & $\begin{array}{l}\text { CK5/6 +/- } \\
\text { EGFR +/- }\end{array}$ \\
\hline $\begin{array}{l}\text { Similar a mama } \\
\text { normal }\end{array}$ & $\begin{array}{l}\text { ER - } \\
\text { PR desconocido } \\
\text { HER - }\end{array}$ & $\begin{array}{l}\text { CK5/6 } \\
\text { EGFR + }\end{array}$ \\
\hline Luminal & $\begin{array}{l}\mathrm{ER}+(-) \\
\mathrm{PR}+/- \\
\mathrm{HER}-(+)\end{array}$ & \\
\hline $\begin{array}{l}\text { Molecular } \\
\text { apocrino }\end{array}$ & $\begin{array}{l}\text { ER - } \\
\text { PR - } \\
\text { HER2 +/- }\end{array}$ & $\begin{array}{l}\mathrm{AR}+ \\
\mathrm{CK5} / 6+/- \\
\text { EGFR +/- }\end{array}$ \\
\hline Bajo claudina & $\begin{array}{l}\text { ER - } \\
\text { PR - } \\
\text { HER2 - }\end{array}$ & $\begin{array}{l}\text { CLDN bajo/- } \\
\text { CDH1 bajo/- } \\
\text { CK5/6 +/- }\end{array}$ \\
\hline $\begin{array}{l}\text { Relacionado- } \\
\text { Interferón }\end{array}$ & $\begin{array}{l}\text { ER -/+ } \\
\text { PR desconocido } \\
\text { HER2- }\end{array}$ & STAT1 \\
\hline $\begin{array}{l}\text { Microarreglos } \\
\text { de proliferación }\end{array}$ & \multicolumn{2}{|l|}{ Tipo histológico especial } \\
\hline Alto & \multicolumn{2}{|l|}{$\begin{array}{l}\text { Adenoideo quístico } \\
\text { Células acinares } \\
\text { Medular } \\
\text { Metaplásico } \\
\text { Lobular pleomorfo } \\
\text { Secretor }\end{array}$} \\
\hline
\end{tabular}

(continúa)

molecular. En el carcinoma secretor y el carcinoma adenoideo quístico se han identificado alteraciones genéticas características y actualmente es deseable demostrarlas para tener un diagnóstico de certeza en estas entidades.

El carcinoma secretor debe tener la $\mathrm{t}(12 ; 15)(\mathrm{p} 13 ; \mathrm{q} 25)$ con el gen de fusión ETV6-NTRK3. ${ }^{44}$

El carcinoma adenoideo-quístico debe tener la $t(6 ; 9)$ (q22-23;p23-24) con el gen de fusión MYB-NFIB.

En los casos de carcinoma lobulillar de difícil diagnóstico, utilizar e-cadherina, $\beta$-catenina y $120 .{ }^{49}$

\subsection{Participación del patólogo en los estudios DE FIRMAS GENÓMICAS}

En la actualidad, la realización de las firmas genómicas se hace de forma centralizada en laboratorios
Tabla 10. Características de los subtipos moleculares y asignación de los tipos histológicos especiales de cáncer de mama (continuación)

\begin{tabular}{|l|l|l|}
\hline $\begin{array}{l}\text { Subtipo } \\
\text { molecular }\end{array}$ & ER, PR, HER2 & Marcador adicional \\
\hline Alto & $\begin{array}{l}\text { Apocrino } \\
\text { Lobulillar } \\
\text { Micropapilar } \\
\text { Lobulillar } \\
\text { pleomórfico }\end{array}$ \\
\hline Bajo & $\begin{array}{l}\text { Medular } \\
\text { Metaplásico }\end{array}$ \\
\hline Bajo/alto & $\begin{array}{l}\text { Apocrino } \\
\text { Carcinoma ductal } \\
\text { Osteoclástico } \\
\text { Lobulillar } \\
\text { Micropapilar } \\
\text { Mucinoso } \\
\text { Neuroendocrino } \\
\text { Lobulillar pleomorfo }\end{array}$ \\
\hline Tubular \\
\hline Alto & $\begin{array}{l}\text { Apocrino } \\
\text { Lobulillar pleomorfo }\end{array}$ \\
\hline Alto & Metaplásico \\
\hline Alto & Medular (?) \\
\hline & Medular (?) \\
\hline
\end{tabular}

AR: receptor de andrógenos; $C D H 1$ : e-cadherina; CLDN: claudina; CK: citoqueratina; EGFR: receptor del factor epidérmico; ER: receptor de estrógeno; PR: receptor de progesterona; STAT1: trasductor de señal y activador de transcripción 1; -: negativo; +: positivo; +/-: positivo ocasional; -/+: raramente positivo.

especializados. Es de suma importancia la participación del patólogo en la selección adecuada del material requerido para el estudio, por lo que se recomienda observar los siguientes puntos:

- Emplear únicamente muestras que en su proceso hayan sido fijadas en formol, al 10\% amortiguado.

- Anexar diagnóstico completo y adecuado, incluyendo marcadores de IHQ de acuerdo con la firma que se realizará.

- Mammaprint pide al menos $3 \mathrm{~mm}$ de carcinoma invasor. Oncotype pide 5 hasta $10 \mathrm{~mm}$ de carcinoma invasor. Endopredict requiere laminillas o bloques que contengan más del $30 \%$ de tumor.

- Evitar seleccionar bloques que contengan áreas extensas de necrosis hemorragia.

- Seleccionar bloques con menos de cinco años de antigüedad.

\section{Linfoma anaplásico de células grandes asociado al uso de implantes}

Esta entidad ha sido reconocida recientemente, por lo que en la actualidad no se cuenta con un manejo y estandarizados, el diagnóstico definitivo se hará en el estudio 
Tabla 11. Recomendaciones para el manejo y reporte de capsulectomías en pacientes con sospecha de linfoma anaplásico de células grandes, asociada a implantes ${ }^{51,52}$

\begin{tabular}{|c|c|c|}
\hline Indicaciones & $\begin{array}{l}\text { Seroma tardío (tiempo de aparición mayor a } 1 \\
\text { año después de la colocación del implante) }\end{array}$ & $\begin{array}{l}\text { Citología positiva o sospecha para linfoma anaplásico de } \\
\text { células grandes }\end{array}$ \\
\hline $\begin{array}{l}\text { Métodos de } \\
\text { fijación y } \\
\text { tiempo }\end{array}$ & $\begin{array}{l}\text { - Alcohol de } 96^{\circ} \text { en una proporción de } 1 \text { a } 1 \\
\text { - Fijación no mayor a } 48 \text { horas }\end{array}$ & $\begin{array}{l}\text { - Formol al } 10 \% \\
\text { - Cápsula completa (de referencia intacta y con el implante } \\
\text { - } 6-48 \text { horas de fijación }\end{array}$ \\
\hline $\begin{array}{l}\text { Descripción } \\
\text { del } \\
\text { procedimiento }\end{array}$ & $\begin{array}{l}\text { - } 10 \text { a } 50 \mathrm{ml} \text { (mínimo) } \\
\text { - Citología convencional o base líquida } \\
\text { - Centrifugar, realizar frotis teñidos con la } \\
\text { técnica de preferencia } \\
\text { - Bloque celular con el sedimento (si hay } \\
\text { material) } \\
\text { - Si es posible realizar marcadores de IHO (al } \\
\text { menos CD30 y ALK) }\end{array}$ & $\begin{array}{l}\text { - Examen macroscópico (medida, color, consistencia, espesor) } \\
\text { - Entintar el espécimen identificado seis caras (superior, inferior, } \\
\text { lateral, media, anterior y posterior) } \\
\text { - Cortar el espécimen por la cara superior en forma de cruz } \\
\text { - Descripción de las superficies (lisa, granular, nodular, } \\
\text { fribrinoide, hemorrágica, aspecto carnoso) } \\
\text { - En caso de identificar alguna de estas características o } \\
\text { presentar tumor, deberá hacerse un muestreo extenso de estas } \\
\text { áreas } \\
\text { - Si no hay ateraciones aparentes se sugiere incluir por cada } \\
\text { cara del espécimen (seis caras) dos fragmentos de tejido por } \\
\text { casete que midan al menos } 2 \mathrm{~cm} \text { de longitud de cada uno, es } \\
\text { decir un total de } 12 \text { casetes } \\
\text { - Cortes de rutina H - E } \\
\text { - IHO: CD30 y ALK } 1 \text { (mínimo) }\end{array}$ \\
\hline $\begin{array}{l}\text { Hallazgos } \\
\text { microscópicos }\end{array}$ & $\begin{array}{l}\text { - Células grandes discoadhesivas con núcleos } \\
\text { de contornos irregulares, cromatina vesicular, } \\
\text { nucléolo, citoplasma amplio } \\
\text { - Células con núcleos en herradura o de forma } \\
\text { arriñonada } \\
\text { - CD30 + y ALK - }\end{array}$ & $\begin{array}{l}\text { - Frecuente observar áreas necróticas con fantasmas celulares } \\
\text { linfoides y cariorrexis, alternando con menor cantidad de } \\
\text { células } \\
\text { neoplásicas viables e infiltrado inflamatorio } \\
\text { - Puede haber extensas áreas de fibrosis/esclerosis } \\
\text { - CD30 positivo en las células neoplásicas además de conservar } \\
\text { inmunorreactividad en las áreas de necrosis } \\
\text { - ALK } 1 \text { negativo (excluye LACG sistémico) }\end{array}$ \\
\hline Otros & $\begin{array}{l}\text { - Citometría de flujo } \\
\text { - Estudios moleculares }\end{array}$ & $\begin{array}{l}\text { - Marcadores de IHQ: granzima B +, perforina +, CD } 3+\text {, CD } 43 \text { +, } \\
\text { EMA +/-, CD } 68 \text {-, CK AE1/AE3 -, CD } 20-\text {, CD } 31 \text {-, melan - A - } \\
\text { - Estudios moleculares }\end{array}$ \\
\hline Reporte & $\begin{array}{l}\text { - Deberá describirse como sospechoso en el } \\
\text { caso de contar únicamente con la evaluación } \\
\text { morfológica, sin confirmación por IHO y/o } \\
\text { citometría de flujo } \\
\text { - Además de recomendar correlación clínico- } \\
\text { radiológica }\end{array}$ & $\begin{array}{l}\text { - Para fines de etapificación deberá consignarse si se trata de } \\
\text { una enfermedad localizada (células presentes solo en la } \\
\text { efusión, cara interna de la cápsula, espesor de la cápsula sin } \\
\text { rebasarla), la cual tiene mejor pronóstico y aumenta únicamente } \\
\text { capsulectomía } \\
\text { - Infiltración más allá de la cápsula, y/o a los tejidos blandos } \\
\text { adyacentes, y/o formación de tumor (tiene peor pronóstico y } \\
\text { pueden ser candidatas a OT adyuvante) }\end{array}$ \\
\hline
\end{tabular}

IHQ: inmunohistoquímica; ALK: quinasa de linfoma anaplásico; OT: quimioterapia.

citológico del líquido obtenido del seroma, o bien en los especímenes de capsulectomías; se sugiere realizar los procedimientos de acuerdo con lo descrito en la tabla 11.

\section{Estadificación del cáncer de mama TNM}

\section{Introducción}

El sistema de estadificación del cáncer de mama de American Joint Comittee on Cancer (AJCC) brinda información pronóstica importante. ${ }^{1}$
El comportamiento del cáncer de mama se ha comprendido tanto por la etapa clínica, como por la identificación y validación de marcadores biológicos pronósticos que son determinantes para el tratamiento.

Los cambios en la $8 .^{\text {a }}$ edición de la AJCC contienen la eliminación del carcinoma lobulillar in situ, debido a que no corresponde a una lesión maligna y solo es un marcador de riesgo. Por otra parte, se incluyen marcadores biológicos para determinar un estadio clínico y patológico pronóstico. ${ }^{2}$

Con base en los parámetros clásicos de tumor ( $T)$, estado ganglionar (N) y metástasis (M) es posible 
determinar el estadio clínico y el patológico anatómico como en la clasificación previa; en esta $8 .^{a}$ edición se adiciona a lo anterior el grado tumoral, los receptores de estrógenos y de progesterona, el HER2 neu y, de tener accesibilidad, el score de recurrencia calculado con Oncotype Dx, para establecer con toda esta información una etapa clínica y patológica pronóstica.

Para el cálculo de dichas etapas, el presente consenso recomienda el uso de plataformas electrónicas como:

- https://itunes.apple.com/gb/app/breast-cancer-staging-nm-8/id1218852568?mt=8

- https://play. google. com/store/apps/details?id=com. wesley. TNMBreast and hl=en_US

Estas pueden ser descargadas en teléfonos inteligentes y otros equipos electrónicos para su consulta.

Existen tres esquemas para la estadificación:

- Etapa anatómica. Se basa exclusivamente en la extensión anatómica de la enfermedad, definida por las categorías $\mathrm{T}, \mathrm{N}$ y $\mathrm{M}$.

- Etapa clínica pronóstica. En donde además del estadio determinado por el T, $\mathrm{N}$ y $\mathrm{M}$ basados en la exploración física y estudios de imagen se debe incluir el grado tumoral, y el estado de los receptores de estrógenos, receptores de progesterona y el receptor de factor de crecimiento epidérmico humano (HER2).

- Estadio patológico pronóstico. Se utiliza para asignar el estadio en pacientes que han sido sometidas a cirugía como tratamiento primario o posterior a neoadyuvancia.

Este sistema de estadificación no se debe de utilizar para todas las histologías de tumores malignos de la mama. ${ }^{2}$ Existe un sistema de estadificación específico para algunas variedades histológicas, como:

- Sarcomas de mama.

- Tumores phyllodes.

- Linfomas de mama.

\section{Estudios de extensión para estadificación inicial}

Estrictamente, no es necesario que una paciente cuente con evaluación radiológica de sitios distantes para clasificarla como M0. Los estudios de extensión deber ser principalmente enfocados a los signos y síntomas de cada paciente. En ausencia de síntomas específicos 0 anormalidades en pruebas sanguíneas generales, para las etapas I y IIB no se requiere ningún estudio de extensión. Para el cáncer de mama localmente avanzado, podrían considerarse los siguientes estudios: $^{3}$
- Tomografía computarizada (TC) o resonancia magnética $(\mathrm{RM})$ abdominal, en casos de elevación en las pruebas de funcionamiento hepático o de la fosfatasa alcalina, o síntomas abdominales o anormalidades a la exploración física (puede sustituirse por ultrasonido abdominal en caso de no contar con TC o RM) (categoría 2A National Comprehensive Cancer Network [NCCN]).

- Tomografía de tórax, en caso de síntomas pulmonares (categoría 2A NCCN).

- Gamagrama óseo en caso de dolor óseo localizado o elevación de fosfatasa alcalina (categoría 2B NCCN).

- Tomografía por emisión de positrones/tomografía computarizada en etapas IIIA en adelante (categoría 2B NCCN).

\section{Carcinoma in situ}

\section{Carcinoma ductal in situ}

Es un grupo heterogéneo de neoplasias, caracterizado por la presencia de células epiteliales malignas que crecen dentro de los conductos mamarios, sin rebasar la membrana basal, y se identifican por microscopia de luz. Adopta diferentes patrones arquitectónicos de crecimiento intraductal y presenta características citológicas y de necrosis variables; puede ser unifocal o multifocal. Se conoce también con el nombre de carcinoma intraductal.

Estos carcinomas se sospechan por la existencia de un hallazgo mastográfico anormal (microcalcificaciones, masa o un área densa asimétrica) o por la existencia de un tumor palpable o secreción por el pezón; una forma de presentación poco frecuente puede ser la enfermedad de Paget (afección por carcinoma ductal in situ [CDIS], confinada exclusivamente al complejo areola-pezón).

El diagnóstico histológico y la determinación de la extensión (tamaño) son indispensables para la selección de la terapéutica adecuada. Es importante recalcar que, en ocasiones, el carcinoma intraductal crece dentro de los ductos de manera discontinua y que la extensión a menudo es mayor que la visualizada en la mastografía o calculada por la clínica.

\subsection{Recomendación de tRATAMIENTO LOCAL Y REGIONAL}

La resección quirúrgica del CDIS es el tratamiento de elección. Las opciones quirúrgicas incluyen la 
cirugía conservadora, la mastectomía total con o sin reconstrucción inmediata y la cirugía oncoplasica de la mama, en caso de sospecha clínica de invasión, es conveniente adicionar biopsia de ganglio centinela.

En cirugía conservadora, la radiografía de la pieza operatoria es un método útil para verificar la escisión completa de la lesión. Siempre deberá orientarse la pieza operatoria resecada, para conocer con precisión cada uno de los márgenes quirúrgicos (superior, inferior, interno, externo, superficial y profundo), con referencia de al menos tres de los márgenes con sedas, grapas metálicas o preferentemente mediante la tinción de la pieza por parte del cirujano. En cirugía conservadora es importante la colocación de una marca radioopaca en el lecho quirúrgico, para orientar al radiooncólogo en caso de aplicarse radioterapia adyuvante.

El margen final patológico en la escisión se considera cercano cuando es $<2 \mathrm{~mm}$ y óptimo cuando es $\geq 2 \mathrm{~mm} .{ }^{1}$ En caso de lecho quirúrgico con fascia, se considera óptimo al reportarse como negativo.

Recomendaciones para reescisión (cirugía conservadora o cirugía oncoplástica de la mama):

- Margen menor de $2 \mathrm{~mm}$. Cabe señalar que la cirugía adicional sistemática puede no estar justificada en pacientes con márgenes $<2 \mathrm{~mm}$ que recibirán radioterapia adyuvante.

- Microcalcificaciones residuales.

En los casos tratados con cirugía conservadora, la radioterapia se administrará a la mama únicamente.

Todas las pacientes con cirugía conservadora se benefician de radioterapia postoperatoria, particularmente aquellas con alto riesgo de recurrencia local: < 50 años, tumor $>15 \mathrm{~mm}$, enfermedad multifocal, grado nuclear intermedio o alto, necrosis central, histología comedo o margen quirúrgico radial $<10 \mathrm{~mm}^{2-4}$

El hipofraccionamiento moderado con esquemas de 40 Gy en 15 fracciones 042.5 Gy en 16 fracciones, no es inferior en control local y resultados cosméticos al esquema convencional de 50 Gy en 25 fracciones, por lo que puede utilizarse.

La irradiación parcial acelerada de mama con radioterapia externa es una opción para pacientes con CDIS (de bajo riesgo), en caso de que esta técnica se encuentre disponible en el centro hospitalario. ${ }^{5-9} \mathrm{El}$ boost en pacientes con CDIS es controvertido. Con base en la evidencia actual pudiera ofrecerse en pacientes menores de 50 años o con márgenes $<2 \mathrm{~mm}^{10}$

Recomendaciones para mastectomía total:

- Enfermedad multicéntrica.

- Relación mama-tumor desfavorable.
- Imposibilidad de conseguir márgenes negativos (sin tumor en tinta).

- Deseo de la paciente.

- Imposibilidad para administrar radioterapia.

El estado de los márgenes quirúrgicos y el alto grado pueden incrementar el riesgo de recurrencia posterior a la cirugía. Las pacientes en las que se identifique microinvasión o invasión en el estudio histológico definitivo, se tratarán de acuerdo con los lineamientos de carcinoma invasor.

En centros especializados, un equipo multidisciplinario podrá valorar en situaciones especiales para proponer la mastectomía profiláctica contralateral, la cual ha demostrado ser segura y eficaz al reducir la posibilidad de un cáncer en el futuro en mujeres asintomáticas con alto riesgo. ${ }^{11}$

En pacientes con factores de buen pronóstico (mencionados en el esquema) la supervivencia libre de enfermedad en el manejo con resección quirúrgica sin radioterapia es mayor del $94 \% .^{12,13}$

\subsection{Ganglio centinela en Carcinoma in Situ}

En general, no se recomienda disección axilar o ganglio centinela; sin embargo, en aquellas pacientes que requerirán mastectomía total para su manejo, o en las que se tenga sospecha de invasión, podrá considerarse la localización y estudio histológico del ganglio centinela, y actuar en consecuencia de su resultado; esto evitará disecciones ganglionares linfáticas innecesarias en el futuro, en caso de encontrarse microinvasión o invasión en la pieza quirúrgica. Cuando se considere realizar biopsia de ganglio centinela y el procedimiento resulte fallido no se recomienda la disección radical de axila. La figura 8 presenta el algoritmo.

\subsection{TRATAMIENTO CON TAMOXIFENO E INHIBIDORES DE AROMATASA}

Se recomienda terapia reductora de riesgo con tamoxifeno por cinco años en pacientes con cirugía conservadora de mama y receptores hormonales positivos. En mujeres posmenopáusicas puede considerarse tratamiento con inhibidor de aromatasa por cinco años. ${ }^{14}$

En caso de mastectomía, ver Capítulo XXI. Quimioprevención.

\subsection{Seguimiento}

La evaluación de la glándula mamaria en casos de CDIS tratados con cirugía conservadora deberá incluir 


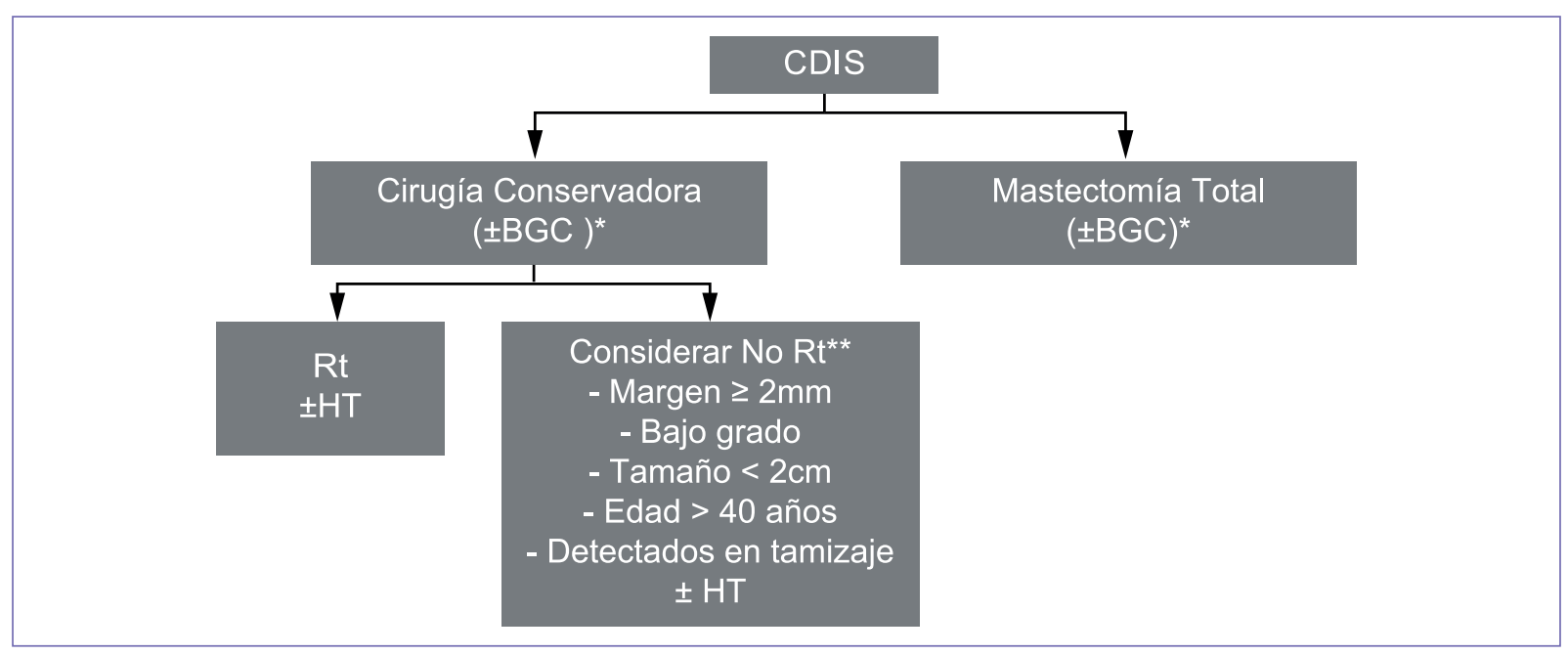

Figura 8. Algoritmo de manejo quirúrgico del carcinoma ductal.

*En sospecha clínica de invasión.

**Debe cumplir TODAS.

CDIS: Carcinoma ductal in situ; BGC: Biopsia de ganglio centinela; Rt: Radioterapia; HT: Hormonoterapia.

una mastografía a los seis meses posteriores al término de tratamiento local. Después se efectuará una mastografía + ultrasonido anual.

\section{Carcinoma lobulillar in situ (neoplasia lobulillar in situ)}

Es una lesión poco frecuente, en la que el diagnóstico histológico y diferencial con la hiperplasia atípica requiere la intervención de patólogos expertos. En general, no se relaciona con masa palpable o cambios mastográficos específicos. Esta lesión se considera como un marcador de riesgo y no un cáncer que evolucione hacia la forma invasora de manera directa. Alrededor del 10 al $15 \%$ de las pacientes presentará durante su vida un carcinoma invasor en cualquiera de las mamas, generalmente de tipo ductal infiltrante. El riesgo de aparición de cáncer de mama invasor se aproxima al $0.5 \%$ por año de seguimiento (acumulable) y cuando se vincula con carga genética de primer grado, el riesgo aumenta al $1 \%$ por año.

La variedad clásica no requiere manejo quirúrgico. Existe evidencia que sostiene que la presencia de variantes agresivas, como el subtipo pleomórfico o la asociación con necrosis o células en anillo de sello, tienen mayor potencial de desarrollar carcinoma invasor que la variante clásica, por lo que el tratamiento de elección en esos casos es la escisión completa de la lesión con márgenes negativos (Fig. 9). ${ }^{15}$
Todas las pacientes con carcinoma lobulillar in situ (CLIS) deberán incluirse en un programa de seguimiento y vigilancia estrechos, además de asesoramiento en relación con quimioprevención o mastectomía bilateral profiláctica. Debido al bajo porcentaje de progresión a enfermedad invasora, el CLIS no requiere manejo con radioterapia.

\section{Manejo del cáncer de mama temprano}

\section{Manejo quirúrgico primario en cáncer de mama}

El manejo quirúrgico primario está indicado para aquellas pacientes con cáncer de mama temprano. Este puede ser con cirugía conservadora o mastectomía total, independientemente del manejo quirúrgico de la axila. Debe ser seguido de las terapias adyuvantes según esté indicado. Como en otros escenarios clínicos, se recomienda la evaluación del caso en equipos multidisciplinarios. La estrategia de realizar biopsias escisionales con estudio transoperatorio de una lesión mamaria sospechosa por clínica e imagen y en caso de malignidad realizar mastectomía radical modificada, debe ser abandonada. En la actualidad es necesario que toda paciente tenga confirmación histológica previa a la cirugía. 


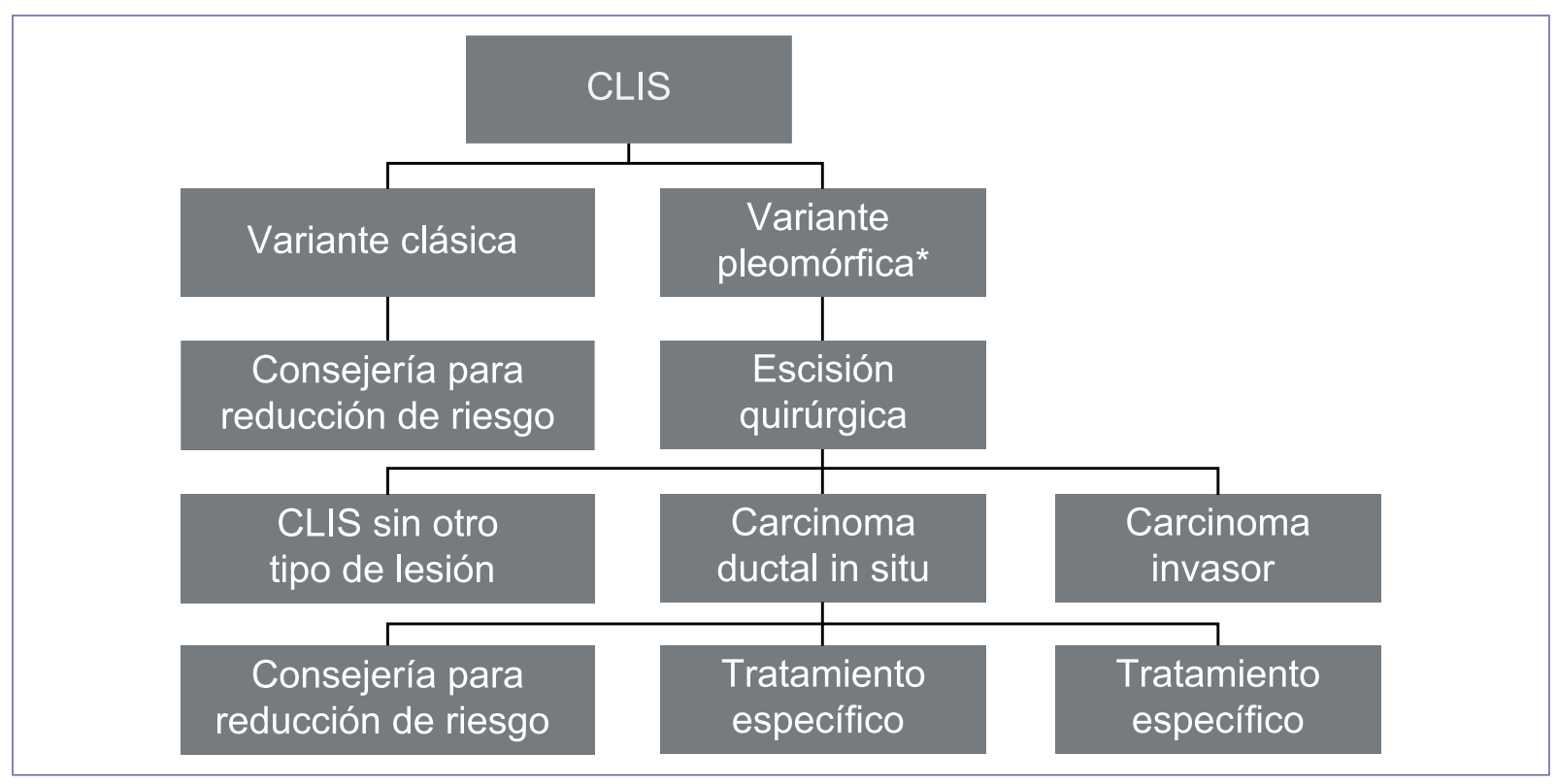

Figura 9. Algoritmo de manejo del carcinoma lobulillar in situ.

* Considerar también variantes con células en anillo de sello o presencia de comedonecrosis.

CLIS: Carcinoma lobulillar in situ.

\subsection{Cirugía conservadora}

La cirugía conservadora de mama es la escisión completa del tumor primario con margen patológico negativo. La mayoría de los casos debe complementarse con radioterapia (RT) adyuvante, y es el tratamiento estándar en etapas tempranas. ${ }^{1}$ La cirugía conservadora y RT adyuvante han demostrado resultados similares en cuanto a recurrencia locorregional y supervivencia global (SG) en comparación con la cirugía radical..$^{2-5}$

- Criterios de selección e indicaciones:

- Relación mama-tumor favorable, que permita anticipar un buen resultado estético.

- Deseo de la paciente.

- Contraindicaciones:

- Carcinoma inflamatorio.

- Relación mama-tumor desfavorable, aun con el uso de técnicas oncoplásticas.

- Imposibilidad de recibir RT adyuvante.

- Imposibilidad de obtener márgenes negativos (multicentricidad).

Aunque la multicentricidad como contraindicación para cirugía conservadora de mama ha sido puesta en cuestionamiento en estudios prospectivos, mostrando resultados estéticos satisfactorios, su seguridad oncológica y resultados a largo plazo no han sido reportados. ${ }^{6}$

El objetivo es obtener márgenes negativos en patología con un resultado estético satisfactorio, lo que puede realizarse mediante resecciones simples o uso de técnicas oncoplásticas. La pieza quirúrgica debe ser siempre orientada y marcada para el reconocimiento del patólogo. Se recomienda la estandarización en los centros hospitalarios para la referencia de la pieza quirúrgica. En caso de márgenes positivos, se debe realizar ampliación del mismo. El lecho quirúrgico debe ser marcado con clips radiopacos para la localización futura (RT y vigilancia).

Las técnicas oncoplásticas actuales permiten movilización de una mayor proporción de tejido mamario, obteniendo mejor resultado estético, sin condicionar mayor riesgo de conversión a mastectomía en caso de ameritar reescisiones. ${ }^{7}$

\subsection{Mastectomía}

- Tipos de mastectomía

- Simple o total.

- Preservadora de piel.

- Preservadora de complejo areola-pezón (CAP).

- Radical modificada. 
- Radical.

Es importante que las pacientes sean informadas de las técnicas y de las posibilidades de reconstrucción, además de los tiempos en los que se pueden realizar (ver Capítulo X. Reconstrucción).

- Indicaciones de mastectomía

- Preferencia de la paciente. Enfermedad multicéntrica sin posibilidad de márgenes libres.

- Relación mama-tumor desfavorable para un buen resultado estético.

- Dificultad para un seguimiento adecuado..$^{8-11}$

\subsection{Cirugía oncoplástica}

La cirugía oncoplástica es un conjunto de técnicas quirúrgicas que permiten efectuar resecciones proporcionalmente mayores con un resultado estético satisfactorio. Se basa en la integración de técnicas de cirugía plástica para el reposicionamiento del tejido mamario sano, después de la resección completa del tumor con márgenes negativos. ${ }^{12}$

Existen tres factores a considerar en la selección de la técnica quirúrgica:

- Relación mama-tumor.

- Localización de la lesion.

- Densidad mamaria.

Clough, et al. proponen clasificar las técnicas oncoplásticas en dos grupos:

- Volumen resecado menor al 20\%. Estas técnicas las puede efectuar un cirujano oncólogo sin entrenamiento específico en cirugía oncoplástica.

- Volumen que resecar del 20 al 50\%. Requieren escisión de piel residual para la remodelación de la mama. Se basan en técnicas de mamoplastía de reducción y requieren entrenamiento específico, y simetrización de la mama contralateral simultánea (preferible) o diferida.

La cirugía oncoplástica ha permitido ampliar las indicaciones del tratamiento conservador de la mama. ${ }^{13-}$ 17 Los resultados óptimos se obtienen con la buena selección de las pacientes candidatas, en el contexto de equipos multidisciplinarios que incluyan oncólogos quirúrgicos con entrenamiento y experiencia en cirugía oncoplástica. ${ }^{18-20}$

En cirugía oncoplástica cobra mayor relevancia el establecimiento del margen adecuado en el transoperatorio, ya que con la gran movilización del tejido que se realiza puede ser difícil localizar el sitio exacto para la ampliación en caso de márgenes positivos, por lo que recomendamos apoyarse de métodos para asegurar dicho margen (entintado de margen, ultrasonido y rayos $\mathrm{X}$ transoperatorios, etc.). El lecho tumoral debe marcarse con grapas después de la resección y antes del reposicionamiento del tejido, para permitir al radiooncólogo mayor precisión en la identificación del área que deberá recibir dosis adicional..$^{19-21}$

\subsection{TRATAMIENTO QUIRÚRGICO DE LA AXILA}

En cáncer invasor, la evaluación axilar es parte fundamental de su manejo; el objetivo primario es la información pronóstica que brinda el estado ganglionar.

En la estadificación inicial, el examen clínico sistemático y los estudios de imagen deberán ser considerados para orientar las decisiones de evaluación/manejo, se recomienda en todas las pacientes la evaluación completa de regiones axilares con ultrasonografía. 22-24

La decisión del tratamiento quirúrgico deberá tomar en cuenta escenarios posibles:

- Estatus de la enfermedad.

- Ganglios negativos (cN0).

- Ganglios positivos (cN+).

- Momento de la cirugía.

- Cirugía primaria.

- Cirugía posneoadyuvancia.

- Respuesta/negativización.

- Persistencia.

- Extensión de la cirugía que otorgara la información necesaria.

- Ganglio centinela (GC).

- Disección radical de axila (DRA).

Los escenarios posibles se resumen y conjugan en las figuras 10-13.

\subsubsection{Ganglio centinela}

En axila clínicamente negativa (cNO), la biopsia de ganglio centinela (GC) es el estándar en la estadificación quirúrgica, con el objetivo de conocer el estado histopatológico, con base en los estudios aleatorizados que han demostrado la seguridad oncológica del procedimiento y una menor morbilidad (linfedema, dolor y alteraciones sensoriales del miembro torácico y del hombro) respecto a los efectos de la disección radical de axila (DRA). ${ }^{24-27}$

La recomendación del procedimiento del GC incluye primordialmente la experiencia del cirujano, quien deberá demostrar dominio de la técnica de mapeo. En lo que respecta a la identificación del GC, esta es independiente del sitio de aplicación del colorante 0 radioisótopo (peritumoral vs. periareolar). 


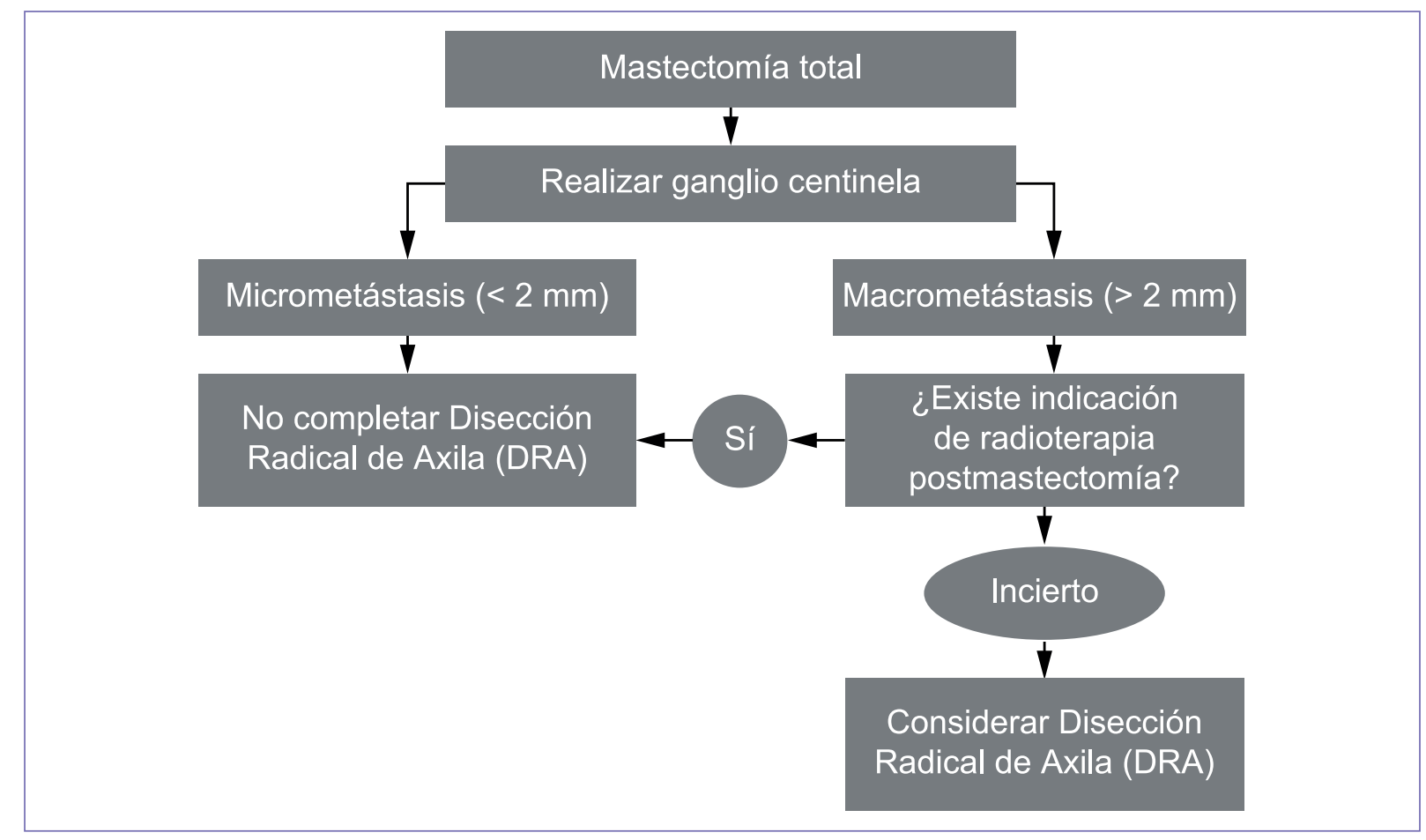

Figura 10. Tratamiento quirúrgico primario. Ganglios clínicamente negativos cN0. DRA: disección radical de axila.

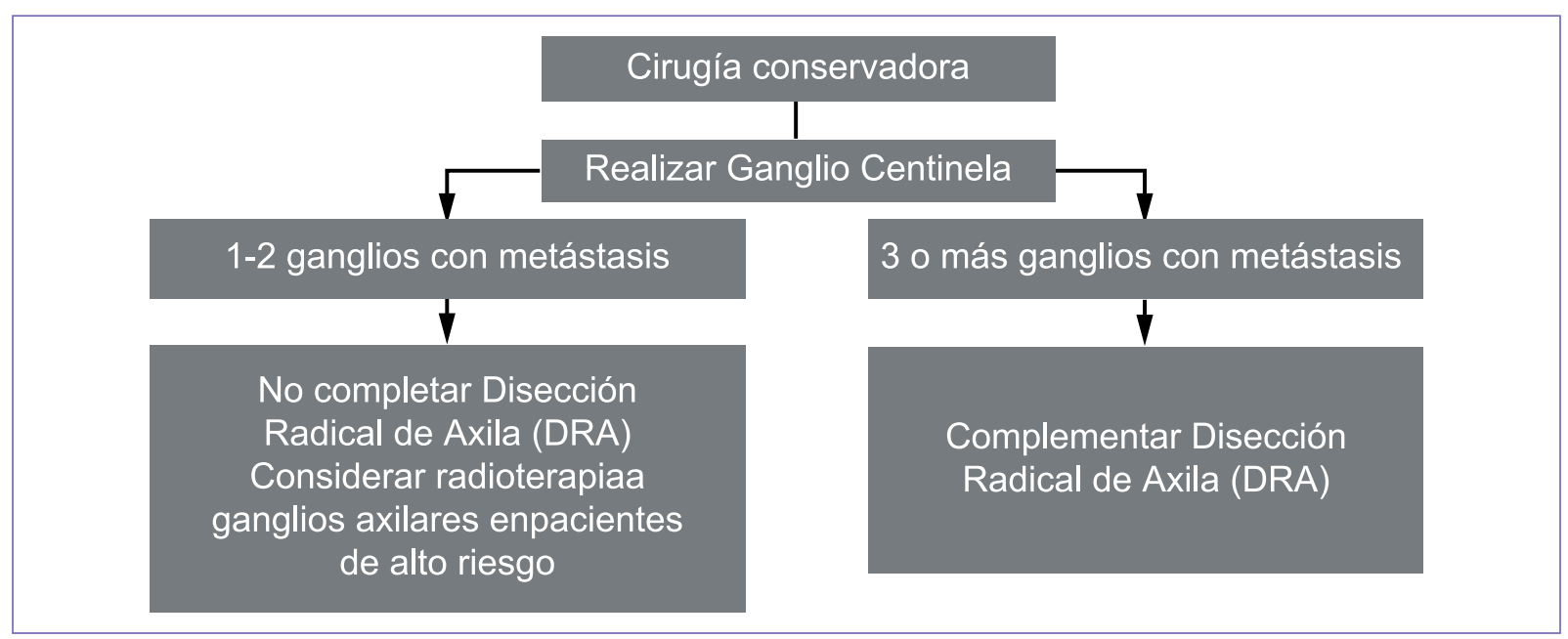

Figura 11. Tratamiento quirúrgico primario. Ganglios clínicamente negativos cNO. DRA: disección radical de axila.

A pesar de que se han demostrado tasas de localización altas con una sola técnica, independientemente de cuál se realice, la recomendación es hacerla con ambas (colorante y radioisótopo), cuando se disponga con departamento de medicina nuclear. Como recomendación puntual, de no contar con las condiciones necesarias (dominio de la técnica, dispositivos quirúrgicos, trazadores o equipo de patología familiarizado con el manejo del ganglio), deberá considerarse la referencia de los pacientes a centros especializados en el procedimiento 


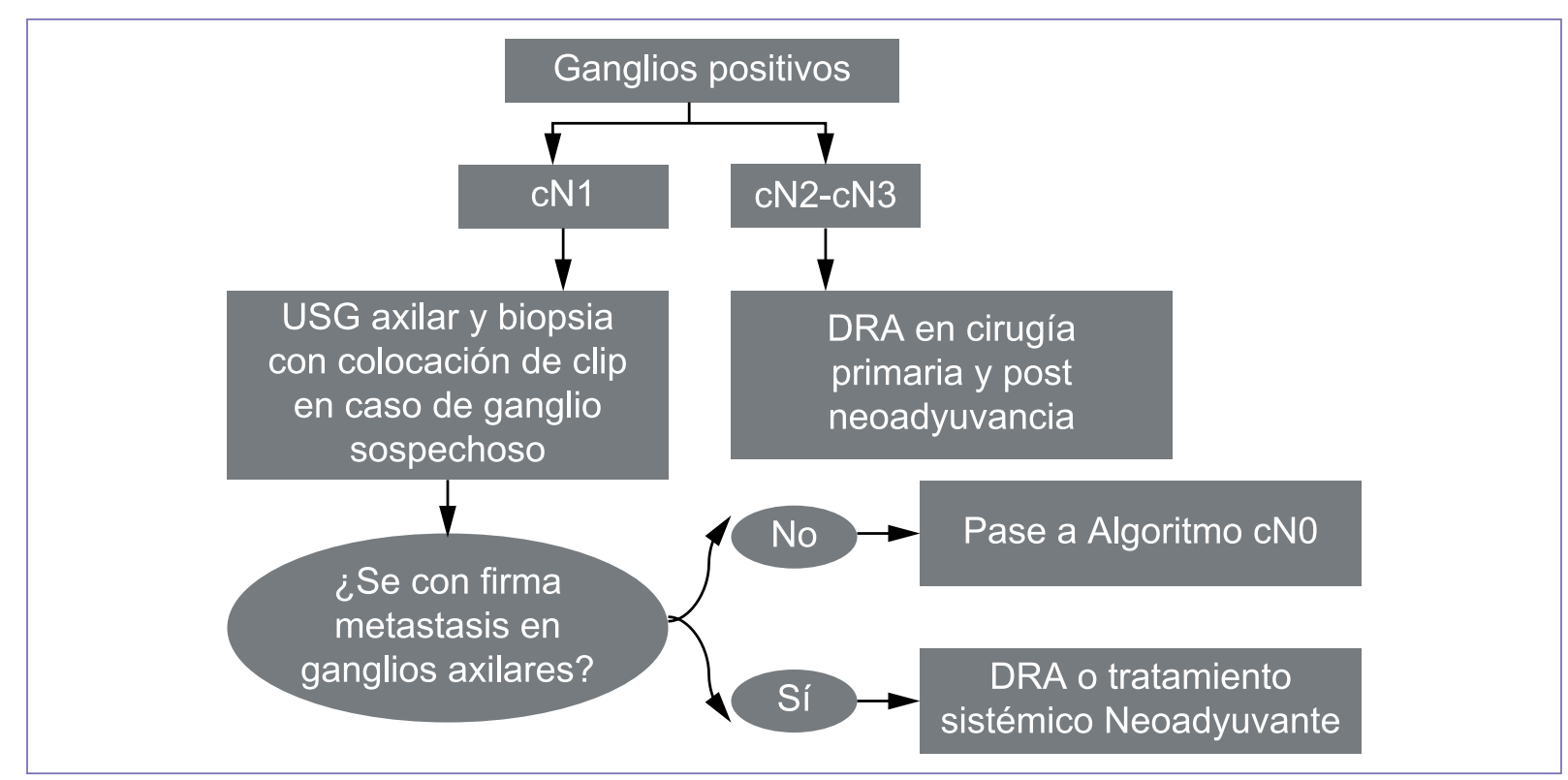

Figura 12. Paciente con ganglios clínicamente positivos $(\mathrm{N}+)$. USG: ultrasonografía; DRA: disección radical de axila.

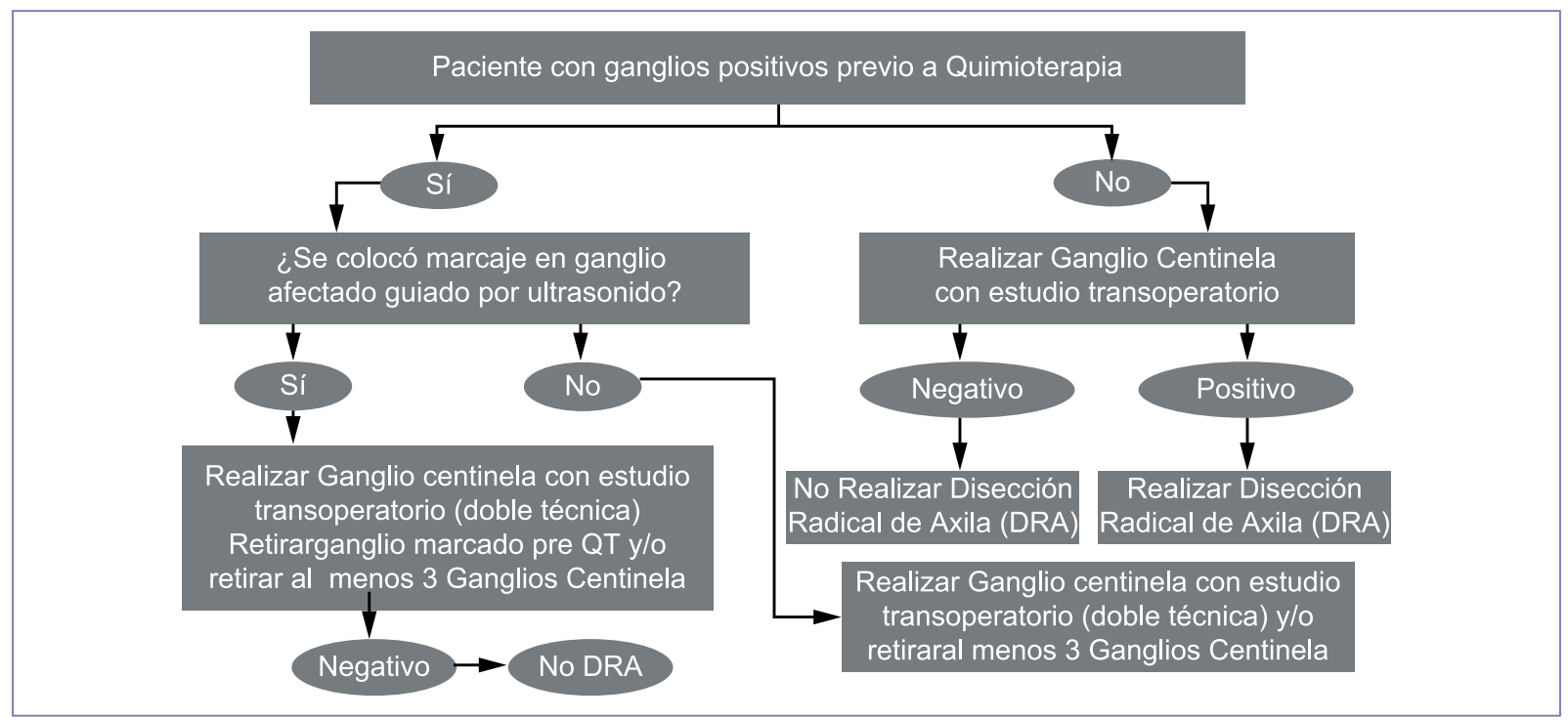

Figura 13. Tratamiento quirúrgico axilar. Posterior a neoadyuvancia (cN1).

DRA: disección radical de axila.

(actualmente se considera oncológicamente incorrecto realizar una disección de axila ante cNO y cirugía primaria). ${ }^{28,29}$

\section{Omisión de la disección radical de axila ante ganglio centinela positivo}

Estudios prospectivos como ACOSOG Z00117, NSABP-32, ${ }^{28}$ IBCSG $23-01^{30}$ y AMAROS ${ }^{31}$ respaldan la recomendación de omitir la DRA en casos seleccionados, así como el uso de RT, para un adecuado control regional en algunos casos con ganglios positivos y con menor morbilidad comparado con la disección axilar.

Es posible omitir la DRA en:

- Pacientes con T1-T2, con GC positivo para micrometástasis.

- Pacientes con tumores T1-T2, tratados con cirugía conservadora y GC; si el resultado es de uno o dos 
GC positivos para macrometástasis y que serán llevadas a tratamiento adyuvante con $R T$ y tratamiento sistémico.

- Pacientes ante cirugía posneoadyuvancia que inicialmente eran $\mathrm{N}+$ corroborada por biopsia y que se consideró $\mathrm{cN} 1$ (< 4 ganglios de afección inicial), preferentemente con colocación de marcador radio-opaco previo al tratamiento, con respuesta completa en la evaluación clínica posterior, debiendo cumplir con lo siguiente: ${ }^{32,33}$

- Doble técnica de mapeo.

- Disección de al menos tres ganglios.

- Disección de ganglio marcado.

\subsubsection{Disección radical de axila}

Desde los resultados del estudio NSABP B- $04,{ }^{25}$ que establece la separación de conceptos de manejo de la mama y la axila, se considera el procedimiento convencional en pacientes que serán llevadas a manejo quirúrgico primario/posneoadyuvancia, que presentan enfermedad ganglionar inicial (preferentemente corroborada por biopsia) o persistente.

La extensión anatómica del procedimiento deberá contener niveles I y II, reservando el nivel III para aquellos casos en que durante el procedimiento quirúrgico se encuentra afección clínica macroscópica. Respecto a la extensión en el número de ganglios, la recomendación considera como óptima una cosecha ganglionar de al menos 10 ganglios (riesgo de recurrencia $<10$ ganglios del 5 al $21 \%$ vs. 3 al $5 \%$ en > 10 ganglios).

Se recomienda completar con DRA a las pacientes llevadas a mastectomía total con GC, el cual en el estudio patológico (transoperatorio y/o definitivo) resulta con enfermedad macrometastásica, además de aquellas pacientes en cirugía primaria con tres o más ganglios centinelas positivos, y en las que en el estudio patológico posneoayuvancia persiste enfermedad.

\subsection{RECONSTRUCCIÓN MAMARIA}

La decisión de realizar una mastectomía parcial o total depende de retos reconstructivos y consideraciones oncológicas. Ciertamente, la etapa del cáncer y la capacidad de obtener bordes negativos en los márgenes tumorales son factores determinantes. De igual forma lo son la relación mama-tumor y la localización de este. La decisión de realizar una mastectomía parcial o total por parte del cirujano oncólogo marcará el inicio del plan reconstructivo. La planeación conjunta para determinar la resección, expectativas de manejo posteriores y el momento reconstructivo es un buen comienzo para ofrecer el tratamiento personalizado más adecuado para cada situación y cada paciente.

\subsubsection{Abordaje reconstructivo para defectos parciales}

En general, la reparación de defectos de mastectomía parcial es más adecuado para pacientes con mamas grandes. ${ }^{34} \mathrm{El}$ suficiente volumen de tejido mamario restante después de la extirpación del tumor permite la reorganización del tejido mamario para moldearlo. ${ }^{35}$ Las pacientes con ptosis también son buenas candidatas para mastectomía parcial, debido a que la mayoría las técnicas emplean una mastopexia o reducción mamaria que reposiciona el complejo pezón-areola más alto en el montículo de mama, devolviendo así la apariencia juvenil de la mama al momento que se retira el tumor. ${ }^{36}$

La quimioterapia (QT) neoadyuvante puede reducir el tamaño de grandes tumores y permitir a las pacientes que responden favorablemente ser buenas candidatas para la conservación de la mama, y así realizar mastectomía parcial, seguida de RT. ${ }^{37-43}$

\subsubsection{Reconstrucción de defectos parciales}

La remodelación del tejido antes de la RT permite el uso de técnicas con tejido local (oncoplástica), sin la necesidad de aumentar las tasas de complicaciones asociadas con el uso de estas mismas técnicas en mamas ya radiadas. La reconstrucción inmediata en el momento de la mastectomía parcial, se emplea mejor en pacientes con enfermedad localizada, cuando se dispone de una evaluación confiable del margen tumoral intraoperatorio.

\subsubsection{Técnicas reconstructivas para defectos parciales}

Las técnicas de reconstrucción a menudo están influenciadas por el momento de la reconstrucción y la asociación a $\mathrm{RT} .{ }^{43} \mathrm{La}$ reconstrucción tardía en una mama completamente radiada frecuentemente requiere la transferencia de un colgajo que en ocasiones incluya una porción de piel. El injerto de grasa autóloga, junto con la liberación percutánea con agujas de las bandas cicatriciales, es un método común para la reparación tardía; sin embargo, generalmente se requieren múltiples eventos quirúrgicos. Las opciones de reconstrucción posterior a RT parcial de mama son 
diferentes; con la RT parcial, el tejido mamario restante no se ha irradiado y se puede usar para reparar el defecto con menor tasa de complicaciones.

Los defectos de cuadrantes inferiores y externos a menudo requieren reparación con trasposición de colgajos, como el de la arteria toracodorsal o el colgajo miocutáneo dorsal ancho, con isla de piel si es necesario. Es importante favorecer la simetría de la mama contralateral en el mismo tiempo quirúrgico cuando sea posible.

\subsubsection{Abordaje reconstructivo tras mastectomía total}

El momento de la reconstrucción es lo más importante en el proceso de toma de decisiones. Si obviamos las características particulares de la paciente como edad, morbilidad asociada e índice de masa corporal, entre otras, en el caso de que se requiera RT o si la paciente tiene un riesgo de requerirla, retrasar la reconstrucción definitiva (implante o tejido autólogo), y colocar un expansor tisular anatómico para preservar la piel de la mama para una reconstrucción tardía (posterior a RT) suele ser la mejor opción. Si no se requiere $\mathrm{RT}$, la reconstrucción inmediata es apropiada y permite mejores resultados estéticos, ya sea con expansor/ implante o con tejido autólogo (colgajo libre 0 pediculado).

Por otra parte, si se realiza reconstrucción mamaria en el momento de la mastectomía y el resultado histopatológico muestra afectación de los ganglios linfáticos, debe administrarse RT posoperatoria. La complicación a nivel de la herida quirúrgica es la más frecuente por RT. Por otro lado, la irradiación de cadenas ganglionares en este contexto puede ser compleja y pueden emplearse técnicas altamente conformadas para cubrir adecuadamente la cadena mamaria interna y los niveles axilares para disminuir la dosis a órganos sanos como el pulmón. ${ }^{44}$

Para estas situaciones existe la opción de realizar reconstrucción diferida-inmediata o «tardía-inmediata», que consiste en colocar en un primer tiempo un expansor tisular retromuscular y reservar para el segundo tiempo un implante definitivo, o bien una opción de tejido autólogo. Con la reconstrucción diferida-inmediata, los pacientes que no requieren RT pueden lograr resultados de herida quirúrgica similares a los realizados con la reconstrucción inmediata, y los pacientes que requieren RT pueden evitar los problemas estéticos asociados con la administración de radiación, después de una reconstrucción inmediata de la mama.
No obstante, la evidencia internacional reciente (nivel 3) señala que si una paciente es candidata a reconstrucción con tejido autólogo en condiciones de salud favorables, esta sea llevada a reconstrucción inmediata, aunque se requiera RT posmastectomía. Esto sustentado en el hecho de que no hay diferencias que impacten en la satisfacción de las pacientes en términos de forma y textura del colgajo, así como no hay diferencias en porcentaje de necrosis grasa. La fibrosis en el colgajo no fue un factor relevante para la forma de la mama o insatisfacción en las pacientes.

Se realiza el método reconstructivo con la mejor opción disponible; es decir, tejido autólogo, implante 0 combinación de ambos. Es importante mencionar que la expansión debe interrumpirse previo a la planeación de la RT. Si se considera que la piel está en mal estado o presenta demasiada hipotrofia, es conveniente disminuir el volumen del expansor previo a la RT. La reconstrucción final se realiza después de 12 meses de finalizada esta, a fin de disminuir la tasa de complicaciones asociadas a morbilidad en el sitio quirúrgico.

\subsubsection{Proceso completo de reconstrucción mamaria}

Independientemente de los múltiples escenarios que pueden presentarse en pacientes con cáncer de mama, salvo excepcionales casos, la reconstrucción total se logra en dos tiempos quirúrgicos, a los cuales puede adicionarse un tercer procedimiento local para refinamientos. Al respecto presentamos las diversas opciones disponibles.

\subsubsection{Reconstrucción con expansor/implante}

Este tipo de reconstrucción implica la colocación de un expansor retromuscular en el primer tiempo quirúrgico, infiltraciones para expansión en consultorio y al lograr el volumen deseado, la eventual colocación de un implante definitivo. El proceso puede completarse en un periodo de 10 a 18 semanas.

\subsubsection{Reconstrucción con expansor + matriz dérmica/implante o implante + injerto 0 inyección grasa}

Se utiliza una matriz dérmica acelular para cubrir el polo inferior del expansor y el músculo pectoral mayor cubrirá el polo superior. Una tendencia reciente es proporcionar una cobertura completa del expansor con matriz dérmica acelular para reducir potencialmente la aparición de contractura capsular. Usando esta 
técnica, todo el expansor queda cubierto con una gran lámina de matriz dérmica acelular y el músculo pectoral mayor queda debajo, reduciendo así el dolor postoperatorio. Este método es conocido como reconstrucción prepectoral. El segundo tiempo reconstructivo implica la colocación del implante definitivo, con o sin el uso de injerto graso para el contorno mamario. La matriz dérmica favorece el grosor de los colgajos cutáneos, para que estos sean un recipiente adecuado para el injerto graso. ${ }^{36,41}$

\subsubsection{Reconstrucción directa (un solo tiempo quirúrgico)}

La seguridad de la mastectomía con preservación del pezón condujo a un mayor uso de este recurso. Este proceso es más recomendado en escenarios de mastectomía reductora de riesgo (MRR), y para aquellas pacientes con cáncer de mama en estadio temprano. ${ }^{36,42}$

Conservando el CAP se mantiene la forma tridimensional y permite un bolsillo adecuado para la inserción de un implante definitivo o un colgajo libre.

\subsubsection{Reconstrucción con colgajos \\ Colgajos pediculados}

El músculo latissimus dorsi y el colgajo perforante de la arteria toracodorsal siguen desempeñando funciones importantes en la reconstrucción posmastectomía. Estos colgajos son buenas opciones para las pacientes obesas, para las cuales no siempre es seguro realizar una reconstrucción con implantes, especialmente cuando no se requieren grandes volúmenes. Estos colgajos también son adecuados para pacientes que se han sometido a RT y que tienen defectos parciales, ya que el suministro de sangre adicional proporcionado a la mama reconstruida puede ayudar a mejorar la calidad del tejido mediante la transferencia de elementos celulares no irradiados al sitio irradiado.

\section{Colgajo libre abdominal}

En la práctica clínica se realiza la reconstrucción mamaria con colgajo libre del tejido abdominal bajo, mejor conocido como colgajo DIEP por sus siglas en inglés (deep inferior epigastric perforator). Para los pacientes que recibieron $\mathrm{RT}$ y en quienes no se preservó la piel, se utiliza este colgajo para reconstrucción tardía, agregando y sustituyendo la piel necesaria. El colgajo DIEP también se puede procurar simultáneamente con la mastectomía, lo que permite realizar reconstrucciones inmediatas, especialmente en pacientes en quienes no se espera emplear RT.

La variante pediculada de reconstrucción con tejido abdominal, mejor conocida como colgajo TRAM, se considera obsoleta y debe evitarse por su morbilidad en sitio donador y resultados no perdurables. Esta última opción reconstructiva se reserva para centros en donde no se disponga de infraestructura y personal calificado en microcirugía.

\section{Colgajo libre no abdominal}

Al respecto las opciones son múltiples. La decisión sobre el sitio donador de tejido dependerá de las características físicas de cada paciente, así como de la disponibilidad de vasos receptores. Algunas opciones para esta alternativa incluyen al colgajo libre de gracilis TUG (oblicuo, transverso, vertical), colgajo de perforante de arteria glútea superior o inferior, colgajo libre de perforante de arteria profunda femoral y colgajo de perforante de arteria lumbar, entre otros. La técnica y éxito de estas opciones también está ligada a la adecuada selección y planeación. ${ }^{43,44}$

\section{Transferencia o injerto graso}

La transferencia de grasa es un método cada vez más popular para perfeccionar las reconstrucciones mamarias. Actualmente, la evidencia disponible no señala un aumento en el riesgo de recurrencia de cáncer mamario en injerto graso; es un complemento útil y seguro para la reconstrucción mamaria. ${ }^{45}$

\section{Consideraciones de reconstrucción y radioterapia}

El método más recomendado cuando se requerirá RT postoperatoria es con tejido autólogo. La reconstrucción tardía, se recomienda realizar al menos a los 12 meses posteriores al término de la RT.

Con expansor tisular debe mantenerse el mismo volumen de expansión durante la planeación y toda la RT, se recomienda hacer el cambio por la prótesis definitiva posterior a 6-12 meses de haber finalizado la RT.

Con implante definitivo, se asocia a un $21 \%$ de contractura capsular, que pudiera condicionar dolor 0 asimetría. $^{46-48}$ 


\subsection{Mastectomía reductora de Riesgo}

La MRR es una opción de intervención en mujeres con alto riesgo para desarrollar cáncer de mama. ${ }^{49} \mathrm{Su}$ práctica se ha visto incrementada en los últimos años, debido a la disponibilidad generalizada de pruebas genéticas para las mujeres que buscan información sobre su riesgo de desarrollar dicha neoplasia. ${ }^{50,51} \mathrm{La}$ decisión para realizar una MRR se ve influenciada por una variedad de factores, que incluyen el riesgo de cáncer de mama percibido por la misma paciente, la ansiedad que genera el tamizaje, los procedimientos diagnósticos y las expectativas que tiene de los resultados cosméticos de la cirugía. ${ }^{52}$

El cirujano oncólogo puede ayudar en el proceso de la toma de decisión, proporcionando una estimación precisa, sobre el riesgo para cáncer de mama individual, tomando en cuenta factores genéticos y no genéticos (Tabla 12).

Existen herramientas para calcular el riesgo a cinco años y de por vida. Están disponibles diversos modelos matemáticos para calcular el riesgo. Entre los más utilizados están el modelo Claus, el modelo Gail, el Tyrer- Cuzik, etc., sin embargo, actualmente no existe ninguno que incluya todos los factores de riesgo. ${ }^{53}$

Las pruebas genéticas para las personas que son portadoras de la mutación en los genes BRCA 1 y 2 , proporcionan información sobre el tipo de mutación y el riesgo de por vida de desarrollar cáncer de mama.

No existe un valor de riesgo único por encima del cual la MRR esté claramente indicada, y es importante que el cirujano y el equipo multidisciplinario le explique a la paciente no solo la evaluación del riesgo, sino también todas las estrategias de intervención disponibles para facilitar un proceso compartido en la toma de decisiones (ver Capítulo IV. Prevención primaria). La asesoría debe incluir una discusión sobre el grado de protección, las opciones de reconstrucción y los riesgos. Además, los antecedentes familiares y el riesgo residual de cáncer de mama con la edad y la esperanza de vida deben considerarse durante el asesoramiento. ${ }^{49}$

La MRR es la forma más efectiva para disminuir la incidencia de cancer de mama. Se ha demostrado que reduce hasta en un $90 \%$ su riesgo en mujeres portadoras de mutaciones en los genes BRCA 1 y 2 , y en un $95 \%$ si se acompaña de una salpingooforectomía bilateral reductora de riesgo (SORR). ${ }^{49}$

Los estudios han demostrado esta protección cercana al $95 \%$ cuando es utilizada una técnica quirúrgica meticulosa para extirpar la mayor cantidad del tejido

Tabla 12. Factores de riesgo y su riesgo relativo ${ }^{53}$

\section{Factor de riesgo}

Factores de riesgo genético

Sexo femenino

114

Edad

4-158

Mutación en el gen de alta penetrancia (BRCA1, BRCA2, p53, STK11)

Mutación en el gen de penetrancia moderada (PTEN, p16, PALB2, CDHI, NFI,

CHEK2, ATM, BRIP1)

Antecedentes de cáncer de mama en madre, hija o hermana

Factores no genéticos

Radiación del manto (tratamiento del linfoma)

\section{Factores de riesgo genético}

Número de alveólos por lobulillo en tejido mamario benigno 11 a 20 (mama involutiva)

$21-40$ 3.23

C 41 1.85

Densidad mamográfica

25 a 50\% (densidades dispersas)

2.4

20 a 75\% (heterogéneamente densa) 3.4

$75 \%$ (denso)

Carcinoma lobulillar in situ en una biopsia de mama

Hiperplasia atípica en una biopsia de mama

Aumento de la densidad mineral ósea

Edad al primer parto (35 años)

$1.31-1.93$

Obesidad (índice de masa corporal

$30 \mathrm{~kg} / \mathrm{m}^{2}$ )

Cualquier enfermedad benigna de la mama 1.47

Alto nivel de insulina circulante 1.46

Cinco años de terapia de reemplazo hormonal combinada (p. ej., estrógeno y progestina)

Nuliparidad (no nacimientos vivos)

$1.26-1.55$

Consumo de alcohol: más de una bebida al día

Menarca antes de los 12 años

1.21 mamario. La incidencia de cáncer después de MRR se atribuye a tejido mamario residual. ${ }^{54}$ 
Los datos disponibles también confieren una ventaja de supervivencia a las mujeres de mayor riesgo que se someten al procedimiento a una edad relativamente temprana. Son necesarios grandes estudios con seguimientos a largo plazo para demostrar el real beneficio en la SG, por lo que las pacientes deben saber que la evidencia confiere el mayor beneficio de la MRR en las portadoras de mutaciones en los genes BRCA 1 y 2 , a una edad temprana (menores de 40 años) y sobre todo cuando se acompaña de SORR (a partir de los 35 años).

Algunas consideraciones para seleccionar pacientes para MRR son:

- Mujeres con una mutación genética de alto riesgo.

- Antecedente de cáncer de mama familiar.

- Antecedente de RT torácica a edad joven (<30 años de edad).

- Carcinoma lobulillar in situ (neoplasia lobulillar in situ).

Existen estas opciones quirúrgicas:

- Mastectomía total (simple).

- Mastectomía preservadora de piel.

- Mastectomía preservadora de pezón (MPP).

Todas deben incluir la prolongación axilar (cola de la mama) y la fascia del pectoral.

De acuerdo con la evidencia actual, el estándar de oro parece estar representado por la mastectomía preservadora de pezón que, gracias a la preservación de la envoltura cutánea y el CAP es capaz de optimizar la cirugía oncológica y los resultados estéticos. Esta técnica no parece comprometer la eficacia oncológica/ preventiva en comparación con los otros tipos de mastectomía; sin embargo, la MPP debe llevarse a cabo con habilidad técnica para no dejar residuos macroscópicos de la glándula mamaria, en particular en la prolongación axilar, las regiones lateral y medial de la glándula y el CAP; es necesario realizar una cuidadosa disección y una meticulosa preparación de los colgajos de piel y del CAP que debe ser razonablemente delgado, sin por ello comprometer su vitalidad. ${ }^{55}$

En ningún procedimiento está indicada la biopsia de GC. 56,57

Siempre se debe realizar un estudio radiológico preoperatorio preciso con mamografía, ecografía y en ocasiones resonancia magnética para descartar la presencia de lesiones mamarias sospechosas y minimizar el riesgo de carcinomas ocultos mediante examen histológico definitivo.

En ausencia de contraindicaciones, todas las pacientes deben ser candidatas a reconstrucción mamaria inmediata con el fin de minimizar el impacto negativo físico y psicológico de la mastectomía.

La reconstrucción mamaria debe ser realizada por cirujanos plásticos, con prótesis permanentes o tejidos autólogos; la elección de la técnica reconstructiva más adecuada depende de varios factores como la estructura físico/anatómica de la paciente, la morfología/grado de ptosis mamaria, las comorbilidades y también los deseos y preferencias de la paciente. ${ }^{58,59}$

En la MPP pueden ocurrir complicaciones como necrosis parcial o total de los colgajos cutáneos y del pezón, y pérdida de la sensibilidad de este, por lo que la paciente debe ser informada de ello antes del procedimiento quirúrgico. El índice de complicaciones es mayor en pacientes con volumen mamario grande, ptosis mamaria, seniles y fumadoras.

\subsection{Mastectomía REDUCtoRa de RIESGo CONTRALATERAL (MRRC)}

Se define como la mastectomía del lado sano, en una mujer con cáncer de mama unilateral. El impacto pronóstico de la mastectomía reductora de riesgo contralateral (MRRC) es difícil de evaluar, ya que los datos disponibles son en gran parte de estudios retrospectivos. Una revisión de Cochrane sobre la eficacia de este procedimiento concluye que la MRRC reduce el riesgo de cáncer de mama contralateral de 90 al 100\%; sin embargo, no parece tener impacto en la SG. ${ }^{60}$ Está claro que el uso de la terapia endocrina y de la QT sistémica tienen un impacto en la disminución de la incidencia del desarrollo de cáncer de mama contralateral, y estos factores deben considerarse completamente en el proceso de toma de decisiones que rodea a la MRRC y su utilidad real. ${ }^{51}$

La práctica de este procedimiento va en aumento, muchas ocasiones a solicitud de las mismas pacientes, debido a que suelen percibir que el riesgo de desarrollar cáncer contralateral es mayor de lo real y que la MRRC se asocia a mayor supervivencia.

En pacientes que no tienen riesgo elevado de cáncer de mama contralateral, una discusión del riesgo asociado con el procedimiento y de la falta de un beneficio de supervivencia con la MRRC y una recomendación contra el procedimiento (cuando no otorga beneficio), por parte del cirujano, son efectivas para reducir el uso innecesario. ${ }^{53}$

La MRRC es una opción para mujeres portadoras de mutaciones de BRCA 1 y 2 , con cáncer de mama en etapas tempranas que serán sometidas a mastectomía total. 61 
La ansiedad asociada a la cancerofobia en cáncer de mama puede propiciar la realización de procedimientos sin beneficio clínico, de modo que el esfuerzo en la educación y consejo adecuado debe ser amplio. ${ }^{62}$

A medida que avanzamos hacia un enfoque de atención cada vez más personalizado y centrado en el paciente, debemos considerar cuidadosamente el respetar las preferencias de los pacientes y su autonomía. ${ }^{63}$

\section{Tratamiento sistémico adyuvante}

Con el objeto de determinar la terapia adyuvante óptima, el oncólogo clínico deberá contar con una información completa de las características biológicas del tumor. En particular, la expresión o no de los receptores hormonales $(\mathrm{RH})$ y el HER2 neu (potenciales blancos terapéuticos), dado que tienen importancia trascendental para brindar el mejor tratamiento individualizado.

\subsection{DefinICIÓN, OBJetivos E INDICACIONES}

Se le llama adyuvancia a todo tratamiento antineoplásico administrado después de un manejo quirúrgico; sus objetivos son prolongar el periodo libre de enfermedad, reducir las recurrencias locales y sistémicas y aumentar la SG. ${ }^{1-3}$ El tratamiento sistémico adyuvante (hormonoterapia $[\mathrm{HT}] \pm \mathrm{QT} \pm$ trastuzumab) deberá ser valorado y administrado por un oncólogo médico, debido al grado de actualización necesario, así como a las complicaciones y toxicidades que pueden relacionarse con él.

En pacientes con ganglios positivos, a causa del alto riesgo de recaída en este grupo, todas las pacientes con ganglios positivos deberán recibir alguna modalidad de tratamiento sistémico adyuvante (QT $\pm \mathrm{HT} \pm$ trastuzumab), sin importar el número de ganglios afectados (ver 2.3. Perfiles genómicos).

En pacientes con ganglios negativos se recomienda la administración de tratamiento adyuvante sistémico (QT $\pm \mathrm{HT} \pm$ trastuzumab) cuando exista alguna de las siguientes condiciones: ${ }^{4,5}$

- Tumor $>1 \mathrm{~cm}$ (más de $3 \mathrm{~cm}$ para histologías favorables como cáncer tubular y mucinoso), con $\mathrm{RH}$ positivos y HER negativo $(H T \pm Q T)$.

- Tumor triple negativo > $5 \mathrm{~mm}$ (QT).

- Tumor > $5 \mathrm{~mm}$ con sobreexpresión del oncogén HER2 neu (QT + trastuzumab $\pm \mathrm{HT}$ ).

- Firma genómica de alto riesgo de recurrencia, en los casos en que esté disponible (QT + HT).
Considerar también tratamiento sistémico (QT \pm hormonoterapia \pm trastuzumab), si alguna de las siguientes características está presente:

- Tumor de alto grado.

- Presencia de invasión linfovascular.

- Oncotype DX con puntuación > 25 o > 50 años con puntuación de 16 a $25 .^{6}$

- Edad < 35 años.

\subsection{ElECCIÓN DEL TRATAMIENTO SISTÉMICO ADYUVANTE}

La terapia sistémica deberá iniciarse tan pronto como sea posible, de preferencia, antes de seia semanas de realizado el tratamiento quirúrgico. No se recomienda la utilización simultánea de RT y QT, debido al incremento de la toxicidad. Cuando ambas están indicadas, se iniciará con QT y al término de ésta se aplicará la RT. Tampoco se sugiere la QT y la hormonoterapia de forma conjunta; esta última no debe comenzar hasta el término de la primera.

\subsection{Momento Óptimo para iniciar la QUIMIOTERAPIA ADYUVANTE}

En años recientes se ha descrito el impacto que tiene el inicio temprano del tratamiento, en términos de disminución del tiempo de recurrencia. Diferentes estudios han demostrado que el tiempo para iniciar QT adyuvante después de la cirugía definitiva debe ser menor a 60 días; a mayor tiempo de inicio de tratamiento, mayor la probabilidad de recurrencia y muerte (hazard ratio [HR]: 1.20 y 1.36 respectivamente). ${ }^{7}$ Cabe señalar que en diversos estudios los retrasos en la administración de QT adyuvante son más frecuentes en pacientes de mayor edad, con más comorbilidades y con desventajas sociodemográficas. ${ }^{7}$

Por otra parte, se ha demostrado que los tumores triple negativo y HER2 positivo son los subtipos en los que el retraso en el inicio del tratamiento adyuvante cobra mayor importancia (HR: 1.54 y 3.09, respectivamente). ${ }^{7}$

En fecha reciente se dieron a conocer los resultados del análisis de cohorte de pacientes con tumores triple negativo, en donde se describe que el inicio de QT adyuvante debe ser menor a 30 días, pues está asociado a mejor supervivencia libre de enfermedad y SG y que por el contrario, iniciar la QT después de transcurrido este tiempo, está asociado con 10\% menor SG a 10 años. $^{8}$ 


\subsection{TRATAMIENTO ADYUVANTE CON QUIMIOTERAPIA}

\subsubsection{Lineamientos generales}

La QT deberá ser indicada y debidamente vigilada por un oncólogo médico, en un área adecuada y con el auxilio de personal de enfermería especializado en oncología y aplicación de medicamentos antineoplásicos. Es necesario contar con los antieméticos necesarios para disminuir la toxicidad digestiva, así como con factores estimulantes de colonias para prevenir o tratar la neutropenia.

Se recomienda el empleo de esquemas basados en antraciclinas, debido al modesto beneficio en supervivencia libre de enfermedad y SG, al compararlos con esquemas de primera generación como el CMF (ciclofosfamida-metotrexato-fluorouracilo). ${ }^{1-3}$ Asimismo, la administración de taxanos ha demostrado beneficio clínico moderado, independientemente de la expresión de $\mathrm{RH}$, del número de ganglios axilares afectados 0 de la función ovárica. ${ }^{3,9,10}$

En las pacientes con tumores triple negativos, se recomienda utilizar los mismos esquemas ya mencionados, dado que hasta el momento no hay evidencia suficiente para indicar otros regímenes o medicamentos.

La mayor evidencia de beneficio con QT adyuvante en pacientes HER2 negativos se obtiene con los esquemas de tercera generación:

- EC/AC (epirubicina-ciclofosfamida/adriamicina-ciclofosfamida) seguido de paclitaxel semanal..$^{11,12}$

- AC seguido de docetaxel trisemanal. ${ }^{13}$

- TAC (taxano-adriamicina-ciclofosfamida). ${ }^{14}$

- TC (docetaxel-ciclofosfamida). ${ }^{15}$

- Dosis densas de AC, seguidas de dosis densas de paclitaxel..$^{16}$

- Dosis densas de AC, seguidas de paclitaxel semanal. ${ }^{16}$

- FAC (fluorouracilo-adriamicina-ciclofosfamida) o FEC (fluorouracilo-epirubicina-ciclofosfamida) seguido de paclitaxel semanal. ${ }^{17,18}$

- FEC-100 seguido de docetaxel trisemanal. ${ }^{16}$

Los esquemas de QT de dosis densas con AC bisemanal, seguido de paclitaxel semanal más filgrastim, logran una reducción del $26 \%$ en el riesgo de recurrencia y de $31 \%$ en la posibilidad de muerte. ${ }^{16}$

Con respecto a la secuencia de aplicación entre antraciclinas y taxanos, un metaanálisis apoya el uso de taxanos, seguido de antraciclinas, como una opción razonable en la práctica clínica diaria. Los resultados obtenidos en respuestas patológicas, en algunos ensayos clínicos fase III, también apoyan dicha sugerencia.

La capecitabina adyuvante debe considerarse en pacientes con enfermedad triple negativa que no alcanzan respuesta patológica completa a la neoadyuvancia. ${ }^{19}$ La inclusión en adyuvancia de otros medicamentos como la gemcitabina, o las sales platinadas a los esquemas con antraciclinas y taxanos no se recomienda de forma sistemática, ya que los estudios hasta el momento no han demostrado beneficio clínico.

\subsection{TRATAMIENTO ADYUVANTE CON HORMONOTERAPIA}

La hormonoterapia adyuvante debe indicarse al menos por cinco años a todas las pacientes con $\mathrm{RH}$ positivos, para prevenir enfermedad metastásica, recurrencia locoregional y tumores contralaterales. Ello reduce las tasas de recurrencia del 10 al $30 \%$ en tumores con expresión moderada y del 40 al $50 \%$ en tumores con elevada expresión. ${ }^{20}$

La superioridad de los inhibidores de aromatasa (IA), en forma adyuvante sobre tamoxifeno solo es modesta: un $3 \%$ de reducción en la recurrencia y un $2 \%$ de reducción en la mortalidad a 10 años. El beneficio de los IA es de mayor valor en el tratamiento de cáncer de alto riesgo (de acuerdo con la etapa clínica o las características biológicas), y en el tratamiento de tumores Iobulillares. ${ }^{21}$

\subsubsection{Carcinoma in situ}

Para carcinoma ductal in situ se recomienda tamoxifeno (20 mg/día) por cinco años, como terapia reductora de riesgo de recaída, en pacientes con cirugía conservadora de mama y $\mathrm{RH}$ positivos. ${ }^{22-24}$

Para mujeres posmenopáusicas se puede considerar tratamiento con IA por cinco años. ${ }^{25,26}$

En caso de mastectomía, ver Capítulo XXI. Quimioprevención.

\subsubsection{Carcinoma invasor}

\section{Premenopáusicas al diagnóstico}

Se recomienda tamoxifeno (20 mg/día) por una duración de cinco años en mujeres premenopáusicas o perimenopáusicas con $\mathrm{RH}$ positivos o desconocidos. ${ }^{24}$

En mujeres que permanecen premenopáusicas después de haber recibido QT (o que hayan recuperado la función ovárica en los primeros ocho meses posteriores al término de la QT) y con algún factor de alto riesgo: menores de 40 años, tumores de etapas avanzadas, ganglios positivos o tumores con características biológicas adversas (luminal $\mathrm{B}$, expresión baja de RE, 
alto grado e índice de proliferación Ki-67 elevado), se recomienda exemestane u otro IA más ablación ovárica (estudios SOFT y TEXT); tamoxifeno más ablación ovárica no es recomendable. ${ }^{27,28}$

La frecuencia de eventos adversos fue mayor en los dos grupos que recibieron supresión ovárica que en el grupo de tamoxifeno solo.

Se recomienda iniciar con ablación médica para valorar la tolerancia y los efectos adversos antes de recomendar un método ablativo permanente con cirugía y RT. ${ }^{29}$

\section{Posmenopáusicas al diagnóstico}

Se recomiendan IA por cinco años o terapia secuencial: tamoxifeno por dos a tres años y continuar con un IA por siete a ocho años o tamoxifeno por cinco o 10 años, de acuerdo con los factores de riesgo (tamaño tumoral, ganglios positivos, grado), intolerancia, contraindicación o falta de acceso a IA. ${ }^{30}$

\subsubsection{Hormonoterapia adyuvante extendida}

La terapia hormonal extendida está dirigida a paciente con alto riesgo para recurrencia tardía: tumores $>2 \mathrm{~cm}$ más factores de riesgo asociados como ganglios positivos, tumores alto grado, pacientes premenopáusicas, alto riesgo para segundo cáncer primario. Antes de considerar prescribir terapia extendida, es importante valorar la expectativa de vida, la presencia de factores clínico-patológicos de alto riesgo, la tolerancia previa al tratamiento, las comorbilidades de cada paciente y los efectos colaterales. ${ }^{29,30}$

Los resultados de los estudios de tamoxifeno ATLAS, ${ }^{31}$ aTTom, ${ }^{32}$ cinco de IA, ${ }^{32-38}$ y la guía de ASCO 2018,31 justifican la hormonoterapia (HT) adyuvante extendida hasta por 10 años en pacientes con ganglios positivos. En el caso de la paciente premenopáusica, el tamoxifeno ha incrementado la tasa de SG y en las posmenopáusicas un IA se asocia a un menor riesgo de recurrencia del cáncer de mama y cáncer de mama contralateral, en comparación con el placebo. ${ }^{33-38}$

De acuerdo con los resultados del estudio MA-17, para las mujeres premenopáusicas quienes al término de los cinco años de adyuvancia sean posmenopáusicas, se pueden considerar continuar con IA por cinco años más. . $^{29,37,38}$

Se define como menopáusicas a las pacientes con ooforectomía bilateral, edad $\geq 60$ años, edad $\leq 60$ años y amenorrea por 12 o más meses en ausencia de QT, tamoxifeno, toremifeno o supresión ovárica y niveles de hormona folículo-estimulante ( $F S H)$ y estradiol en rangos de posmenopausia. En caso de estar bajo tratamiento con tamoxifeno y edad $\leq 60$ años, son necesarios niveles de FSH y estradiol sérico en valores de posmenopausia. En mujeres que al inicio de la QT sean premenopáusicas, la amenorrea no es indicador del estado de menopausia, por lo que se aconseja efectuar mediciones seriales de estos niveles hormonales previos a la indicación de IA. ${ }^{38,39}$

\subsection{TRATAMIENTO ADYUVANTE CON TERAPIAS BLANCO (TRASTUZUMAB/PERTUZUMAB)}

En pacientes con tumores que presentan sobreexpresión de HER2 neu +++ por inmunohistoquímica o hibridación fluorescente in situ +, el uso del anticuerpo monoclonal trastuzumab, en combinación con la QT adyuvante, ha permitido la obtención de beneficio tanto en la supervivencia libre de recaída (HR: 0.62), como en la SG (HR: 0.66).40-42

Se recomienda iniciar la adyuvancia de trastuzumab junto con la QT con taxanos posterior al uso de antraciclinas, debido a que esta secuencia ha demostrado ser útil y segura. ${ }^{43}$

No se aconseja la administración simultánea de trastuzumab con antraciclinas, dado que se incrementa la cardiotoxicidad.

Se debe considerar el esquema TCH (docetaxel, carboplatino y trastuzumab), por seis ciclos, sin empleo de antraciclinas, en pacientes con alto riesgo de enfermedad cardiovascular (antecedentes de disfunción cardiaca, edad mayor, hipertensión, obesidad o uso previo de antraciclinas). ${ }^{44,45}$

Actualmente se aconseja que la duración del tratamiento adyuvante con trastuzumab sea de un año, ya que aplicaciones por menos o más tiempo no han demostrado, hasta el momento, mejores resultados. ${ }^{45-48}$

En casos seleccionados con ganglios negativos y tumores pequeños $(<3 \mathrm{~cm})$, el esquema con paclitaxel semanal + trastuzumab por 12 semanas, seguido de trastuzumab cada tres semanas, hasta completar un año, puede ser una opción. ${ }^{49}$

Las pacientes que reciban trastuzumab deberán ser valoradas cuidadosamente debido al riesgo de cardiotoxicidad, en especial aquellas con antecedente personal de enfermedad cardiaca o de alto riesgo. Deberá evaluarse la fracción de eyección (FE) del ventrículo izquierdo antes de comenzar este agente, cada 12 semanas y al finalizar el tratamiento. Todas las pacientes que reciban este medicamento deberán ser vigiladas mediante ecocardiografía o gammagrama nuclear, 
Tabla 13. Conducta que seguir para la vigilancia cardiológica y ajuste de dosis del fármaco

\begin{tabular}{|l|l|l|l|}
\hline \multirow{2}{*}{} & \multicolumn{3}{|c|}{ Baja absoluta en FEVI } \\
\cline { 2 - 4 } & $<10 \%$ & $10-15 \%$ & $>15 \%$ \\
\hline FEVI normal & Continuar & Continuar & Suspender \\
\hline $\begin{array}{l}1 \text { a } 5 \% \text { por } \\
\text { debajo } \\
\text { del LN de la } \\
\text { FEVI }\end{array}$ & Continuar & Suspender & Suspender \\
\hline $\begin{array}{l}>5 \% \text { por debajo } \\
\text { del } \\
\text { LN de la FEVI }\end{array}$ & Suspender & Suspender & Suspender \\
\hline
\end{tabular}

FEVI: fracción de eyección del ventrículo izquierdo; LN: límite normal.

para detectar de forma temprana una disminución de la función ventricular (Tabla 13).

En la actualidad puede considerarse también la utilización de doble bloqueo anti-HER2 adyuvante (trastuzumab + pertuzumab), pero solo en pacientes con ganglios positivos. ${ }^{50,51}$

\subsection{BISFOSFONATOS E INHIBIDORES DEL LIGANDO DEL RECEPTOR ACTIVADOR DEL NF-KB EN ADYUVANCIA Y CON INHIBIDORES DE AROMATASA}

Tanto los bisfosfonatos como los inhibidores del ligando del receptor activador del NF-KB (RANKL) permiten mejorar los resultados en la salud ósea al reducir la osteopenia u osteoporosis secundarias al tratamiento sistémico. ${ }^{52-54}$

- Terapia adyuvante:

- Los bisfosfonatos como terapia adyuvante se recomiendan para mujeres posmenopáusicas o mujeres premenopáusicas tratadas con análogos de la hormona liberadora de gonadotropina $(\mathrm{GnRH})$, con cáncer de mama temprano y alto riesgo de recurrencia.

- El tratamiento debe iniciarse junto con la QT (neo) adyuvante y continuar durante dos a cinco años.

- La dosis recomendada de ácido zoledrónico es de $4 \mathrm{mg}$ IV cada seis meses.

- Los bisfosfonatos, como agentes modificadores de la enfermedad, no se recomiendan en mujeres premenopáusicas, ni tampoco en hombres o mujeres con otros tumores sólidos.

- No se recomienda el denosumab para la prevención de metástasis (Figura 14).55,56
- Pérdida ósea relacionada con los IA. Las pacientes que inician con un IA deben someterse a una densitometría mineral ósea (DMO) de cadera y columna, así como a evaluación de los factores de riesgo para fractura siguiendo las conductas señaladas en la figura 15.

Se recomienda ácido zoledrónico $4 \mathrm{mg} I V$ cada seis meses, durante los cinco años de terapia con IA o denosumab $60 \mathrm{mg} \mathrm{SC}$ cada seis meses por dos años.

La determinación de biomarcadores de recambio óseo no es de uso sistemático en pacientes que reciben IA. ${ }^{58,59}$

Recomendaciones con el uso bisfosfonatos e inhibidores de RANKL:58-61

- Valoración oral previa a su administración.

- Examen de la cavidad oral cada seis a 12 meses.

- Evitar las cirugías dentales durante el tratamiento.

- No se recomiendan en pacientes con infecciones orales preexistentes o con mala higiene bucal.

- El ácido zoledrónico está contraindicado en pacientes con depuración de creatinina $<30 \mathrm{ml} / \mathrm{min}$.

- El denosumab debe usarse con precaución en pacientes con depuración de creatinina $<40 \mathrm{ml} / \mathrm{min}$.

- La paciente debe recibir suplemento con calcio $(1,200 \mathrm{mg})$ y vitamina $\mathrm{D}(1,000 \mathrm{mg})$ diariamente.

- Realizar densitometría ósea de control cada uno a dos años.

\subsection{Perfiles genómicos y terapia adyuVANTE SISTÉMICA}

Las pruebas de perfiles genómicas se pueden utilizan como apoyo para conocer pronóstico y/o en la toma de decisiones para administrar terapia adyuvante sistémica en pacientes con tumores RE/RP (receptor de estrógenos/receptor de progesterona) positivos, HER2 negativo. No deben utilizarse en pacientes con tumores triples negativos o HER2 positivos. Las recomendaciones para el uso de las cuatro firmas moleculares disponibles en México (Oncotype DX, MammaPrint, Endopredict y PAM50) se exponen a continuación.

\subsubsection{Oncotype DX}

Prueba de 21 genes con valor pronóstico y predictivo, con una amplia validación en el que se genera un puntaje de recurrencia de acuerdo a la expresión de cada uno de los genes. Se recomienda en tumores con $\mathrm{RH}$ positivos, HER2 negativo, de $1.1 \mathrm{a} 5 \mathrm{~cm}$ (o de 0.5 a $1 \mathrm{~cm}$ y alguna característica desfavorable: moderada 


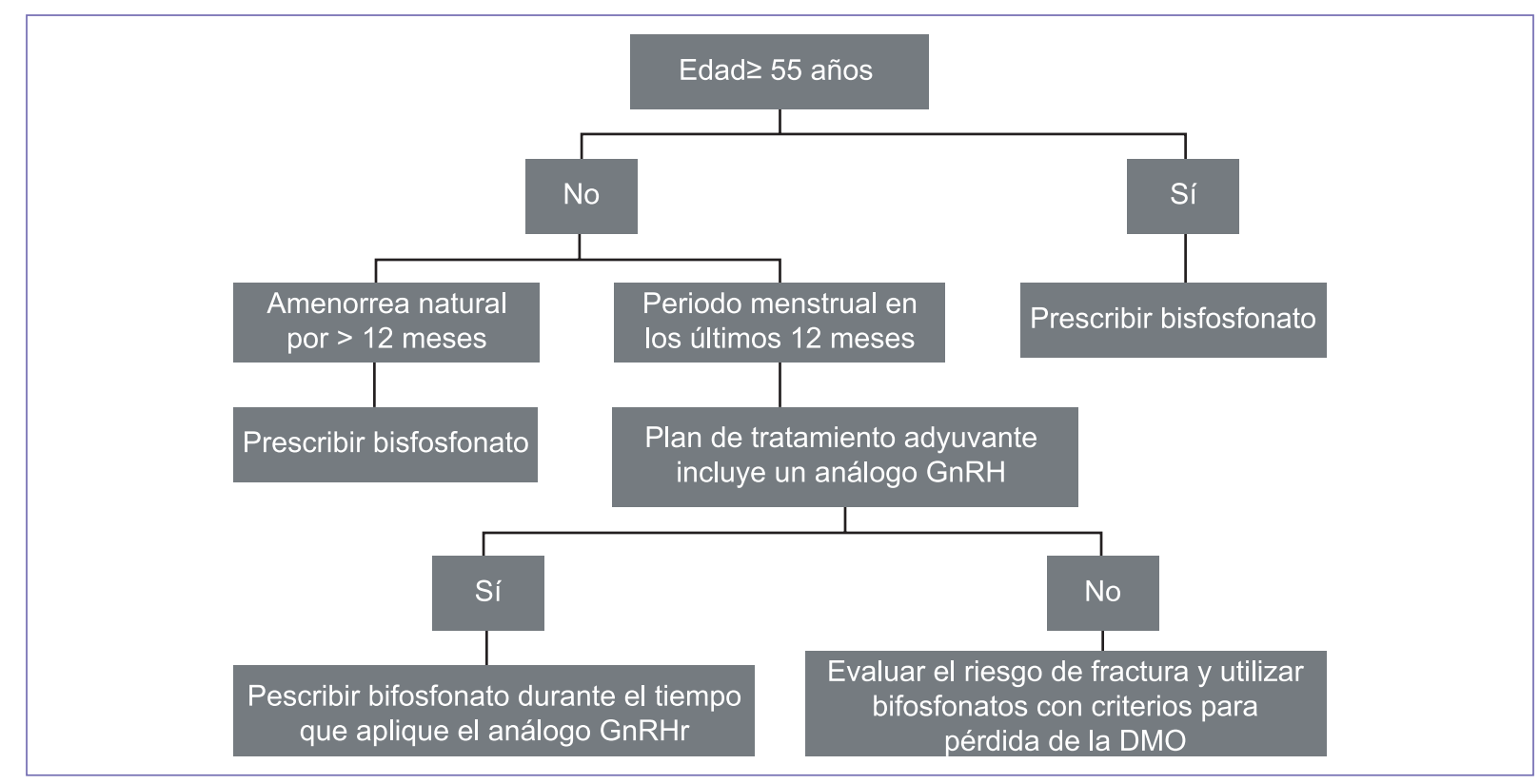

Figura 14. Flujograma de decisión para tratamiento con bisfosfonatos como tratamiento adyuvante. ${ }^{57}$ $\mathrm{GnRH}$ : hormona liberadora de gonadotropina; DMO: densidad mineral ósea.

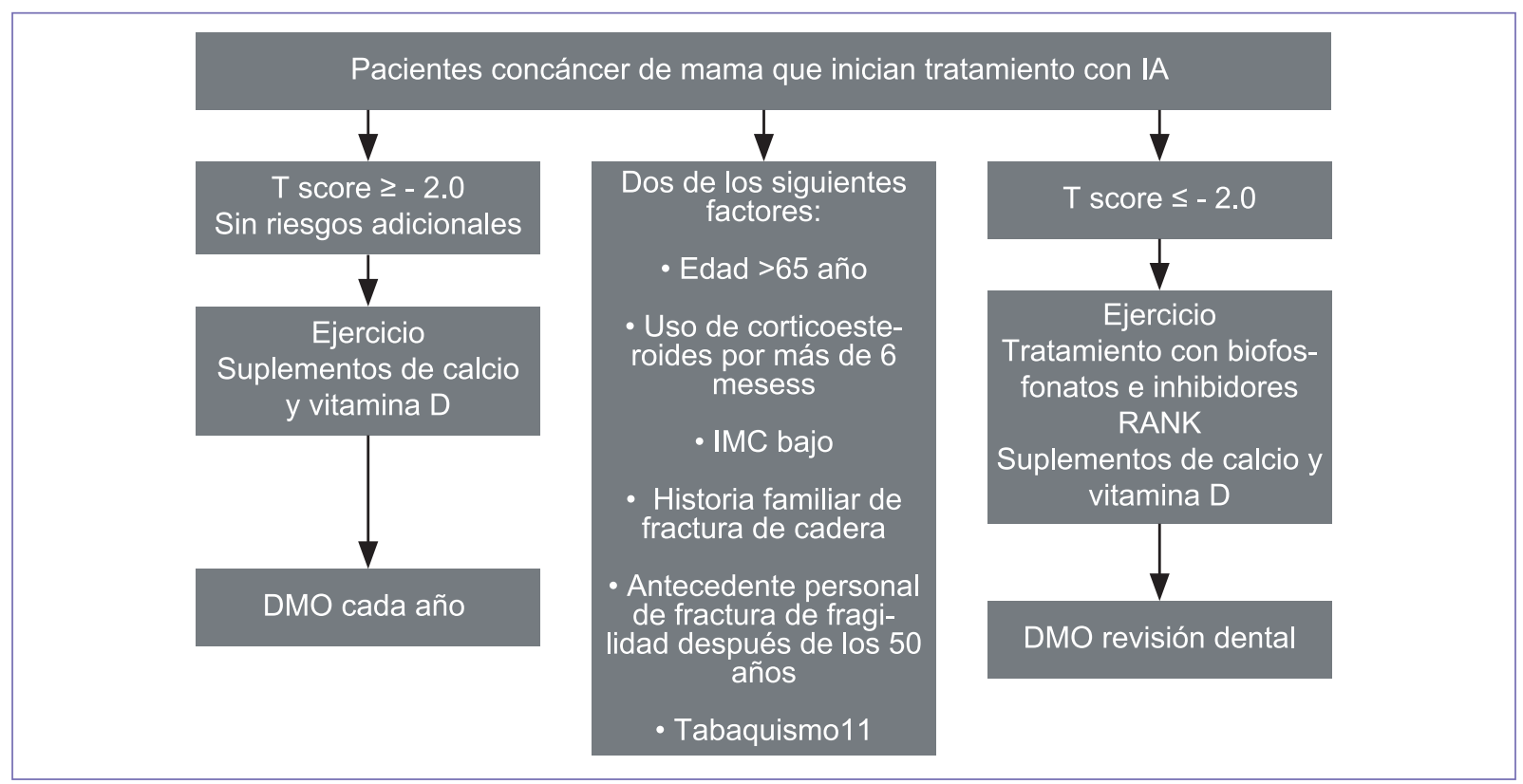

Figura 15. Flujograma para valorar los riesgos de fractura.

DMO: densidad mineral ósea: IMC: índice de masa corporal; RANKL: ligando del receptor activador del NF-KB.

o pobremente diferenciado o invasión linfovascular) y ganglios linfáticos axilares negativos.

En caso de puntuación de recurrencia $<26$ se recomienda solo terapia endocrina, de 26 a 30 terapia endocrina + QT adyuvante, y $>31$ terapia endocrina + QT adyuvante.
En mujeres < 50 años con puntuación de 16 a 25 considerar agregar QT adyuvante por beneficio en recurrencia a distancia. ${ }^{62,63}$ También puede utilizarse en pacientes posmenopáusicas con tumores con $\mathrm{RH}$ positivos, de uno a tres ganglios positivos. En mujeres posmenopáusicas con una puntuación de recurrencia 
$<25$ se puede omitir la administración de QT adyuvante por ausencia de beneficio en supervivencia libre de enfermedad invasiva. En el grupo de mujeres premenopáusicas con uno a tres ganglios positivos no se recomienda el uso de Oncotype para tomar decisiones de terapia adyuvante sistémica. ${ }^{64}$

\subsubsection{MammaPrint}

Prueba de 70 genes que tiene utilidad pronóstica en la que se genera un resultado como bajo 0 alto riesgo genómico. Se recomienda en pacientes con tumores con RH positivos, HER2 negativo, menores de $5 \mathrm{~cm}$, ganglios linfáticos axilares negativos y riesgo clínico alto $(>3 \mathrm{~cm}$; $>2 \mathrm{~cm}$ moderadamente 0 pobremente diferenciados; $>1 \mathrm{~cm}$ pobremente diferenciados). En las pacientes con resultado de bajo riesgo genómico se recomienda terapia endocrina sin QT. Puede utilizarse en pacientes con $\mathrm{RH}$ positivos, de 1 a 3 ganglios positivos y riesgo clínico alto (> $2 \mathrm{~cm}$; o moderadamente/pobremente diferenciados). En pacientes con ganglios positivos y bajo riesgo genómico, el beneficio de la QT adyuvante en supervivencia libre de metástasis es limitado. ${ }^{65}$

\subsubsection{EndoPredict}

Prueba de 12 genes que se puede utilizar en pacientes con tumores RH positivos, HER2 negativo T1 o T2 y ganglios negativos. Los pacientes con baja puntuación de riesgo ( $<3.3287)$, tienen un pronóstico similar a T1a-T1b N0 M0, con una recurrencia a distancia del $4 \%$ a 10 años. Los pacientes con 1-2 ganglios positivos y baja puntuación de riesgo tienen una posibilidad de recurrencia a distancia del $5.6 \%$ a 10 años. ${ }^{66}$

\subsubsection{PAM50 (Prosigna)}

Se puede utilizar en pacientes con tumores $\mathrm{RH}$ positivos, HER2 negativo, T1 ० T2, ganglios negativos. Los pacientes con baja puntuación (0-40) de recurrencia tienen pronóstico similar a T1a-T1b NO MO. Los pacientes con 1-3 ganglios positivos y baja puntuación de recurrencia tienen un riesgo de recurrencia a distancia menor del $3.5 \%$ a 10 años, si son tratados únicamente con terapia endocrina. ${ }^{65}$

\subsection{TOXICIDAD A MEDIANO Y LARGO PLAZOS DERIVADA DEL TRATAMIENTO MÉDICO DEL CÁNCER MAMARIO}

El diagnóstico temprano y la implementación de los nuevos avances terapéuticos han mejorado el pronóstico de las pacientes con cáncer de mama temprano e incrementado de forma importante el número de sobrevivientes. Es por ello que conocer las toxicidades derivadas del tratamiento médico y estar familiarizado con el manejo recomendado de estas resulta fundamental, dado el gran impacto que producen en la calidad de vida de las enfermas. ${ }^{67}$

\subsubsection{Cardiotoxicidad}

\section{Antraciclinas}

La cardiotoxicidad relacionada con el uso de adriamicina o epirubicina se presenta como una disfunción sistólica asintomática, con disminución de la FE de hasta más del $15 \%$ cuando se usan dosis acumuladas de doxorubicina mayores de $240 \mathrm{mg} / \mathrm{m}^{2}$. El riesgo de desarrollar cardiotoxicidad con epirubicina es del $1 \%$ con dosis acumuladas de $550 \mathrm{mg} / \mathrm{m}^{2}$ y del $1.5 \%$ con dosis acumuladas de $700 \mathrm{mg} /$ $\mathrm{m}^{2}$; el riesgo se incrementa de manera importante con dosis más altas, por lo que dosis mayores de $900 \mathrm{mg} / \mathrm{m}^{2}$ no se recomiendan. Un porcentaje menor de pacientes puede presentar insuficiencia cardiaca, la cual aumenta con la dosis acumulada y por lo general no es reversible. ${ }^{68}$

Factores de riesgo asociados:

- Edad mayor de 65 años.

- Historia de hipertensión o comorbilidades cardiacas.

- Dosis acumuladas altas (1\% de riesgo con dosis de $240 \mathrm{mg} / \mathrm{m}^{2}, 5 \%$ con $400 \mathrm{mg} / \mathrm{m}^{2}$ e incremento drástico del riesgo a partir de $550 \mathrm{mg} / \mathrm{m}^{2}$ de adriamicina).

- Historia de radiación a mediastino.

- Combinación con trastuzumab.

Recomendaciones:

- Realizar ecocardiograma o técnica de adquisición sincronizada múltiple (MUGA) basal en pacientes mayores de 50 años o en mujeres jóvenes con comorbilidades cardiacas.

- No exceder dosis (el riesgo es bajo con AC x 4, FAC $x 4$, EC x 4 o FEC x 4).

- Monitorización clínica de síntomas y en su caso referencia oportuna a cardiología.

\section{Trastuzumab}

La cardiotoxicidad por trastuzumab es generalmente reversible y se asocia con el daño causado por el bloqueo anti-HER2 a nivel de los miocitos cardiacos. La incidencia de insuficiencia cardiaca es del 1.5 al $5 \%$, pero la de disminución asintomática de la FE es del 4 al $20 \%$. Los factores de riesgo son poco claros; sin embargo, se sabe 
que pacientes de edad avanzada, con FE basal del 50 al $54 \%$, comorbilidades cardiacas y uso de medicamentos antihipertensivos tienen mayor riesgo. ${ }^{69,70}$ El riesgo de cardiotoxicidad puede ser mayor en aquellas que son tratadas con antraciclinas secuenciales.

El manejo con betabloqueadores e inhibidores de la enzima convertidora de angiotensina mejora la FE y en muchos casos puede normalizarse la función cardiaca. En pacientes seleccionadas es posible reiniciar el tratamiento con trastuzumab, pero esto solo debe hacerse en quienes son manejadas de manera conjunta con un cardiólogo.

Recomendaciones:

- Ecocardiograma o MUGA antes del inicio del tratamiento y cada tres meses hasta finalizarlo (meses 0 , 3, 6, 9 y 12).

- Si hay disminución de la FE, suspender el trastuzumab y tratar insuficiencia cardiaca.

- Bajo la estrecha supervisión de cardiología es posible reiniciar el tratamiento si la FE mejora.

\subsubsection{Leucemia y síndrome mielodisplásico}

La leucemia mielocítica aguda y el síndrome mielodisplásico se han relacionado con el uso de agentes alquilantes y se presentan entre cinco y siete años después del tratamiento. ${ }^{71}$ También se ha reportado incremento del riesgo de neoplasias hematológicas secundarias con la administración de inhibidores de la topoisomerasa II, incluidas antraciclinas, y suelen presentarse de tres a cinco años después de su empleo. El riesgo asociado con el uso de taxanos no está bien caracterizado, dado la relativamente reciente introducción de este tipo de fármacos.

Posterior a la terapia antineoplásica la tasa acumulada a cinco años es del $0.24 \%$, pero se eleva al $0.48 \%$ a los 10 años después de finalizado el tratamiento. En comparación con pacientes tratadas únicamente con cirugía, las que reciben QT tienen un riesgo 6.8 veces mayor y el riesgo se incrementa 7.6 veces si son tratadas con QT y RT; sin embargo, es importante recordar que el número absoluto de pacientes que desarrollan una neoplasia hematológica secundaria es pequeño, con una tasa de $0.46 / 100$ años-persona en pacientes tratadas con $\mathrm{QT}^{72}$

\subsubsection{Neuropatía}

La neuropatía es una complicación muy frecuente en pacientes que reciben tratamiento con taxanos. La incidencia es del 13 al 27\% y varía según el tipo y la frecuencia del taxano utilizado. ${ }^{73}$ En casos severos, esta complicación puede llegar a ser incapacitante y permanente. Los factores vinculados con esta toxicidad son: edad avanzada, raza, obesidad, diabetes mellitus e historia de abuso de alcohol. A la fecha no existe un método preventivo eficaz y las opciones terapéuticas tienen beneficio limitado. ${ }^{74,75}$

Tratamiento:

- Duloxetina.

- Gabapentina, pregabalina. Beneficio limitado en estudios clínicos; su efecto aparece a dosis altas y después de semanas a meses de tratamiento. Su administración es limitada por la somnolencia y cansancio que ocasionan.

- Opioides en casos severos.

- Antidepresivos. Nortriptilina, venlafaxina y fluoxetina han mostrado efectos en el manejo de la neuropatía diabética y la neuralgia posherpética. No hay datos en pacientes con neuropatía asociada con el uso de taxanos.

- Acupuntura.

- Terapia de relajación.

- Terapia ocupacional.

- Neuroestimulación eléctrica.

- Masaje.

\subsubsection{Fatiga}

Se denomina así a la sensación persistente de cansancio asociada de manera no proporcional con actividades físicas. Se presenta hasta en el $80 \%$ de las pacientes tratadas con QT y persiste por seis a 12 meses después de la finalización de esta en el 30\% de los casos. Desafortunadamente, las estrategias terapéuticas son limitadas, con mejoras en los síntomas que ocurren de manera lenta. Por otra parte, la evidencia ha demostrado que incrementar la actividad física es la estrategia más eficaz para mejorar la fatiga. ${ }^{76}$

Recomendaciones:

- Evaluar la presencia de fatiga a intervalos frecuentes.

- Si la fatiga es moderada-severa, descartar otras causas (recurrencia de la enfermedad, alteraciones vigilia-sueño, depresión, ansiedad, dolor, anormalidades nutricionales, hipotiroidismo, deficiencia de vitamina $\mathrm{D}$, etc.) y tratar de manera correspondiente. Intervenciones: 
- Incremento de la actividad física (150 min de ejercicio aeróbico moderado a la semana y dos a tres sesiones de entrenamiento de fuerza).

- Para pacientes que no se encuentren en condición de ejercitarse, se recomienda caminar o, mínimamente, terapia física.

- Intervenciones cognitivas y psicosociales. Técnicas de relajación, grupos de apoyo, etc.

- Intervenciones mente-cuerpo. Yoga, acupuntura, masaje.

- Intervenciones farmacológicas. Este tipo de estrategias deben considerarse solo cuando todas las alternativas previamente mencionadas han sido evaluadas.

Se puede usar modafanilo o metilfenidato; estudios aleatorizados han mostrado poca eficacia en pacientes con cáncer de mama, pero puede haber mejoría en casos de fatiga severa. La evidencia sugiere que la mejoría en los síntomas es frecuente cuando se emplea modafanilo durante el tratamiento, con eficacia limitada en pacientes que han concluido la terapia. ${ }^{77,78}$

\subsubsection{Disfunción cognitiva}

Las causas de esta compleja toxicidad que se presenta a mediano y largo plazos son hasta el momento poco claras. La incidencia de daño cognitivo secundario a QT es del 20 al 30\%. Existen reportes que señalan que del 17 al $75 \%$ de las mujeres sufren cambios cognitivos a causa del tratamiento instituido y probablemente también por el impacto del diagnóstico. En la actualidad no existen intervenciones comprobadas para la prevención o el manejo de las alteraciones cognitivas relacionadas con el diagnóstico y el tratamiento del cáncer mamario; tampoco las guías internacionales proponen lineamientos específicos. ${ }^{79} \mathrm{En}$ pacientes con deterioro cognitivo persistente, la evaluación neurocognitiva resulta fundamental.

\subsubsection{Síntomas menopáusicos inducidos por tratamiento médico}

La prevalencia de los síntomas climatéricos inducidos por la QT y el tratamiento hormonal (bochornos y sudoraciones nocturnas, sequedad vaginal y atrofia, incontinencia, dispareunia, insomnio, irritabilidad, artralgias, fatiga) varía de acuerdo con la edad, el tipo de tratamiento y el número de ciclos de QT administrados. Estos síntomas llegan a presentarse en más del $40 \%$ de las pacientes.
Ya que la terapia hormonal de reemplazo está contraindicada (ver Capítulo XX. Terapia hormonal de reemplazo), se han utilizado múltiples medicamentos como manejo farmacológico con resultados por lo general no satisfactorios.

\section{Recomendaciones}

- Ejercicio físico.

- Respiración pausada.

- Relajación muscular, meditación, yoga.

- Terapia conductual cognitiva.

- Combinación de intervenciones conductuales.

- Hipnosis.

- Acupuntura.

- Venlafaxina. ${ }^{80}$

\subsubsection{Insuficiencia ovárica por quimioterapia}

Todas las pacientes en edad fértil deben recibir asesoría acerca de la probable pérdida de la función ovárica y ser referidas a un especialista en oncofertilidad, si es posible. Existen importantes avances en este campo: existen clínicas en esta área que proponen criopreservación o bien protocolos de estimulación o de protección ovárica, con buen margen de seguridad. Se tiene evidencia de que la goserelina administrada de manera simultánea con la QT en pacientes con tumores con $\mathrm{RH}$ negativos ayuda a preservar la función ovárica. Una revisión más detallada de este tema se puede encontrar en la sección sobre el cáncer de mama en mujeres jóvenes.

En sobrevivientes con cáncer de mama, evidencia limitada sugiere que el embarazo posterior a un tratamiento no incrementa las tasas de recurrencia y no compromete la salud del producto. Se recomienda que las pacientes que deseen embarazarse lo hagan de dos a tres años después del término de la QT. Todas deberán recibir asesoría estrecha de su oncólogo y su ginecólogo. 81

\section{Radioterapia postoperatoria en cáncer de mama temprano}

La oportunidad para el inicio de RT debe ser un factor prioritario para los médicos y las autoridades. El inicio de RT después de cirugía conservadora sin QT adyuvante debe ser en las primeras ocho semanas, después de QT neoadyuvante y cirugía, en 30 días y luego de cirugía y QT adyuvante en el primer mes (no retrasar más de siete meses a partir de cirugía). 


\subsection{RADIOTERAPIA POSTOPERATORIA EN MUJERES TRATADAS CON CIRUGÍA CONSERVADORA (ETAPAS T1-T2, NO)}

Las pacientes tratadas con cirugía conservadora deberán recibir RT externa a la mama. La dosis será de 40 a 42.5 Gy en hipofraccionamiento 050 Gy en fraccionamiento convencional. ${ }^{1} \mathrm{La}$ dosis adicional al lecho quirúrgico (boost) será de 10-16 Gy, según el contexto clínico. Se recomienda que el cirujano coloque referencias radioopacas en el lecho, que faciliten una mayor precisión en la administración del boost. $^{2}$

\subsubsection{Hipofraccionamiento}

El hipofraccionamiento (dosis mayor por fracción, menor número de fracciones y menor tiempo total de tratamiento) se realiza con una planeación 3D. Se recomienda que la cobertura del $95 \%$ del volumen del PTV (volumen planeado de tratamiento) reciba el $95 \%$ de la dosis y no mayor del $105 \%$ de la dosis de prescripción. ${ }^{1}$ El hipofraccionamiento ofrece el mismo control local que el fraccionamiento convencional sin impactar negativamente en el resultado cosmético. ${ }^{1}$

\subsubsection{Hipofraccionamiento en etapas tempranas}

La RT hipofraccionada está indicada en poscirugía conservadora por carcinoma invasor. Los esquemas de hipofraccionamiento moderado administran dosis de 40 Gy en 15 fracciones 042.5 Gy en 16 fracciones. Los resultados a cinco años del hipofraccionamiento extremo con 26 Gy en cinco fracciones no son inferiores a los esquemas de hipofraccionamiento moderado en control local y cosmesis. ${ }^{3}$ La decisión de prescribir estos esquemas deberá ser a juicio del radiooncólogo, considerando que se cumplan las dosis de restricción a órganos sanos especificadas para cada esquema (Tabla 14). ${ }^{4}$

\subsubsection{Radioterapia acelerada parcial de la mama}

Es un tratamiento alternativo que solo incluye el blanco de radiación al área que rodea la cavidad de la tumorectomía posterior a la cirugía conservadora. Los criterios para tratar pacientes con esta modalidad son: edad $>50$ años, tumores $<2 \mathrm{~cm}$, ganglios negativos, margen quirúrgico $>2 \mathrm{~mm}$, receptores de estrógenos positivos. ${ }^{5-11}$
Tabla 14. Dosis de restricción a órganos sanos

\begin{tabular}{|c|c|c|}
\hline Esquema & $\begin{array}{l}\text { Dosis } \\
\text { total/\# fr }\end{array}$ & $\begin{array}{l}\text { DVH pulmón } \\
\text { ipsilateral/ } \\
\text { corazón }\end{array}$ \\
\hline $\begin{array}{l}\text { Hipofraccionamiento } \\
\text { moderado } \\
\text { ciclo mamario }\end{array}$ & $\begin{array}{l}42.6 \mathrm{~Gy} / 16 \mathrm{fr} \\
40 \mathrm{~Gy} / 15 \mathrm{fr}\end{array}$ & V16\% < 16\% \\
\hline $\begin{array}{l}\text { Hipofraccionamiento } \\
\text { extremo }\end{array}$ & $26 \mathrm{~Gy} / 5 \mathrm{fr}$ & $\begin{array}{l}\text { Pulmón ipsilateral } \\
\text { V8 }<15 \% \\
\text { Corazón V7 }<5 \% \text {, } \\
\text { V1.5\% }<30 \%\end{array}$ \\
\hline $\begin{array}{l}\text { Irradiación parcial de } \\
\text { la } \\
\text { mama } \\
\text { Intraoperatoria } \\
\text { IMRT/3D }\end{array}$ & $\begin{array}{l}20 \mathrm{~Gy} / 1 \mathrm{fr} \\
40 \mathrm{~Gy} / 10 \mathrm{fr} \\
30 \mathrm{~Gy} / 5 \mathrm{fr}\end{array}$ & $\begin{array}{l}\text { Piel }>5 \mathrm{~mm} \\
\text { Pulmón contralateral } \\
\text { V5 }<10 \% \\
\text { Pulmón ipsilateral V10 } \\
<20 \% \\
\text { Corazón V3 }<10 \% \\
\text { Mama ipsilateral sana } \\
\text { V15 }<50 \% \\
\text { Mama contralateral } \\
\text { Dmx } 1 \mathrm{~Gy}\end{array}$ \\
\hline
\end{tabular}

IMRT: radioterapia de intensidad modulada; DVH: histograma dosis-volumen.

Las modalidades para este abordaje incluyen la braquiterapia intersticial, RT intraoperatoria y RT de intensidad modulada (IMRT).12-15 La braquiterapia es la técnica con mayor información y seguimiento con un control local a 10 años comparable a la RT externa 3D, con fraccionamiento convencional, pero con menor toxicidad cutánea y mejores resultados cosméticos. ${ }^{16}$

La técnica de IMRT tiene resultados favorables y equivalentes a la RT externa 3D con fraccionamiento convencional. ${ }^{17}$ Las pacientes cardiópatas con cáncer de mama izquierda que cumplan los criterios mencionados obtienen mayor beneficio porque la dosis al corazón es menor. ${ }^{18}$

\subsubsection{Boost al lecho quirúrgico}

En pacientes seleccionadas poscirugía conservadora debe ofrecerse una dosis adicional de RT al lecho quirúrgico debido al riesgo de recurrencia local. ${ }^{19}$

Con base en guías internacionales se ofrece este tratamiento con dosis de 10-16 Gy: mujeres < 50 años, 51-70 años con tumores de alto grado, márgenes positivos no resecables, tumor $>3 \mathrm{~cm}$, componente intraductal extenso, invasión linfovascular, afección ganglionar, enfermedad multicéntrica o multifocal o enfermedad residual posterior a QT neoadyuvante..$^{20,21}$ Puede considerarse el escalamiento de dosis mayor a 16 Gy en pacientes < 40 años con márgenes cercanos o positivos con enfermedad triple negativo ${ }^{19}$. El boost 
puede omitirse en las pacientes que cumplan las siguientes características: mujeres $>70$ años con tumores de bajo grado o intermedio, $\mathrm{RH}$ positivos con márgenes de resección $>2$ mm;20-22 mujeres $>50$ años con tumor $<3 \mathrm{~cm}$, unicéntrico, unifocal, sin afección ganglionar, con un margen de resección $>2 \mathrm{~mm}$, sin invasión linfovascular ni componente intraductal extenso ni triple negativo que recibirán terapia endocrina. ${ }^{20-22}$

\subsection{INDICACIONES DE RADIOTERAPIA POSTOPERATORIA A CADENAS GANGLIONARES}

En pacientes con pT1-2 y pN1-3 deberá determinarse la necesidad de RT en función de los siguientes factores clínicos e histopatológicos: edad < 40 años, ruptura capsular o más de dos de los siguientes factores: premenopáusicas, $\mathrm{RH}$ negativos, invasión linfovascular, tumores de alto grado, tumor inicial $\geq 2 \mathrm{~cm}$ y componente intraductal extenso. ${ }^{23}$

\subsection{RADIOTERAPIA ASOCIADA A QUIMIOTERAPIA, TERAPIAS BLANCO Y HORMONOTERAPIA}

El uso de RT concomitante a la QT no se recomienda. No hay información que contraindique la administración concomitante de RT con terapias blanco. El empleo concomitante de hormonoterapia con RT no ha demostrado incremento estadísticamente significativo de la toxicidad pulmonar, cardiaca o dérmica, no obstante, el inicio de la hormonoterapia posterior a la RT permite a los médicos tratantes, saber a cuál de los dos tratamientos atribuir ciertos efectos adversos. ${ }^{24}$

\section{Manejo neoadyuvante}

\section{Introducción}

Si bien en un principio la neoadyuvancia se empleó en estadios localmente avanzados, en el presente esta modalidad de tratamiento se utiliza también en pacientes con tumores considerados inicialmente operables, mayores de $2 \mathrm{~cm}$ y/o con ganglios positivos, por lo que en este capítulo comprende el tratamiento de los carcinomas mamarios en estadio III y ciertos casos de tumores etapas IIA/IIB o T2-3 N0 M0, y T1-2, N1 M0, ${ }^{1}$ especialmente los subtipos HER2 positivo o triple negativo.

El abordaje inicial de estas pacientes debe incluir: - Evaluación clínica:
- Mastografía bilateral y ultrasonido mamario y axilar y/o resonancia magnética (RM) en casos indicados.

- Biopsia del tumor primario con aguja de corte y biopsia por aspiración con aguja fina de los ganglios axilares.

- Estudio histológico completo que incluya la determinación de receptores hormonales y HER2 neu.

- Estudios de imagen del tumor primario y de los sitios potencialmente metastásicos mediante telerradiografía o tomografía compuatrizada (TC) de tórax, ultrasonido o TC de abdomen, rastreo óseo (este último para pacientes con tumores en etapas III). La tomografía por emisión de positrones-TC con 18-fluorodesoxiglucosa es una alternativa para el estadiaje.

- Se sugiere, además:

- Colocación de un clip radioopaco en el lecho tumoral y/o ganglios axilares, en las pacientes candidatas a cirugía conservadora y/o ganglio centinela.

- Determinación de un panel monogénico (BRCA) o multigénico en pacientes con tumores triple negativo o sospecha de cáncer hereditario.

- En mujeres premenopáusicas, considerar la posibilidad del uso de análogos LHRH (hormona liberadora de gonadotropina) para preservar fertilidad y/o función ovárica y la referencia oportuna a biología de la reproducción.

La propuesta terapéutica la debe definir el grupo médico multidisciplinario y se debe basar en las características de cada paciente (edad, estado menstrual, enfermedades concomitantes, preferencias, etc.), el estado clínico de la enfermedad y las variables histológicas e inmunohistoquímicas del tumor primario.

A pesar de que la paciente tenga un tumor estadio clínico localmente avanzado, se recomienda cirugía inicial cuando la enfermedad sea técnicamente resecable, la opción de cirugía conservadora no sea deseada por la paciente, tumores con histologías favorables (p. ej., tumores bien diferenciados, histología mucinosa o tubular, receptores hormonales positivos con títulos altos, HER2 negativo) o baja probabilidad de respuesta a la quimioterapia (QT) con alto riesgo de toxicidad. ${ }^{1}$

\subsection{Ventajas de La Quimioterapia neoAdYuvante}

- Permite desescalar el manejo quirúrgico locorregional de mama y axila.

- Evaluar respuesta patológica. 
Tabla 15. Esquemas de quimioterapia neoadyuvante recomendados de acuerdo con el subtipo de tumor

\begin{tabular}{|c|c|c|c|}
\hline & $\begin{array}{l}\text { Tumores } \\
\text { hormonosensibles }\end{array}$ & $\begin{array}{l}\text { Tumores } \\
\text { HER2-positivo }\end{array}$ & $\begin{array}{l}\text { Tumores } \\
\text { triple negativo }\end{array}$ \\
\hline $\begin{array}{l}\text { Esquemas } \\
\text { recomendados }\end{array}$ & $\begin{array}{l}\text { ddAC } \times 3-4 \text { ciclos } \\
\text { seguido de taxanos* } \\
\text { AC } \times 3-4 \text { ciclos seguido } \\
\text { de taxanos }\end{array}$ & $\begin{array}{l}\text { AC } \times 4-\text { Taxano + } \\
\text { trastuzumab }+ \text { Pertzumab } \times 4 \\
0 \\
\text { TCHP } \times 6 \\
0 \\
\text { AC } \times 4-\text { Paclitaxel/trastuzumab } \\
\times 12\end{array}$ & $\begin{array}{l}\text { ddAC x 4- ddPaclitaxel x } 4 \\
\text { ddAC x 4- paclitaxel } \\
\text { semanal x } 12+\text { carboplatino } \\
\text { AC x 3-4-Docetaxel x 3- } \\
4 \text { + carboplatino }\end{array}$ \\
\hline
\end{tabular}

AC: adriamicina-ciclofosfamida; TCHP: taxotere-carboplatino-herceptin-pertuzumab.

- La respuesta patológica completa (RPC) definida como ypTo/is, ypNo

- Este desenlace se asocia con mejor pronóstico (hazard ratio [HR] para supervivencia global: 0.36 , intervalo de confianza del 95\%: 0.30-0.44). ${ }^{2}$

- Permite individualizar el tratamiento adyuvante basado en la respuesta inicial a la QT.

\subsection{Desventajas de LA QUimioterapia NEOADYUVANTE}

- Pérdida de la información del estadiaje inicial.

- Posibilidad de sobretratamiento, si la información está basada en información incompleta (p. ej., el tamaño de la lesión puede sobreestimarse debido a la asociación de carcinoma in situ visto por imagen).

- Progresión de la enfermedad, que puede ocurrir en el $2 \%$ de los casos.

- Aumento en la probabilidad de recurrencia (15.7 vs. $5.6 \%)$, en pacientes tratadas con cirugía conservadora en comparación con las tratadas con mastectomía. $^{3}$

Si la paciente inicia con QT neoadyuvante, se recomienda marcaje con clip radioopaco del sitio del tumor primario, para una adecuada valoración quirúrgica. ${ }^{4} \mathrm{Es}$ importante destacar que previo al tratamiento neoadyuvante debe documentarse y registrarse el número de lesiones, su localización, distancia a la piel y pared torácica, así como extensión hacia el pezón.

Se conoce que la posibilidad de obtener una RPC posterior a una terapia neoadyuvante está relacionada con el subtipo de cáncer: hormonosensible/HER2 negativo $7 \%$, triple negativo 30\% y HER2 positivo 32 a $67 \%{ }^{5}$ En tumores hormonosensibles HER2 negativos, el uso de firmas genéticas (Oncotype Dx) puede predecir la respuesta a la QT neoadjuvante (mayor en puntuación de recurrencia $(\mathrm{RS})>30$ ), por lo que si se cuenta con este recurso, puede considerarse su uso. ${ }^{6}$

\section{Quimioterapia y terapias blanco neoadyuvantes}

El tratamiento neoadyuvante recomendado se basa en 6-8 ciclos de QT, ya que se asocian con mayores posibilidades de RPC. ${ }^{5,7}$ Los principales esquemas recomendados se especifican en la tabla 15.

La adición de otros farmacos al esquema neoadyuvante como gemcitabina, capecitabina y nab-paclitaxel no está indicada. La inmunoterapia (inhibidores del check-point) administrada de forma concomitante (pembrolizumab/atezolizumab) para tumores triple negativo, a pesar de que ha demostrado incrementar la tasa de RPC, aun no está aprobada en nuestro país, por lo que no está recomendada., 8

En cuanto a los tumores HER2 positivos, no se recomienda la terapia con doble bloqueo HER2 con lapatinib, neratinib o TDM-1 (conjugado anticuerpo-quimioterápico).

\subsection{CÁNCER de MAMA INFLAMATORIO}

El cáncer de mama inflamatorio debe tratarse con QT neoadyuvante (más trastuzumab/pertuzumab en tumores con sobreexpresión de HER2 neu). Con base en la respuesta al tratamiento sistémico, deberá evaluarse manejo locorregional con mastectomía radical modificada y radioterapia posoperatoria. Si la respuesta a la QT neoadyuvante es escasa y el tumor no es resecable, podrá valorarse administrar radioterapia y luego efectuar cirugía radical.

\section{Hormonoterapia neoadyuvante}

La hormonoterapia neoadyuvante está recomendada en mujeres posmenopáusicas con receptores hormonales positivos y etapas II-III o en pacientes en quienes la toxicidad de la QT no sea aceptable o que padecen múltiples comorbilidades. El objetivo es incrementar la 
posibilidad de resección del tumor y/o de cirugía conservadora. El uso de la terapia endocrina neoadyuvante se ha asociado a tasas de RPC del $14 \%$, con una alta tasa de probabilidad de realizar cirugía conservadora. ${ }^{10}$

Se recomienda el empleo de un inhibidor de la aromatasa (IA). Tras iniciar la hormonoterapia, si se obtiene respuesta objetiva, se recomienda continuarla por al menos 4-6 meses seguido del tratamiento quirúrgico local. Se valorará continuar con hormonoterapia o QT adyuvante conforme a la respuesta patológica y las condiciones de la paciente. ${ }^{11}$

El uso de inhibidores de CDK 4/6 en combinación con IA en neoadyuvancia no está indicado. ${ }^{12}$

\section{Evaluación de respuesta durante el tratamiento neoadyuvante}

Después de cada ciclo de QT, deberá valorarse la respuesta y tras la administración de tres a cuatro ciclos, se recomienda evaluar la respuesta de forma clínica. En los casos con enfermedad estable y/o progresión, se sugiere correlación radiológica; la mamografia, tomosíntesis y ultrasonido son adecuados para evaluar la respuesta a tratamiento neoadyuvante..$^{13} \mathrm{Si}$ existe respuesta objetiva se debe continuar el tratamiento neoadyuvante hasta completarlo. De lo contrario, si no hay respuesta o se observan datos de progresión, puede considerarse cambio de esquema de QT (taxanos o antraciclinas) por dos a cuatro ciclos más y posteriormente, de acuerdo con la respuesta, valorar cirugía y/o radioterapia.

Si bien el mejor estudio de imagen para evaluar la respuesta es la RM de la mama, ya que posee la mayor correlación con la respuesta patológica, no es indispensable ni se encuentra disponible en todos los centros. En caso de tener acceso a este método se recomienda realizar también antes de iniciar el tratamiento sistémico para tener una comparación basal. Por otra parte, es importante hacer notar que la RM tiende a sobreestimar o subestimar el tamaño de la lesión residual de acuerdo con el tipo de respuesta (concéntrica o fragmentada). ${ }^{14}$

La respuesta fragmentada es de particular dificultad, ya que solo en el $65 \%$ de los casos se observa una reducción de más del $50 \%$ en el tamaño de la lesión; esto debe ser evaluado de forma individual y probablemente considerar la utilización de cirugía oncoplástica, para asegurar el margen negativo. ${ }^{15}$

\section{Tratamiento posterior a neoadyuvancia}

\subsection{Tratamiento quirúrgico}

La tendencia actual en cirugía es lograr un buen resultado oncológico, reduciendo la extensión y morbilidad de esta; la realización de cirugía conservadora de mama y ganglio centinela, en lugar de disecciones axilares electivas y mastectomía, es ejemplo de esta tendencia.

En teoría, la cirugía posterior a neoadyuvancia permite aumentar la posibilidad de cirugía conservadora; sin embargo, esto solo sucede con una adecuada planeación del procedimiento a realizar. Las pacientes consideradas para neoadyuvancia deben ser evaluadas por el cirujano previo al inicio del tratamiento. Estrategias importantes en la planeación de cirugía incluyen el marcaje preoperatorio, tanto de la lesión primaria como de ganglios sospechosos, y la decisión del tipo de estudio que realizar para la evaluación de la respuesta al tratamiento sistémico. La cirugía conservadora de mama posterior a neoadyuvancia ha mostrado el mismo resultado en supervivencia global y periodo libre de enfermedad, comparada con la mastectomía en tiempos actuales. ${ }^{2}$

El proceso que seguir en la planeación de la cirugía es similar al caso de tratamiento quirúrgico primario. Las lesiones no palpables deben localizarse de forma preoperatoria; esto puede llevarse a cabo con arpón o con semillas radioactivas si se cuenta con este recurso; ambas estrategias son adecuadas y equivalentes en su efectividad para el marcaje de la lesión. Tras una respuesta clínica o radiológica completa, el área con el clip se debe de resecar con una porción de tejido circundante, sin necesidad de ampliar al área donde se localizaba la lesión inicialmente. Debe realizarse estudio de imagen del tejido resecado para confirmar la presencia de lesión residual y/o del marcaje pretratamiento. ${ }^{16}$ Considerando todos los subtipos, la posibilidad de ser elegible para cirugía conservadora despues de QT neoadyuvante es del 69-87\%; y con terapia endocrina neoadyuvante es de alrededor del $77 \%{ }^{17,18}$

Actualmente, el uso de biopsia con aguja de corte posterior a la QT neoadyuvante, en pacientes con respuesta radiológica completa o parcial (y un área de reforzamiento por RM menor a $2 \mathrm{~cm}$ ), no es adecuado para determinar la RPC (falsos negativos: $37-71 \%$ ), de modo que la cirugía debe seguirse considerando el estándar. ${ }^{19}$ 
En caso de no reunirse los requisitos para cirugía conservadora, se procederá a realizar mastectomía total. El manejo de la axila es independiente del manejo de la mama.

\subsection{TRATAMIENTO SISTÉMICO ADYUVANTE}

En pacientes con receptores hormonales positivos se indicará hormonoterapia (ver Capítulo X).

En tumores HER2 neu positivos, que tengan RPC, se continuará el trastuzumab/pertuzumab o trastuzumab, hasta completar un año de tratamiento.

En los tumores triple negativo que no alcancen RPC, es decir, que hayan tenido enfermedad residual en mama y/o axila, se recomienda la administración de capecitabina por seis meses (ocho ciclos). ${ }^{20}$

En los tumores HER2 neu positivos, que no alcancen RPC, se recomienda el uso de TDM-1 trisemanal, por 14 dosis. ${ }^{21}$ En caso de no tener disponible el fármaco, se sugiere continuar con trastuzumab.

\subsection{RADIOTERAPIA}

\subsubsection{Indicaciones}

La radioterapia a mama o pared torácica y regiones ganglionares axilo-supraclaviculares y cadena mamaria interna, es un estándar en pacientes con cáncer de mama localmente avanzado. Su indicación es independiente de la respuesta a QT neoadyuvante y debe ofrecerse con base en la etapa clínica al diagnóstico. ${ }^{22,23}$

Las pacientes que obtienen mayor beneficio en control local y supervivencia libre de enfermedad son aquellas con ypN2-3 y pacientes con subtipos moleculares triple negativo y HER2 neu puro. ${ }^{24,25}$

Las indicaciones incluyen:

- Tumores iniciales T3 o T4.

- Márgenes quirúrgicos positivos.

- Más de tres ganglios axilares positivos (N2).

- Cirugía conservadora posquimioterapia neoadyuvante.

La dosis recomendada de radioterapia a la pared torácica y las zonas linfoportadoras es de 50 Gy. En caso de margen positivo se recomienda administrar dosis adicional a la pared costal. $22-27$

\subsubsection{Hipofraccionamiento en etapas avanzadas}

Aunque existen estudios con resultados favorables, el uso de radioterapia hipofraccionada no es un estándar en pacientes mastectomizadas con cáncer de
Tabla 16. Indicaciones para empleo de técnicas modernas de radioterapia

Técnica de inspiración profunda sostenida

Disminuye dosis a arterias coronarias en cáncer de mama izquierdo ${ }^{34}$

Radioterapia de intensidad modulada o arcos volumétricos modulados

Disminuyen la incidencia de radiodermitis ${ }^{35}$

Mejoran la cobertura a áreas ganglionares cuando no es posible con RT conformal ${ }^{36}$

Anatomía desfavorable (pectus excavatum, pectus carinatum, tórax en tonel o tórax cifoescoliótico)

Bolus en pacientes mastectomizadas

Se utiliza para lograr la irradiación adecuada de la piel Se desaconseja fuertemente el uso de gasa húmeda No se ha comprobado su eficacia para evitar recurrencias en pared torácica ${ }^{37}$

Se utiliza a discreción del radiooncólogo tratante

RT: radioterapia.

mama localmente avanzado. ${ }^{28,29}$ El hipofraccionamiento no se utiliza en ningún caso en pacientes mastectomizadas con reconstrucción mamaria. ${ }^{30}$

\subsubsection{Indicaciones para el empleo de técnicas modernas}

Las diversas técnicas disponibles en la actualidad permiten mejorar la distribución de la dosis en el volumen que irradiar y disminuir la dosis de radiación a tejidos sanos. En la tabla 16 se resumen las indicaciones precisas para su empleo: ${ }^{31-33}$

\subsubsection{Enfermedad inflamatoria}

Las pacientes con T4d requieren radioterapia posoperatoria para disminuir el potencial de progresión. La dosis total con fraccionamiento convencional es de 60 Gy. ${ }^{38,39}$ Esta dosis puede escalarse a 66 Gy en caso de enfermedad residual posterior a QT neoadyuvante, márgenes cercanos o positivos, o en pacientes menores de 45 años. ${ }^{39}$ La radioterapia deberá dirigirse en la primera fase a la pared torácica y a todas las regiones ganglionares incluyendo la mamaria interna, y en la segunda fase a la pared torácica pueden utilizarse campos de fotones, electrones o ambos, asegurándose de obtener una adecuada cobertura de la dosis en piel. ${ }^{40}$ 
Tabla 17. Factores dosimétricos que favorecen el desarrollo de neumonitis por radiación

$\%$ de volumen pulmonar total que recibe $>20 \mathrm{~Gy}(\mathrm{~V} 20),>30 \%$

$\%$ de volumen pulmonar total que recibe $>5 \mathrm{~Gy}(\mathrm{~V} 5),>65 \%$

Dosis pulmonar media, $>20 \mathrm{~Gy}$

Volumen pulmonar absoluto que recibe $>5 \mathrm{~Gy},<500 \mathrm{cc}$

\subsubsection{Toxicidad por radioterapia}

Deben respetarse las dosis de tolerancia de cada órgano en riesgo cercano a la zona de irradiación. Estas restricciones de dosis han sido establecidas para cada órgano y volumen de tratamiento en particular por el grupo de análisis cuantitativo de efectos clínicos en tejidos normales (QUANTEC) y por protocolos del grupo de radioterapia oncológica (RTOG), entre otros. ${ }^{33}$

\section{Toxicidad aguda}

Dermatitis por radioterapia. Hasta el $95 \%$ de las pacientes que reciben radioterapia desarrollarán dermatitis. El grado de afección de la piel depende de factores como: irradiación en áreas con pliegues o donde la integridad de la piel está alterada, índice de masa corporal elevado, uso de QT o inmunoterapia concomitantes, comorbilidades, tabaquismo, exposición crónica al sol, tipo de piel, peso y técnica de radioterapia utilizada. Este efecto es esperable y obligado que ocurra. ${ }^{34} \mathrm{El}$ $10 \%$ de las pacientes desarrollará dermatitis húmeda, de predominio en pliegues cutáneos. Esta complicación es reversible y no amerita suspensión del tratamiento, pero sí requiere un manejo adecuado y seguimiento estrecho. ${ }^{35}$

\section{Toxicidad subaguda y crónica}

Toxicidad pulmonar. La toxicidad pulmonar se produce en el 1 al $5 \%$ de las pacientes con cáncer de mama que se tratan con radioterapia. Los factores que aumentan el riesgo de neumonitis por radiación incluyen el uso concomitante de QT u hormonoterapia, irradiación de la pared torácica con electrones, campo supraclavicular, antecedente de tabaquismo, enfermedad pulmonar obstructiva crónica o enfermedad pulmonar intersticial. ${ }^{36} \mathrm{La}$ incidencia de neumonitis grado $>2$ es de $1.8 \%$ en series modernas de pacientes tratadas con esquemas hipofraccionados 0 con fraccionamiento normal y a menudo se diagnostica a las 7.5 semanas de iniciada la radioterapia. ${ }^{37,41}$
El volumen de pulmón irradiado es un factor predictivo para el desarrollo de neumonitis (Tabla 17).

Se recomienda fuertemente cumplir las restricciones de dosis en pulmón según el esquema y fraccionamiento de radioterapia que se elija (Tabla 18).

Toxicidad cardiaca y cardioprotección. La toxicidad temprana es subclínica, con cambios identificables a partir de seis meses de haber finalizado radioterapia en pacientes con cáncer de mama izquierda. Se caracterizan por alteraciones en la ecocardiografía Doppler y perfusión miocárdica, así como elevación de péptido natriurético tipo b y troponina I. La toxicidad tardía se caracteriza por estenosis coronaria y cardiopatía isquémica con un periodo de latencia de 10 años. El empleo de técnicas modernas de radioterapia ayuda a disminuir la dosis de irradiación cardiaca. Es necesario usar la mejor técnica disponible para lograr este objetivo. ${ }^{24}$ Las restricciones de dosis dependen del fraccionamiento utilizado (Tabla 19).

\subsection{Segundos primarios}

Existe un aumento en el riesgo de segundos tumores no mamarios asociados a la radioterapia en pared torácica por cáncer de mama [riesgo relativo (RR: 1.12)]. El riesgo de padecer cáncer pulmonar, esofágico o sarcoma inducido por radiación debe tomarse en cuenta durante la planeación de radioterapia (RR: 1.39, 1.53 y 2.53 respectivamente). ${ }^{25}$

\section{Tratamiento del cáncer de mama metastásico/recurrente}

\section{Introducción}

El cáncer de mama metastásico es una enfermedad heterogénea, hasta el momento incurable, con manifestaciones clínicas variables y cuyo tratamiento depende del sitio y el número de las metástasis, las características de la paciente, el inmunofenotipo tumoral y la sensibilidad o la resistencia a los tratamientos médicos oncológicos previos. ${ }^{1}$

Esta etapa de la enfermedad no es curable; sin embargo, en coincidencia con la introducción de novedosos y más eficaces tratamientos sistémicos, incluyendo terapias de soporte tempranas, en las dos últimas décadas se ha observado una mejoría en la mediana de supervivencia, con rangos muy variables, de meses a muchos años, dependiendo del inmunofenotipo. ${ }^{2-4}$ 
Tabla 18. Restricciones de dosis para pulmón ipsilateral según fraccionamiento

\begin{tabular}{|l|l|l|l|}
\hline $\begin{array}{l}\text { Convencional } \\
\text { con campos } \\
\text { tangenciales }\end{array}$ & $\begin{array}{l}\text { Convencional } \\
\text { con campos } \\
\text { tangenciales } y \\
\text { ganglios }\end{array}$ & $\begin{array}{l}\text { Hipofraccionado } \\
\text { con campos } \\
\text { tangenciales }\end{array}$ & $\begin{array}{l}\text { Hipofraccionado } \\
\text { campos } \\
\text { tangenciales y } \\
\text { ganglios }\end{array}$ \\
\hline V20 Gy $<20 \%$ & V20 Gy $<30 \%$ & V16 Gy $<15 \%$ & V18 Gy $<35 \%$ \\
\hline V10 Gy $>35 \%$ & V10 Gy $<50 \%$ & V8 Gy $<35 \%$ & \\
\hline V5 Gy $<50 \%$ & V5 Gy $<65 \%$ & V4 Gy $<50 \%$ & \\
\hline
\end{tabular}

Tabla 19. Restricciones de dosis para corazón según fraccionamiento

\begin{tabular}{|l|l|l|l|}
\hline $\begin{array}{l}\text { Convencional } \\
\text { con campos } \\
\text { tangenciales }\end{array}$ & $\begin{array}{l}\text { Convencional } \\
\text { con campos } \\
\text { tangenciales y } \\
\text { ganglios }\end{array}$ & $\begin{array}{l}\text { Hipofraccionado } \\
\text { Con campos tangenciales }\end{array}$ & $\begin{array}{l}\text { Hipofraccionado } \\
\text { campos } \\
\text { tangenciales y } \\
\text { ganglios }\end{array}$ \\
\hline $\begin{array}{l}\text { Dosis media } \\
<4 \mathrm{~Gy}\end{array}$ & $\begin{array}{l}\text { Dosis media }<4 \mathrm{~Gy} \\
\text { V20 Gy }<5 \%\end{array}$ & $\begin{array}{l}\text { Dosis media } \\
<3.2 \mathrm{~Gy}\end{array}$ & Dosis media $<3 \mathrm{~Gy}$ \\
\hline & $\begin{array}{l}\text { Mama izquierda } \\
\text { V15 Gy }<30 \% \\
\text { V25 Gy }<5 \%\end{array}$ & $\begin{array}{l}\text { Mama izquierda } \\
\text { V16 Gy }<5 \%\end{array}$ & $\begin{array}{l}\text { Mama izquierda } \\
\text { V22.5 Gy }<10 \%\end{array}$ \\
\hline $\begin{array}{l}\text { Mama derecha } \\
\text { V25 Gy }<0 \%\end{array}$ & Mama derecha \\
V15 Gy $<10 \%$ & V16 Gy $<0 \%$ & Mama derecha \\
\hline
\end{tabular}

Las metas del tratamiento en el cáncer mamario metastásico son:

- Prolongar el intervalo libre de progresión y la supervivencia global.

- Paliar los síntomas relacionados con la enfermedad.

- Mantener una adecuada calidad de vida con buen estado funcional.

Los factores clínico-patológicos más importantes para decidir la mejor estrategia terapéutica son:

- Edad.

- Síntomas relacionados con la enfermedad y estado funcional.

- Enfermedades concomitantes.

- Intervalo libre de enfermedad.

- Número y localización de metastasis.

- Tratamiento previo y respuesta a este.

- Receptores hormonales, HER2 neu y mutaciones de BRCA 1 y 2.

- Preferencias de la paciente.1,3

En pacientes con etapas I a III y que posteriormente presentan recurrencia tumoral, se recomienda evaluación de la extensión de la enfermedad incluyendo realizar una biopsia de un sitio metastásico para confirmar el diagnóstico y determinar el estado de receptores hormonales y HER2, ya que se ha demostrado que hasta en un $30 \%$ de los casos cambia su inmunofenotipo. Lo anterior significa que en una proporción importante de pacientes deberá cambiar el tratamiento evitando terapias insuficientes o excesivas y puede modificar de manera drástica la supervivencia. También se recomienda evaluar la presencia de mutaciones germinales de BRCA 1 y 2 en vista de disponer de opciones terapéuticas aprobadas. No se recomienda realizar otros biomarcadores. ${ }^{1,5-8}$

\section{Tratamiento de acuerdo con el subtipo de cáncer de mama}

\subsection{Cáncer de mama metastásico con RECEPTORES HORMONALES POSITIVOS Y HER2 NEU NEGATIVO}

La terapia endocrina más un inhibidor de ciclina es el tratamiento de elección debido a que se ha demostrado incremento de supervivencia global tanto en primera como en segunda línea de tratamiento, ${ }^{1}$ además de mejoría de otros parámetros de eficacia como 
supervivencia libre de progresión (SLP) y tasas de respuesta, incluyendo pacientes con enfermedad visceral. Sin embargo, en las pacientes con síntomas importantes y/o metástasis viscerales de progresión rápida (crisis visceral) ${ }^{2}$, la quimioterapia debe ser la primera opción, debido a que produce mayores porcentajes de respuesta y paliación.

\subsubsection{Tratamiento hormonal en pacientes premenopáusicas}

Debido a los beneficios de la terapia endocrina + otras terapias blanco en pacientes posmenopáusicas, se recomienda la ablacion ovarica médica o quirúrgica en pacientes premenopáusicas y tratarlas como posmenopáusicas. $^{2}$

Un inhibidor de aromatasa (IA), preferentemente, o tamoxifeno + ribociclib, está indicado como tratamiento de primera línea en pacientes premenopáusicas. ${ }^{3}$

El tamoxifeno como monoterapia es una opción en las pacientes que no acepten la supresión o ablación ovárica.

\subsubsection{Tratamiento hormonal en pacientes posmenopáusicas}

\section{Primera línea}

Si se trata de enfermedad metastásica de novo o enfermedad recurrente, con un periodo mayor a un año de haber terminado la hormonoterapia adyuvante, la recomendación es IA + un inhibidor CDK 4/6.4-7

La eficacia de los inhibidores de CDK 4/6 (palbociclib, ribociclib y abemaciclib) es similar, radicando la diferencia en el perfil de toxicidad; la elección será por el médico tratante de acuerdo con commorbilidades y características de los pacientes.

Un IA es también una opción en pacientes para las que no se tenga disponibilidad de inhibidores CDK 4/6. ${ }^{8}$

Otra posibilidad adicional de primera línea es el fulvestrant, principalmente en pacientes con ausencia de metástasis viscerales. ${ }^{9}$

\section{Segunda línea}

Si las pacientes ya recibieron un IA no esteroideo (anastrozol/letrozol) o presentan progresión durante el tratamiento adyuvante con IA no esteroideo, las opciones de tratamiento pueden ser:
- Fulvestrant + inhibidor CDK 4/6 (palbocicib, ribociclib o abemaciclib) siempre y cuando no se hubiera usado este último en la primera línea. ${ }^{10-13}$

- Exemestano más everolimús..$^{14-15}$

- IA esteroideo (exemestano). ${ }^{16-17}$

- Fulvestrant. ${ }^{17}$

- Fulvestrant + everolimús. ${ }^{18}$

\subsubsection{Tercera línea}

La tercera línea dependerá de la primera y segunda líneas recibidas. Hasta el momento no existe una secuencia estándar.

El abemaciclib monodroga es una opción de tratamiento de tercera línea, en pacientes que no han recibido inhibidor CDK 4/6 en líneas previas, ya sea tratamiento endocrino o de quimioterapia. ${ }^{19}$

En las pacientes con respuesta o claro beneficio clínico inicial con hormonoterapia y que progresan con una primera línea, deberá intentarse una segunda, tercera e incluso cuarta líneas hormonales dependiendo del fármaco utilizado previamente, dado que a menudo se obtiene de nuevo respuesta tumoral, lo que significa la posibilidad de supervivencia libre de quimioterapia, con mejor calidad de vida. En caso de resistencia comprobada al manejo hormonal, deberá cambiarse a quimioterapia.

Para las pacientes con receptores positivos que hayan recibido quimioterapia hasta el máximo beneficio se sugiere continuar con hormonoterapia de mantenimiento y el fármaco elegido se administrará hasta la progresión. $^{2}$

\subsection{Cáncer de mama metastásico/recurRente} CON RECEPTORES HORMONALES POSITIVOS Y HER2 NEU POSITIVO (TRIPLE POSITIVO)

El tratamiento recomendado es la quimioterapia asociada a terapia anti-HER2, debido al incremento en la supervivencia global demostrado (ver Apartado 2.3)..$^{20,21}$

En pacientes con respuesta completa y/o que presentan una toxicidad limitante de dosis, es posible suspender la quimioterapia y continuar con el bloqueo anti-HER2 en combinación con terapia endocrina (monodroga). 22,23

En pacientes posmenopáusicas no candidatas a quimioterapia, con alta expresión de receptores hormonales, de novo o con un periodo libre de enfermedad largo y ausencia de enfermedad visceral, podría utilizarse el doble bloqueo anti-HER2 (trastuzumab/lapatinib o pertuzumab/trastuzumab), en combinación con un 
IA no esteroideo. Esta estrategia demostró un beneficio en SLP, pero no en supervivencia global. La terapia anti-HER2 (trastuzumab o lapatinib) con terapia endocrina es otra alternativa, pero se debe tomar en cuenta tiene una mediana de SLP menor. ${ }^{20-26}$

\subsection{CÁNCER DE MAMA METASTÁsico/RECURRENTE CON RECEPTORES HORMONALES NEGATIVOS Y HER2 NEU POSITIVO}

Para decidir el manejo paliativo es importante estratificar a los pacientes, con base en la exposición previa a terapias anti-HER2 y el tiempo transcurrido entre la última dosis de terapia anti-HER2 y la recurrencia o progresión de la enfermedad. ${ }^{27}$

\subsubsection{Primera línea}

El tratamiento estándar para pacientes en etapa IV de novo o expuestos a terapia anti-HER2 durante la neoadyuvancia y con más de 12 meses de supervivencia libre de enfermedad es docetaxel o paclitaxel en combinación con un doble bloqueo anti-HER2 basado en trastuzumab y pertuzumab, ya que ha demostrado claramente un beneficio en la supervivencia global, la SLP y la tasa de respuestas. ${ }^{28,29}$

En pacientes que no pueden recibir pertuzumab, debe considerarse la combinación de trastuzumab más taxano o vinorelbina como una alternativa. ${ }^{30,31}$

Si un paciente expuesto a terapia anti-HER2 durante la neoadyuvancia presenta progresión de la enfermedad durante el tratamiento $o$ en un periodo menor a seis meses de finalizada su última dosis, es recomendable utilizar TDM-1 (conjugado anticuerpo-quimioterápico). ${ }^{32}$

\subsubsection{Segunda línea y posteriores}

Con base en los resultados del estudio PHEREXA, no se recomienda el uso de pertuzumab más allá de la progresión a la primera línea de tratamiento. ${ }^{33}$

En pacientes previamente tratadas con un esquema basado en trastuzumab y con progresión de la enfermedad, el tratamiento indicado es TDM-1. ${ }^{32}$

En pacientes que no pueden recibir TDM-1, debe considerarse la opción de continuar con trastuzumab, en combinación con un agente de quimioterapia o lapatinib/ capecitabina. Los esquemas mencionados previamente y el doble bloqueo con trastuzumab/lapatinib pueden ser utilizados en tercera línea y subsecuentes. ${ }^{34}$

En todas las pacientes se recomienda mantener el bloqueo con terapia anti-HER2 durante todas las fases del tratamiento antineoplásico, excepto en los casos en que esté contraindicado, ya que está demostrado su impacto en el control de la enfermedad. ${ }^{35-38}$

\subsection{CÁNCER de mama metastásico/RECURRENTE TRIPLE NEGATIVO O CON RECEPTORES HORMONALES POSITIVOS HER2 NEGATIVO NO CANDIDATAS A HORMONOTERAPIA (BRCA POSITIVO/NEGATIVO)}

La elección del tratamiento debe tomar en cuenta el tratamiento adyuvante (Tabla 20) y el intervalo libre de recurrencia. En pacientes con un intervalo mayor de un año, es posible evaluar la reinducción de fármacos. Para pacientes con tumores triple negativos, el tratamiento estándar es la quimioterapia, sin que sea posible recomendar, en la actualidad, un esquema 0 secuencia específicos. ${ }^{39-41}$

En pacientes previamente tratados con mutación germinal de BRCA se puede considerar el uso de olaparib. ${ }^{42}$

\subsubsection{Quimioterapia de primera línea: ¿en combinación o secuencial?}

No se recomienda poliquimioterapia de forma estándar. Se prefiere el tratamiento con fármacos como monodroga y de forma secuencial debido a su mejor tolerancia y menor deterioro en la calidad de vida. El uso de poliquimioterapia puede ser considerado en pacientes con buen estado funcional, en las que se busca una rápida respuesta o paliación de síntomas, y/o en caso de crisis visceral y/o en los casos en que se considere que la expectativa de vida solo permite una oportunidad de tratamiento. $39,40,43,44$

Con respecto a lo anterior, la crisis visceral es una disfunción orgánica grave representada por síntomas y signos, estudios de laboratorio y enfermedad rápidamente progresiva. La crisis visceral no se refiere exclusivamente a la presencia de metástasis viscerales, sino que implica compromiso visceral significativo que obliga a una terapia eficaz y de acción rápida, en particular si otra opción de tratamiento, después de una ulterior progresión, no es potencialmente posible.

La piedra angular de la quimioterapia de primera línea se basa en antraciclinas y taxanos. En pacientes previamente expuestas, las opciones de tratamiento incluyen capecitabina, gemcitabina, vinorelbina, o eribulina (Tabla 20).

En caso de que se elija una combinación se recomienda un taxano (paclitaxel o docetaxel) más capecitabina o gemcitabina. Ambos esquemas se han 
Tabla 20. Cáncer de mama metastásico triple negativo o con receptores hormonales positivos, HER2 neu negativo no candidato a hormonoterapia

\begin{tabular}{|l|l|l|l|l|}
\hline \multicolumn{2}{|c|}{ Adyuvancia } \\
\hline
\end{tabular}

asociado con mayores tasas de respuestas e intervalo libre de progresión vs. taxano como monodroga. ${ }^{45-50}$ La eficacia de ambos esquemas es similar y la elección dependerá de las características de cada paciente y los recursos disponibles.

La elección del tratamiento depende de las características de las pacientes, la tolerancia y respuesta a tratamientos previos, así como de la disponibilidad. ${ }^{39,40}$

La eribulina es el único fármaco que ha demostrado impacto en supervivencia global, en pacientes previamente tratados con taxanos/antraciclinas, en población con tumores triple negativo. ${ }^{51-53}$

\subsubsection{Sales de platino}

Existen estudios que muestran la efectividad del platino y sus derivados en tumores triple negativos. ${ }^{57-59} \mathrm{El}$ estudio TNT, un ensayo fase III, evaluó el uso de docetaxel vs. carboplatino, el cual no mostró superioridad de la sal platinada en población triple negativa no seleccionada (BRCA mutación germinal vs. mutado); sin embargo, en la población con mutación germinal BRCA presente se observó una superioridad en la SLP a favor de carboplatino..$^{60}$ Aunque las sales de platino no se recomiendan como terapia de primera línea en población no seleccionada, puede representar una opción en población con mutación germinal de BRCA. ${ }^{57-59}$

\subsubsection{Bevacizumab}

El uso de bevacizumab más un agente de quimioterapia incrementa el control de la enfermedad y la SLP, pero no impacta en la supervivencia global como terapia de primera línea en cáncer de mama metastásico. ${ }^{60-65}$ Es una opción de tratamiento utilizar bevacizumab más taxano en pacientes con tumores triple negativo o en aquellas con receptores hormonales positivos, que cursan con una evolución clínicamente agresiva y se consideran candidatas a quimioterapia de primera línea.

\subsubsection{Inmunoterapia}

Atezolizumab más nab-paclitaxel (no se recomienda el uso de atezolizumab con paclitaxel), como terapia de primera línea, demostró incremento en la SLP en la población PD-L1 (ligando 1 de muerte programada) positiva (VENTANA/SP142) ${ }^{66}$

Pembrolizumab más quimioterapia (paclitaxel, nab-paclitaxel o gemcitabina más carboplatino), en pacientes con cáncer de mama triple negativo avanzado, que expresan PD-L1 (CPS > 10\%/clona IHC 22C3 pharmDx), como terapia de primera línea, demostró ser superior vs. quimioterapia en la SLP. ${ }^{67}$

En pacientes con cáncer de mama y mutación germinal de BRCA, previamente tratadas con no más de dos líneas de tratamiento, el olaparib demostró impacto en la SLP, pero no en supervivencia global, por lo que puede ser considerado una opción de tratamiento. ${ }^{42,68}$

\subsubsection{Duración del tratamiento}

La duración del tratamiento no se ha definido por completo. Varios estudios han demostrado que continuar la quimioterapia puede incrementar el intervalo libre de progresión, pero sin prolongar la supervivencia. ${ }^{69,70}$

En la práctica clínica se recomienda continuar la quimioterapia hasta la progresión o toxicidad, dependiendo del fármaco aplicado (intravenoso frente a oral), las dosis máximas acumuladas y el impacto en la calidad de vida de las pacientes. 


\section{Bisfosfonatos e inhibidores del ligando del receptor activador del NF-K en metástasis óseas}

Tanto los bisfosfonatos como los inhibidores del ligando del receptor activador del NF-KB (RANKL) permiten mejorar los resultados en el manejo de las metástasis óseas, la hipercalcemia maligna y la salud ósea al reducir la osteopenia u osteoporosis secundarias al tratamiento sistémico. ${ }^{1-3}$

Los pacientes con evidencia radiográfica de metástasis óseas deben recibir tratamiento, ya sea con denosumab (120 mg subcutáneo cada 4 semanas) ${ }^{4}$ o con ácido zoledrónico (4 mg por vía intravenosa en $15 \mathrm{mi}-$ nutos), cada 3 a 4 semanas. ${ }^{5-7}$

- La duración total del tratamiento con bisfosfonatos, debe ser hasta de dos años.

- El ácido zoledrónico puede aplicarse cada tres a cuatro semanas o cada tres meses, desde un inicio. $^{8}$

- Después de un año de tratamiento y en caso de enfermedad estable, se recomienda la administración de ácido zoledrónico cada 12 semanas durante el segundo año, ${ }^{9}$ y después reconsiderar su uso según la actividad de las metástasis óseas.

- No se conoce la duración óptima del tratamiento con denosumab.

Las recomendaciones generales con el uso de bifosfonatos e inhibidores RANKL son las mismas que en adyuvancia (ver capítulo $\mathrm{X}$, Manejo del cáncer de mama temprano).

\section{Papel de la cirugía en enfermedad metastásica}

El tratamiento estándar del cáncer de mama en estadio IV tradicionalmente se enfoca hacia un terreno paliativo, en el cual se incluye quimioterapia, radioterapia, terapia hormonal y terapias blanco, dejando el papel de la cirugía solo para prevención o tratamiento de síntomas locales; ${ }^{1}$ sin embargo, en los últimos 20 años, centros en todo el mundo han publicado series de pacientes con cáncer de mama metastásico que experimentaron resección en varios sitios (hígado, cerebro, pulmón), reportando resultados favorables, ${ }^{2}$ principalmente en aquellas con metástasis al momento del diagnóstico. De hecho, la mediana de supervivencia global del cáncer de mama metastásico casi se ha triplicado de 13 meses en 1985 a 33 meses en 2016, gracias al tratamiento multimodal. . $^{3,4}$

\subsection{RESECCIÓN DE ENFERMEDAD METASTÁSICA}

\subsubsection{Metástasis hepáticas}

El hígado representa, como único sitio de metástasis a distancia, solo el $10 \%$ de los casos, por lo que la resección hepática ha tenido un papel limitado en el tratamiento, ya que lo más frecuente es que se acompañen de metástasis a otro nivel. ${ }^{5}$ Se ha reportado que la tasa de supervivencia a cinco años después de la resección quirúrgica de las metástasis hepáticas, combinado a la terapia sistémica, oscila entre el 40 y el $61 \%$. Las técnicas quirúrgicas actuales permiten que la resección tenga una mortalidad postoperatoria inferior al $6 \%$ y una morbilidad entre el 0.8 y el $5.4 \%$ en centros de referencia. ${ }^{6}$ Otra opción válida es utilizar ablación de las metástasis con radiofrecuencia o con termoterapia intersticial inducida con láser, con lo que se reporta supervivencia media de $30 \mathrm{a}$ 60 meses y supervivencia a cinco años del 27 al $41 \%{ }^{7}$

En relación con factores pronósticos, la mayoría de los estudios enfatiza la importancia de la resección R0, ya que el margen positivo es un factor adverso para la supervivencia. ${ }^{6,7}$ Otros factores predictores adversos para la supervivencia han sido el tamaño de las lesiones $(>5 \mathrm{~cm})$, el estatus de los receptores hormonales negativos, pobre respuesta a la quimioterapia, la invasión vascular, el número de metástasis y el intervalo libre de enfermedad $<1$ año después de la resección primaria de cáncer de mama. ${ }^{8}$

\subsubsection{Metástasis pulmonares}

La enfermedad metastásica es frecuentemente generalizada y en pocas ocasiones está solo localizada a nivel pulmonar. En una serie de 13,502 pacientes con cáncer de mama en la Clínica Mayo se encontraron apenas $60(0.4 \%)$ con metástasis pulmonares aisladas, de los cuales 40 fueron llevados a resección. ${ }^{9}$

La resección quirúrgica completa de metástasis pulmonares puede realizarse con morbilidad y mortalidad bajas, ya sea realizada por toracotomía o por cirugía toracoscópica asistida por vídeo. El análisis de series de casos ha establecido los siguientes criterios de selección quirúrgica bien aceptados:

- La enfermedad primaria está bajo control.

- Metástasis limitadas al pulmón y pleura.

- Capacidad de extirpar por completo la enfermedad metastásica.

- Reserva fisiológica pulmonar para tolerar el procedimiento planificado. ${ }^{10}$

Un hallazgo común en la mayoría de los estudios que evalúan el papel de la resección de las metástasis 
pulmonares es que el intervalo libre de enfermedad, entre el manejo inicial del primario y la aparición de metástasis pulmonares, impacta muy significativamente en la supervivencia. El intervalo libre de enfermedad de más de 36 meses a la recurrencia ha logrado supervivencias a cinco años de hasta el $75 \%$ en lesiones únicas llevadas a resección y tratamiento sistémico.11

Otros factores asociados con mejoría de la supervivencia han sido los receptores hormonales positivos, positividad para HER2 neu y metástasis solitarias. Como en el caso de las metástasis hepáticas, las pacientes con lesiones únicas e intervalo libre de enfermedad prolongado deben considerarse candidatas a metastasectomía pulmonar.

\subsubsection{Metástasis cerebrales}

El cáncer de mama representa la segunda causa de lesiones metastásicas en el cerebro y generalmente están asociadas a tumores con receptores hormonales negativos, HER2 positivo, pacientes premenopáusicas y con enfermedad metastásica en pulmón y/o hígado. ${ }^{12}$ Las pacientes que no reciben ningún tipo de tratamiento tienen un pronóstico de supervivencia de un a dos meses, la cual se incrementa hasta seis meses en las que reciben radioterapia y cuando está indicada la cirugía puede incluso llegar hasta 16 meses. $^{13}$

Las indicaciones de la cirugía son limitadas, siendo una opción razonable en lesiones únicas, tamaño $<5 \mathrm{~cm}$, ausencia de metástasis extracraneales y sobre todo pacientes con adecuado estado funcional.

\subsubsection{Otros sitios metastásicos}

Este grupo es menos estudiado y en general no ha mostrado beneficio en la supervivencia. Un ejemplo es el de las metástasis óseas; según varios reportes, en esas pacientes la resección quirúrgica no ha mostrado mejoría en el pronóstico, ${ }^{14}$ siendo la radioterapia la modalidad paliativa de elección. Por otra parte, algunos estudios han reportado que la resección de metástasis en esternón o caja torácica se asocia con incremento de la supervivencia. ${ }^{15}$ Menos estudiadas aún por su baja frecuencia son las metástasis adrenales, ováricas y gastrointestinales; en estos casos no se recomienda la resección, salvo en situaciones de paliación de síntomas.

\subsection{ReSECCIÓN DEL TUMOR PRIMARIO EN ENFERMEDAD METASTÁSICA}

Este es un escenario clínico donde las controversias son aún mayores, ya que las recomendaciones se basan en estudios retrospectivos, donde algunos de ellos muestran beneficio en supervivencia global; sin embargo, deben ser tomados con cautela dado el sesgo de selección, basada principalmente en la baja carga tumoral, ausencia de metástasis viscerales y edad más joven, entre otros factores. ${ }^{16-21}$ Otros estudios, no obstante, también retrospectivos, no han mostrado beneficio derivado de la resección del tumor primario, en este contexto. ${ }^{22-24}$

Los estudios prospectivos en este escenario son pocos y los resultados también controvertidos. Entre ellos, el estudio turco (Protocolo MF0701), que a 40 meses de seguimiento, es el único que ha mostrado beneficio en supervivencia, disminuyendo el riesgo de muerte en un $34 \%$; sobre todo, en pacientes menores de 55 años, con receptores de estrógenos y progesterona positivos, HER2 neu negativo y metástasis óseas solitarias. ${ }^{25}$ Pese a ello, otros estudios, como el realizado en la India, no mostró beneficio en la supervivencia global, en ningún subgrupo de pacientes etapa clínica IV, con resección del tumor primario, posterior a recibir tratamiento sistémico. ${ }^{26}$ De igual forma, el estudio prospectivo fase III (ABCSG20 POSYTIVE) realizado en Australia ${ }^{27}$ y el estudio TBCRC 013 realizado en los Estados Unidos ${ }^{28}$ tampoco demostraron beneficios en supervivencia global a 37.5 y 54 meses de seguimiento, respectivamente.

Los datos disponibles no son concluyentes, por lo que la resección del tumor primario en pacientes con etapa clínica IV al momento del diagnóstico no debe ser considerada como una opción de tratamiento para todas ellas. Sin embargo, parece ser una alternativa razonable que puede ser discutida con pacientes seleccionadas, con características clínicas favorables, buen estado general, menores de 55 años, enfermedad con receptores hormonales positivos, HER2 neu negativo, volumen tumoral limitado y metástasis óseas solitarias.

\subsection{Resección Paliativa del tUMOR PRIMARIO EN ENFERMEDAD METASTÁSICA}

En este escenario clínico no hay controversia: la cirugía está indicada en pacientes con tumor fungante, ulcerado o hemorrágico, y tiene la finalidad de mejorar la calidad de vida, sin esperar impacto en 
supervivencia. En caso de tumores primarios no resecables, se puede considerar radioterapia paliativa. ${ }^{29}$

\section{Papel de la radioterapia en enfermedad metastásica}

El tratamiento de la enfermedad metastásica distingue tres grupos, de acuerdo con diferentes características: el primero incluye a pacientes con buenas condiciones generales, tumor primario controlado y enfermedad confinada a tres o menos sitios, otro grupo con mal estado funcional o diseminación metastásica extensa y un tercer grupo que requiere control local por sangrado, infección o dolor. La decisión del tratamiento para estas pacientes deberá realizarse por un equipo multidisciplinario.

\subsection{Radioterapia al primario}

El manejo local de este grupo de pacientes es controvertido y debe individualizarse. El estudio fase III ECOG-ACRIN 2108 sobre la eficacia del tratamiento local, posterior a quimioterapia en pacientes con cáncer metastásico de novo, reportó que el control local fue mayor en las pacientes tratadas con cirugía y radioterapia, con un riesgo de progresión local o recurrencia 2.5 veces mayor en pacientes que únicamente reciben quimioterapia. Estos hallazgos enfatizan la necesidad de un tratamiento multidisciplinario. ${ }^{1,2}$

\subsection{Metástasis óseas}

La dosis y volumen que irradiar se seleccionan de acuerdo con la intención del tratamiento. El objetivo es controlar síntomas y evolución de la enfermedad. Los esquemas de radioterapia incluyen 37.5 Gy en 15 sesiones, 30 Gy en 10 sesiones, 20 Gy en 5 sesiones 0 una dosis única de $8 \mathrm{~Gy} .^{3}$

\subsection{Metástasis Cerebrales}

Las modalidades de radioterapia comprenden: irradiación a encéfalo total, radiocirugía estereotáctica (SRS) y la irradiación encefálica, con preservación de hipocampos. La radioterapia a encéfalo total se utiliza en lesiones cerebrales metastásicas múltiples, pacientes con enfermedad leptomeníngea, tumor primario no controlado o mal estado funcional. ${ }^{4}$ La revisión actualizada de Cochrane del 2018 favorece el empleo del esquema de 30 Gy en 10 fracciones. ${ }^{5}$ Siempre que esté disponible la técnica de protección de hipocampos, se recomienda su empleo con el objetivo de reducir el deterioro cognitivo ocasionado por la radioterapia a encéfalo total. ${ }^{6}$ La SRS en dosis única es el estándar para las pacientes con 1-10 lesiones metastásicas $<3 \mathrm{~cm}$ y buen estado funcional. ${ }^{7,8} \mathrm{En}$ pacientes con lesiones $>3.1 \mathrm{~cm}$ se prefiere la SRS en 2-5 fracciones. $^{8}$

\subsection{RadIOTERAPIA ESTEREOTÁXICA EXTRACRANEAL EN ENFERMEDAD OLIGOMETASTÁSICA}

Las guías ESTRO-ASTRO definen enfermedad oligometastásica a la presencia de 1-5 lesiones, detectables por imagen. ${ }^{9}$ En cáncer de mama, las metástasis óseas, pulmonares y hepáticas, son las más comunes.

\subsubsection{Radioterapia estereotáxica extracraneal en metástasis óseas y vertebrales}

Se utiliza como técnica de alta precisión que administra entre 1-8 fracciones con finalidad ablativa y precisión submilimétrica. Mejora la supervivencia global, además de la supervivencia libre de enfermedad, y debido al alto control local permite retrasar el inicio de terapia sistémica o transición a siguiente línea de tratamiento. ${ }^{10}$ Para metástasis óseas en columna las indicaciones de este tratamiento son: Karnofsky performance score (KPS) $>60$, con enfermedad metastásica demostrada, lesión única o múltiple ( $\leq 2$ vértebras consecutivas o hasta tres sitios no contiguos), sin datos de compresión medular ni fractura patológica, tumor residual o recurrente posterior a cirugía y con un intervalo mayor de seis meses, en casos de reirradiación. ${ }^{10}$

\subsubsection{Radioterapia estereotáxica extracraneal en metástasis hepáticas}

Indicada en pacientes no candidatas a manejo quirúrgico o que rechazan la cirugía. Los criterios para ofrecer esta técnica incluyen: mujeres con adecuado funcionamiento hepático, estado funcional ECOG (Eastern Cooperative. Oncology Group) 0-2, con enfermedad extrahepática ausente o estable, 1-5 lesiones con diámetro máximo de $10 \mathrm{~cm}$ y volumen hepático sano $>1,000 \mathrm{~cm}^{3}$. La quimioterapia debe suspenderse al menos tres semanas antes del procedimiento y debe reiniciarse dos semanas después de este. ${ }^{11}$ 


\subsubsection{Radioterapia estereotáxica extracraneal en metástasis pulmonares}

La radioterapia estereotáxica extracraneal (SBRT) en metástasis pulmonares proporciona control local a 1 , 3 y 5 años del 80,58 y $46 \%$, respectivamente. Se asocia con mayor supervivencia en lesiones pequeñas con volumen < $11 \mathrm{cc}$ y una dosis biológica equivalente $\geq 100$ Gy. $^{12}$ Las complicaciones son bajas. ${ }^{13}$

\subsection{RADIOTERAPIA PARA CONTROL DE SÍNTOMAS}

Se ofrece con esquemas hipofraccionados en casos de dolor, secreción fétida y enfermedad voluminosa, sangrado tumoral, urgencias oncológicas y carcinomatosis meníngea. ${ }^{14,15}$

\section{Evaluación y manejo de la recurrencia locorregional}

La enfermedad recurrente exclusivamente en la mama o la axila es un evento con frecuencia menor al $10 \% .{ }^{1}$ Inicialmente debe establecerse la extensión de la recurrencia, esto es si hay enfermedad a distancia o no. La distinción de enfermedad puramente recurrente 0 segundos primarios toma en cuenta factores clásicos como los de Warren, además de considerar cuadrante de la lesión, perfil de expresión hormonal, incluso genético, que puede verse modificado según el tratamiento previo. ${ }^{2}$

Deben realizarse MMG/US (mamografía/ultrasonido), evaluación de la extensión (solo local, regional y/o a distancia). En caso de enfermedad a distancia, se procede a las recomendaciones de enfermedad metastásica. Los estudios para descartar enfermedad a distancia son tomografía por emisión de positrones, gammagrafía ósea o tomografía computarizada.

El manejo de la enfermedad recurrente debe considerar que este evento en sí es un predictor de enfermedad a distancia y factor pronóstico adverso, por lo que el tratamiento sistémico deberá ser considerado en cualquiera de sus formas.

\subsection{ManeJo Quirúrgico}

Se recomienda una decisión multidisciplinaria sobre el manejo de la recurrencia locorregional, acorde al tratamiento inicial del primario. Las pacientes con mastectomía previa y recurrencias en la pared torácica pueden ser llevadas a resección local. La mayoría se presentan en la piel y tejido subcutáneo, aunque las recurrencias a pared torácica pueden ocurrir en alrededor del $59 \%$ de los casos. ${ }^{3}$ La resecabilidad dependerá de la extensión a la piel, posibilidad de cobertura de tejidos blandos y afección a estructuras óseas.

Por otra parte, en pacientes tratadas previamente con cirugía conservadora que presentan recurrencia local, la mastectomía es aceptada como el manejo estándar en la recurrencia ipsilateral de cáncer de mama.

La reestadificación axilar con disección de los niveles I y II es el manejo estándar. La realización de ganglio centinela (GC) posterior a cirugía axilar previa es posible, la tasa de identificación varía del 66 al $71 \%{ }^{4}$ y la localización de GC no axilares aumenta hasta $43 \% ; 5$ aunque la tasa de GC positivo parece ser baja $(8 \%)$. La tasa de falsos negativos es del $9.4 \%$ y la exactitud del procedimiento es del $97.1 \%$. Se sugiere utilizar más de una técnica de identificación (colorante, radiotrazador, magnético) y considerar el posible drenaje extraaxilar.

\subsection{Manejo con radioterapia}

Podría considerarse en tres escenarios:

- Como control local después de resección de la recurrencia en pacientes sin antecedente de radioterapia, en cuyo caso se aplican las técnicas de irradiación ya conocidas según se trate de mastectomía o cirugía conservadora.

- Un segundo curso de radioterapia puede darse a la mama previamente tratada, la pared torácica o las áreas ganglionares para un tumor recurrente 0 segundo primario tomando en cuenta la dosis previa de irradiación, sitio a irradiar y la dosis de irradiación que recibieron los órganos circundantes.

- Como reirradiación de enfermedad no resecable para control local y paliación de síntomas como sangrado o dolor. ${ }^{6}$

La selección de pacientes es compleja y debe hacerse por un equipo multidisciplinario, ya que el riesgo de toxicidad local suele aumentar con la reirradiación. Debe considerarse, además, que un tumor que recurre en un sitio irradiado puede ser más resistente a un nuevo esquema de tratamiento. Las técnicas utilizadas son variadas e incluyen campos limitados, electrones, bifraccionamiento, braquiterapia superficial, radioterapia intraoperatoria, irradiación parcial de mama, tratamiento sistémico concomitante e hipertermia. Aunque son alternativas interesantes, solo se han probado en muestras pequeñas y su uso debe limitarse únicamente en el contexto de ensayos clínicos. ${ }^{7,8}$ 
Tabla 21. Integración de los cuidados de soporte y paliativos en la atención oncológica estándar: Actualización de la Guía de práctica clínica de la Sociedad Americana de Oncología Clínica. Recomendación principal

Los cuidados de soporte y paliativos deben iniciarse simultáneamente con el tratamiento antineoplásico. La referencia al servicio de cuidados de soporte y paliativos puede ser complementado con el abordaje habitual por el oncólogo.

Esta referencia debe incluir a los familiares del paciente (evidencia basada en: los beneficios son mayores que los riesgos; calidad de la evidencia, intermedia; solidez de la recomendación, fuerte)

Los componentes esenciales de los servicios de cuidados de soporte y paliativos deben incluir:

- Capacidad para establecer relaciones empáticas y comprometidas con pacientes y familiares

- Manejo de síntomas, distrés y deterioro funcional (por ejemplo, dolor, disnea, fatiga, insomnio, ansiedad, depresión, etc.)

- Estrategias para evaluar y educar sobre el concepto de enfermedad y pronóstico

- Orientación para establecer metas de tratamiento

- Evaluación y soporte de los mecanismos y necesidades de afrontamiento

- Asistencia con toma de decisiones médicas

- Coordinación con otros especialistas

- Criterios de referencia y contrarreferencia

En los pacientes recientemente diagnosticados con cáncer avanzado, el panel de expertos sugiere la incorporación de los cuidados de soporte y paliativos dentro de las primeras 8 semanas después del diagnóstico

Evidencia basada en: consenso informal; calidad de la evidencia, intermedia; solidez de la recomendación, moderada

Deben existir en los modelos ambulatorios de oncología programas y recursos para proporcionar cuidados de soporte y paliativos de manera ambulatoria a pacientes muy sintomáticos o con necesidades físicas o psicosociales no satisfechas

Evidencia basada en: los beneficios son mayores que los riesgos; calidad de la evidencia, intermedia; solidez de la recomendación, moderada

Modificado de: www.asco.org/research-guidelines/quality-guidelines/guidelines/patient-and-survivor-care\#/9671

\subsection{MANEJO SISTÉMICO}

En mujeres con recurrencia local y después de que se haya realizado una resección completa de la enfermedad, la administración de tratamiento adyuvante ha mostrado una mejoría en supervivencia libre de enfermedad y global en todas las pacientes, con un mayor beneficio en el grupo de mujeres con receptores hormonales negativos. ${ }^{9} \mathrm{Al}$ igual que en la recurrencia a distancia se recomienda, de ser posible, contar con una reevaluación del subtipo tumoral para determinar el mejor tratamiento sistémico recomendable, de acuerdo con el manejo previo, tiempo a la recurrencia y a las características de la paciente.

\section{Integración de cuidados de soporte y paliativos en el manejo de pacientes con cáncer de mama avanzado}

\section{Introducción}

Las opciones de tratamiento modificador de la enfermedad en las pacientes con cáncer de mama son cada vez mayores, lo que ha impactado en la mejoría de su supervivencia; sin embargo, conforme la enfermedad avanza, las posibilidades de respuesta disminuyen y la centralidad en el manejo de las pacientes es el brindar confort, por medio de cuidados de soporte y paliativos. $^{1}$

Los cuidados paliativos son definidos por la International Association of Hospice and Palliative Care ${ }^{2}$ como la asistencia activa, holística, de personas de todas las edades con sufrimiento severo, relacionado con la salud debido a una enfermedad grave, y especialmente de quienes están cerca del final de la vida. Su objetivo es mejorar la calidad de vida de los pacientes, sus familias y sus cuidadores. Incluyen prevención, identificación precoz, evaluación integral y control de problemas físicos, incluyendo dolor y otros síntomas angustiantes, sufrimiento psicológico, sufrimiento espiritual y necesidades sociales. ${ }^{2}$

La integración temprana de los cuidados de soporte y paliativos al manejo de los pacientes con cáncer puede mejorar la calidad de vida, el control sintomáti$c 0$, la satisfacción del paciente y la familia, la atención al final de la vida, la supervivencia y los costos de atención. ${ }^{3}$

La Sociedad Americana de Oncología Clínica (ASCO) establece en su guía de manejo que los pacientes con cáncer avanzado deben recibir la atención de cuidados de soporte y paliativos de manera temprana, simultáneamente con los tratamientos antineoplásicos (Tabla 21). ${ }^{4}$ Las estrategias para la integración actualmente son motivo de estudio; no obstante, es 
importante que el oncólogo adquiera los conocimientos necesarios para brindar la atención de soporte y paliativa básica como parte de su práctica clínica, derivando a los especialistas en cuidados paliativos, los casos que requieran un manejo más especializado para el alivio de los síntomas. ${ }^{5}$

\section{Evaluación de necesidades de cuidados paliativos}

Es esencial la evaluación sistemática y estructurada de los síntomas físicos, psicológicos, psiquiátricos, alteraciones cognitivas, concepto de enfermedad y pronóstico, necesidades de atención, preocupaciones existenciales, así como distrés emocional y económico. Un buen control sistemático mejora la confianza de los pacientes y sus familias.

El uso de instrumentos validados de evaluación de síntomas ayuda a identificar, tratar y dar seguimiento sintomático. La autoevaluación de síntomas mediante las diferentes escalas disponibles es importante, ya que los médicos tienden a subestimar su severidad, lo que impacta en la oportunidad de establecer un tratamiento que pueda contribuir a mejorar tanto el síntoma como la calidad de vida.

Es esencial en este modelo evaluar la complejidad sintomática del paciente en siete aspectos básicos:

- Aspectos físicos del cuidado (síntomas).

- Aspectos psicológicos y psiquiátricos.

- Aspectos sociales.

- Aspectos espirituales, religiosos y existenciales.

- Aspectos culturales de la atención.

- Cuidado del paciente que se aproxima al final de la vida.

- Aspectos éticos y jurídicos de la atención.

Una estrategia frecuentemente utilizada en los servicios de cuidados de soporte y paliativos son las reuniones familiares, en las que se abarcan aspectos médicos, metas de tratamiento, identificación de redes de apoyo y recomendaciones para el cuidador primario.

Esta evaluación de varios dominios no es común en las consultas oncológicas, ya que la evidencia demuestra que se enfocan principalmente en el tratamiento del cáncer, la respuesta a él y las complicaciones médicas, mientras se subvalúan los síntomas y las habilidades de afrontamiento, que de manera sistemática realizan los servicios de cuidados de soporte y paliativos. ${ }^{5,6}$

La discusión de la evaluación oncológica-paliativa integral debe incluir la revisión, tanto de riesgos como de beneficios, de la terapia anticáncer y pronóstico, además de asegurar que la paciente y su familia comprenden la incurabilidad de la enfermedad. En este contexto, la opinión del oncólogo sobre el beneficio del envío a cuidados de soporte y paliativos debe ser considerada (Fig. 16). ${ }^{6}$

\section{Manejo de síntomas por el oncólogo}

Los síntomas que presenta la paciente con cáncer de mama son variados y cambiantes durante el proceso de la enfermedad, pero se acentúan en la etapa avanzada y en la fase terminal. Dolor, depresión, ansiedad, fatiga, disnea, insomnio, náuseas y pérdida de peso son síntomas frecuentes que ocasionan cada vez mayor dependencia de las pacientes, y contribuyen de manera importante a incrementar su sufrimiento. Otros síntomas asociados a compresión medular, metástasis cerebrales, linfedema y anemia, impactan también negativamente en la calidad de vida. ${ }^{6-8}$

\subsection{DOLOR}

El dolor por cáncer es un síndrome caracterizado por una constelación de síntomas y signos; está presente hasta en el $70 \%$ de las pacientes con cáncer de mama avanzado debido a la progresión de la enfermedad. ${ }^{6-8}$ Su manejo requiere un enfoque que incluya las terapias antitumorales, terapia analgésica y atención psicológica.

La causa más frecuente de dolor por cáncer en este grupo de pacientes está relacionado con la presencia de metástasis óseas y sus complicaciones. Otras causas incluyen el dolor por infiltración de la pared torácica, plexopatía braquial y dolor abdominal por distensión, entre otros.

El dolor neuropático secundario al uso de taxanos impacta la calidad de vida de las pacientes y presenta retos importantes en su manejo. La identificación de biomarcadores es un campo activo de investigación. Los antidepresivos como la duloxetina han mostrado resultados prometedores.

Es importante que el oncólogo se familiarice con las opciones farmacológicas para manejo del dolor, particularmente el uso de opioides potentes, para el tratamiento de dolor severo.

La figura 17 muestra algunas recomendaciones para el manejo del dolor. Enfatizamos la posibilidad de consultar a los especialistas en dolor y cuidados paliativos, en casos complejos. ${ }^{7}$ 


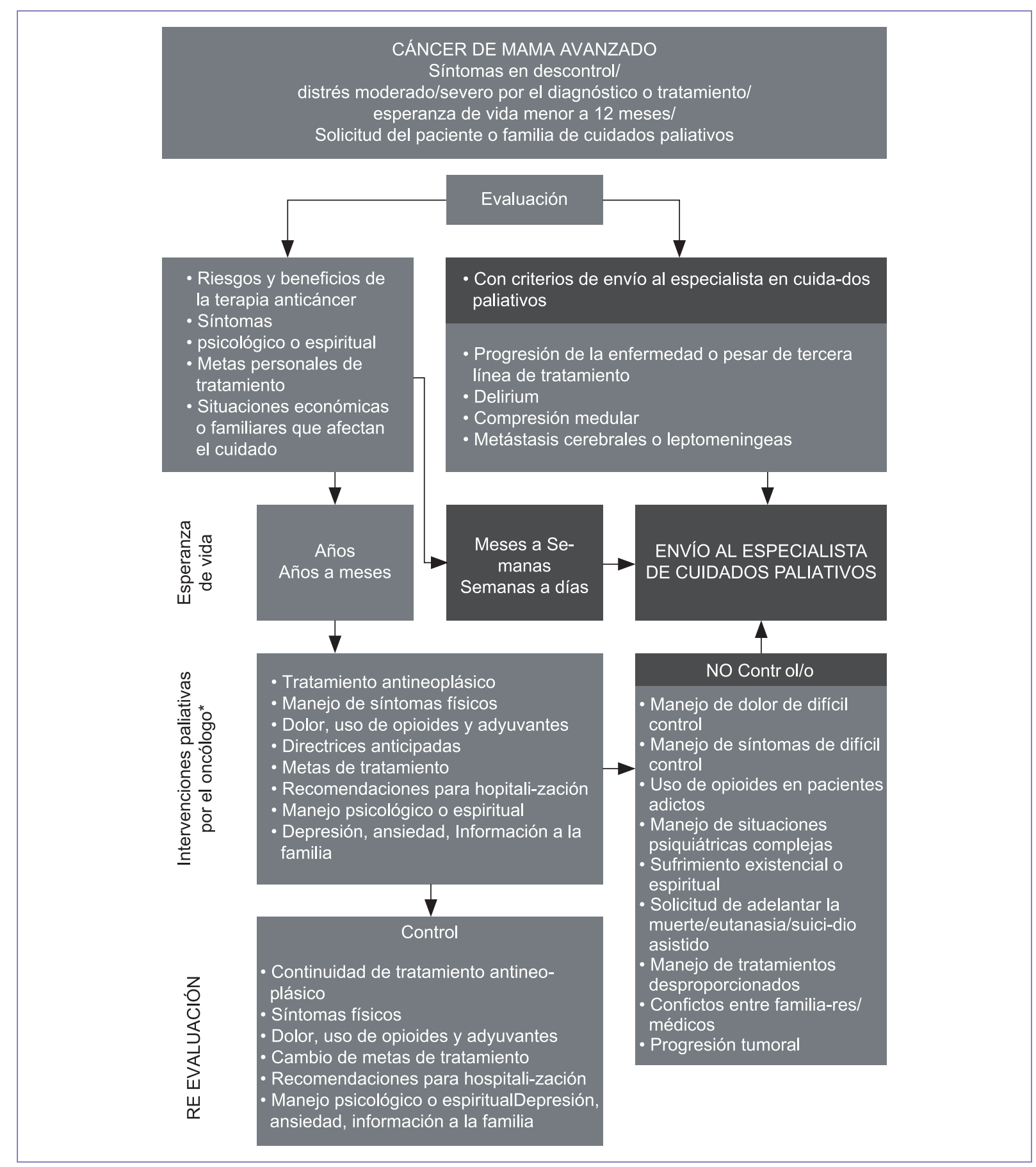

Figura 16. Papel del oncólogo en cuidados paliativos.

\subsection{DISNEA}

La disnea es un síntoma frecuente en pacientes con cáncer de mama metastásico a pulmón. La Asociación Americana de Tórax la define como la experiencia subjetiva de malestar respiratorio, que consiste en sensaciones cualitativamente distintas que varían de intensidad. El tratamiento de causas subyacentes debe ser considerado siempre (anemia, insuficiencia cardiaca, asma, infección pulmonar, etc.). Los opioides (dosis bajas de morfina oral) son el fármaco de elección para la paliación del síntoma. En la figura 18 se describe el flujograma para su manejo. ${ }^{6-8}$ 
Cáncer Mama Estadi o

Clínico IV Recurrente o

Metastásico Con pronóstico de

vida mayor a seis meses

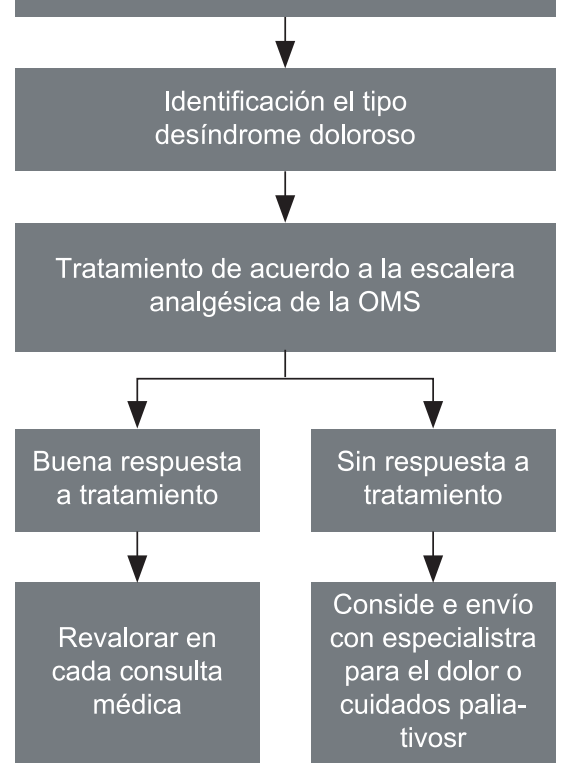

Cáncer Mama

Estadio Clínico IV

Recurrente o Metastásicocon

pronóstico de vida de semanas o días

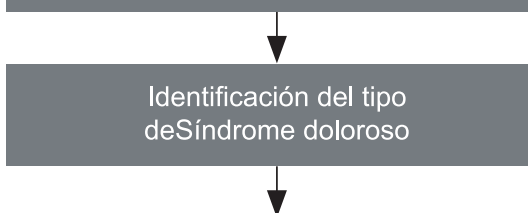

Tratamiento de acuerdo a la escalera analgésica de la OMS

- Dosis inicial de morfina $5 \mathrm{mg}$ VO c $8 \mathrm{hr}$

Adicionalmente

- No disminuya la dosis de opioide en

función de hipotensión, bradipnea,

o disminución del estado de concien-cia

si el opioide está indicado por

dolor o disnea

- Titule el analgésico opioide para

brindar control adecuado del dolor

- En caso de considerar retirar elopioide,

disminuya gradualmente $25 \%-50 \%$

cada / 24 hrs para evitar crisis de dolor

o abstinencia

- Evite el uso de antagonistas de opioides

- Considere riesgos/beneficios de la

disminución del nivel de consciencia

para el control del dolor en base a

las preferencias del paciente

- Modi fique la ruta de administración

tratando de brindar el mayor confort

al paciente

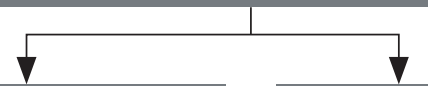

Buena respuesta

altratamiento

- Aborde las necesidades del

cuidador y familiares

- Discuta las preferencias de

morir en hospital o domicilio

- Oriente sobre trámite

funerarios

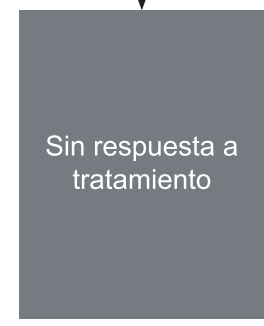

\section{更}

Considere envío con especialista para el doloro cuidados paliativos

Considere envío a cuidados paliativos para con-trol de dolor, manejo al final de la vida y duelo

Figura 17. Manejo del dolor. ${ }^{8}$

OMS: Organización Mundial de la Salud.

Modificado de Clinical Practice Guidelines in Oncology. Version 1.2016.

\subsection{FATIGA}

La sensación de fatiga es frecuente en pacientes durante el tratamiento modificador de la enfermedad y puede persistir incluso en pacientes supervivientes. La evaluación de este síntoma debe descartar factores potencialmente tratables como la anemia, disfunción tiroidea, dolor, depresión e insomnio. 


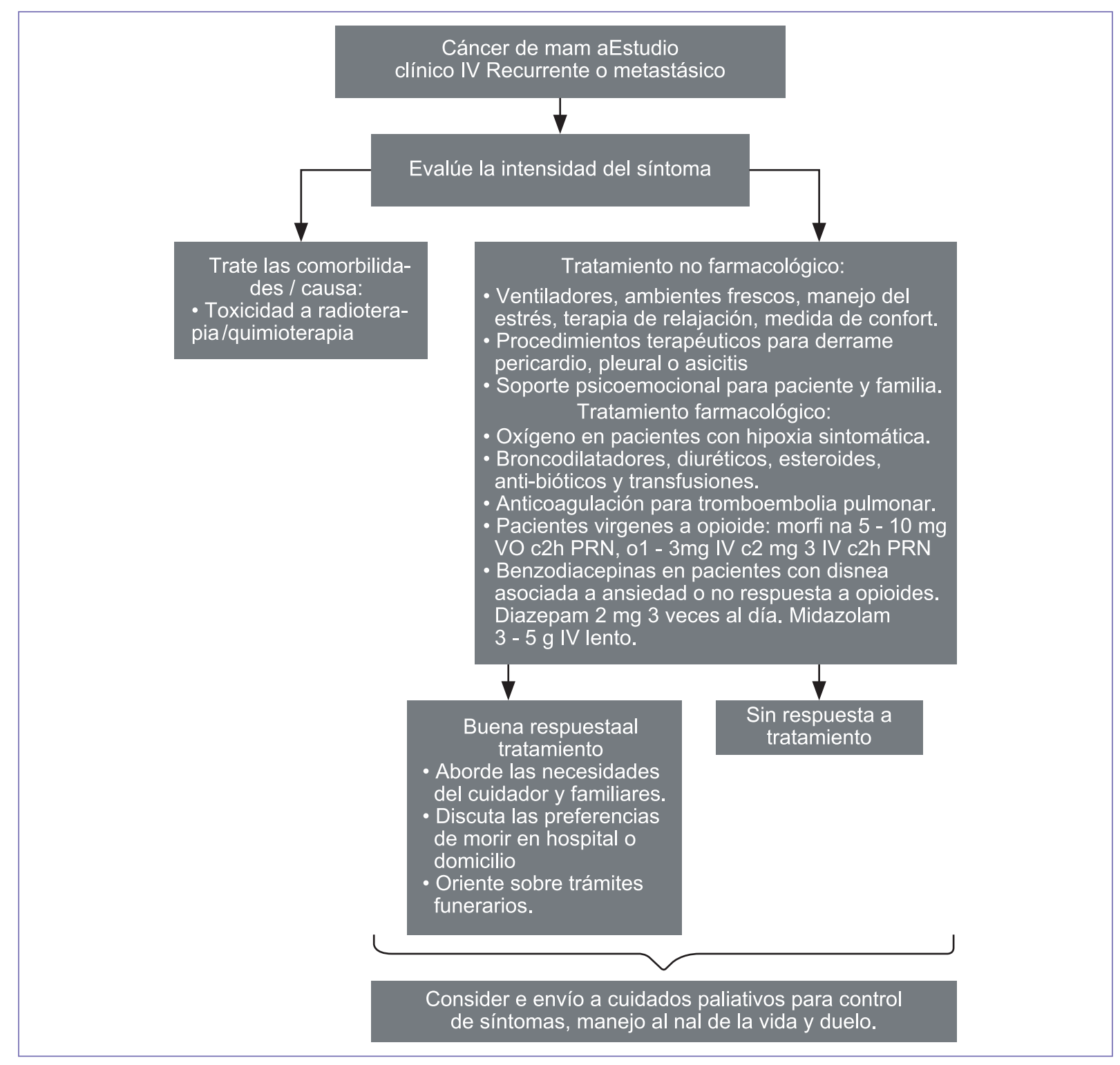

Figura 18. Disnea. ${ }^{8}$

PRN: por razón necesaria.

Modificado de Clinical Practice Guidelines in Oncology. Version 1.2016.

\subsection{ANorexia}

La anorexia y la pérdida de peso son frecuentes en pacientes con cáncer avanzado y contribuyen a la sensación de cansancio, siendo parte importante de las preocupaciones de la familia. El acetato de megestrol estimula el apetito e incremento de peso, pero no mejora la calidad de vida ni incrementa la masa muscular; sin embargo, aumenta el riesgo de edema y fenómenos tromboembólicos. Los corticoesteroides mejoran el apetito, sin embargo, su uso prolongado ocasiona múltiples efectos secundarios.

\subsection{DELIRIUM}

El delirium es la complicación neuropsiquiátrica más frecuente en las pacientes con cáncer de mama avanzado metastásico. Se caracteriza por una disfunción cerebral global de etiología indeterminada, caracterizada por fluctuaciones en el estado de alerta, atención, pensamiento, percepción, memoria, comportamiento psicomotor, emociones y el ciclo de sueño-vigilia. La mayor parte de las veces su etiología es multifactorial, puede ser ocasionado por alteraciones directamente en el sistema nervioso central (metástasis) o por efecto 
indirecto de la enfermedad o tratamiento. El delirium puede ser hiperactivo o hipoactivo, este último es el más frecuente y es subdiagnosticado en pacientes con cáncer avanzado en cuidados paliativos. Existen diferentes instrumentos de tamizaje, para la Evaluación de Delirium, el más simple es el método de evaluación de confusión.

\section{Criterios de envío a cuidados de soporte y paliativos de pacientes ambulatorias}

La interacción con los especialistas en cuidados de soporte y paliativos enriquecerá la práctica de la oncología en síntomas de difícil control, en algunas situaciones al final de la vida y durante el duelo. ${ }^{9}$

En el seguimiento de los pacientes, la incorporación de la telemedicina es un campo que debe considerarse.

\section{Conclusión}

El enfoque sintomático de soporte y paliativo, además de mejorar la calidad de vida de las pacientes con cáncer de mama, puede ayudar a ellas y a sus familias a tener una visión realista de las metas de tratamiento a corto y largo plazo. También puede ayudar al oncólogo a incorporar aspectos esenciales en la atención de sus pacientes y acompañarlas en las etapas de la enfermedad. Los síntomas contenidos en esta sección no abarcan la totalidad de problemas presentes en las mujeres con cáncer de mama avanzado; sin embargo, dan una visión general del abordaje sintomático de soporte y paliativo para oncólogos. La visión será, en todo momento, centrada en la paciente y sus necesidades.

\section{Cáncer de mama en mujeres jóvenes}

\section{Introducción}

Este consenso considera una paciente joven con cáncer de mama a aquella con edad igual o menor de 40 años. Esta delimitación se basa en las diferencias observadas con respecto a los factores de riesgo, las características tumorales y los desenlaces clínicos, así como en los intereses particulares para este grupo de edad: fertilidad, autoimagen, percepción de la calidad de vida y objetivos personales. Los efectos secundarios del tratamiento a largo plazo son particularmente importantes en pacientes jóvenes debido a su potencial de tener una supervivencia larga.
En México, se ha reportado que este grupo de pacientes jóvenes con cáncer de mama se enfrenta a necesidades no cubiertas en cuanto a apoyo psicológico, información sobre preservación de fertilidad, orientación sobre el uso de anticonceptivos efectivos y asesoría en aspectos de sexualidad. ${ }^{1-6}$ Asimismo, las mujeres jóvenes mexicanas requieren mayor información médica, tanto por escrito como de forma electrónica, y solicitan una forma más efectiva de comunicación por parte de sus proveedores de salud. ${ }^{4}$

\section{Abordaje multidisciplinario}

Los siguientes son conceptos relacionados con el diagnóstico y tratamiento recomendado para este grupo de pacientes.

La edad joven no debe ser por sí sola una razón para prescribir terapia más agresiva que las recomendaciones generales. ${ }^{7,8}$

Es altamente recomendable el tratamiento multidisciplinario, así como la planeación del tratamiento individual en los siguientes aspectos:

- Apoyo psicosocial personalizado.

- Consejería genética.

- Referencia para preservación de reserva ovárica y fertilidad.

- Abordaje de alteraciones sexuales y de imagen corporal

- Síntomas de menopausia prematura.

- Sobrepeso u obesidad.

- Salud ósea.

- Promoción para la incorporación a grupos de apoyo.

- Provisión de material educativo (material de apoyo sugerido: www. jovenyfuerte.com.mx).

\subsection{ReCOMENDACIONES ESPECÍFICAS DE DIAGNóstico Y TRATAMIENTO}

\subsubsection{Diagnóstico}

El diagnóstico, los estudios de imagen y el estadiaje en mujeres jóvenes deben seguir los algoritmos estándares consistentes con aquellos para mujeres mayores (ver Capítulo V). Puede darse consideración adicional a la tomosíntesis, el ultrasonido y la resonancia magnética de mama en mujeres jóvenes, en particular en pacientes con tejido mamario extremadamente denso o con predisposición genética.

\subsubsection{Manejo quirúrgico y de radioterapia}

Las recomendaciones para el tratamiento quirúrgico de las mujeres jóvenes con cáncer de mama temprano 
no deben diferir de las indicadas para pacientes mayores. Aunque la edad joven es un factor de riesgo independiente para recurrencia local, ${ }^{9}$ el tratamiento con cirugía conservadora de mama y radioterapia no afecta la supervivencia global cuando se compara con el tratamiento quirúrgico con mastectomía y puede considerarse una opción para este grupo de pacientes. ${ }^{10-12}$

Las recomendaciones específicas de radioterapia adyuvante para el grupo de pacientes jóvenes con cáncer de mama se revisan en la sección correspondiente de radioterapia.

\subsubsection{Tratamiento sistémico adyuvante}

Las indicaciones para quimioterapia son las mismas que en otras pacientes. A pesar de que no se ha estudiado de forma dirigida el empleo de firmas genómicas en pacientes jóvenes, existe evidencia creciente sobre su uso en mujeres premenopáusicas, lo que apoya su empleo para predecir el beneficio adicional de quimioterapia adyuvante en pacientes con cáncer de mama hormonosensible de 40 años o menores. ${ }^{13}$

Las pacientes con cáncer de mama hormonosensible deben recibir terapia endocrina adyuvante por lo menos cinco años (ver Capítulo XII). Si se utiliza un análogo de la hormona liberadora de gonadotropina $(\mathrm{GnRH})$ en este grupo etario, debe administrarse mensualmente (no cada tres meses) para optimizar la supresión y eficacia ovárica. ${ }^{14}$ En aquellas pacientes en tratamiento con inhibidores de aromatasa, se debe verificar de forma periódica que la supresión ovárica sea adecuada con la medición periódica de niveles de estradiol..$^{15}$ En los casos de supresión inadecuada, es necesario discutir estrategias alternativas (ooforectomía o continuar con tamoxifeno solo).

En pacientes premenopáusicas que se encuentren bajo supresión ovárica con doble bloqueo hormonal, se debe considerar la adición de ácido zoledrónico semestral.

\subsubsection{Tratamiento sistémico para enfermedad metastásica}

Las recomendaciones para el manejo del cáncer de mama avanzado no difieren de las de otro grupo etario (ver Capítulo XII).

En el caso de pacientes jóvenes con cáncer de mama metastásico hormonosensible HER 2 negativo, se recomienda el uso de supresión o ablación ovárica adecuada y emplear las mismas líneas de tratamiento con agentes endócrinos o terapias dirigidas como en mujeres posmenopáusicas (inhibidores de aromatasa, fulvestrant, inhibidores de ciclinas, everolimús) (Capítulo XII). ${ }^{16}$

\subsection{Aspectos RELEVANTES QUE CONSIDERAR EN PACIENTES JÓVENES CON CÁNCER DE MAMA}

\subsubsection{Genética}

A toda mujer joven con edad de 40 años o menor y cáncer de mama debe ofrecérsele consejería genética, independientemente del subtipo de cáncer de mama (ver Capítulo XXI) ${ }^{7,8}$ El estatus de mutaciones debería ser parte del algoritmo de la toma individualizada de decisiones de las pacientes. Se deben discutir las diferentes opciones de tratamiento con una cantidad suficiente de tiempo y con apoyo psicológico, dadas las implicaciones y secuelas que pueden producir a largo plazo. A las mujeres que no recibieron la consejería al momento del diagnóstico de cáncer de mama, se les deberá ofrecer durante el seguimiento, para abordar los temas de monitoreo y estrategias de reducción de riesgo de tumores primarios adicionales en la paciente y sus familiares.

\subsubsection{Aspectos de fertilidad y preservación ovárica}

Se debe preguntar sistemáticamente acerca del interés de la paciente en tener hijos en un futuro. Para aquellas interesadas, se debe informar acerca de las estrategias aprobadas para preservación de fertilidad y deben ser referidas a una consulta por especialistas en biología de la reproducción antes de iniciar tratamiento sistémico. ${ }^{17,18}$

Se puede considerar la administración concomitante de análogos de la GnRH de forma mensual, con quimioterapia, en pacientes premenopáusicas con cáncer de mama interesadas en preservar la función ovárica y/o la fertilidad. ${ }^{18,19}$ Su empleo en pacientes con receptores hormonales positivos y negativos no confiere riesgo de recurrencia. ${ }^{20} \mathrm{El}$ uso de análogos de la GnRH no reemplaza el uso de métodos de preservación, por lo que se debe continuar ofreciéndolos en caso de que la paciente busque preservar fertilidad, y se debe hacer la referencia con el especialista en biología de la reproducción para su evaluación y manejo. La indicación de los análogos de la GnRH no debe retrasar el inicio del tratamiento con quimioterapia.

Las pacientes deben ser informadas de la posibilidad de embarazo incluso durante la terapia endocrina a 
pesar de presentar amenorrea y se debe informar de la necesidad de un anticonceptivo no hormonal adecuado.

El uso de anticonceptivos hormonales exógenos está contraindicado en mujeres jóvenes sobrevivientes y deben considerarse estrategias alternas:

- Si la paciente tiene fertilidad satisfecha, buscar opciones definitivas (oclusión tubárica bilateral 0 vasectomía).

- Si la paciente aún no tiene fertilidad satisfecha, dispositivo intrauterino (DIU) ( $T$ de cobre).

- El uso de DIU con levonorgestrel es controvertido.

- Otra opción para pacientes con fertilidad no satisfecha es el preservativo (considerar fallas relacionadas con el empleo incorrecto).

- Interrogar sobre uso de anticonceptivos hormonales e indicar suspensión.

- Se recomienda realizar una prueba de embarazo antes del inicio del tratamiento sistémico con quimioterapia y/u hormonoterapia

No se ha demostrado detrimento en el pronóstico de pacientes con embarazos subsecuentes al diagnóstico de cáncer de mama. ${ }^{21,22}$ Los médicos deben discutir caso por caso esta posibilidad con las interesadas en buscar un embarazo y no desalentar su deseo de maternidad, incluyendo aquellas con receptores hormonales positivos o con presencia de mutación germinal de BRCA.,17,18,23,24

El tiempo de la búsqueda del embarazo debe ser personalizado, tomando en cuenta la edad y la reserva ovárica de la paciente, los tratamientos antineoplásicos previos y el tiempo de su finalización, así como el riesgo individual de recaída. ${ }^{24}$ En general, se recomienda buscar el embarazo dos a tres años después del término de la quimioterapia en pacientes con tumores hormononegativos. ${ }^{25}$ Para pacientes con cáncer de mama hormonosensible está activo el estudio POSITI$\mathrm{VE}$, que permite suspender de forma temporal el tratamiento antihormonal por dos años, y se esperan los resultados en breve. ${ }^{27}$

Todas las mujeres jóvenes deben ser informadas y aconsejadas sobre los riesgos y síntomas relacionados de la amenorrea y menopausia prematura resultantes del tratamiento sistémico antes de iniciarlo (quimioterapia o terapia endocrina). Durante el tratamiento y la vigilancia se debe preguntar de forma sistemática acerca de los síntomas relacionados con la menopausia, la afectación de la calidad de vida, de manera de ofrecer alternativas de manejo $y$, de ser necesario, modificar el tratamiento endocrino.

La menopausia prematura y/o la amenorrea relacionadas con el tratamiento aumentan el riesgo de disminución de la densidad ósea en pacientes premenopáusicas, por lo que se recomienda monitorearla y tratar en consecuencia (ver Capítulo X, Apartado 2.7).

\subsubsection{Aspectos psicológicos}

Las mujeres jóvenes con cáncer de mama tienen un mayor riesgo de estrés psicológico. Todas las pacientes con malestar o necesidades psicológicas deben ser evaluadas con regularidad. La atención psicológica debe estar disponible e integrada de forma sistemática en los tratamientos y el seguimiento del cáncer. La atención a las parejas y a los familiares de las pacientes debe integrarse tempranamente y se debe proponer de manera oportuna las intervenciones psicosociales de pareja, en caso de que se requieran.

Se recomienda la práctica de meditación con atención plena (mindfulness) mediante un programa corto de intervención (6-8 semanas) en pacientes jóvenes con síntomas depresivos, ya que disminuye dicho malestar de forma sostenida por seis meses. Asimismo, dicha práctica mejora síntomas de ansiedad, bochornos, fatiga e insomnio. En la actualidad, existen entrenamientos virtuales de estas prácticas. El proveer sesiones educativas se asocia a mejorar los síntomas depresivos.

\section{$\mathrm{XV}$. Tratamiento en pacientes adultas mayores}

Este consenso considera una edad $\geq 65$ años para definir a una persona adulta mayor. ${ }^{1}$ En estas pacientes, la edad cronológica no necesariamente refleja la edad fisiológica y, por tanto, no debe dictar el tratamiento. ${ }^{2}$ La valoración geriátrica permite reconocer problemas no encontrados normalmente, identifica pacientes vulnerables/frágiles, y conduce a cambios en el manejo planeado hasta en el $50 \%$ de los casos. Adicionalmente, permite calcular la expectativa de vida y predecir toxicidades y riesgo de hospitalización, lo que puede mejorar la toma de decisiones terapéuticas y generar intervenciones encaminadas a prevenir complicaciones y a aminorar el impacto negativo del tratamiento sobre la calidad de vida. ${ }^{2,3}$

\section{Recomendaciones para valoración geriátrica}

Utilizar la herramienta de tamizaje geriátrico G8 (Tabla 22) en todas las mujeres $\geq 65$ años al iniciar 
Tabla 22. Cuestionario G8 de tamizaje geriátrico

\begin{tabular}{|c|c|c|}
\hline & Ítems & Respuestas posibles (puntos) \\
\hline \multirow[t]{2}{*}{$\mathrm{F}$} & \multirow{2}{*}{$\begin{array}{l}\text { ¿Toma más de tres medicamentos } \\
\text { por día? }\end{array}$} & 0 = sí \\
\hline & & $1=$ no \\
\hline \multirow[t]{2}{*}{ G } & \multirow{2}{*}{$\begin{array}{l}\text { En comparación con otras personas de su edad, } \\
\text { ¿cómo considera el paciente } \\
\text { su estado de salud? }\end{array}$} & $0=$ no $\tan$ bueno \\
\hline & & $0.5=$ no sabe \\
\hline \multirow[t]{4}{*}{$\mathrm{H}$} & \multirow[t]{3}{*}{ Edad } & $0=>85$ años \\
\hline & & $1=80-85$ años \\
\hline & & $2=<80$ años \\
\hline & Puntaje total (0-17) & \\
\hline
\end{tabular}

Tabla 23. Valoración geriátrica en cáncer de mama3

\begin{tabular}{|l|l|}
\hline Dominio & Herramienta sugerida* \\
\hline Funcionalidad & $\begin{array}{l}\text { Actividades básicas de Katz (bañarse, } \\
\text { vestirse, ir al baño, traslados, comer, } \\
\text { continencia) } \\
\text { Actividades instrumentadas de Lawton } \\
\text { (teléfono, transporte público, finanzas, } \\
\text { compras, preparar comidas, cuidado de la } \\
\text { casa, lavado de ropa, tomar sus propios } \\
\text { medicamentos) }\end{array}$ \\
\hline Comorbilidad & Índice de Charlson \\
\hline Depresión & PHQ-2 \\
\hline Cognición & Mini-Cog \\
\hline Nutrición & Pérdida de peso no intencional > 10\% \\
\hline Caídas & $\geq 1$ caída en los últimos seis meses \\
\hline
\end{tabular}

PHQ-2: Patient Health Questionnaire 2

*Las herramientas pueden obtenerse en http://consensocancermamario.com/

tratamiento. Las pacientes con $\mathrm{G} 8>14$ puntos no requieren valoraciones adicionales. ${ }^{3-5}$

En pacientes con $\mathrm{G} 8 \leq 14$ puntos se recomienda la referencia a un médico con experiencia en geriatría para una valoración geriátrica, que incluirá los dominios de la tabla $23.3,5$

De acuerdo con la valoración geriátrica, las pacientes pueden clasificarse en tres grupos (apto, frágil o vulnerable), que podrán utilizarse para decisiones terapéuticas (Fig. 19). ${ }^{6}$

Se recomienda realizar una interconsulta a geriatría para implementar intervenciones multidisciplinarias destinadas a tratar los déficits encontrados en la valoración geriátrica de forma concurrente al tratamiento. ${ }^{3,7}$

\section{Cálculo de expectativa de vida}

Recomendamos utilizar el índice de Suemoto (validado en México y disponible en https://eprognosis.ucsf. edu/suemoto.php) para calcular la expectativa de vida a 10 años. En la opción «¿Su paciente tiene cáncer?» se deberá seleccionar NO para obtener la mortalidad por riesgos competitivos. Esto ayudará a sopesar el riesgo-beneficio de las intervenciones terapéuticas y a individualizar el tratamiento. ${ }^{3,8}$

\section{Toxicidad de la quimioterapia}

Recomendamos el uso de la calculadora de toxicidad específica para cáncer de mama del Cancer and Aging Research Group (CARG). ${ }^{9}$ Dicha calculadora no debe usarse para determinar qué pacientes pueden o no recibir tratamiento, sino para identificar pacientes con mayor riesgo de toxicidades graves con el objetivo de instaurar medidas preventivas y de seguimiento estrecho. Otra alternativa es la calculadora CRASH, disponible en www.moffitt.org/eforms/crashscoreform. ${ }^{10}$

\section{Recomendaciones específicas de tratamiento}

\subsection{Cirugía}

En adultos mayores, la edad no es un factor que determine el tipo de tratamiento quirúrgico. Sin embargo, es importante evaluar el riesgo quirúrgico con base en la comorbilidad asociada, ya que se ha observado que esta limita la oportunidad de dicho tratamiento y puede conducir a deterioro funcional. ${ }^{11}$ 


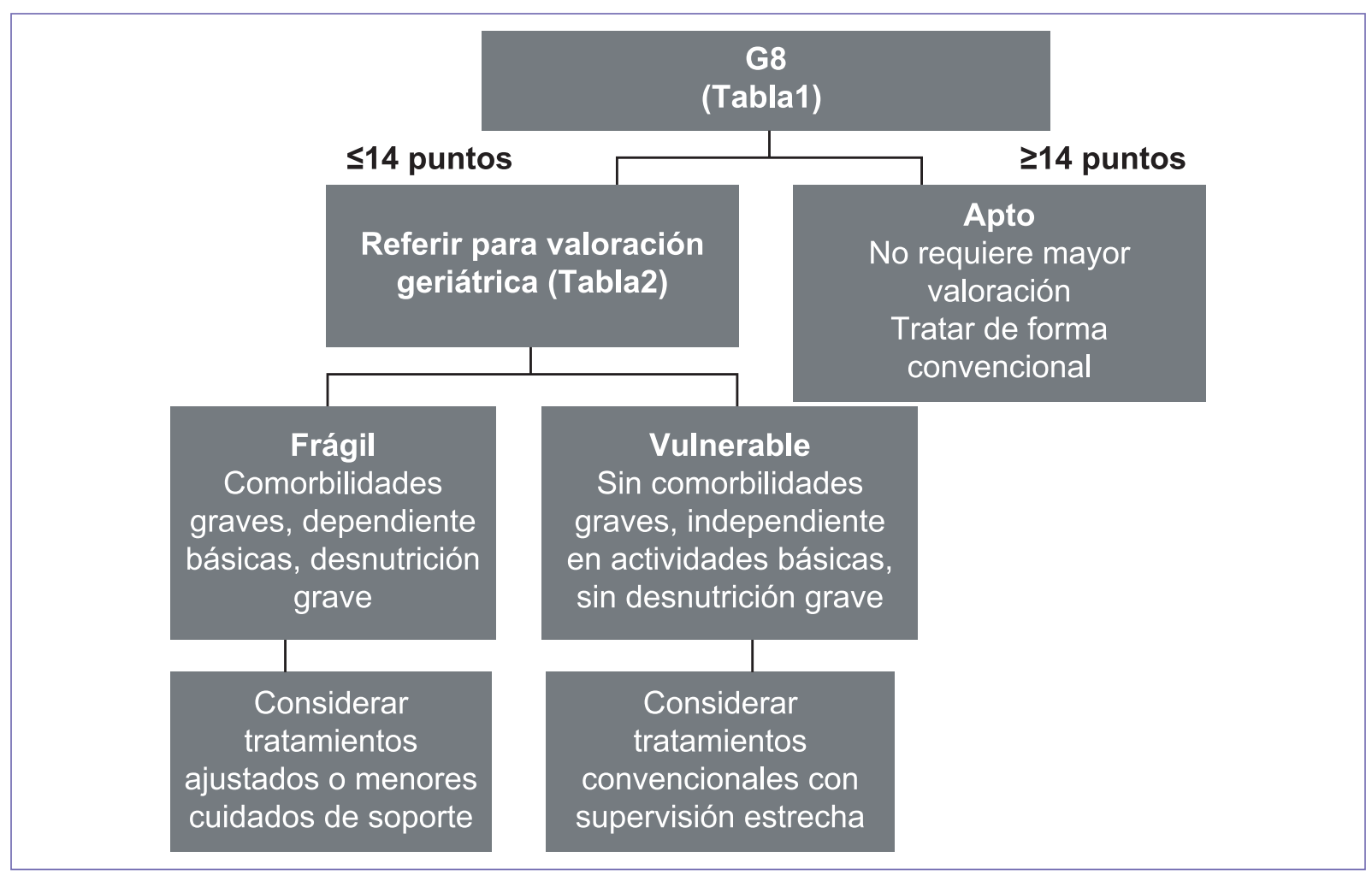

Figura 19. Clasificación de valoración geriátrica.

\subsection{RADIOTERAPIA}

En pacientes adultas mayores elegibles para radioterapia (RT) se recomienda decidir el tratamiento basándose en la valoración geriátrica y discutir su relación riesgo-beneficio.

En pacientes con etapa 0/l de buen pronóstico (grado 1 , ganglios negativos, receptores hormonales positivos $[\mathrm{RH}+]$ ) tratadas con terapia hormonal, la RT adyuvante después de cirugía conservadora impacta en el control locorregional, aunque no parece haber beneficio en supervivencia global ni en supervivencia libre de recurrencia a distancia.12,13 Por lo tanto, no administrar RT puede ser una opción aceptable en dichas pacientes, aceptando una tasa de recurrencia local del $10 \%$ a 10 años.

\subsection{TrataMIENTO SISTÉMICO}

El beneficio de la quimioterapia (QT) y/o terapia hormonal adyuvante debe determinarse utilizando herramientas clínicas y genómicas convencionales, y sopesarse contra la expectativa de vida y el riesgo de toxicidad. No existen esquemas adyuvantes específicos para adultos mayores, pero los esquemas modificados (como capecitabina monodroga) son menos eficaces, por lo que recomendamos esquemas convencionales. ${ }^{14}$ En mujeres mayores candidatas a QT, los esquemas sin antraciclinas (como taxotere-carboplatino [TC]) conllevan menor riesgo de hospitalización y pueden ser preferidos, sobre todo en $\mathrm{RH}+{ }^{15}$ El tratamiento endocrino primario puede usarse en pacientes frágiles con tumores $\mathrm{RH}+$ no candidatas a cirugía. ${ }^{16}$

En enfermedad metastásica se recomiendan los mismos tratamientos que en pacientes más jóvenes. Recomendamos utilizar la valoración geriátrica, para determinar si las pacientes son candidatas a QT.3,5

\section{Cáncer de mama en el hombre}

\section{Introducción}

En el hombre, el cáncer mamario representa menos del $1 \%$ del total de los casos de cáncer de mama. ${ }^{1}$ En 2020 se estimaron 2,620 casos nuevos en Estados Unidos. ${ }^{2}$ Los principales factores de riesgo son mutación del gen BRCA 2, síndrome de Klinefelter, criptorquidia, radioterapia previa en tórax y uso de estrógenos exógenos. ${ }^{3,4} \mathrm{La}$ edad promedio al diagnóstico es de 68.4 años, ${ }^{5,6}$ en comparación con 58.2 años reportada en la contraparte femenina. ${ }^{7}$ El tipo histológico predominante es el ductal invasor, presente en alrededor del 
$90 \%$ de los casos. Más del $90 \%$ son luminales, mientras que HER 2 es positivo solo en el $11 \%$ de los tumores y menos del $3 \%$ es reportado como triple negativo. ${ }^{8-10}$ En el hombre, el diagnóstico se realiza en estadios más avanzados, debido a la baja sospecha diagnóstica, ${ }^{11}$ alcanzando una supervivencia global a cinco años del $85.0 \%$, comparado con el $90.2 \%$ logrado en el sexo femenino. ${ }^{12}$

\section{Tratamiento}

El tratamiento del cáncer mamario en el hombre ha sido prácticamente extrapolado de los datos disponibles del cáncer mamario en la mujer y se trata por etapa de manera semejante, tomando en cuenta la edad, el estado general de salud del paciente, así como las características patológicas del tumor, incluida la expresión de receptores hormonales y HER 2 .

El tratamiento local recomendado es la mastectomía radical, modificada con ganglio centinela o disección axilar, de acuerdo con el estadio clínico.

La cirugía conservadora de la mama no está indicada. Las recomendaciones de quimioterapia y radioterapia siguen los mismos lineamientos que en la mujer. ${ }^{13}$

Se recomienda tamoxifeno por cinco años como estándar en pacientes con tumores con receptores hormonales positivos. El uso de tamoxifeno por 10 años también sigue los mismos lineamientos que en la mujer. Los inhibidores de aromatasa no están indicados.

No se recomienda el empleo de plataformas genómicas para decisión de tratamiento adyuvante como OncoType, Mammaprint o Endopredict, ya que no existe información suficiente para evaluar su utilidad. Por otra parte, a pesar de que no hay evidencia del beneficio del trastuzumab adyuvante en hombres con cáncer de mama HER 2 positivo, debe considerarse su empleo según las indicaciones establecidas. ${ }^{13}$

En cuanto al cáncer de mama localmente avanzado, hasta el $40 \%$ se diagnostica en esta etapa. Deben tratarse siguiendo las directrices propuestas para la mujer.

En la enfermedad metastásica con receptores hormonales positivos, el tamoxifeno es el tratamiento de elección, excepto en los casos de tumores en rápido crecimiento o con metástasis viscerales, en los que es necesario buscar una pronta respuesta objetiva con terapia citotóxica. Se debe considerar el manejo con inhibidores de aromatasa + agonista de la hormona liberadora de la hormona luteinizante, así como la utilización de inhibidores de CDK4/6 o everolimús + doble bloqueo hormonal con las mismas indicaciones que en la mujer. ${ }^{14}$

Finalmente, en pacientes con receptores negativos $u$ hormonorrefractarios, la quimioterapia con esquemas y dosis iguales que los utilizados en la mujer, es el tratamiento de elección.

Los pacientes con tumor HER 2 positivo deberán ser valorados para agregar trastuzumab y pertuzumab a su manejo sistémico, con base en los mismos lineamientos que para la mujer. ${ }^{15}$ En pacientes con mutación germinal BRCA 1/2, considerar el uso de inhibidores de la poli(ADP)-ribosa polimerasa; ${ }^{16-18}$ y en aquellos triple negativo con expresión del ligando 1 de muerte programada $>1 \%$, el uso de atezolizumab + nab-paclitaxel debe ser valorado. ${ }^{19}$

\section{Cáncer de mama asociado al embarazo y a la lactancia}

\section{Lineamientos generales}

Se define como cáncer asociado al embarazo aquel que se diagnostica durante el periodo de gestación, y hasta el primer año posterior a la terminación del embarazo. ${ }^{1}$

Los cambios fisiológicos de la glándula mamaria durante la gestación y la lactancia dificultan y retrasan el diagnóstico. ${ }^{2}$

El tratamiento de la mujer embarazada con cáncer de mama debe ser multidisciplinario e incluir al grupo oncológico, especialistas en gineco-obstetricia, en medicina materno-fetal, pediatría y psicología. ${ }^{1,3}$

Se recomienda enviar a estas pacientes a centros especializados en el área y debe considerarse incluirlas en grupos de trabajo multicéntricos.

La vigilancia fetal debe realizarse cada 3-4 semanas o en su caso, previo a cada ciclo de quimioterapia.

\section{Diagnóstico}

El estudio de imagen inicial recomendado es el ultrasonido mamario. ${ }^{4}$

La mastografía deberá solicitarse para valorar la extensión de la enfermedad, presencia de microcalcificaciones, descartar multicentricidad y para evaluar la mama contralateral. Debe realizarse con protección abdominal. La dosis que recibe el útero es menor a 0.03 Gy. ${ }^{2,5}$ 
Para corroborar el diagnóstico debe realizarse biopsia por aguja de corte con anestesia local; es importante comunicar el estado de gravidez de la paciente al servicio de patología que manejará los especímenes.

Los estudios de extensión sugeridos son:5,6

- Radiografía de tórax con protección abdominal.

- Ultrasonido hepático.

- Resonancia magnética de columna toracolumbar, sin medio de contraste, en caso de sospecha de enfermedad ósea.

- Con información limitada, se ha propuesto resonancia de cuerpo entero durante el segundo y tercer trimestre, como una opción a otros estudios de extensión. ${ }^{7}$

Debe evitarse:

- Estudios que exponen al feto a alta radiación, como la tomografía computarizada (TC), estudios de medicina nuclear y tomografía por emisión de positrones/TC.

- Medios de contraste como el gadolinio. ${ }^{5,8}$

\section{Cirugía}

La cirugía es un procedimiento seguro durante cualquier trimestre del embarazo.

La decisión del tipo de cirugía debe realizarse acorde a las características tumorales, etapa clínica y trimestre del embarazo.

En etapas I y II, la mastectomía no ha demostrado ofrecer mayor supervivencia, en comparación con la cirugía conservadora. ${ }^{9}$

- La cirugía conservadora de mama está indicada en el segundo y tercer trimestres de la gestación, seguida de radioterapia al finalizar el embarazo.

- El tratamiento axilar estándar es la disección de niveles I y II. En cuanto a la realización de ganglio centinela, el radiocoloide tecnecio 99 aparenta ser seguro en cualquier trimestre del embarazo; sin embargo, debido a la poca información científica hasta ahora, se recomienda utilizarlo en el tercer trimestre de la gestación. La dosis recomendada es de 18.537 $\mathrm{MBq}(0.51 .0 \mathrm{mCi})$ con una vida media de 6 horas; con esta dosis, la exposición del útero a la radiación es menor a 5 mGy. 5,10

- Debe evitarse el uso de colorantes como azul patente o azul de metileno.

- Debido a los cambios fisiológicos propios del embarazo que generan mayor congestión y volumen mamario y a la escasa experiencia publicada, ${ }^{11}$ los integrantes de este consenso no recomiendan la reconstrucción mamaria inmediata durante el embarazo.

\section{Radioterapia}

El tratamiento con radioterapia estácontraindicado durante todo el embarazo debido a su teratogenicidad y la inducción de neoplasias malignas, así como alteraciones hematológicas. ${ }^{12}$

\section{Tratamiento sistémico}

\subsection{Quimioterapia}

La quimioterapia se recomienda a partir del segundo trimestre de la gestación. ${ }^{13}$

Se recomienda realizar examen fetal con ultrasonido previo al inicio de la quimioterapia para excluir anormalidades preexistentes, así como medición de la presión arterial y determinación de proteinuria antes de cada ciclo..$^{14,15}$

Los esquemas basados en antraciclinas y taxanos son los recomendados. Las dosis deberán ser calculadas de acuerdo con una superficie corporal real..$^{16} \mathrm{La}$ experiencia en cohortes retrospectivas no ha mostrado incrementar el daño en los fetos. ${ }^{17,18}$ Se prefiere paclitaxel semanal que docetaxel. La eficacia y seguridad de las dosis densas y uso de platinos aún no es del todo claro. ${ }^{19}$

La exposición a quimioterapia in utero a partir del segundo trimestre no afecta el desarrollo cognitivo, cardiaco y físico de los niños. ${ }^{20}$ La exposición a antraciclinas y su efecto a largo plazo no parece causar efectos en el desarrollo. Respecto a los taxanos, no se cuenta con suficiente información. ${ }^{21,22}$

Debe evitarse la administración de quimioterapia después de la semana 35 de gestación a fin de evitar complicaciones obstétricas. ${ }^{23,24}$

Se recomienda iniciar quimioterapia a dosis estándares y posterior al primer ciclo hacer las modificaciones pertinentes.

\subsection{TERAPIAS BIOLÓGICAS}

Actualmente, está contraindicado el uso de terapias anti HER2 durante la gestación, ya que se ha asociado a oligo/anhidramnios e hipoplasia pulmonar. ${ }^{25-27}$

Por otra parte, el protocolo MotHer, que es un estudio observacional de dos cohortes, prospectivo, en mujeres que recibieron trastuzumab, pertuzumab y TDM-1 durante el embarazo o seis meses previos al embarazo (Clinical Trial: NCT00833963), ${ }^{28}$ nos brindará mayor información al respecto. 


\subsection{TERAPIA ENDOCRINA}

Está contraindicado el uso de tamoxifeno u otra terapia endocrina durante el embarazo. ${ }^{1}$

\subsection{ANTIEMÉtICOS y TERAPIAS DE SOPORTE}

Los antieméticos y los factores estimulantes de coIonias deben utilizarse de acuerdo con las recomendaciones de manejo habitual.

El uso de bisfosfonatos no se recomienda.

\subsection{TERMINACIÓN DEL EMBARAZO}

El tiempo en que debe interrumpirse el embarazo y la vía de terminación de la gestación debe obedecer a indicación obstétrica.

En caso de recibir quimioterapia, esta no debe aplicarse tres semanas antes de la fecha probable de parto o después de la semana 35, para evitar nadir.

La interrupción del embarazo durante el primer trimestre solo debe considerase en etapas avanzadas que requieran tratamiento sistémico, por el alto riesgo teratogénico. Esta decisión debe ser tomada por la paciente en conjunto con el grupo multidisciplinario. ${ }^{29}$

\subsection{LACTANCIA}

La lactancia debe evitarse si la paciente está recibiendo terapia sistémica, terapias biológicas o radioterapia..$^{13}$

\section{Pronóstico}

La terminación temprana del embarazo no mejora la supervivencia.

Existe información contradictoria para considerar la presencia de embarazo, por sí sola, como un factor independiente de mal pronóstico. ${ }^{30,31}$

\section{Otros aspectos}

Las portadoras de mutaciones en BRCA 1 y $B R C A$ 2 no se protegen por embarazos tempranos, ${ }^{24} \mathrm{y}$ tampoco se ha identificado que tengan mayor riesgo de cáncer de mama durante el embarazo. ${ }^{32}$

Respecto a la inmunoterapia e inhibidores CDK4/6, no se cuenta con información suficiente para emitir recomendación alguna.

El uso de dexametasona y factores estimulantes de colonias no están contraindicados de acuerdo con la evidencia retrospectiva. ${ }^{33,34}$

\section{Manejo de histologías poco frecuentes}

\section{Tumor phyllodes}

El tumor phyllodes (TP) es una neoplasia fibroepitelial, que representa el $1 \%$ de los tumores de mama. ${ }^{1}$ Las pacientes portadoras de síndrome de Li-Fraumeni, con mutación de TP53, tienen mayor riesgo de desarrollar TP. ${ }^{2,3}$

La edad de presentación es muy variable, con promedio a los 40 años. ${ }^{4-6}$ Generalmente son tumores de gran tamaño y rápido crecimiento; en ocasiones pueden ulcerar la piel o invadir la pared torácica. Pacientes asintomáticas, TP menores de $3 \mathrm{~cm}$, multifocalidad y/o bilateralidad, son poco frecuentes. ${ }^{7,8}$

\subsection{Diagnóstico}

En estudios de imagen, los TP se asemejan a los fibroadenomas. En el ultrasonido se identifican lesiones redondeadas ovales o lobuladas bien definidas y circunscritas, de contenido heterogéneo y con septos internos sin reforzamiento. La presencia de márgenes mal definidos, con alto índice de resistencia, sombra acústica posterior y marcada hipoecogenicidad, sugieren TP borderline o maligno. ${ }^{9,10}$ En la mastografía, el tumor puede tener márgenes oscurecidos 0 calcificaciones gruesas. ${ }^{11}$ En resonancia magnética, el nódulo aparece como una señal hipointensa en $\mathrm{T} 1$ y señal hiper/isointensa en T2.

La biopsia con aguja de corte es el método diagnóstico recomendado; sin embargo, es necesario el estudio completo de la pieza quirúrgica para clasificarlo, ya que el tumor frecuentemente es heterogéneo. No se recomienda la biopsia con aspiración con aguja fina por la baja eficacia diagnóstica. ${ }^{12-14} \mathrm{~A}$ diferencia de los fibroadenomas, los TP cuentan con mayor celularidad estromal y actividad mitótica.

Ante la sospecha clínica de TP, en paciente con tumor reportado como fibroadenoma en la biopsia, debe hacerse escisión para descartalo. El estudio transoperatorio se recomienda para evaluar márgenes, no para descartar TP.

\subsection{CLASIFICACIÓN}

La clasificación aceptada por la Organización Mundial de la Salud (OMS) divide a los TP en benignos, borderline (limítrofes) o malignos, tomando en cuenta la hipercelularidad estromal, pleomorfismo celular, 
Tabla 24. Clasificación de la Organización Mundial de la Salud para tumor phyllodes (2012)

\begin{tabular}{|l|l|l|l|}
\hline Característica & Benigno & Borderline & Maligno \\
\hline Celularidad estromal & \multicolumn{1}{|c|}{ Histológica } & Marcada \\
\hline Atipia celular estromal & Leve & Moderada & Marcada \\
\hline Mitosis (por 10 campos de alto poder) & Leve & Moderada & $\geq 10$ \\
\hline Sobrecrecimiento & $<5$ & $5-9$ & Presente \\
\hline & Ausente & Ausente o focal & Infiltrantes \\
\hline Bordes del tumor & Bien definidos (empujantes) & Bien definidos (empujantes) & Focalmente infiltrantes \\
\hline
\end{tabular}

mitosis, márgenes, patrón estromal y elementos heterólogos (T1) (Tabla 24). ${ }^{15-17}$

El mismo tumor puede contener varias características a la vez. La frecuencia de los TP benignos es del 41 al $67 \%$, borderline del 11.8 al $45 \%$ y malignos del 12 al 33\%., 5,19 En la serie mexicana más grande de $\mathrm{TP}$, la frecuencia fue del 72.3, 16.2 y $11.4 \%$, respectivamente. ${ }^{4}$

Los diagnósticos diferenciales son fibroadenoma, hamartoma, adenoma, lipoma, papilomatosis juvenil, sarcoma, carcinoma y tumores metastásicos. ${ }^{1}$

\subsection{Tratamiento QUIRÚRgICO}

El tratamiento quirúrgico es la piedra angular, ya sea mediante escisión amplia o mastectomía, con la premisa de obtener márgenes libres de tumor. En TP benigno se recomienda márgenes tridimensionales negativos $>1 \mathrm{~mm}$, mientras que en borderline y malignos lo ideal es $>1 \mathrm{~cm}$, ya que es el principal factor pronóstico de recurrencia local. ${ }^{20-22}$

Los TP borderline y malignos tienen alto riesgo de recurrencia, por lo que la mastectomía es el tratamiento más recomendado. Las reintervenciones quirúrgicas para ampliar márgenes ocurren en el 12.7 a 34\%.,23 Los procedimientos oncoplásicos pueden utilizarse para mejorar el resultado estético, reportándose hasta en el $23 \%$ las cirugías conservadoras. ${ }^{4}$ La reconstrucción mamaria inmediata puede realizarse, sin embargo, no se recomienda ante la posibilidad de radioterapia adyuvante.

La disección axilar no está indicada, ya que las metástasis ganglionares ocurren en $<5 \%$. ${ }^{11}$ Solo se realizará linfadenectomía en pacientes en las que, clínicamente, exista afectación ganglionar.
Tabla 25. Recomendaciones para radioterapia en tumor phyllodes

\begin{tabular}{|c|c|}
\hline Característica & Benigno \\
\hline Benigno & Ninguna \\
\hline $\begin{array}{l}\text { Características de } \\
\text { TP maligno: } \\
\text { - Sobrecrecimiento } \\
\text { estromal } \\
\text { - Atipia celular } \\
\text { - Alto número de } \\
\text { mitosis }\end{array}$ & $\begin{array}{l}\text { Radioterapia a pared torácica en } \\
\text { cualquiera de estas condiciones: } \\
\text { - Posterior a mastectomía y si los } \\
\text { márgenes son positivos o cercanos } \\
(<1 \mathrm{~cm}) \\
\text { - Involucro a la fascia muscular o pared } \\
\quad \text { torácica } \\
\text { - Tumor mayor a } 5 \mathrm{~cm} \\
\text { - Posterior a cirugía conservadora con } \\
\text { márgenes }<1 \mathrm{~cm} \\
\text { - Ganglios positivos }\end{array}$ \\
\hline Recurrencia & $\begin{array}{l}\text { Posterior a resección quirúrgica de la } \\
\text { recurrencia (borderline o maligno) o en } \\
\text { caso de ser irresecable }\end{array}$ \\
\hline
\end{tabular}

TP: tumor phyllodes.

\subsection{Terapia adYUVANTE}

\subsubsection{Radioterapia postoperatoria}

Hasta el momento, no existen estudios prospectivos aleatorizados que apoyen su uso sistemático como tratamiento adyuvante. La decisión de utilizarla se basa en criterios histopatológicos, el estado de los márgenes y tamaño tumoral, independientemente del tipo de cirugía. ${ }^{24}$ En recurrencia local, la radioterapia si puede utilizarse.

De acuerdo con a la escasa literatura publica$\mathrm{da}^{5,25,26}$ y las recomendaciones de otras guías de tratamiento, ${ }^{22,27}$ en la tabla 25 se sintetizan las indicaciones para radioterapia en TP. 


\subsubsection{Tratamiento sistémico adyuvante}

Aunque el componente epitelial de los TP contiene receptores de estrógenos alfa en el 28 al 48\%, estrógenos beta en el 34.7 al $58 \%$, progesterona en el 75 al $95 \%$ y andrógenos en el 4.5 al $14 \%$, la hormonoterapia no ha demostrado beneficio. ${ }^{28} \mathrm{El}$ uso de quimioterapia citotóxica con antraciclinas, ifosfamida, cisplatino y etopósido tampoco ha demostrado beneficio en supervivencia libre de enfermedad o global. ${ }^{29}$

\subsection{FACTORES PRONÓSTICOS}

A mayor agresividad de TP, mayor riesgo de recurrencia local. Los factores de mal pronóstico para recurrencia local son: mayor número de mitosis, celularidad estromal (moderada/severa), bordes infiltrantes, atipia estromal severa, sobrecrecimiento estromal severo y necrosis tumoral. Además, en subtipos de alto riesgo (TP borderline y malignos) la cirugía conservadora y márgenes positivos se han identificado como factores adversos. , $30^{30}$

\subsection{Seguimiento}

Se recomienda la autoexploración mamaria, además de seguimiento clínico semestral, los primeros dos años y posteriormente anual, con estudios complementarios como ultrasonido, mastografía y/o resonancia magnética anuales. ${ }^{11}$

Las recurrencias locales se reportan del 3.6 al $18 \%$ para TP benignos, del 13 al 29\% para borderline y del 18 al $42 \%$ para malignos, mientras que las recurrencias a distancia ocurren en el 0, 2 y 14\%, respectivamente, siendo pulmón el sitio más frecuente. $5,6,30,31$

En presencia de recurrencia, se recomienda realizar tele de tórax c/s tomografía de tórax contrastada. El tratamiento de las recurrencias locales consiste en resección amplia de la lesión, asegurando márgenes libres de tumor y radioterapia a pared torácica posterior a la resección. En pacientes con recurrencia a distancia, sobre todo a nivel de pulmonar, el tratamiento será con base en las recomendaciones para manejo de sarcomas. ${ }^{22}$

\section{Histologías poco frecuentes en cáncer de mama}

Estas histologías se documentan en menos del 5\% de los casos, alguna de ellas con frecuencias tan bajas como el $0.1 \% \%^{1,2}$ Debido a la rareza de estos tumores, la información obtenida de la literatura no es concluyente con algunos tratamientos, debiendo tomar más en cuenta la biología tumoral. ${ }^{3,4}$

En la mayoría de estas entidades, el tratamiento quirúrgico es la piedra angular, siguiendo los lineamientos ya conocidos para realizar mastectomía o cirugía conservadora, acorde a las características clínicas y etapa. Las recomendaciones para estadificación axilar, son las mismas que para el carcinoma ductal invasor. El uso de quimioterapia es controvertido en la mayoría de las estirpes de buen pronóstico, mientras que en las de mal pronóstico se recomienda ampliamente. En algunos casos la recomendación es utilizar agentes citotóxicos diferentes a los habituales, como las sales platinadas.

La hormonoterapia está indicada según el estatus de los receptores hormonales de estrógeno y/o progesterona; debido a que es limitada la experiencia en receptores de andrógenos en estas histologías, en esta sección no se considerarán. Las indicaciones para radioterapia adyuvante son las mismas recomendadas para el carcinoma ductal infiltrante. Se ha sugerido el uso de terapias blanco en estas raras neoplasias de acuerdo con las características inmunohistoquímicas; sin embargo, la rareza y la falta de homogeneidad en el manejo oncológico hacen que esta recomendación siga siendo limitada. El pronóstico en estas histologías también es muy heterogéneo. ${ }^{5}$

En la actualización de la clasificación de tumores mamarios por parte de la OMS ${ }^{1,6}$ el carcinoma medular ya no se considera como una variante histológica, sino que se integra a los diferentes patrones morfológicos del carcinoma invasor. Se agregaron dos variantes (cistadenocarcinoma mucinoso y carcinoma de células altas de polaridad reversa) y se modificó la terminología en los tumores neuroendocrinos.

En las tablas 26-29 se describen las principales características de estas histologías poco frecuentes, según el pronóstico (bueno, intermedio y malo).

\section{Seguimiento posterior al tratamiento con intención curativa y en enfermedad metastásica}

\section{Introducción}

Al concluir el tratamiento primario para el cáncer de mama, habitualmente con cirugía, quimioterapia y radioterapia, inicia la etapa de vigilancia y control 
Tabla 26. Estirpes de buen pronóstico. Receptores hormonales generalmente positivos

\begin{tabular}{|c|c|c|c|c|c|}
\hline & $\begin{array}{l}\text { Carcinoma mucinoso, } \\
\text { puros y mixtos }\end{array}$ & $\begin{array}{l}\text { Carcinoma } \\
\text { tubular }\end{array}$ & $\begin{array}{l}\text { Carcinoma } \\
\text { cribiforme }^{1,2}\end{array}$ & $\begin{array}{l}\text { Tumores } \\
\text { neuroendocrinos }{ }^{1,10,11}\end{array}$ & $\begin{array}{l}\text { Carcinoma papilar } \\
\text { (intraquístico y } \\
\text { sólido) }{ }^{12-14}\end{array}$ \\
\hline Frecuencia & $1-4 \%$ (puros) & $\begin{array}{l}<2 \% \\
>90 \% \text { debe tener } \\
\text { arquitectura } \\
\text { tubular }\end{array}$ & $0.1-0.6 \%$ & $<1 \%$ & $0.7 \%$ \\
\hline $\begin{array}{l}\text { Edad de } \\
\text { presentación }\end{array}$ & 71 & $60(27-92)$ & $54-63$ & $60-70$ & $60-70$ \\
\hline Grado & Generalmente grado I & $\begin{array}{l}\text { Generalmente } \\
\text { grado I }\end{array}$ & $\begin{array}{l}\text { Generalmente } \\
\text { grado I }\end{array}$ & Grado I-II & $\begin{array}{l}\text { Grado I } \\
40-47 \% \text {, grado II } \\
40-50 \%\end{array}$ \\
\hline $\begin{array}{l}\text { Actividad } \\
\text { proliferativa }\end{array}$ & Baja & Baja & Baja & Baja & Baja \\
\hline $\begin{array}{l}\text { Receptores } \\
\text { hormonales }\end{array}$ & Generalmente positivos & $\begin{array}{l}\text { Generalmente } \\
\text { positivos }\end{array}$ & $\begin{array}{l}\text { Generalmente } \\
\text { positivos }\end{array}$ & $\begin{array}{l}\text { RE positivos } 95 \% \\
\text { RP positivo } 80 \%\end{array}$ & $\begin{array}{l}\text { Positivos } \\
>80 \%\end{array}$ \\
\hline HER 2 & Generalmente negativo & $\begin{array}{l}\text { Generalmente } \\
\text { negativo }\end{array}$ & Negativo & Generalmente negativo & Negativo \\
\hline $\begin{array}{l}\text { Afectación } \\
\text { ganglionar }\end{array}$ & Raro, $<12 \%$ & $4-17 \%$ & $10 \%$ & $\begin{array}{l}\text { Variable, generalmente } \\
\text { elevado }\end{array}$ & $3-12 \%$ \\
\hline Pronóstico & $\begin{array}{l}\text { PLE } 5 \text { años } \\
85-95 \% \\
\text { SV } 5 \text { años } \\
94-98 \% \\
\text { SV } 10 \text { años } \\
89-94 \% \\
\text { SV } 15 \text { años } \\
85 \% \\
\text { SV } 20 \text { años } \\
81 \%\end{array}$ & $\begin{array}{l}\text { PLE } 5 \text { años } \\
94 \% \\
\text { SV } 5 \text { años } \\
88 \%\end{array}$ & $\begin{array}{l}\text { SV } 5 \text { años } \\
100 \% \text { (en } \\
\text { variante pura) }\end{array}$ & $\begin{array}{l}\text { Similar al carcinoma } \\
\text { ductal invasor etapa } \\
\text { por etapa }\end{array}$ & $\begin{array}{l}\text { SV } 5 \text { años } \\
>80 \% \\
\text { Depende } \\
\text { del grado } \\
\text { y etapa }\end{array}$ \\
\hline $\begin{array}{l}\text { Tratamiento } \\
\text { quirúrgico }\end{array}$ & Recomendado & Recomendado & Recomendado & Recomendado & Recomendado \\
\hline Quimioterapia & Poco beneficio & Poco beneficio & $\begin{array}{l}\text { Controvertido } \\
\text { en variantes } \\
\text { mixtas }\end{array}$ & Recomendado & Papel limitado \\
\hline Hormonoterapia & Recomendado & Recomendado & $\begin{array}{l}\text { Controvertido } \\
\text { en variantes } \\
\text { mixtas }\end{array}$ & Recomendado & Recomendado \\
\hline Radioterapia & Recomendado & Recomendado & $\begin{array}{l}\text { Controvertido } \\
\text { en variantes } \\
\text { mixtas }\end{array}$ & Recomendado & Recomendado \\
\hline
\end{tabular}

RE: receptores de estrógeno; RP: receptores de progesterona; RH: receptores hormonales (estrógeno y/o progesterona); PLE: periodo libre de enfermedad; SV: supervivencia.

denominada «seguimiento». Los objetivos del seguimiento son: detectar recurrencias y cáncer de mama contralateral, evaluar y tratar complicaciones relacionadas con el tratamiento (p. ej., osteoporosis, segundos primarios), motivar a la paciente a continuar terapia endocrina y tratar sus efectos secundarios.
En la tabla 30 se describen las recomendaciones aceptadas internacionalmente para el seguimiento de estas pacientes. Es importante destacar que la aparición de metástasis luego del tratamiento primario adecuado, es ajena al accionar médico; además, anticipar el diagnóstico de la recaída no aumenta la supervivencia ni la calidad de vida. 
Tabla 27. Estirpes de buen pronóstico. Receptores hormonales generalmente negativos

\begin{tabular}{|c|c|c|c|c|}
\hline & $\begin{array}{l}\text { Carcinoma adenoideo } \\
\text { quístico }^{15}\end{array}$ & Carcinoma secretor ${ }^{16}$ & $\begin{array}{l}\text { Carcinoma de células altas } \\
\text { de polaridad reversa }{ }^{1,17,18}\end{array}$ & $\begin{array}{l}\text { Cistoadenocarcinoma } \\
\text { mucinoso }^{1}\end{array}$ \\
\hline Frecuencia & $\begin{array}{l}<1 \% \\
\text { Histología similar al de } \\
\text { glándulas salivales }\end{array}$ & $<-0.2 \%$ & $<0.1 \%$ & $<0.1 \%$ \\
\hline Frecuencia & $58-66$ & $25-40$ & 39-89 (media 64 años) & 41-96 (mediana 61 años) \\
\hline Grado & Bajo & $\begin{array}{l}\text { Generalmente grado I } \\
\text { y II }\end{array}$ & Generalmente grado I & Generalmente grado I \\
\hline $\begin{array}{l}\text { Actividad } \\
\text { proliferativa }\end{array}$ & Baja & $\begin{array}{l}\text { Baja. Ausencia de } \\
\text { atipia nuclear, } \\
\text { ausencia de alto } \\
\text { índice mitótico }\end{array}$ & $\begin{array}{l}\text { Bajo } \\
\text { Expresión Ki67 20\% }\end{array}$ & Bajo \\
\hline $\begin{array}{l}\text { Receptores } \\
\text { hormonales }\end{array}$ & $\begin{array}{l}\text { RE positivo } 0-46 \% \text {, RP } \\
\text { positivo } 0-36 \%\end{array}$ & $\begin{array}{l}\text { Generalmente } \\
\text { negativos }\end{array}$ & Generalmente negativos & Generalmente negativos \\
\hline HER 2 & Generalmente negativo & Negativo & Negativo & Generalmente negativo \\
\hline $\begin{array}{l}\text { Afección } \\
\text { ganglionar }\end{array}$ & $0-8 \%$ & $20-30 \%$ & $<10 \%$ & Muy raro \\
\hline Pronóstico & $\begin{array}{l}\text { Bueno } \\
\text { SV } 5 \text { años } \\
\sim 90 \%\end{array}$ & $\begin{array}{l}\text { Recurrencias } \\
\text { reportadas } \\
12-20 \text { años después }\end{array}$ & $\begin{array}{l}\text { Bueno } \\
\text { PLE 3-132 meses }\end{array}$ & Bueno \\
\hline $\begin{array}{l}\text { Tratamiento } \\
\text { quirúrgico }\end{array}$ & $\begin{array}{l}\text { Recomendado } \\
\text { Se prefiere mastectomía } \\
\text { Alto porcentaje } \\
\text { de márgenes positivos en } \\
\text { cirugías conservadoras } \\
\text { (33-86\%) Estadificación } \\
\text { axilar cuestionable por alto } \\
\text { potencial de metastatizar } \\
\text { sin afección ganglionar } \\
\text { previa }\end{array}$ & Recomendado & Recomendado & Recomendado \\
\hline Quimioterapia & Beneficio incierto & Beneficio incierto & Beneficio incierto & Beneficio incierto \\
\hline $\begin{array}{l}\text { Hormono } \\
\text { terapia }\end{array}$ & Beneficio incierto & Recomendado* & Recomendado* & Recomendado* \\
\hline Radioterapia & Si incrementa SV & $\begin{array}{l}\text { Beneficio incierto } \\
\text { Recomendado } \\
\text { en cirugía } \\
\text { conservadora }\end{array}$ & Beneficio incierto & Beneficio incierto \\
\hline
\end{tabular}

* Recomendado en receptores hormonales positivos (estrógeno y/o progesterona).

\subsection{Seguimiento en PACIENTES Con enfermedad METASTÁSICA}

El objetivo es detectar progresión de la enfermedad, evitar toxicidad o el uso de un tratamiento ineficaz, así como la optimización de recursos. La reevaluación de la paciente está también indicada si hay deterioro, incremento de síntomas o aparición de nuevos signos, independientemente del intervalo transcurrido desde el control previo (Tabla 31).

\section{Terapia hormonal de reemplazo}

\section{Introducción}

Las mujeres mexicanas presentan síndrome climatérico alrededor de los $49+5$ años, hasta el $80 \%$ de ellas presentarán sintomatología vasomotora e insomnio y un $40 \%$ depresión, atrofia genital, enfermedades cardiovasculares y disminución en la densidad ósea. ${ }^{1}$ 
Tabla 28. Estirpes de pronóstico intermedio

\begin{tabular}{|l|l|}
\hline Frecuencia & Carcinoma apocrino ${ }^{19}$ \\
\hline Edad de presentación & $0.3-4 \%$ \\
\hline Grado & $52-61$ \\
\hline Actividad proliferativa & Grado II: 50-56\% \\
\hline Receptores hormonales & $\begin{array}{l}\text { MIB-1 } 29 \% \\
\text { Generalmente RH negativos. }\end{array}$ \\
\hline Heceptores androgénicos \\
\hline Afección ganglionar 2 & generalmente positivos \\
\hline Pronóstico & Positivo en 33-54\% \\
\hline Tratamiento quirúrgico & $21-26 \%$ \\
\hline Ouimioterapia & $\begin{array}{l}\text { Mejor que carcinoma ductal } \\
\text { invasor }\end{array}$ \\
\hline Hormonoterapia & Recomendado \\
\hline Terapias blanco & Recomendado \\
\hline Radioterapia & $\begin{array}{l}\text { Recomendado* (inhibidor de } \\
\text { aromatasa) }\end{array}$ \\
\hline & $\begin{array}{l}\text { Poca evidencia con anti-HER } \\
\text { Susceptible de terapias } \\
\text { blanco }\end{array}$ \\
\hline Recomendado \\
\hline
\end{tabular}

RH: receptores hormonales (estrógeno y/o progesterona); MIB: anticuerpo específico dirigido contra la proteína Ki-67 que expresa un índice de proliferación. ${ }^{*}$ Recomendado en receptores hormonales positivos (estrógeno y/o progesterona).

En mujeres sin cáncer de mama frecuentemente se recomienda usar terapia hormonal de reemplazo (THR) para controlar y disminuir los síntomas de moderados a severos, pero por otro lado se ha demostrado que su administración incrementa el riesgo de desarrollar cáncer de mama (1.66) y está directamente relacionado con la dosis y el tiempo de uso. ${ }^{2}$

\section{Terapia hormonal de reemplazo en mujeres con cáncer de mama}

La bibliografía actual al respecto de la THR en mujeres con cáncer de mama se basa en estudios observacionales en su mayoría, siendo las variables de THR imposibles de controlar en lo que se refiere a su vía de administración, ya sean tópicos, transvaginales, orales, estrógenos o estrógenos con progestágenos, y por otro lado no incluyen datos como etapa clínica, estado de receptores hormonales y estado ganglionar. ${ }^{3}$

El protocolo HABITS, estudio controlado, doble ciego, fue detenido en el 2003 por el incremento en el riesgo de recurrencia y muerte por cáncer de mama en las pacientes expuestas a THR; sin embargo, el estudio Stockholm, aleatorizado, con pacientes con cáncer de mama en etapas clínicas tempranas, el 50\% de ellas con uso de tamoxifeno y solo el $16 \%$ de ellas con ganglios positivos, demostró que no hay diferencia significativa ni en el periodo libre de enfermedad ni en el riesgo de muerte por cáncer de mama; en este estudio también se encontró que el uso de THR a base de estrógenos demostró tener menor riesgo que la terapia combinada (estrógenos con progesterona). 4

Aunque se ha utilizado tibolona como alternativa para el manejo de síntomas menopáusicos, su administración no se recomienda debido a un incremento del riesgo de recurrencia tanto locorregional como sistémica (hazard ratio [HR]: 1.4) en mujeres con antecedente de cáncer de mama según los resultados del estudio LIBERATE. ${ }^{6}$

Estudios recientes han demostrado que la THR vaginal tópica con estrógenos en pacientes con atrofia vulvovaginal moderada a severa no incrementa el riesgo de recurrencia en sobrevivientes de cáncer de mama, especialmente en mujeres usuarias de tamoxifeno, que se utilice por menos de 18 meses y en mujeres que no respondan al uso de lubricantes vaginales. Sin embargo, en cuanto al uso de hormonales orales o tópicos no transvaginales aún no se hace alguna recomendación por falta de evidencia. ${ }^{7}$

Con base en lo anterior, el presente consenso considera que la utilización de THR está contraindicada en mujeres sobrevivientes de cáncer de mama.

\section{Genética y cáncer mamario}

\section{Introducción}

Aproximadamente el $20 \%$ de las pacientes con cáncer de mama tienen familiares de primer o segundo grado con antecedente de la misma enfermedad, lo que se considera una presentación familiar. Del 5 al $10 \%$ de los casos se asocian a un síndrome hereditario y el 25 al $40 \%$ de estas pacientes son menores de 35 años de edad. ${ }^{1,2}$

Los genes relacionados con el cáncer hereditario de mama pueden dividirse en los que confieren alta susceptibilidad para el desarrollo de cáncer (mayor de $50 \%$ ) (BRCA1, BRCA2, CDH1, NF1, PTEN, TP53 y STK11) y moderada susceptibilidad (20 a 50\%) (ATM, BRIP1, CHEK2, PALB2, RAD51C, RAD51D y NBS1).2-4 La prevalencia de la mutación germinal de los genes $B R C A 1$ y $B R C A 2$ en la población general varía entre 1 en 50 a 1 en 800 , dependiendo del grupo étnico; 
Tabla 29. Estirpes de mal pronóstico

\begin{tabular}{|c|c|c|c|c|}
\hline & Carcinoma metaplásico ${ }^{20-22}$ & $\begin{array}{l}\text { Carcinoma metaplásico subtipo } \\
\text { células escamosas }{ }^{20-22}\end{array}$ & $\begin{array}{l}\text { Carcinoma } \\
\text { neuroendocrino } 0^{1,9,10,23}\end{array}$ & $\begin{array}{l}\text { Carcinoma } \\
\text { icropapilar invasor }{ }^{24}\end{array}$ \\
\hline Frecuencia & $\begin{array}{l}0.2-0.6 \% \\
\text { Se dividen en epiteliales } \\
\text { puros y mixtos }\end{array}$ & $\begin{array}{l}<0.1 \% \text {, } \\
\text { Son tumores con carcinoma de } \\
\text { tipo escamoso en }>90 \%\end{array}$ & $\begin{array}{l}\text { Células pequeñas: } \\
0.1 \% \\
\text { Células grandes: } \\
<0.1 \%\end{array}$ & Puro: $0.9-2 \%$ \\
\hline $\begin{array}{l}\text { Edad de } \\
\text { presentación }\end{array}$ & $46-61$ & $54-64$ & $43-70$ & 52.5 \\
\hline Grado & $\begin{array}{l}\text { Generalmente } \\
\text { grado III }\end{array}$ & $\begin{array}{l}\text { Generalmente } \\
\text { grado III }\end{array}$ & Grado III & Grado II-III en $75 \%$ \\
\hline $\begin{array}{l}\text { Actividad } \\
\text { proliferativa }\end{array}$ & Alta. Ki67 y p53 elevados & $\begin{array}{l}\text { Alta. } \\
\text { Ki67 elevado y citoqueratinas } 5 \\
\text { y } 6 \text { positivos, EGFR } \\
\text { positivo en } 85 \% \text {, y } \\
\text { p } 63 \text { positivo en } 70 \%\end{array}$ & Alta & Alta \\
\hline $\begin{array}{l}\text { Receptores } \\
\text { hormonales }\end{array}$ & $\begin{array}{l}\text { RH negativos } \\
70-100 \%\end{array}$ & $\mathrm{RH}$ negativos $>85 \%$ & $\begin{array}{l}\text { RE positivos } 30-50 \% \\
\text { RP positivos }<30 \%\end{array}$ & $\begin{array}{l}\text { RE positivos } 61-100 \% \\
\text { RP positivos } 46-86 \%\end{array}$ \\
\hline HER2 & Generalmente negativo & Generalmente negativo & Negativo & Positivo en $50 \%$ \\
\hline $\begin{array}{l}\text { Afección } \\
\text { ganglionar }\end{array}$ & $\begin{array}{l}<30 \% \text {. Alta capacidad } \\
\text { para metastatizar }\end{array}$ & $\sim 30 \%$ & $\sim 40 \%$ & $66-100 \%$ \\
\hline Pronóstico & $\begin{array}{l}\text { SV } 5 \text { años } 63 \% \\
\text { SV de } 8 \text { meses posterior a } \\
\text { recurrencia. }\end{array}$ & SV 5 años $50-67 \%$ & $\begin{array}{l}\text { Peor que carcinoma } \\
\text { ductal invasor, } \\
\text { etapa por etapa }\end{array}$ & $\begin{array}{l}\text { Recurrencias locales } \\
22-71 \% \text { a } 30 \text { meses }\end{array}$ \\
\hline $\begin{array}{l}\text { Tratamiento } \\
\text { quirúrgico }\end{array}$ & $\begin{array}{l}\text { Recomendado. } \\
\text { Generalmente mastectomía } \\
\text { por ser tumores de gran } \\
\text { tamaño }\end{array}$ & $\begin{array}{l}\text { Recomendado. Generalmente } \\
\text { mastectomía por ser tumores } \\
\text { de gran tamaño }\end{array}$ & $\begin{array}{l}\text { Recomendado de } \\
\text { acuerdo con la etapa }\end{array}$ & Recomendado \\
\hline Quimio terapia & $\begin{array}{l}\text { Poco beneficio. } \\
\text { Doxorubicina, ifosfamida }\end{array}$ & $\begin{array}{l}\text { Los agentes convencionales } \\
\text { para cáncer de mama no han } \\
\text { demostrado tener diferencia en } \\
\text { SV global ni en PLE. } \\
\text { Tendencia a usar sales } \\
\text { platinadas y taxanos }\end{array}$ & $\begin{array}{l}\text { Recomendado, con } \\
\text { esquemas utilizados } \\
\text { para el carcinoma de } \\
\text { células pequeñas de } \\
\text { pulmón }\end{array}$ & Recomendado \\
\hline $\begin{array}{l}\text { Hormono } \\
\text { terapia }\end{array}$ & Recomendado* & Recomendado* & Recomendado* & Recomendado \\
\hline $\begin{array}{l}\text { Terapias } \\
\text { blanco }\end{array}$ & $\begin{array}{l}\text { Potencial beneficio con } \\
\text { inhibidores de la tirosina } \\
\text { cinasa y de la vía } \\
\text { PI3K-Akt y MAPK }\end{array}$ & $\begin{array}{l}\text { Se ha sugerido inhibidores de } \\
\text { EGFR }\end{array}$ & $\begin{array}{l}\text { En estudio } \\
\text { antiangiogénicos e } \\
\text { inhibidores mTOR }\end{array}$ & \\
\hline Radioterapia & $\begin{array}{l}\text { Poca evidencia en } \\
\text { beneficio }\end{array}$ & $\begin{array}{l}\text { Iniciar lo antes posible por el } \\
\text { alto riesgo de recurrencia local, } \\
\text { aunque la radiosensibilidad es } \\
\text { cuestionable }\end{array}$ & $\begin{array}{l}\text { Recomendado, aunque } \\
\text { con beneficio } \\
\text { cuestionable en SV }\end{array}$ & Recomendado \\
\hline
\end{tabular}

RH: receptores hormonales (estrógeno y/o progesterona); RE: receptores de estrógeno; RP: receptores de progesterona; PLE: periodo libre de enfermedad; SV: supervivencia; EGFR: receptor del factor de crecimiento epidérmico; MAPK: mitogen-activated protein kinase.

${ }^{*}$ Recomendado en receptores hormonales positivos (estrógeno y/o progesterona).

siendo responsables del 3 al $8 \%$ de todos los casos de cáncer de mama. Dichas mutaciones explican hasta el $60 \%$ de las presentaciones hereditarias de cáncer de mama y causan el síndrome de cáncer de mama y ovario hereditario $(\mathrm{SCMOH})$. $^{3-6}$
Las mujeres portadoras de variantes patogénicas (VP) en BRCA 1 tienen un riesgo acumulado a los 80 años de hasta el $72 \%$ para desarrollar cáncer de mama y para BRCA 2 de hasta el $69 \%$, con un riesgo acumulado de presentar cáncer de mama contralateral del 
Tabla 30. Recomendaciones para el seguimiento

\begin{tabular}{|c|c|}
\hline Procedimiento & Frecuencia \\
\hline $\begin{array}{l}\text { Instrucción a la } \\
\text { paciente sobre los } \\
\text { síntomas y signos de } \\
\text { recurrencia }\end{array}$ & Al término de su tratamiento radical \\
\hline Examen físico & $\begin{array}{l}\text { Primeros } 2 \text { años cada } 3 \text { a } 4 \text { meses } \\
\text { Tercero a quinto años cada } 6 \text { meses } \\
\text { A partir del quinto año, anual }\end{array}$ \\
\hline $\begin{array}{l}\text { Autoexploración } \\
\text { mamaria }\end{array}$ & Mensual \\
\hline Mamografía & Anual \\
\hline Marcadores tumorales & No se recomiendan \\
\hline $\begin{array}{l}\text { TC de tórax, abdomen, } \\
\text { PET, centellografía } \\
\text { ósea y enzimas } \\
\text { hepáticas }\end{array}$ & $\begin{array}{l}\text { Solo si hay sintomatología } \\
\text { específica }\end{array}$ \\
\hline $\begin{array}{l}\text { Escrutinio de otros } \\
\text { tumores } \\
\text { (cervicouterino, } \\
\text { colorrectal, ovárico, } \\
\text { endometrial, etc.) }\end{array}$ & Seguir guías de detección temprana \\
\hline $\begin{array}{l}\text { Instrucciones a la } \\
\text { paciente sobre } \\
\text { ejercicio, } \\
\text { actividad física y } \\
\text { control de peso. } \\
\text { Evaluar e impulsar } \\
\text { la adherencia a la } \\
\text { terapia endocrina y } \\
\text { vigilar/tratar } \\
\text { sus posibles eventos } \\
\text { adversos. } \\
\text { Hacer énfasis en el } \\
\text { uso de métodos } \\
\text { anticonceptivos (de } \\
\text { barrera o definitivos) }\end{array}$ & En cada consulta \\
\hline
\end{tabular}

$40 \%$ en portadores de VP en BRCA 1 y del $26 \%$ asociado a BRCA 2. El riesgo acumulado a los 80 años de desarrollar cáncer de ovario es de hasta el $44 \%$ con mutación BRCA 1 y del 17\% con mutación BRCA 2., ${ }^{6,7}$

EI SCMOH tiene un modelo de herencia autosómico dominante, por lo que los familiares de primer grado de las pacientes portadoras tienen un riesgo del $50 \%$ de heredarlo. ${ }^{4}$ Es esencial que el personal médico y paramédico identifique a pacientes con alto riesgo de padecer cáncer hereditario, para su canalización con el equipo multidisciplinario, que debe incluir a un experto en genética del cáncer para una valoración integral. El tipo de cáncer y la edad al momento del diagnóstico en los familiares son claves para la integración de un síndrome de cáncer hereditario. En algunos casos puede no haber antecedentes de cáncer en la familia, pero esto no excluye la posibilidad de que se trate de un síndrome de cáncer hereditario. Está indicado realizar el estudio molecular a la población de riesgo alto (Tabla 32). 6,7

Toda paciente que se realice estudio molecular germinal debe recibir asesoramiento antes y después de la prueba. Una valoración incompleta 0 inadecuada está asociada con efectos adversos, entre los que se incluyen: efectos emocionales negativos, medidas incorrectas quirúrgicas y de seguimiento, así como interpretación errada de las pruebas, además de consecuencias económicas.

Los paneles multigenes para cáncer hereditario tienen un papel importante en el diagnóstico de estas pacientes; sin embargo, una de sus limitaciones es el desconocimiento del nivel de riesgo para muchos genes, falta de guías clínicas y alto porcentaje de variantes de significado clínico incierto (sin repercusión directa en el manejo clínico), y deben ser indicados por profesionales de la salud con entrenamiento en el tema, para una interpretación cuidadosa de los resultados y el consiguiente asesoramiento. Incluso en pacientes que cumplen criterios clínicos para un síndrome de cáncer hereditario, el resultado de un panel puede ser inesperado.,8 Este estudio no es un tamizaje que pueda ofrecerse a la población general.

El fenotipo tumoral triple negativo se relaciona principalmente con variantes patogénicas en BRCA 1. Hasta el $20 \%$ de las pacientes con este fenotipo tumoral son portadoras de mutaciones germinales y, por tanto, esta característica debe incluirse en los criterios diagnósticos, independientemente de la historia familiar. ${ }^{9,10}$

En población mexicana un $30-40 \%$ de los casos diagnosticados con $\mathrm{SCMOH}$ puede tener una deleción fundadora en BRCA 1 que consiste en la pérdida de los exones 9 al 12, por lo que debe buscarse intencionadamente. ${ }^{11}$

\section{Seguimiento de una paciente portadora de variantes patogénicas de genes de alto riesgo para desarrollar cáncer de mama}

Se recomienda iniciar con autoexploración mamaria mensual a partir de los 18 años; examen clínico anual o semestral, así como mastografía y resonancia magnética de mamas a partir de los 30 años: ${ }^{7}$ sin embargo, la edad de inicio puede ser acorde con la edad más temprana de presentación en la familia. 
Tabla 31. Seguimiento en pacientes con enfermedad metastásica

\begin{tabular}{|l|l|l|l|}
\hline Evaluación & Basal & Ouimioterapia & Terapia endocrina \\
\hline $\begin{array}{l}\text { Evaluación } \\
\text { de síntomas }\end{array}$ & Sí & Antes de cada ciclo & Cada 1-3 meses \\
\hline Examen físico & Sí & Antes de cada ciclo & Cada 1-3 meses \\
\hline BH + PFH, QS & Sí & Cada 2-4 ciclos & Cada 2-6 meses \\
\hline TC tórax-abdomen- & Sí & Cada 4 ciclos & Cada 4-6 meses \\
\hline pelvis & Opcional & Opcional & Opcional \\
\hline
\end{tabular}

TC: tomografía computarizada; BH: biometría hemática; PFH: pruebas de función hepática; OS: química sanguínea.

Tabla 32. Criterios de la National Comprehensive Cancer Network versión $2.2021^{7}$ A. Individuos con familiar portador de variante patogénica o
probablemente patogénica
B. Individuo con antecedente de prueba molecular parcial o limitada
Historia personal de cáncer de mama y
Diagnóstico antes de los 45 años
Diagnostico entre los 45-50 años e
Historia familiar desconocida o limitada
Segundo tumor primario de mama
Un familiar cercano con cáncer de mama, ovario, páncreas o próstata
C. Diagnóstico antes de los 60 años y diagnóstico de cáncer de mama triple negativo
D. Cualquier edad y
Ancestria judía Ashkenazi
Un familiar cercano con diagnóstico de cáncer de mama antes de los 50 años y/o cáncer de ovario, páncreas o de próstata metastásico, intraductual, cribiforme o de alto grado
Tres familiares con cáncer de mama
E. Cáncer de mama en hombre
F. Paciente con variante patogénica identificada en panel somático que podría
tener implicación si se identifica en forma germinal
G. Si es que puede influenciar la toma de decisiones terapéuticas, como en el caso de paciente con cáncer de mama metastásico HER 2-

\section{Quimioprevención y otros} procedimientos en pacientes portadoras de variantes patogénicas de genes de alto riesgo para desarrollar cáncer de mama

La quimioprevención con tamoxifeno e inhibidores de la aromatasa, la mastectomía reductora de riesgo y la combinación de mastectomía/ooforectomía-salpingectomía, ${ }^{1,6}$ solo deben ser consideradas en un grupo de pacientes cuidadosamente seleccionadas por un equipo multidisciplinario, con base en el riesgo objetivo de desarrollar cáncer mamario, así como el deseo personal de la paciente después del asesoramiento genético (ver Capítulo X. Mastectomía reductora de riesgo y Capítulo IV. Prevención primaria).

\section{Aspectos psicooncológicos en cáncer mamario}

\section{Introducción}

La psicooncología es una especialidad que se encarga de los aspectos psicológicos, sociales, culturales, antropológicos, ético-espirituales y de la sexualidad de los pacientes con cáncer. En este contexto, el diagnóstico de cáncer mamario posee un significado amenazador para la paciente y se presenta como un riesgo prematuro de muerte. Este efecto dependerá de una variedad de factores como la edad, la situación socioeconómica, el afrontamiento ante la enfermedad, el apoyo social y emocional que tenga la paciente.

\section{Problemas psicológicos}

Dentro de los problemas psicológicos más prevalentes en pacientes con cáncer de mama está el distrés, definido por la National Comprehensive Cancer Network (NCCN) como una experiencia emocional desagradable de naturaleza psicológica (cognitiva, conductual, emocional), social y/o espiritual, que interfiere con la capacidad para enfrentar el cáncer, sus síntomas físicos y/o su tratamiento. ${ }^{1}$

En este grupo de pacientes, el distrés, depresión $y$ ansiedad constituyen los problemas de salud mental más prevalentes, que se encuentran estrechamente vinculados entre sí. Estos problemas están asociados a problemas de sueño, dolor y fatiga, 
principalmente en el subgrupo de pacientes con cáncer metastásico afectaciones en la imagen corporal y bienestar psicosocial. ${ }^{2}$ Es fundamental el diagnóstico y tratamiento de estas patologías, así como el tipo de afrontamiento de la paciente, ya que puede influir en la duración de la estancia hospitalaria, el autocuidado, la adhesión terapéutica y la calidad de vida.

En las pacientes pueden presentarse efectos en la sexualidad, sintomatología depresiva, ansiedad, alteraciones en la imagen corporal, problemas de relación de pareja, en el cuidado de los hijos, estigmatización y sensación de discriminación. A las mujeres jóvenes con cáncer de mama o sometidas a alguna intervención preventiva les preocupa su fertilidad futura y su imagen corporal; constituyen aspectos extremadamente importantes para ellas, y que requieren estrategias para un mejor afrontamiento y potenciar la autoestima, proporcionando información sobre el embarazo tras el diagnóstico o técnicas de fecundación, facilitando la asistencia a grupos de apoyo o asociaciones para compartir experiencias comunes. ${ }^{3,4}$ Los sobrevivientes pueden presentar sintomatología ansiosa, menor función ejecutiva, alteraciones en la memoria de trabajo y problemas de concentración, en comparación con las mujeres sin antecedentes de cáncer.

Se ha identificado que las y los cuidadores primarios de este grupo de pacientes presentan afectaciones psicosociales como ansiedad, depresión y sobrecarga. Además, se ha reportado que el cáncer impacta significativamente en la relación de pareja. ${ }^{5}$ Las más afectadas son aquellas que tienen pocas habilidades de resolución de problemas, problemas conyugales previos al diagnóstico y que difieren en sus percepciones y expectativas respecto al cáncer. ${ }^{6}$

\section{Evaluación}

Existen cuatro herramientas breves para identificar a los pacientes y parejas con necesidades de intervención psicosocial:

- Termómetro de distrés (Holland, 1999). Identifica el nivel de malestar emocional; validado para población mexicana, por Almanza- Muñoz, Juárez y Pérez en 2008.

- Escala hospitalaria de ansiedad y depresión HADS (Zigmond y Snaith, 1983). ${ }^{7}$ Identifica sintomatología ansiosa y depresiva; validada para población mexicana por Galindo, et al. en 2015.
- Escala de evaluación de Desgaste de Zarit (1980). ${ }^{8}$ Para las parejas de las pacientes que llevan el rol de cuidadores primarios; validada para población mexicana por Galindo, et al. en 2015. ${ }^{8}$

- Escala de ajuste diádico (DAS) (1976). Evalúa la calidad de la relación de pareja; validado en población mexicana Moral de la Rubia en 2009. ${ }^{9}$

\section{Terapia psicológica}

Las terapias cognitivo-conductuales (TCC) se consideran como la alternativa terapéutica para población oncológica que presenta afectaciones psicológicas. El objetivo es modificar las cogniciones y conductas que complican los problemas de salud por medio de técnicas basadas en la investigación científica buscando corregir patrones de pensamiento $y$ creencias irracionales asociadas con el aspecto físico, el atractivo y la valía, mejorando los recursos de afrontamiento y promoviendo la autorregulación emocional.

Los objetivos de las TCC en cáncer se dividen en dos grupos: a) abordaje de problemas psicológicos asociados al diagnóstico, tratamiento y periodo de seguimiento, y b) manejo de efectos secundarios del tratamiento oncológico como náuseas, vómitos, dolor, insomnio, incontinencia y disfunción sexual.

Estas pacientes pueden beneficiarse de diferentes formas de intervención psicológica profesional, que pueden clasificarse de la manera siguiente:

- Intervenciones educativo-informativas (counselling).

- Intervenciones psicoterapéuticas individuales (conductuales, cognitivas, dinámicas).

- Intervenciones mediadas por procesos psicológicos en grupo. ${ }^{10}$

La TCC modifica los patrones que contribuyen a los problemas; también puede emplear principios del condicionamiento y el aprendizaje para modificar comportamientos problemáticos.

Existe suficiente evidencia de que los programas cognitivo-conductuales son eficaces para mejorar el control de algunos síntomas, el estado afectivo relacionado con situaciones concretas y el afrontamiento a la enfermedad en sus diversas fases. ${ }^{11}$ Se recomienda realizar más estudios, para incrementar la evidencia en población mexicana respecto a los efectos a largo plazo y en grupos de pacientes poco representados.

Finalmente, en pacientes con cáncer avanzado y en cuidados paliativos, la terapia de dignidad ha mostrado efectos positivos en el bienestar emocional (Tabla 33). 
Tabla 33. Alternativas de evaluación y tratamiento psicooncológico

\begin{tabular}{|l|l|l|l|}
\hline Objetivo & Instrumento & $\begin{array}{l}\text { Periodo de } \\
\text { tratamiento }\end{array}$ & $\begin{array}{l}\text { Alternativas } \\
\text { terapéuticas }\end{array}$ \\
\hline & \multicolumn{1}{|c|}{ Pacientes con cáncer de mama } \\
\hline $\begin{array}{l}\text { Evaluar el nivel de malestar } \\
\text { emocional, } \\
\text { necesidades, apoyo social y } \\
\text { afrontamiento }\end{array}$ & Termómetro de distrés & $\begin{array}{l}\text { Diagnóstico } \\
\text { Inicio de tratamiento }\end{array}$ & $\begin{array}{l}\text { Información } \\
\text { Psicoeducación } \\
\text { Validación emocional } \\
\text { Técnicas de relajación }\end{array}$ \\
\hline $\begin{array}{l}\text { Evaluar el nivel de síntomas de } \\
\text { ansiedad y depresión }\end{array}$ & $\begin{array}{l}\text { Escala hospitalaria } \\
\text { de ansiedad y } \\
\text { depresión } \\
\text { HADS }\end{array}$ & Periodo de tratamiento & $\begin{array}{l}\text { Psiquiatría y/o neurología } \\
\text { Terapia cognitivo-conductual }\end{array}$ \\
\hline $\begin{array}{l}\text { Conocer el grado de ajuste } \\
\text { (acuerdo) que consideran las } \\
\text { parejas dentro de su relación }\end{array}$ & $\begin{array}{l}\text { Escala de } \\
\text { ajuste diádico }\end{array}$ & $\begin{array}{l}\text { Tratamiento } \\
\text { paliativo }\end{array}$ & Tratamiento \\
\hline $\begin{array}{l}\text { Evaluar el nivel de sobrecarga } \\
\text { asociado al } \\
\text { cuidado de la paciente }\end{array}$ & $\begin{array}{l}\text { Escala de } \\
\text { evaluación de } \\
\text { desgaste de Zarit }\end{array}$ & $\begin{array}{l}\text { Diagnóstico } \\
\text { Inicio de tratamiento } \\
\text { Periodo de tratamiento }\end{array}$ & $\begin{array}{l}\text { Información } \\
\text { Psicoeducación }\end{array}$ \\
\hline $\begin{array}{l}\text { Terapia cognitivo-conductual } \\
\text { Periodo de tratamiento }\end{array}$ & $\begin{array}{l}\text { Terapia cognitivo-conductual } \\
\text { Tratamiento paliativo }\end{array}$ & \\
\hline
\end{tabular}

\section{Rehabilitación física de la paciente con cáncer de mama}

\section{Introducción}

Los avances en los tratamientos y el incremento de la supervivencia de los pacientes con cáncer de mama demandan que los métodos de rehabilitación sean cada vez más efectivos para lograr una mejor calidad de vida, tanto en los supervivientes de la enfermedad, como en pacientes en etapa terminal. Después del tratamiento quirúrgico se pueden presentar complicaciones, algunas de las cuales se relacionan exclusivamente con la mama, otras con la disección ganglionar axilar, con la recanalización de los vasos linfáticos, ${ }^{1}$ con el tratamiento oncológico (quimioterapia y radioterapia) y otras con procesos infecciosos.

\section{Linfedema}

Se estima que el $20 \%$ de los pacientes con disección axilar desarrollarán linfedema a los seis meses, el $36 \%$ al año y el $54 \%$ a los 36 meses, incrementándose el riesgo de acuerdo con el número de ganglios linfáticos extirpados y a la radioterapia. Por otra parte, el sobrepeso y la obesidad aumentan el riesgo hasta en el $80 \%$ de los casos impactando en los resultados del tratamiento. ${ }^{2-5}$

En la actualidad, la rehabilitación indicada es poco conocida, y por ello la incidencia de linfedema es mayor de la que existiría si se realizara una adecuada prevención. ${ }^{6}$
El linfedema tiene como complicaciones: ${ }^{7}$

- Infecciones recurrentes (linfagitis, erisipela, celulitis).

- Trastorno de la imagen corporal.

- Baja autoestima situacional y crónica.

- Deterioro de la interacción social.

- Trastorno de la identidad personal.

- Intolerancia a la actividad.

- Déficit de autocuidado.

\subsection{EtAPAS del LINFEDEMA}

\subsubsection{Etapa 0: de latencia}

- No hay datos clínicos de linfedema.

\subsubsection{Etapa I: reversible}

- Aumento evidente de volumen.

- Por lo general la elevación del miembro reduce el edema (edema que no se ve favorecido con la administración de diurético, por la concentración de proteína en el líquido linfático), pero no detiene su progresión.

\subsubsection{Etapa II: espontáneamente irreversible}

- Volumen del miembro aumentado significativamente.

- Presencia de fibrosis linfática (zonas de mayor estancamiento), lo que reduce la capacidad de transporte linfático. 
- La elevación del miembro no reduce el edema.

\subsubsection{Etapa III: elefantiasis linfoestática}

- El miembro incrementa de volumen de manera exagerada.

- Presencia de fibrosis linfática.

- Extremidades más propensas a infecciones.

- Incapacidad física.

\section{Manejo del linfedema en pacientes tratadas con intención curativa}

La paciente debe conocer el riesgo de presentar linfedema y sus consecuencias, y que este riesgo disminuye con la rehabilitación. Debe brindarse capacitación sobre el masaje de la cicatriz y movilización de fascia una vez retirados los puntos y drenajes. Esto es eficaz para reducir adherencias en los planos profundos, mejorar la flexibilidad y movilidad, disminuir el grosor de la cicatriz y piel sana circundante, y para prevenir el espasmo muscular del músculo pectoral mayor, hombro copado y capsulitis adhesiva.

La movilización de la articulación escapulohumeral debe iniciar desde el primer día posquirúrgico: flexión y extensión de hombro con el codo flexionado a $90^{\circ}$. No deben hacerse movimientos de abducción de hombro por siete días, ya que los capilares linfáticos en la axila tardan ese tiempo en restablecerse.

A partir del octavo día se debe iniciar el movimiento del brazo, con ejercicios pasivos (con ayuda de otra persona) de flexión, abducción y rotación de hombro. Una vez logrado el arco de movimiento completo habrá de comenzar un programa de ejercicios activos para mantener el sistema linfático permeable y programa de estiramientos musculares de hombro para mantener una dinámica muscular adecuada. En caso de contar con catéter puerto, los ejercicios se adaptarán para prevenir futuras lesiones.

Los cuidados para la disminución de riesgos de linfedema en el brazo, el pecho y la espalda del lado de la cirugía son:

- Evitar esfuerzos (cargar máximo $5 \mathrm{~kg}$ ). Se puede trabajar la progresión con trabajo físico y con guía de un profesional.

- Evitar heridas, quemaduras, picaduras de insectos.

- No dormir sobre el brazo afectado.

- Mantener el peso ideal.

- No aplicar termoterapia, crioterapia, ni contrastes; ni en el cuadrante ni en la extremidad afectada.

- No realizar tratamientos de acupuntura en el cuadrante ni en el miembro afectado.
- Utilizar manga de compresión preventiva indicada por un fisioterapeuta especializado.

- No usar diuréticos, salvo por una indicación médica muy necesaria (p. ej. linfedema combinado).

Si el paciente presenta tétrada de Celso, tumor y rubor con calor y doloren el brazo, y este aumenta de volumen de manera repentina, cambia de color o su temperatura se eleva, hay que acudir al médico; son signos de alarma para descartar o confirmar una trombosis venosa profunda y/o infección.

La prenda de compresión especializada preventiva (20$30 \mathrm{mmHg}$ ), deberá ser indicada por un especialista en tratamiento de linfedema, brindando las indicaciones correspondientes para viaje, actividad física y realizar actividades de esfuerzo en el hogar y en el ámbito laboral.

El tratamiento indicado para linfedema es la terapia descongestionante compleja (TDC) ${ }^{8,9} \mathrm{o}$ el tratamiento físico combinado (TFCL). ${ }^{10}$ Aunque el linfedema no tiene curación, este tratamiento puede reducir el edema linfático y mantenerlo controlado.

Los cuatro componentes de la TDC son:

- El meticuloso cuidado de las uñas y la piel del cuadrante afectado.

- El drenaje linfático manual (DLM).

- La terapia compresiva con vendas de tracción corta o Circaid y prendas de compresión médica.

- Ejercicios miolinfokinéticos. ${ }^{10}$

Esta terapia es suave, no invasiva y en la mayoría de los casos devuelve a la paciente el control sobre su linfedema y la reincorpora a una vida funcional. Una paciente que ya tiene linfedema debe recibir tratamiento antes de usar una manga. El uso de la manga sin tratamiento edematiza la mano y hacer pensar a la paciente y el médico que la manga no funciona.

El vendaje neuromuscular con la técnica adecuada y respetando la anatomía linfática se coloca con la intención de estimular el drenaje linfático (TDC); gracias a la elasticidad y adhesivo en $\mathrm{S}$ del vendaje, fisiológicamente estimula los receptores aferentes, ejerciendo un cambio de presión intersticial complementando favorablemente la intervención. ${ }^{11}$

La presoterapia secuencial forma parte complementaria del DLM, consensuada bajo una presión de trabajo entre 20 y $40 \mathrm{mmHg}$, con una duración de 20 a 45 minutos promedio.

\subsection{Papel del ejercicio en el control del LINFEDEMA}

El ejercicio físico también puede ayudar a controlar el linfedema y los síntomas músculo-esqueléticos, secundarios a los tratamientos farmacológicos. Métodos no 
farmacológicos como la actividad física, que incluyen una variedad de métodos terapéuticos en conjunto con el uso de analgésicos, tienen como objetivo ayudar al paciente con cáncer a ganar o mantener su funcionalidad y restaurar el sentido del control sobre el dolor. ${ }^{12}$

\section{Terapia descongestionante compleja o tratamiento físico combinado y terapia física como tratamiento paliativo en pacientes con enfermedad avanzada}

La intención de esta terapia en pacientes con enfermedad avanzada o en etapa terminal es mantener la autosuficiencia el mayor tiempo posible, preservando la movilidad y la fuerza muscular y disminuyendo notablemente el dolor. Si bien el linfedema no mejorará de modo considerable, es factible mantener un buen control de este.

\section{COVID-19 y cáncer de mama}

\section{Introducción}

La pandemia por coronavirus 2 del síndrome respiratorio agudo grave (SARS-CoV-2), decretada por la Organización Mundial de la Salud en marzo del 2020, se convirtió en una emergencia de salud pública global que representó un reto para combinar la continuidad de la atención de los pacientes oncológicos, con la seguridad de pacientes y trabajadores., ${ }^{1,2}$

El espectro clínico de la infección por SARS-CoV-2 puede ir desde el portador asintomático hasta una neumonía fulminante con síndrome de insuficiencia respiratoria aguda. ${ }^{3}$ Los pacientes con mayor riesgo de mortalidad por enfermedad por coronavirus 2019 (COVID-19) son varones, adultos mayores y con comorbilidades asociadas como: hipertensión, obesidad, diabetes, tabaquismo, enfermedad pulmonar obstructiva crónica, asma, insuficiencia renal y cáncer. ${ }^{4-7}$ Los pacientes oncológicos tienen un mayor riesgo de contagio y de desarrollar formas más graves de la enfermedad; ${ }^{6-9}$ sin embargo, la heterogeneidad del cáncer de mama plantea múltiples escenarios clínicos con diferentes probabilidades de complicación por COVID-19 y objetivos diversos en el tratamiento oncológico. ${ }^{4,10}$ Los servicios de oncología deben de continuar activos, ya que el retraso en el tratamiento tiene un impacto negativo en la supervivencia, por lo que será necesario establecer estrategias de priorización, acordes a los recursos de cada unidad médica para todas las modalidades terapéuticas, por lo que el manejo multidisciplinario es vital y no negociable. La telemedicina puede ser una herramienta adicional. ${ }^{1,11-14}$

Mientras continúe la pandemia, es deseable establecer un triaje respiratorio para la atención diaria de pacientes ambulatorios, con el objetivo de minimizar los posibles contagios, así como tener un control de las entradas y salidas a la unidad médica. ${ }^{10,12,15}$

Debe implementarse el uso de cubrebocas, higiene de manos, distanciamiento social, evitar saturar las salas de espera, tener ventilación en las áreas de consulta, sala de quimioterapia ambulatoria y radioterapia. ${ }^{10,13}$ De ser factible, incluir la evaluación de la región de tórax en las simulaciones de radioterapia y en los estudios de extensión para detectar alteraciones radiológicas en pacientes asintomáticos y de esta manera proteger al personal de salud y los pacientes. ${ }^{4,15}$

La educación al paciente para que pueda identificar los síntomas relacionados con COVID-19 y, en su caso, es indispensable buscar atención médica temprana. ${ }^{3,14}$

Para pacientes en seguimiento que no tengan síntomas, los estudios de vigilancia pueden ser retrasados: ${ }^{12}$ sin embargo, si hay sintomatología de posible recurrencia tumoral, se indicará a la paciente que debe solicitar una consulta oncológica en breve para descartar o confirmar dicha recurrencia.

\section{Recomendaciones quirúrgicas}

Evitar en lo posible los diferimientos en la programación quirúrgica en pacientes con intento curativo, ya que desde los tres meses de retraso quirúrgico inicia una reducción en la supervivencia. ${ }^{11,12}$ Se deberá realizar prueba de reacción en cadena de la polimerasa (PCR) entre las 24 a 48 horas previas al procedimiento quirúrgico electivo + tomografía computarizada de tórax. ${ }^{4,13}$ De ser negativas, se continuará con el programa de tratamiento quirúrgico programado. Los procedimientos quirúrgicos por biopsias con atipia, cirugía reductora de riesgo, reconstrucción mamaria y enfermedad benigna se pueden diferir y priorizar otros diagnósticos. ${ }^{1,12}$

Durante el pico de la pandemia o nueva ola de contagios es posible tomar las siguientes acciones, para optimizar los turnos quirúrgicos.

\subsection{Carcinoma ductal in Situ}

Diferir por tres a seis meses el manejo quirúrgico. - Preferir tratamientos sistémicos neoadyuvantes en pacientes con tumores mayores de $2 \mathrm{~cm}$ y/o axila 
clínicamente positiva, en los fenotipos triple negativo y HER 2 positivo.

- Pacientes con cT1a-c, cN0, deben de ir a procedimiento quirúrgico. ${ }^{12,16}$

- En pacientes CT1-3 cN0 con expresión de receptores hormonales y características biológicas de bajo riesgo pueden llevarse a cirugía; incluso en etapas clínicas cT1-3 cN1 o cT4 cN0-1 si las circunstancias del contexto sanitario local lo ameritan. ${ }^{13}$

\subsection{Posterior a tratamiento sistémico NEOADYUVANTE}

- Podría retrasarse el manejo quirúrgico entre cuatro y ocho semanas de ser necesario.

- Casos inusuales/emergencias quirúrgicas/consideraciones especiales.

- Pacientes con progresión de la enfermedad durante el manejo sistémico, angiosarcoma y tumor phyllodes maligno, deben ser considerados como prioridad quirúrgica y no deben ser retrasados. ${ }^{2}$

\section{Recomendaciones en oncología médica}

Las unidades de quimioterapia ambulatoria deben continuar sus actividades. No es recomendable suspender y/o retrasar los tratamientos sistémicos con intento curativo y/o paliativo. ${ }^{1,12}$ En pacientes bajo tratamiento paliativo con múltiples líneas de quimioterapia tratamiento, mal pronóstico y estado funcional comprometido, puede considerarse enviar a mejor soporte médico. $^{12}$

Hasta el momento de esta edición no existe evidencia que restringa el uso de quimioterapia, terapia dirigida, terapia anti-HER 20 inmunoterapia en pacientes oncológicos durante la pandemia, por lo que la prescripción de las indicaciones «estándar» debe continuar. $., 13,17-19$

Si un paciente presenta una prueba positiva por PCR para SARS-CoV-2 debe suspender su tratamiento hasta recuperación del cuadro y en caso de no tener complicaciones puede reiniciar su terapia sistémica entre los 14 y 21 días posteriores al inicio de síntomas. ${ }^{12}$

Con el objetivo de disminuir los tiempos de estancia en la unidad médica y la movilidad de los pacientes se pueden realizar las siguientes acciones:

- Preferir los esquemas trisemanales intravenosos, las terapias orales y subcutáneas que no comprometan el resultado terapéutico oncológico., 1,12,13,20

- Es pertinente que los pacientes acudan sin acompañante a sus tratamientos ambulatorios y consultas, excepto cuando se requiera de una asistencia continua. ${ }^{21}$
- Las citas de seguimiento y control de síntomas deben ser indicadas con el mayor intervalo de tiempo y de ser factible por telemedicina. 3,4,12,13,17,21

- Es pertinente ampliar el uso de factor estimulante de colonias en esquemas con riesgo moderado (10$20 \%$ ) y alto de neutropenia febril (> 20\%), sobre todo en adultos mayores. ${ }^{4,12}$

- Los esteroides pueden ser utilizados, cuando se encuentre indicado.

- Los estudios de evaluación de respuesta en el escenario metastásico deben ser diferidos lo más posible, en ausencia de síntomas. ${ }^{3,12}$

- Buscar estrategias de surtimiento de medicamentos en periodos mayores a los habituales, entrega en domicilio, entrega a familiar, prescripción vía telefónica. 2,3,12,21

- Las terapias sistémicas como la endocrina y las terapias anti-HER 2 pueden ser utilizadas como «puente» para evitar desfases en la atención oncológica. ${ }^{12}$

- Se recomienda el uso de ácido zoledrónico y denosumab trimensual, para el manejo de metástasis óseas; de ser factible preferir denosumab por su aplicación subcutánea. ${ }^{3,12}$

- Suspender la aplicación de moduladores óseos (denosumab, bisfosfonatos) en el escenario de osteoporosis ${ }^{3}$

\subsection{ENFERMEDAD HORMONOSENSIBLE (RH+/HER 2 NEGATIVO)}

- La terapia endocrina neoadyuvante puede utilizarse en pacientes con cT1-2 cN0-1 M0, receptor hormonal $[\mathrm{RH}]+/ \mathrm{HER}$ 2negativo y Ki67 menor del $15 \%$, en espera de un turno quirúrgico. ${ }^{3,12,13}$ Inhibidores de aromatasa en pacientes posmenopáusicas y en pacientes premenopáusicas supresión ovárica con tamoxifeno o inhibidor de aromatasa. ${ }^{2,3,12,13}$

- Es deseable contar con firmas genómicas en pacientes pT1-2 pN0-1, para definir la necesidad real de quimioterapia en el terreno adyuvante. ${ }^{3}$

- En pacientes premenopáusicas candidatas a utilizar análogos de la hormona liberadora de la hormona luteinizante se debe dar preferencia a la posología trimestral. ${ }^{12}$

- Se recomienda capecitabina como la primera opción de quimioterapia en pacientes con resistencia endocrina. ${ }^{3}$

- De ser necesario, el uso de inhibidores de ciclina como terapia de primera línea, en pacientes con baja carga tumoral o enfermedad ósea, puede ser diferido o bien considerar ajuste de dosis para reducir el riesgo de neutropenia. ${ }^{3}$

- El uso de inhibidores de la diana de rapamicina en células de mamífero debe individualizarse. 


\subsection{ENFERMEDAD HER 2 POSITIVA}

- Puede extenderse la posología de la terapia anti-HER 2 de tres a cuatro semanas en un escenario de pico de la pandemia o un incremento considerable de contagios. ${ }^{3}$

\section{Recomendaciones en radioterapia}

Durante esta pandemia, las acciones en el tratamiento de radioterapia se resumen en el acrónimo RADS (Remote visits, Avoid radiation, Defer radiation, Shorten radiation): visitas remotas (telemedicina), omitir radiación (en situaciones seguras para los pacientes), demorar radioterapia (siempre y cuando sea posible retrasarla para momentos de menor contagio por COVID-19) y acortar el tratamiento (utilizar hipofraccionamiento en los casos posibles). ${ }^{22}$

Ante la sospecha de COVID-19 en alguna paciente con cáncer de mama que acude al servicio de radioterapia se recomiendan los siguientes lineamientos:

- Paciente que iniciará radioterapia y diagnóstico de COVID-19. No iniciar tratamiento hasta haber cumplido 14 días en confinamiento domiciliario, a partir del inicio de síntomas. Reiniciará tratamiento según indicaciones por infectología.

- Paciente en tratamiento con radioterapia + sospechoso de COVID-19. Suspender tratamiento, realizar hisopado nasofaríngeo e individualizar el regreso. Al reiniciar radioterapia se deberá calcular la BED (dosis biológica equivalente) y las sesiones que recuperar.

- Paciente en tratamiento que resulta positivo a COVID-19. Suspender tratamiento y enviar a confinamiento domiciliario por 14 días. Individualizar el regreso, calcular BED y sesiones que recuperar.

- Paciente COVID-19 positivo que amerita radioterapia urgente (compresión medular y síndrome de vena cava superior). Se administrará tratamiento siempre y cuando el departamento cuente con el material de protección necesario y en el último turno de un solo equipo. ${ }^{23}$

Las indicaciones de radioterapia en pacientes con cáncer de mama son las mismas, a pesar de la pandemia. No se recomienda omitir este tratamiento a pacientes que reciban un beneficio en supervivencia y/o control local. Incluso en adultos mayores, que tengan indicación de tratamiento, deberá indicarse el momento adecuado para recibir radioterapia. ${ }^{3,24}$

Los casos deberán priorizarse, dependiendo el riesgo de recurrencia 0 afección a la vida y la función como sigue:
- Riesgo bajo. Pacientes $>70$ años, tumor $<3 \mathrm{~cm}$, márgenes negativos, grado 1-2, luminal $A$, ganglios negativos en tratamiento adyuvante con hormonoterapia. Se considera retrasar tratamiento hasta 16 semanas o discutir con la paciente la omisión de este.

- Riesgo intermedio. Carcinoma ductal in situ y las condiciones que no cumplan bajo o alto riesgo. Se considera retrasar tratamiento hasta 16 semanas.

- Riesgo alto. Compresión medular, sangrado, metástasis en el sistema nervioso central, radioterapia paliativa, radioterapia posmastectomía con factores de alto riesgo (tumor inflamatorio, ganglios positivos, subtipos alto riesgo). ${ }^{25}$

El uso de hipofraccionamiento debe favorecerse en la mayoría de las pacientes durante la pandemia. Algunas excepciones son glándula mamaria de gran volumen, inclusión de mamaria interna o alguna otra situación anatómica que ocasione dosis altas de radiación en órganos sanos. ${ }^{26-28}$

\section{Vacunación}

Si el paciente oncológico tiene acceso a un esquema de vacunación anti-COVID, es deseable que lo reciba. ${ }^{29} \mathrm{Si}$ el paciente se encuentra en tratamiento sistémico activo deberá restringirse la aplicación de la vacuna, en caso de presentar neutropenia grave y/o neutropenia febril. ${ }^{29}$ No se recomienda administrar una vacuna anti-COVID durante los 14 días posteriores a procedimiento quirúrgico. Las pacientes en vigilancia por cáncer de mama pueden ser vacunadas. ${ }^{29,30}$

\section{Financiamiento}

Agradecemos el financiamiento para la realización de la reunión plenaria de esta novena revisión, como apoyo irrestricto, a Astra Zeneca, Pfizer, Novartis, Roche y Asofarma.

\section{Responsabilidades éticas}

Protección de personas y animales. Los autores declaran que para esta investigación no se han realizado experimentos en seres humanos ni en animales.

Confidencialidad de los datos. Los autores declaran que en este artículo no aparecen datos de pacientes.

Derecho a la privacidad y consentimiento informado. Los autores declaran que en este artículo no aparecen datos de pacientes. 


\section{Referencias bibliográficas}

\section{Introducción}

1. Primer Consenso Nacional sobre Tratamiento del Cáncer Mamario. Rev Inst Nal Cancerol (Mex). 1995;41(3):136-45.

2. Primera revisión del Consenso Nacional sobre Tratamiento del Cáncer Mamario. Ginecol Obst Mex. 2002;70:349-58.

3. Segunda revisión del Consenso Nacional sobre el Diagnóstico y Tratamiento del Cáncer Mamario. GAMO. 2006;5(Supl. 2).

4. Tercera revisión del Consenso Nacional sobre el Diagnóstico y Tratamiento del Cáncer Mamario. GAMO. 2008;7(Supl. 6):1-35.

5. Cuarta revisión del Consenso Nacional sobre el Diagnóstico y Tratamiento del Cáncer Mamario. GAMO. 2011;10(Supl. 6):1-58.

6. Consenso Mexicano sobre Diagnóstico y Tratamiento del Cáncer Mamario. Quinta revisión. GAMO. 2013;12(Supl. 3).

7. Consenso Mexicano sobre Diagnóstico y Tratamiento del Cáncer Mamario. Sexta revisión. GAMO. 2015;14(Supl. 2).

8. Consenso Mexicano sobre Diagnóstico y Tratamiento del Cáncer Mamario. Séptima revisión. México: Masson Doyma México; 2017.

9. Consenso Mexicano sobre Diagnóstico y Tratamiento del Cáncer Mamario. Octava revisión. GAMO. 2019;18(3):141-231.

10. Norma Oficial Mexicana NOM-041-SSA-2-2011 para la Prevención, Diagnóstico, Tratamiento, Control y Vigilancia Epidemiológica del Cáncer de Mama. México, Secretaría de Salud; 2003. pp. 6-7.

\section{Epidemiología del cáncer mamario en México}

1. Globocan 2004. International Agency for Research on Cancer. Breast Cancer estimated incidence, mortality and prevalence worldwide in 2012.

2. Organización Panamericana Sanitaria/Organización Mundial de la Salud. Situación de la salud en las Américas. Indicadores básicos 2014. Washington D.C. Organización Panamericana Sanitaria/Organización Mundial de la Salud; 2014

3. Colditz G, Baer H, Tamimi R. Breast cancer. En: Schottenfeld D, Fraumeni JK Cancer epidemiology and prevention. $3^{\text {rd }}$ edition. New York: Oxford Press; 2006.

4. Secretaría de Salud, Dirección General de Epidemiología. Anuarios de morbilidad 2015 [Internet]. México: Secretaría de Salud, Dirección General de Epidemiología. Disponible en: http//www.epidemiologia.salud. gob.mx/anuario/html/anuarios.html

5. Consejo Nacional de Población. Documento metodológico: Proyecciones de la población de México 2010-2050. México: Consejo Nacional de Población; 2012.

6. Rodríguez-Cuevas S, Macías CG, Franceschi D, et al. Breast carcinoma presents a decade earlier in Mexican women than in the United States or European countries. Cancer. 2001;91(4):863-8.

7. Consenso Mexicano sobre Diagnóstico y Tratamiento del Cáncer Mamario 2017. Séptima revisión. México: Masson Doyma México; 2017.

8. Lozano R, Naghavi M, Foreman K, et al. Global and regional mortality from 235 causes of death for 20 age groups in 1990 and 2010. A systematic analysis for the Global Burden of Disease Study 2010. Lancet. 2012;380(9859):2095-128.

9. Unger-Saldaña K, Miranda A, Zarco-Espinosa G, et al. Health System delay and its effects on clinical stage of breast cancer: Multicenter study. Cancer. 2015;121(3):2198-206.

10. Maffuz-Aziz A, Labastida-Almendaro S, Sherwell-Cabello S, et al. Supervivencia de pacientes con cáncer de mama. Análisis por factores pronóstico, clínicos y patológicos. Ginecol Obst Mex. 2016;84(8):498-506.

\section{Información y factores de riesgo}

1. Globocan 2018 [Internet]. International Agency for Research on Cancer. Disponible en: http://gco.iarc.fr/

2. United Nations. Sustainable Development Goals [Internet]. United Nations. Disponible en: https://www.un.org/sustainabledevelopment/sustainable-development-goals/

3. Ramos AK, Correa A. Trinidad N. Perspectives on breast health education and services among recent Hispanic immigrant women in the Midwest: A qualitative study in Lancaster County, Nebraska. J Cancer Educ. 2016;31(4):666-72.

4. Curbow B, Bowie J, Garza MA, et al. Community-based cancer screening programs in older populations: Making progress but can we do better? Prev Med. 2004;38:676-93.

5. UICC. Prevention: Breast cancer risk factors and prevention. The Breast Health Global Initiative; 2017.

6. Soto-Perez-de-Celis E, Smith DD, Rojo-Castillo MP, et al. Implementation of a school based educational program to increase breast cancer awareness and promote intergenerational transmission of knowledge in a rural Mexican community. Oncologist. 2017;22(10):1249-56.

7. Norma Oficial Mexicana NOM-041-SSA2-2011 para la Prevención, Diagnóstico, Tratamiento, Control y Vigilancia Epidemiológica del Cáncer de Mama. México: Secretaría de Salud; 2011.
8. Prevención, tamizaje y referencia oportuna de casos sospechosos de cáncer de mama en el primer nivel de atención. Guías de Evidencia y Recomendación: Guía de Práctica Clínica. México: CENETEC; 2017.

9. Haines A. Identification assessment and management of overweight and obesity: summary of updated NICE guidance. BMJ. 2014;349:g6608.

10. Aguilar-Cordero MJ, González-Jiménez E, García-López AP. Obesidad y su implicación en el cáncer de mama. Nutr Hosp. 2011;26(4):899-903.

11. Arnold M, Pandeya N, Byrnes G, et al. Global burden of cancer attributable to high body mass, index in 2012: a population based study. Lancet Oncol. 2015;16(1):36-46.

12. Blair CK, Robien K, Inove-Choi, et al. Physical inactivity and risk of poor quality of life among elderly cancer survivors compared to women without cancer. The lowa Women's Health Study. J Cancer Surviv. 2016;10(1):103-12.

13. Ortiz-Rodríguez SP, Torres-Mejía G, Mainero-Ratchelous F, et al. Actividad física y cáncer de mama en mujeres mexicanas. Salud Publica Mex. 2008;50(2):126-35.

14. Casla-Barrio S, Sampedro-Molinuelo J, López-Díaz de Durana A, et al. Cáncer de mama y ejercicio físico. Estudio piloto. Rev Andal Med Deporte. 2012;5(4):134-9.

15. Elme A, Utriainen $M$, Kellokumpu-Lehtinen $P$, et al. Obesity and physical inactivity are related to impaired physical health of breast cancer survivors. Anticancer Res. 2013;33:1595-602.

16. Centros para el Control y la Prevención de Enfermedades. Actividad física para un peso saludable [Internet]. EE.UU.: Centros para el Control y la Prevención de Enfermedades. Disponible en: www.cdc.gov./healthyweight physical activity/index.html

\section{Prevención primaria del cáncer mamario}

1. Fisher B, Costantino JP, Wickerham DL, et al. Tamoxifen for the prevention of breast cancer: current status of the National Surgical Adjuvant Breast and Bowel Project P-1 study. J Natl Cancer Inst. 2005:97(22):1652-962.

2. King MC, Wieand S, Hale K, et al. Tamoxifen and breast cancer incidence among women with inherited mutations in BRCA1 and BRCA2. National Surgical Adjuvant Breast and Bowel Project (NSABP-P1) Breast Cancer Prevention Trial. JAMA. 2001;286(18):2251-6.

3. National Institute for Healthcare and Excellence. Familial breast cancer: classification, care and managing breast cancer related risks in people with a family history of breast cancer. Clinical Guideline [CG164] [Internet]. National Institute for Healthcare and Excellence; 25 de junio de 2013. Disponible en: https://www. nice.org.uk/guidance/cg164

4. Visvanathan $K$, Hurley $P$, Bantug $E$, et al. Use of pharmacologic intervention for breast cancer risk reduction: American Society of Clinical Oncology Clinical Practice Guideline. J Clin Oncol. 2013;31(23):2942-62.

5. Gradishar WJ, Anderson BO, Balassanian R, et al. Breast Cancer, Version 4.2017, NCCN Clinical Practice Guidelines in Oncology. J Natl Compr Canc Netw. 2018 Mar;16(3):310-20.

6. Nelson HD, Smith B, Griffin J, et al. Use of medications to reduce risk for primary breast cancer: A systematic review for the U.S. Preventive Services Task Force. Ann Intern Med. 2013;158(8):604-14.

7. Barrett-Connor E, Mosca L, Collins P, et al. Effects of raloxifene of cardiovascular events and breast cancer in postmenopausal women. N Eng J Med. 2006;355:125-37.

8. Ettinger B, Black DM, Mitlak BH, et al. Reduction of vertebral fracture risk in postmenopausal women with osteoporosis treated with raloxifene. Results from a 3-year randomized clinical trial. JAMA. 1999;282(7):637-45.

9. Martino S, Cauley JA, Barrett-Connor E, et al. Continuing outcomes relevant to Evista: breast cancer incidence in postmenopausal osteoporotic women in a randomized trial of raloxifene. J Natl Cancer Inst. 2004;96(23):1751-61.

10. Vogel VG, Costantino JP, Wickerham DL, et al. Update of the National Surgical Adjuvant Breast and Bowel Project Study of Tamoxifen and Raloxifene (STAR) P-2 Trial: Preventing Breast Cancer. Cancer Prev Res. 2010;3(6):696-706

11. De Censi A, Puntoni M, Guerrieri-Gonzaga A, et al. Randomized placebo controlled trial of low - dose tamoxifen to prevent local and contralateral recurrence in breast intraepithelial neoplasia. J Clin Oncol. 2019;37:1629-37.

12. Goss PE, Ingle JN, Alés-Martínez JE, et al. Exemestane for breast-cancer prevention in postmenopausal women. N Engl J Med. 2011;364(25):2381-91.

13. Cuzick J, Sestak I, Forbes JF, et al. Anastrozole for prevention of breast cancer in high risk postmenopausal women (IBIS-II): an international, double blind, randomized placebo-controlled trial. Lancet. 2014;383(9922):1041-8.

\section{Diagnóstico temprano. Evaluación de la mama por imagen}

1. Oeffinger KC, Fontham ET, Etzioni R, et al. Breast Cancer Screening for Women at Average Risk: 2015 Guideline Update From the American Cancer Society. JAMA. 2015;314(15):1599-614.

2. Yuan WH, Hsu HC, Chen YY, et al. Supplemental breast cancer-screening ultrasonography in women with dense breasts: a systematic review and meta-analysis. Br J Cancer. 2020;123(4):673-88. 
3. Keating NL, Pace LE. Breast cancer screening in 2018: time for shared decision making. JAMA. 2018;319(17):1814-5.

4. Buchberger W, Geiger-Gritsch S, Knapp R, et al. Combined screening with mammography and ultrasound in a population- based screening program. Eur J Radiol. 2018;101:24-9.

5. Witten M, Parker CC. Screening mammography: recommendations and controversies. Surg Clin North Am. 2018;98(4):667-75.

6. Engmann NJ, Scott CG, Jensen MR, et al. Abstract 3226: Overweight and obese women with high volumetric breast density at high breast cancer risk. Cancer Res. 2018;78(13 Suppl):3226.

7. Skaane $\mathrm{P}$, Bandos Al, Niklason LT, et al. Digital mammography versus digital mammography plus tomosynthesis in breast cancer screening: the Oslo Tomosynthesis Screening Trial. Radiology. 2019;291(1):23-30.

8. Maxwell AJ, Michell M, Lim YY, et al. A randomised trial of screening with digital breast tomosynthesis plus conventional digital $2 \mathrm{D}$ mammography versus $2 \mathrm{D}$ mammography alone in younger higher risk women. Eur J Radiol. 2017;94:133-9.

9. Patel BK, Covington M, Pizzitola VJ, et al. Initial experience of tomosynthesis-guided vacuum-assisted biopsies of tomosynthesis-detected (2D mammography and ultrasound occult) architectural distortions. AJR Am J Roentgenol. 2018;210(6):1395-400.

10. Lehman CD, Wellman RD, Buist DS, et al. Diagnostic accuracy of digital screening mammography with and without computer-aided detection. JAMA Intern Med. 2015;175(11):1828-37.

11. Zanardo M, Cozzi A, Trimboli RM, et al. Technique, protocols and adverse reactions for contrast-enhanced spectral mammography (CESM): a systematic review. Insights Imaging. 2019;10(1):76.

12. Ciatto S, Houssami N, Bernardi D, et al. Integration of $3 D$ digital mammography with tomosynthesis for population breast-cancer screening (STORM): a prospective comparison study. Lancet Oncol. 2013;14(7):583-9.

13. American College of Radiology. ACR BI-RADS Atlas. Breast imaging reporting and data system. American College of Radiology; 2013.

14. Bevers TB, Anderson BO, Bonaccio E, et al.; National Comprehensive Cancer Network. NCCN clinical practice guidelines in oncology: breast cance screening and diagnosis. J Natl Compr Canc Netw. 2009;7(10):1060-96.

15. Sung JS, Stamler S, Brooks J, et al. Breast cancers detected at screening MR imaging and mammography in patients at high risk: method of detection reflects tumor histopathologic results. Radiology. 2016;280(3):716-22.

16. Malherbe K, Annamaraju P. Breast ultrasound [Internet]. StatPearls [última actualización: 19 de enero de 2021]. Disponible en: https://www. ncbi.nlm.nih.gov/books/NBK557837

17. Geisel J, Raghu M, Hooley R. The role of ultrasound in breast cancer screening: the case for and against ultrasound. Semin Ultrasound CT MR. 2018:39(1):25-34

18. Barr RG, Nakashima K, Amy D, et al. WFUMB guidelines and recommendations for clinical use of ultrasound elastography: Part 2: breast. Ultrasound Med Biol. 2015;41(5):1148-60.

19. Brem RF, Lenihan MJ, Lieberman J, et al. Screening breast ultrasound: past, present, and future. AJR Am J Roentgenol. 2015;204(2):234-40.

20. Thigpen D, Kappler A, Brem R. The role of ultrasound in screening dense breasts-a review of the literatura and practical solutions for implementation. Diagnostics (Basel). 2018;8(1):20.

21. Rosen PP. Pathologic examination of breast and lymph node specimens including sentinel lymph nodes. En: Rosen's Breast Pathology. Filadelfia, PA: Lippincott-Williams and Wilkins; 2009. pp. 1034-1102.

22. Marino MA, Avendano $D$, Zapata $P$, et al. Lymph node imaging in patients with primary breast cancer: concurrent diagnostic tools. Oncologist 2020;25(2):e231-e242.

23. Vidya RI, lqbal FM, Bickley B. Pre-operative axillary staging: should core biopsy be preferred to fine needle aspiration cytology? Ecancermedicalscience. 2017; $11: 724$

24. Wengert GJ, Helbich TH, Kapetas P, et al. Density and tailored breast cancer screening: practice and prediction-an overview. Acta Radiol Open. 2018;7(9):2058460118791212.

25. Teller P, Jefford VJ, Gabram SG, et al. The utility of breast MRI in the management of breast cancer. Breast J. 2010;16(4):394-403.

26. Kuhl CK, Schrading S, Strobel K, et al. Abbreviated breast magnetic resonance imaging (MRI): first postcontrast subtracted images and maximum-intensity projection-a novel approach to breast cancer screening with MRI. J Clin Oncol. 2014;32(22):2304-10.

27. Shawky, M., Ali, Z.A.E., Hashem, D.H. et al. Role of positron-emission tomography/computed tomography (PET/CT) in breast cancer. Egypt $\mathrm{J}$ Radiol Nucl Med 51, 125(2020).

28. Koo HR, Moon WK, Chun IK, et al. Background 18F-FDG uptake in positron emission mammography (PEM): correlation with mammographic density and background parenchymal enhancement in breast MRI. Eur J Radiol. 2013;82(10):1738-42.

\section{Procedimientos de intervención guiados por imagen}

1. Rochat CJ, Baird GL, Lourenco AP. Digital mammography stereotactic biopsy versus digital breast tomosynthesis-guided biopsy: differences in biopsy targets, pathologic results, and discordance rates. Radiology. 2020;294(3):518-27.
2. Shah AD, Mehta AK, Talati N, et al. Breast tissue markers: Why? What's out there? How do I choose? Clin Imaging. 2018;52:123-36.

3. Adepoju L, Qu W, Kazan V, et al. The evaluation of national time trends, quality of care, and factors affecting the use of minimally invasive breast biopsy and open biopsy for diagnosis of breast lesions. Am J Surg. 2014;208(3):382-90

\section{Estudio histopatológico}

1. Morrow M, van Zee KJ, Solin LJ, et al. Society of Surgical Oncology-American Society for Radiation Oncology, American Society of Clinical Oncology Consensus Guideline of margins of breast-conserving with whole breast irradiation in ductal carcinoma in situ. J Clin Oncol. 2016;34:4040-6.

2. Amin MB, Edge SB, Greene FL, et al., editores. AJCC Cancer Staging Manual. $8^{\text {th }}$ ed. New York: Springer; 2017.

3. Guidi A, Tworek J, Mais D, et al. Breast specimen processing and reporting with an emphasis on margin evaluation. Arch Pathol Lab Med. 2018;142:496-506

4. Tan $\mathrm{PH}$, Ellis IO, Allison K. The World Health Organization (WHO) Classification of Breast Tumours. $5^{\text {th }}$ Ed. World Health Organization; 2019.

5. Salgado R, Denkert C, Demaria S, et al. The evaluation of tumor infiltrating lymphocytes (TILS) in breast cancer: Recommendations by an International TILS Working Group. Ann Oncol. 2015;26:259-27.

6. Dieci MV, Radosevic-Robin N, Fineberg S, et al. Update on tumor-infiltrating lymphocytes (TILs) in breast cancer, including recommendations to assess TILs in residual disease after neoadjuvant therapy and in carcinoma in situ: a report of the International Immuno-Oncology. Semin Cancer Biol. 2018;52:16-25.

7. Yang X, Rao J, Yang W, et al. Evaluation of the predictive and prognostic values of stromal tumor-infiltrating lymphocytes in HER2-positive breast cancers treated with neoadjuvant chemotherapy. Target Oncol. 2018;13(6):757-67

8. Hendry S, Salgado R, Gevaert T, et al. A practical review for pathologists and proposal for a standardized method from the International Immuno-Oncology Biomarkers Working Group: Part 2: TILs in melanoma, gastrointestinal tract carcinomas, non-small cell lung carcinoma and mesothelioma, endometrial and ovarian carcinomas, squamous cell carcinoma of the head and neck, genitourinary carcinomas, and primary brain tumors. Adv Anat Pathol. 2017;24:311-35.

9. Pruneri G, Lazzeroni M, Bagnardi V, et al The prevalence and clinical relevance of tumor infiltrating lymphocytes (TILs) in ductal carcinoma in situ of the breast. Ann Oncol. 2017;28(2):321-8.

10. Symmans WF, Peintinger F, Hatzis $C$, et al. Measurement of residual breast cancer burden to predict survival after neoadjuvant chemotherapy. $\mathrm{J}$ Clin Oncol. 2007;25:4414-422.

11. Apple SK, Suthar F. How do we measure a residual tumor size in histopathology (the gold standard) after neoadjuvant chemotherapy? Breast. 2006;15:370-76

12. Ueng SH, Mezzeti H, Tavassoli FA. Papillary neoplasms of the breast. Arch Pathol Lab Med. 2009;133:893-907.

13. Rosen PP. Columnar cell hyperplasia is associated with lobular carcinoma in situ and tubular carcinoma. Am J Surg Pathol. 1999;23:1561.

14. Tarek MA, Abdel-Fatah, Powe AG. High frequency of coexistence of columnar cell lesions, lobular neoplasia and low grade ductal carcinoma in situ with invasive tubular carcinoma and invasive lobular carcinoma. Am J Surg Pathol. 2007;31:417-26.

15. Zhong $\mathrm{F}$, Rui $\mathrm{Bi}, \mathrm{Yu} \mathrm{B}$, et al. Carcinoma arising in microglandular adenosis of the breast: triple negative phenotype with variable morphology. Int J Clin Exp Pathol. 2014;7(9):6149-56.

16. Salarieh, Sneige N. Breast carcinoma arising in microglandular adenosis. A review of literature. Arch Pathol Lab Med. 2007:131:1397-99.

17. Lester SC, Bose S, Chen $Y-Y$, et al. Protocol for the examination of specimens from patients with ductal carcinoma in situ of the breast. Arch Pathol Lab Med. 2009;133(1):15-25

18. Dadmanesh F, Fan X, Dastane A, et al. Comparative analysis of size estimation by mapping and counting number of blocks with ductal carcinoma in situ in breast excision specimens. Arch Pathol Lab Med. 2009;133:26-30

19. Motomura K, Nagumo S, Komoike Y, et al. Intraoperative imprint cytology for the diagnosis of sentinel node metastases in breast cancer. Breast Cancer. 2007;14:350-3.

20. Pérez-Sánchez VM, Vela-Chávez TA, Villarreal-Colin P, et al Intraoperative touch imprint cytology of sentinel lymph nodes in breast cancer: experience at a tertiary care center in Mexico. Med Oncol. 2010;27:233-6.

21. Cserni G. Pathological evaluation of sentinel lymph nodes. Surg Oncol Clin N Am. 2007;16:17-34.

22. Reintgen $M$, Kerivan $L$, Reintgen $E$, et al. Breast lymphatic mapping and sentinel lymph node biopsy. Clin Breast Cancer. 2016;16:155-65.

23. Allison K, Hammond ME, Hayes DF, et al. Estrogen and Progesterone Receptor Testing in Breast Cancer: American Society of Clinical Oncology/College of American Pathologists Guideline Update. Arch Pathol Lab Med. 2020;144:545-63. 
24. Seol H, Lee HJ, Choi $Y$, et al. Intratumoral heterogeneity of HER2 gene amplification in breast cancer: its clinicopathological significance. Mod Path. 2012;25:938-48.

25. Gown AM. Current issues in ER and HER2 testing by $I H C$ in breast cancer. Mod Pathol. 2008;21:S8-S15.

26. Kos S, Dabbs DJ. Biomarker assessment and molecular testing for prognostication in breast cancer. Histopathology. 2016;68:70-85.

27. Wolff AC, Hammond EH, Hicks DG, et al. Recommendations for human epidermal growth factor receptor 2 testing in breast cancer: American Society of Clinical Oncology/College of American Pathologists. Clinica Practice Guideline Update. Arch Pathol Lab Med. 2014;138:241-56.

28. Wolff AC, Hammond EH, Allison K, et al. Human epidermal growth factor receptor 2 testing in breast cancer: American Society of Clinical Oncology/College of American Pathologists Clinical Practice Guideline Focused Update. Arch Pathol Lab Med. 2018;142:1364-82.

29. Dowsett M, Nielsen T. Assessment of Ki67 in breast cancer: Recommendations from the International Ki67 in Breast Cancer Working Group. J Natl Cancer Inst. 2011;103:1656-64.

30. Penault-Llorca F, Radosevic-Robin N. Ki67 assessment in breast cancer: an update. Pathology. 2017;49(2):166-71

31. Jang $\mathrm{MH}$, Kim HJ, Chung YR, et al. A comparison of Ki 67 counting methods in luminal breast cancer: The average method vs. The hot spot method. PLoS One. 2017;12(2):e0172031.

32. Brown R. Quality management in immunohistochemistry. En: Nakhleh RE, Fitzgibbons PL, College of American Pathologists, editores. Quality management in anatomic pathology: promoting patient safety through systems improvement and error reduction. Northfield, III.: College of American Pathologists; 2005. pp. 93-110.

33. Arnould L, Roger P, Mac Grogan G, et al. Accuracy of Her2 status determination on breast core-needle biopsies (immunohistochemistry, FI$\mathrm{SH}, \mathrm{CISH}$ and SISH vs FISH). Mod Pathol. 2012;25:675-82.

34. Perou CM, Sorlie T, Eisen MB, et al. Molecular portraits of human breast tumors. Nature. 2000;406:747-52.

35. Rakha EA, El-Sayed ME, Reis-Filho JS, et al. Expression profiling technology: its contribution to our understanding of breast cancer. Histopathology. 2008; $52: 67-81$

36. Marchio C, Reis-Filho JS. Molecular diagnosis in breast cancer. Diag Histopathol. 2008;14:202-13

37. Geyer FC, Marchio C, Reiss-Filho JS. The role of molecular analysis in breast cancer. Pathology. 2009;41:77-88.

38. Barghava R, Striebel J, Beriwal S, et al. Prevalence, morphologic features and proliferation index of breast carcinoma molecular classes using inmunohistochemical surrogate markers. Int $\mathrm{J}$ Clin Exp Pathol. 2009;2:444-55

39. Lara-Medina F, Pérez-Sánchez V, Saavedra-Pérez D, et al. Triple-negative breast cancer in Hispanic patients. High prevalence, poor prognosis, and association with menopausal status, body mas index and parity. Cancer. 2011;117:3658-69.

40. Robles-Castillo J, Ruvalcaba-Limón E, Maffuz-Aziz A, et al. Cáncer de mama en mujeres mexicanas menores de 40 años. Ginecol Obstet Mex. 2011;79(8):482-8

41. Goldhirsch A, Winer EP, Coates AS, et al. Personalizing the treatment of women with early breast cancer: highlights of the St Gallen International Expert Consensus of the primary therapy of early breast cancer 2013. Ann Oncol. 2013;24(9):2206-23.

42. Coates AS, Winer EP, Goldhirsch A, et al. Tailoring therapies-improving the management of early breast cancer: highlights of the St Gallen International Expert Consensus of the primary therapy of early breast cance 2015. Ann Oncol. 2015;26(8):1533-46.

43. Senkus E, Kyriades S. Primary breast cancer: ESMO Clinical Practice Guidelines for diagnosis, treatment and follow up. Ann Oncol. 2015;26(supp5):8-30.

44. Bertucci F, Finetti $P$, Cervera N, et al. How basal are triple negative breast cancers? Int J Cancer. 2008;123:36-40.

45. Nielsen TO, Hse FD, Jensen K, et al. Inmunohistochemical and clinical characterization of the basal-like subtype of invasive breast carcinoma. Clin Can Res. 2004;10:5367-74.

46. Perou CM. Molecular stratification of triple-negative breast cancers. Oncologist. 2011;16(suppl 1):61-70.

47. Lehmann BD, Bauer JA, Chen $X$, et al. Identification of human triple-negative breast cancer subtypes and preclinical models for selection of targeted therapies. J Clin Invest. 2011;121:2750-67.

48. Weigelt B, Geyer FC, Reis-Filho JS. Histological types of breast cancer: How special are they? Mol Oncol. 2010;4:192-208.

49. Cadoo KA, McArdle O, O'Shea A-M, et al. Management of unusual histological types of breast cancer. Oncologist. 2012;17:1135-45.

50. Christgen M, Steinemann D, Kühnle $E$, et al. Lobular breast cancer: Clinical, molecular and morphological characteristics. Pathol Res Pract. 2016;212(7):583-97.

51. Lyapichev K, Piña-Oviedo S, Medeiros LJ, et al. A proposal for pathologic processing of breast implant capsules in patients with suspected breast implant anaplastic large cell lymphoma. Mod Pathol. 2020; 33(3):367-79
52. Jaffe E, Ashar B, Clemens MW, et al. Best practices for the pathologic diagnosis of breast implant-associated anaplastic large-cell lymphoma. J Clin Oncol. 2020;38(10):1102-11.

\section{Estadificación del cáncer de mama TNM}

1. AJCC cancer staging manual. 8th Edition. Springer; 2018.

2. Giuliano A, Connolly JL, Edge SB, et al. Breast cancer-major changes in the American Joint Committee on Cancer eighth edition cancer staging manual. CA Cancer J Clin. 2017;67(4):290-303.

\section{Carcinoma lobulillar in situ}

1. Morrow M, van Zee KJ, Solin LJ, et al. Society of Surgical Oncology-American Society for Radiation Oncology-American Society of Clinical Oncology Consensus Guideline on Margins for Breast-Conserving Surgery with Whole Breast Irradiation in Ductal Carcinoma In situ. Ann Surg Oncol. 2016:23(12):3801-10.

2. Skandarajah AR, Mann B. Selective use whole breast radiotherapy after breast conserving surgery for invasive breast cancer and DCIS. Surgeon. 2013;11(5):278-85.

3. Cutuli B, Bernier J, Poortmans P. Radiotherapy in DCIS, an underestimated benefit? Radiother Oncol. 2014;112:1-8.

4. Allred D, Bryant J, Land S, et al. Estrogen receptor expression as a predictive marker of the effectiveness of tamoxifen in the treatment of DCIS: findings from NSABP protocol B-24. Breast Cancer Res Treat. 2002;76(suppl 1):S36[A30].

5. Olivotto I, Link E, Phillips $C$, et al. International comparison of cosmetic outcomes of breast conserving surgery and radiation therapy for women with ductal carcinoma in situ of the breast. Radiother Oncol. 2020;142:180-5.

6. Offersen B, Alsner J, Nielsen $\mathrm{H}$, et al. Hypofractionated versus standard fractionated radiotherapy in patients with early breast cancer or ductal carcinoma in situ in a randomized phase III trial: The DBCG HYPO Trial. J Clin Oncol. 2020;38(31):3615-25.

7. Whelan T, Julian J, Berrang S, et al. External beam accelerated partial breast irradiation versus whole breast irradiation after breast conserving surgery in women with ductal carcinoma in situ and node-negative breast cancer (RAPID): a randomised controlled trial. Lancet. 2019;394(10215):2165-72.

8. King $M$, Link $E$, Whelan $T$, et al. Quality of life after breast-conserving therapy and adjuvant radiotherapy for non-low-risk ductal carcinoma in situ (BIG 3-07/TROG 07.01): 2-year results of a randomised, controlled, phase 3 trial. Lancet Oncol. 2020;21(5):685-98.

9. Goldberg M, Whelan TJ. Accelerated Partial Breast Irradiation (APBI): Where are we now? Curr Breast Cancer Rep. 2020 Oct 18:1-10. doi: 10.1007/s12609-020-00384-x. Online ahead of print.

10. Cambra M, Moreno F, Sanz X, et al. Role of boost radiotherapy for local control of pure ductal carcinoma in situ after breast-conserving surgery: a multicenter, retrospective study of 622 patients. Clin Transl Oncol, 2020;22(5):670-80.

11. Doke K, Butler S, Mitchell MP. Current therapeutic approaches to DCIS. J Mammary Gland Biol Neoplasia. 2018;23(4):279-91.

12. Goodwin A, Parker S, Ghersi D. Postoperative radiotherapy for ductal carcinoma in situ of the breast. A systematic review on the randomized trials. Breast. 2009;18:143-9.

13. McCormick B. Is it time to personalize local treatment options for women with "good risk" DCIS? Breast J. 2018;3:231-2.

14. Hong YK, McMasters KM, Egger ME, et al. Ductal carcinoma in situ, current trends, controversies and review of the literature. Am J Surg. 2018:216:998-1003.

15. NCCN Clinical Practice Guidelines in Oncology (NCCN Guidelines) Breast Cancer Risk Reduction. Version 1.2021- March 24, 2021.

\section{Manejo del cáncer de mama temprano}

\section{Manejo quirúrgico primario en cáncer de mama}

1. Veronesi U. Comparing radical mastectomy with quadrantectomy, axillary dissection, and radiotherapy in patients with small cancers of the breast. N Engl J Med. 1981;2:305(1):6-11.

2. Veronesi U. Conservative treatment of early breast cancer. Long-term results of 1232 cases treated with quadrantectomy, axillary dissection, and radiotherapy. Ann Surg. 1990;211(3):250-9.

3. Clarke M, Collins R, Darby S, et al. Effects of radiotherapy and of differences in the extent of surgery for early breast cancer on local recurrence and 15-year survival: an overview of the randomized trials. Lancet. 2005;366(9503):2087-106

4. Anderson SJ, Wapnir I, Dignam JJ, et al. Prognosis after ipsilateral breast tumor recurrence and locoregional recurrences in patients treated by breast-conserving therapy in five National Surgical Adjuvant Breast and Bowel Project protocols of node-negative breast cancer. J Clin Oncol. 2009;27(15):2466-73. 
5. Houssami N, Macaskill $P$, Marinovich ML, et al. Meta-analysis of the impact of surgical margins on local recurrence in women with early-stage invasive breast cancer treated with breast-conserving therapy. Eur $J$ Cancer. 2010:46(18):3219-32.

6. Rosenkranz KM, Ballman K, McCall L, et al. Cosmetic outcomes following breast conservation surgery and radiation for multiple ipsilateral breas cancer: Data from the Alliance Z11102 Study. Ann Surg Oncol. 2020;27:4650-61.

7. Heeg $E$, Jensen MB, Hölmich LR, et.al. Rates of re-excision and conversion to mastectomy after breast-conserving surgery with or without oncoplastic surgery: a nationwide population-based study. $\mathrm{Br} J$ Surg 2020;107(13):1762-72.

8. Halsted WS. The results of operations for the cure of cancer of the breast performed at the Johns Hopkins Hospital from June, 1889, to January, 1894. Ann Surg. 1894;20(5):497-555.

9. Fisher B, Montague E, Redmond C, et al. Findings from NSABP Protocol No. B-04-comparison of radical mastectomy with alternative treatments for primary breast cancer. I. Radiation compliance and its relation to treatment outcome. Cancer. 1980;46(1):1-13.

10. Chiesa F, Sacchini VS. Risk-reducing mastectomy. Minerva Ginecol. 2016;68(5):544-7.

11. Gonzalez EG, Rancati AO. Skin-sparing mastectomy. Gland Surg. 2015;4(6):541-53.

12. Clough KB, Kaufman GJ, Nos C, et al. Improving breast cancer surgery: A classification and quadrant per quadrant atlas for oncoplastic surgery. Ann Surg Oncol. 2010;17:1375-91.

13. Giacalone PL, Roger P, Dubon O, et al. Comparative study of the accuracy of breast reconstruction in oncoplastic surgery and quadrantectomy in breast cancer. Ann Surg Oncol. 2007;14(2):605-14.

14. Rietjens M, Urban CA, Petit JY, et al. Long-term oncologic results of breast conservative treatment with oncoplastic surgery. Breast. 2007;16(4):387-95.

15. Acea B. Técnicas oncoplásticas en el tratamiento quirúrgico del cáncer de mama. 2. a edición. Elsevier Masson; 2009.

16. Staub G, Fitoussi A, Falcou MC, et al. Breast cancer surgery: use of mammoplasty. Results. Series of 298 cases. Ann Chir Plast Esthet. 2007;53(2):124-34.

17. Sherwell-Cabello S, Maffuz-Aziz A, Villegas-Carlos F, et. al. Factibilidad y resultado estético de la cirugía oncoplasica en el tratamiento de cáncer de mama. Cir Cir. 2015;83(3):199-205.

18. Andree C, Farhadi J, Goosens D, et al. A position statement on optimizing the role of oncoplastic breast surgery. Eplasty. 2012:12:e40.

19. Eaton BR, Losken A, Okwan-Duodu D, et al. Local recurrence patterns in breast cancer patients treated with oncoplastic reduction mammoplasty and radiotherapy. Ann Surg Oncol. 2014;21:93-9.

20. Pezner RD, Tan MC, Clancy SL, et al. Radiation therapy for breast cancer patients who undergo oncoplastic surgery. Am J Clin Oncol. 2013;36:535-9

21. Shah C, Al Hilli Z, Schwarz G. Oncoplastic surgery in breast cancer. Don't forget the boost. An Surg Oncol. 2018;25:2509-11.

22. Kim T, Giuliano AE, Lyam GH. Lymphatic mapping and sentinel lymph node biopsy in early stage breast carcinoma: a meta-analysis. Cancer. 2006;106:4-16.

23. Mansel RE, Fallowfield L, Kissin M, et al. Randomized multicenter tria of sentinel node biopsy versus standard axillary treatment in operable breast cancer: the ALMANAC trial. J Natl Cancer Inst. 2006:98:599-609.

24. Veronesi U, Viale G, Paganelli G, et al. Sentinel lymph node biopsy in breast cancer: ten-year results of a randomized controlled study. Ann Surg. 2010;251(4):595-600.

25. Krag DN, Anderson SJ, Julian TB, et al. Sentinel-lymph node resection compared with convencional axillary-lymph node dissection in clinically node-negative patients with breast cancer: overall survival findings from the NSABP B-32 randomised phase 3 trial. Lancet Oncol. 2010;11:927-33.

26. Giuliano AE, Hunt KK, Ballman KV, et al. Axillary dissection vs no axillary dissection in women with invasive breast cancer and sentinel node metastases: a randomized clinical trial. JAMA. 2011;305:569-75.

27. Giuliano $A E, M c C a l l ~ L$, Beitsch $P$, et al. Locoregional recurrence after sentinel lymph node dissection with or without axillary dissection in patients with sentinel lymph node metastases: The American College of Surgeons Oncology Group Z0011 randomized trial. Ann Surg. 2010;252:426-33

28. Weaver DL, Ashikaga T, Krag DN, et al. Effect of occult metastases on survival in node-negative breast cancer. N Engl J Med. 2011;364(5):412-21.

29. Cox CE. Lymphatic mapping in breast cancer: combination technique. Ann Surg Oncol. 2001;8:67S-70S.

30. Galimberti V, Cole BF, Zurrida S, et al.; International Breast Cancer Study Group Trial 23-01 investigators. Axillary dissection versus no axillary dissection in patients with sentinel-node micometastases (IBCSG 23-01): a phase 3 randomized controlled trial. Lancet Oncol. 2013;14(4):297-305.

31. Donker M, van Tienhoven G, Straver M, et.al. Radiotherapy or surgery of the axilla after a positive sentinel node in breast cancer (EORTC 10981-22023 AMAROS):a randomized, multicentre, open-label, phase 3 non-inferiority trial. Lancet Oncol. 2014;15:1303-10.
32. Boughey JC, Suman VJ, Mitterndorf EA, et al. Sentinel lymph node surgery after neoadjuvant chemotherapy in patients with node-positive breast cancer: the ACOZOG Z1071 (Alliance), clinical Trial. JAMA. 2013;310(14):1455-61.

33. Kuehn T, Bauerfeind I, Fehm T, el al. Sentinel-lymph-node biopsy in patients with breast cancer before and after neoadjuvant chemotherapy (SENTINA): a prosprective, multicenter cohort study. Lancet Oncol. 2013;14(7):609-18.

34. Kronowitz SJ, Kuerer HM, Buchholz TA, et al. A management algorithm and practical oncoplastic surgical techniques for repairing partial mastectomy defects. Plast Reconstr Surg. 2008;122:1631-47.

35. Losken A, Hamdi M. Partial breast reconstruction: Current perspectives. Plast Reconstr Surg. 2009;124:722-36.

36. Spear SL, Rottman SJ, Seiboth LA, et al. Breast reconstruction using a staged niple sparing mastectomy following mastopexy or reduction. Plast Reconstr Surg. 2012;129:572-81.

37. Losken A, Styblo TM, Carlson GW, et al. Management algorithm and outcome evaluation of partial mastectomy defects treated using reduction or mastopexy techniques. Ann Plast Surg. 2007;59:235-42.

38. Akay CL, Meric-Bernstam F, Hunt KK, et al. Evaluation of the MD Anderson Prognostic Index for local- regional recurrence after breast conserving therapy in patients receiving neoadjuvant chemotherapy. Ann Surg Oncol. 2012;19:901-7.

39. Kronowitz SJ. Delayed-immediate breast reconstruction: Technical and timing considerations. Plast Reconstr Surg. 2010;125:463-74.

40. Khouri RK, Eisenmann-Klein M, Cardoso E, et al. Brava $\AA$ and autologous fat transfer is a safe and effective breast augmentation alternative: Results of a 6-year, 81-patient, prospective multicenter study. Plast Reconstr Surg. 2012;129:1173-87.

41. de Alcantara Filho P, Capko D, Barry JM, et al. Sacchini vs. Nipple-sparing mastectomy for breast cancer and risk-reducing surgery: The Memorial Sloan- Kettering Cancer Center experience. Ann Surg Oncol. 2011;18:3117-22.

42. Kronowitz SJ. Redesigned gluteal artery perforator flap for breast reconstruction. Plast Reconstr Surg. 2008;121:728-34.

43. Parra L, Marcelli S. Immediate breast reconstruction with abdominal free flap and adjuvant radiotherapy: Evaluation of quality of life and outcomes. Plast Reconstr Surg. 2017;140:681.

44. Ho AY, Hu ZI, Mehrara BJ, et al. Radiotherapy in the setting of breast reconstruction: types, techniques and timing. Lancet Oncol. 2017:18:e742-e753.

45. Hanson S, Kapur S, Garvey PB, et al. Oncologic safety and surveillance of autologous fat grafting following breast conservation therapy. Plast Reconstr Surg. 2020;146(2):215-25.

46. Shumway DA, Momoh AO, Sabel MS, et al. Integration of breast reconstruction and postmastectomy radiotherapy. J Clin Oncol. 2020;38(20):2329-40.

47. Kaidar-Person O, Vrou Offersen B, Hol S. ESTRO ACROP consensus guideline for target volume delineation in the setting of postmastectomy radiation therapy after implant-based immediate reconstruction for early stage breast cancer. Radiother Oncol. 2019;137:159-66.

48. Naoum GE, Salama L, Niemierko A, et al. Single stage direct-to-implant breast reconstruction has lower complication rates than tissue expander and implant and comparable rates to autologous reconstruction in patients receiving postmastectomy radiation. Int J Radiat Oncol Biol Phys. 2020;106(3):514-24.

49. Daly MB, Pal T, Berry MP, et al. Genetic/familial high-risk assessment: Breast and ovarian, 2.2019, NCCN Clinical Practice Guidelines in Oncology. J Natl Compr Canc Netw. 2021;19(1):77-102.

50. NCCN Clinical Practice Guidelines in Oncology (NCCN Guidelines) Breast Cancer Risk Reduction. Version 1.2021- March 24, 2021.

51. Meiser B, Butow $\mathrm{P}$, Friedlander $\mathrm{M}$, et al. Intention to undergo prophylactic bilateral mastectomy in women at increased risk of developing hereditary breast cancer. J Clin Oncol 2000;18(11):2250-7.

52. The Breast Cancer Risk Assesment Tool. https://bcrisktool.cancer.gov/

53. KK. Hunt, Euhus DM, Boughey JC, et al. SSO Breast Disease Working Group Statement on Prophylactic. Ann Surg Oncol. 2017;24:375-97.

54. Meijers-Heijboer $H$, van Geel B, van Putten WL, et al. Breast cancer after prophylactic bilateral mastectomy in women with a BRCA1 or BRCA2 mutation. N Engl J Med. 2001;345(3):159-64.

55. Lostumbo L, Carbine NE, Wallace J. Prophylactic mastectomy for the prevention of breast cancer. Cochrane Database Syst Rev. 2010;(11):CD002748.

56. Ramaswami R. Contralateral prophylactic mastectomy. N Engl J Med. 2017;377:13.

57. ESMO Clinical Practice Guidelines: Breast Cancer Guidelines [Internet]. European Society for Medical Oncology. Disponible en: https://www. esmo.org/guidelines/breast-cancer

58. Amor Pan JR, Barón Duarte FJ, Regueiro García A, et al. Bioética y oncología. Una puerta abierta a la oportunidad. 2. ${ }^{a}$ edición. Sociedad Oncológica de Galicia; 2017.

59. Carbine NE, Lostumbo L, Wallace J, et al. Risk-reducing mastectomy for the prevention of primary breast cancer. Cochrane Database Syst Rev. 2018:4: CD002748.

60. Franceschini G, Di Leone A, Terribile D, et al. Bilateral prophylactic mastectomy in BRCA mutation carriers: what surgeons need to know. Ann Ital Chir. 2019;90:1-2. 
61. Srethbhakdi A, Brennan ME, Hamid G, et al. Contralateral prophylactic mastectomy for unilateral breast cancer in women at average risk: Systematic review of patient reported outcomes. Psychooncology. 2020;29(6):960-73.

62. Lopez CD, Bluebond-Langner R, Houssock CA, et al. Plastic and reconstructive surgeons' knowledge and comfort of contralateral prophylactic mastectomy: A survey of the American Society of Plastic Surgeons. Front Oncol. 2019;8:647.

63. Nagaraja V, Edirimanne S, Eslick GD. Is sentinel lymph node biopsy necessary in patients undergoing prophylactic mastectomy? A systematic review and meta-analysis. Breast J. 2016;22(2):158-65.

\section{Tratamiento sistémico adyuvante}

1. Early Breast Cancer Trialists' Collaborative Group (EBCTCG). Effects of chemotherapy and hormonal therapy for early breast cancer on recurrence and 15-year survival: an overview of the randomized trials. Lancet. 2005;365:1687-717.

2. Early Breast Cancer Trialists' Collaborative Group (EBCTCG), Peto R Davies $\mathrm{C}$, et al. Comparisons between different polychemotherapy regimens for early breast cancer: meta-analyses of long-term outcome among 100,000 women in 123 randomized trials. Lancet. 2012;379:432-44.

3. Gradishar WJ, Anderson BO, Balassanian R, Blair SL, Burstein HJ, Cyr A, et al. Breast Cancer, Version 4.2017, NCCN Clinical Practice Guidelines in Oncology. J Natl Compr Canc Netw. 2018 Mar;16(3):310-320.

4. Aebi S, Davidson T, Gruber G, et al. Primary breast cancer: ESMO clinical practice guidelines for diagnosis, treatment and follow-up. Ann Oncol. 2011;22(suppl 6):vi12-24.

5. Goldhirsch A, Wood WC, Coates AS, et al. Strategies for subtypes-dealing with the diversity of breast cancer: highlights of the St. Gallen International Expert Consensus on the Primary Therapy of Early Breast Cancer 2011. Ann Oncol. 2011;22:1736-47.

6. Sparano J, Gray R, Della F, et al. Adjuvant chemotherapy guided by a 21 gene expression assay in breast cancer. N Engl J Med. 2018; 379(2):111-21.

7. Chavez-MacGregor M, Clarke CA, Lichtensztajn DY, et al. Delayed initiation of adjuvant chemotherapy among patients with breast cancer. JAMA Oncol. 2016;2(3):322-9

8. Morante Z, Ruiz R, Araujo JM, et al. Impact of the delayed initiation of adjuvant chemotherapy in the outcomes of triple negative breast cancer. Clin Breast Cancer. 2021;21(3):239-46.e4.

9. Ferguson $T$, Wilcken $N$, Vagg $R$, et al. Taxanes for adjuvant treatment of early breast cancer. Cochrane Database Syst Rev. 2007;4:CD004421.

10. De Laurentiis M, Cancello G, D'Agostino D, et al. Taxane-based combinations as adjuvant chemotherapy of early breast cancer: a meta-analysis of randomized trials. J Clin Oncol. 2008;26:44-53.

11. Sparano JA, Zhao F, Martino S, et al. Long-term follow-up of the E1199 phase III trial evaluating the role of taxane and schedule in operable breast cancer. J Clin Oncol. 2015;33(21):2353-60.

12. Sparano JA, Wang M, Martino S, et al. Weekly paclitaxel in the adjuvant treatment of breast cancer. N Engl J Med. 2008;358:1663-71.

13. von Minckwitz G, Raab G, Caputo A, et al. Doxorubicin with cyclophosphamide followed by docetaxel every 21 days compared with doxorubicin and docetaxel every 14 days as preoperative treatment in operable breast cancer: the GEPARDUO study of the German Breast Group. J Clin Oncol. 2005;23(12):2676-85

14. Martin M, Pienkowski T, Mackey J, et al. Adjuvant docetaxel for node-positive breast cancer. N Engl J Med. 2005;352:2302-13.

15. Jones S, Holmes FA, O'Shaughnessy J, et al. Docetaxel with cyclophosphamide is associated with an overall survival benefit compared with doxorubicin and cyclophosphamide: 7-year follow-up of US Oncology Research Trial 9735. J Clin Oncol. 2009;27:1177-83.

16. Citron ML, Berry DA, Cirrincione $C$, et al. Randomized trial of dose-dense versus conventionally scheduled and sequential versus concurrent combination chemotherapy as postoperative adjuvant treatment of node-positive primary breast cancer: first report of Intergroup Trial C9741/ Cancer and Leukemia Group B Trial 9741. J Clin Oncol. 2003;21:1431-9.

17. Martin M, Rodriguez-Lescure A, Ruiz A, et al. Randomized phase 3 tria of fluorouracil, epirubicin, and cyclophosphamide alone or followed by paclitaxel for early breast cancer. J Natl Cancer Inst. 2008;100:805-14

18. Roche H, Fumoleau $P$, Spielmann $M$, et al. Sequential adjuvant epirubicin-based and docetaxel chemotherapy for node-positive breast cancer patients: the FNCLCC PACS 01 Trial. J Clin Oncol. 2006;24:5664-71.

19. Masuda N, Lee SJ, Ohtani S, et al. Adjuvant capecitabine for breast cancer after preoperative chemotherapy. N Engl J Med. 2017;376:2147-59.

20. Early Breast Cancer Trialists' Collaborative Group. Relevance of breast cancer hormone receptors and other factors to the efficacy of adjuvant tamoxifen: patient level meta-analysis of randomised trials. Lancet. 2011;378:771-84

21. Metzger Filho O, Giobbie-Hurder A, Mallon E, et al. Relative effectiveness of letrozole compared with tamoxifen for patients with lobular carcinoma in the BIG 1-98 trial. J Clin Oncol. 2015;33:2772-9.
22. Cuzick J, Sestak I, Pinder SE, et al. Effect of tamoxifen and radiotherapy in women with locally excised ductal carcinoma in situ: long-term results from the UK/ANZ DCIS trial. Lancet Oncol. 2011;12:21-9.

23. Masuda N, Lee S-J, Ohtani S, et al. Adjuvant capecitabine for breast cancer after preoperative chemotherapy. Engl J Med. 2017;376:2147-59.

24. Wapnir IL, Dignam JJ, Fisher B, et al. Long term-outcomes of invasive ipsilateral breast tumor recurrences after lumpectomy in NSABP B-27 and B-24 randomized clinical trials for DCIS. J Natl Cancer Inst. 2011;103:478-88.

25. Fisher B, Costantino JP, Wickerham DL, et al. Tamoxifen for the prevention of breast cancer: current status of the National Surgical Adjuvant Breast and Bowel Project P-1 study. J Natl Cancer Inst. 2005;97:1652-62.

26. Margolese RG, et al. Anastrazole versus tamoxifen in postmenopausal women in ductal carcinoma in situ undergoing lumpectomy plus radiotherapy (NSAB B-35): a randomised, double-blind, phase 3 clinical trial. Lancet. 2016;387:845

27. Forbes JF, Sestak I, Howell A, et al. IBIS-II investigators. Anastrazole versus tamoxifen for the prevention of locoregional and contralateral breast cancer in postmenopausal women with locally excised ductal carcinoma in situ (IBIS-II DCIS): a double-blind, randomised controlled trial. Lancet. 2016;387(10021):866-73.

28. Francis PA, Pagani O, Fleming GF, et al. Tailoring adjuvant endocrine therapy for premenopausal breast cancer. N Engl J Med. 2018;379:122-37.

29. Pagani O, Francis PA, Fleming GF, et al. Absolute improvement in freedom from distant recurrence to tailor adjuvant endocrine therapies for premenopausal women: results from TEXT and SOFT. J Clin Oncol. 2020;38:1293-303.

30. Burstein HJ. Systemic therapy for estrogen receptor-positive, HER2-negative breast. Cancer N Engl J Med. 2020;383(26):2557-70.

31. Burstein $\mathrm{HJ}$, Lacchetti $\mathrm{C}$, Anderson $\mathrm{H}$, et al. Adjuvant endocrine therapy for women with hormone receptor-positive breast cancer: ASCO Clinical Practice Guideline Focused Update. J Clin Oncol. 2019;37(5):423-38.

32. Davies C, Pan H, Godwin J, et al.; Adjuvant tamoxifen: Longer Against Shorter (ATLAS) Collaborative Group. Long-term effects of continuing adjuvant tamoxifen to 10 years versus stopping at 5 years after diagnosis of oestrogen receptor-positive breast cancer: ATLAS, a randomised trial. Lancet. 2013;381(9869):805-16. Erratum in: Lancet. 2013;381(9869):804

33. Bartlett JMS, Sgroi DC, Treuner K, et al. Breast Cancer Index and prediction of benefit from extended endocrine therapy in breast cancer patients treated in the Adjuvant Tamoxifen-To offer more? (aTTom) trial. Ann Oncol. 2019;30(11):1776-83.

34. Goss PE, Ingle JN, Pritchard $\mathrm{KI}$, et al. Extending aromatase-inhibitor adjuvant therapy to 10 years. N Engl J Med. 2016;375:209-19.

35. Blok EJ, Kroep JR, Meershoek-Klein Kranenbarg E, et al. Optimal duration of extended adjuvant endocrine therapy for early breast cancer: Results of the IDEAL trial (BOOG 2006 05). J Natl Cancer Inst. 2018;110(1).

36. Tjan-Heijnen VCG, van Hellemond IEG, Peer PGM, et al. Extended adjuvant aromatase inhibition after sequential endocrine therapy (DATA): A randomised, phase 3 trial. Lancet Oncol. 2017;18:1502-11.

37. Colleoni M, Luo W, Karlsson P, et al. Extended adjuvant intermittent letrozole versus continuous letrozole in postmenopausal women with breast cancer (SOLE): A multicentre, open-label, randomised, phase 3 trial. Lancet Oncol. 2018;19:127-38

38. Mamounas $\mathrm{E}$, Bandos $\mathrm{H}$, Lembersky $\mathrm{B}$, et al A randomized, double-blinded, placebo-controlled clinical trial of extended adjuvant endocrine therapy $(\mathrm{tx})$ with letrozole $(\mathrm{L})$ in postmenopausal women with hormone-receptor $(+)$ breast cancer $(\mathrm{BC})$ who have completed previous adjuvant tx with an aromatase inhibitor (Al): Results from NRG Oncology/NSABP B-42. Cancer Res. 2017;77(4 Suppl):abstr S1-05.

39. Gnant MSG, Greil R, et al. A prospective randomized multi-center phase-III trial of additional 2 versus additional 5 years of anastrozole after initial 5 years of adjuvant endocrine therapy: Results from 3,484 postmenopausal women in the ABCSG 16 trial. Cancer Res. 2018;78(4 Suppl):abstr GS3-01.

40. NCCN Clinical Practice Guidelines in Oncology (NCCN Guidelines) Breast Cancer. Version 5.2021- June 28, 2021.

41. Zardavas D, Tryfonidis K, Goulioti T M, et al. Targeted adjuvant therapy in breast cancer. Exp Rev Anticancer Ther. 2016:16(12):1263-75.

42. Dahabreh IJ, Linardou $H$, Siannis $F$, et al. Trastuzumab in the adjuvant treatment of early-stage breast cancer: a systematic review and meta-analysis of randomized controlled trials. Oncologist. 2008;13:620-30.

43. Gianni L, Dafni U, Gelber RD, et al. Treatment with trastuzumab for 1 year after adjuvant chemotherapy in patients with HER2-positive early breast cancer: a 4-year follow-up of a randomized controlled trial. Lancet Oncol. 2011;12:236-44.

44. Pérez EA, Romond E, Suman VJ, et al. Trastuzumab plus adjuvant chemotherapy for human epidermal growth factor receptor 2-positive breast cancer: planned joint analysis of overall survival (OS) from NSABP B-31 and NCCTG N9831. J Clin Oncol. 2014;32(33):3744-52.

45. Lambertini M, Pondé NF, Solinas C, et al. Adjuvant trastuzumab: a 10year overview of itsbenefit. Exp Rev Anticancer Ther. 2017;17(1):61-74. 
46. Slamon DJ, Eiermann W, Robert NJ, et al. Ten year follow-up of the BCIRG-006 trial comparing doxorubicin plus cyclophosphamide followed by docetaxel (ACT) with doxorubicin plus cyclophosphamide followed by docetaxel and trastuzumab (ACTH) with docetaxel, carboplatin and trastuzumab (TCH) in HER2+ early breast cancer patients. Cancer Res. 2018;76(4 Suppl):abstr S5-04.

47. Perez EA, Suman VJ, Davidson NE, et al. Sequential versus concurrent trastuzumab in adjuvant chemotherapy for breast cancer. J Clin Oncol. 2011;29:4491-7.

48. Jackisch C, Piccart MJ, Gelber RD, et al. HERA trial: 10 years follow up of trastuzumab after adjuvant chemotherapy in HER2 positive early breast cancer - Final analysis. Cancer Res. 2016;76(4 Suppl):abstr PD5-01.

49. Pivot X, Romieu G, Debled M, et al. 6 months versus 12 months of adjuvant trastuzumab for patients with HER2-positive early breast cance (PHARE): a randomized phase 3 trial. Lancet Oncol. 2013;14(8):741-8.

50. Tolaney SM, Barry WT, Dang CT, et al. Adjuvant paclitaxel and trastuzumab for nodenegative, HER2-positive breast cancer. N Engl J Med. 2015;372(2):134-41.

51. von Minckwitz G, Procter M, de Azambuja E, et al. Adjuvant pertuzumab and trastuzumab in early HER2-positive breast cancer. N Engl J Med. 2017:377(2):122-31.

52. Piccart M, Procter M, Fumagalli D, et al. Interim overall survival analysis of APHINITY (BIG 4-11): A randomized multicenter, double-blind, placebo-controlled trial comparing chemotherapy plus trastuzumab plus pertuzumab versus chemotherapy plus trastuzumab plus placebo as adjuvant therapy in patients with operable HER2-positive early breast cancer. Cancer Res. 2020;80(4 Suppl):abstr GS1-04.

53. Angelucci A, Alesse E. Molecular pathology of cancer. Metastasis: Suggestions for future therapy. En: Bologna M, editor. Biotargets of cancer in current clinical practice. Springer; 2012. pp.469-515.

54. Kremer R, Gagnon B, Meguerditchian AN, et al. Effect of oral bisphosphonates for osteoporosis on development of skeletal metastases in women with breast cancer: results from a pharmaco-epidemiological study. J Natl Cancer Inst. 2014;106(11).

55. Hadji P, Aapro MS, Body JJ, et al. Management of aromatase inhibitor-associated bone loss in postmenopausal women with breast cancer: practical guidance for prevention and treatment. Ann Oncol. 2011;22(12):2546-55

56. Gnant M, Pfeiler G, Dubsky PC, et al. Adjuvant denosumab in breast cancer (ABCSG-18): a multicentre, randomized, double-blind, placebo-controlled trial. Lancet. 2015;386:433-43.

57. Coleman R, Body JJ, Aapro M, et al. Bone health in cancer: ESMO Clinical Practice Guidelines. Ann Oncol. 2014;25(Suppl 3):iii124-37.

58. Hadji P, Coleman RE, Wilson C, et al. Adjuvant bisphosphonates in early breast cancer: consensus guidance for clinical practice from a European Panel. Ann Oncol. 2016:27(3):379-90.

59. Cummings S. Denosumab for prevention of fractures in postmenopausa women with osteoporosis. N Engl J Med. 2009;361:756-65.

60. Gnant M. Role of bisphosphonates in postmenopausal women with breast cancer. Cancer Treat Rev. 2014;40(3):476-84.

61. Ben-Aharon I, Vidal L, Rizel S, et al. Bisphosphonates in the adjuvant setting of breast cancer therapy - effect on survival: a systematic review and meta-analysis. PLoS One. 2013;8(8):e70044.

62. Lintermans A, van Asten $\mathrm{K}$, Wildiers $\mathrm{H}$, et al. A prospective assessmen of musculoskeletal toxicity and loss of grip strength in breast cancer patients receiving adjuvant aromatase inhibitors and tamoxifen, and relation with BMI. Breast Cancer Res Treat. 2014;146(1):109-16

63. Sparano JA, Gray RJ, Makower DF, et al. Adjuvant chemotherapy guided by a 21- gene expression assay in breast cancer. N Engl J Med. 2018;379:111-21

64. Geyer CE, Tang G, Mamounas EP, et al. 21-Gene assay as predictor of chemotherapy benefit in HER2-negative breast cancer. NPJ Breast Cancer. 2018:4:37.

65. Kalinsky K, Barlow WE, Meric-Bernstam F, et al. First results from a phase III randomized clinical trial of standard adyuvant endocrine therapy $(\mathrm{ET})+$ chemotherapy (CT) in patients (pts) with 1-3 positive nodes, hormone receptor-positive (HR+) and HER2- negative (HER2-) breas cancer (BC) with recurrence score (RS) < 25: SWOG S1007. Cancer Res. 2021;81 (4 Suppl):abstr GS3-00.

66. Cardoso F, van Veer LJ, Bogaerts J, et al. 70-gene signature as an aid to treatment decisions in early-stage breast cancer. $\mathrm{N}$ Engl $\mathrm{J}$ Med. 2016;375:717-29.

67. Sestak I, Buus R, Cuzick J, et al. Comparison of the performance of 6 prognostic signatures for estrogen receptor-positive breast cancer: A secondary analysis of a randomized clinical trial. JAMA Oncology. 2018;4:545-53.

68. Institute of Medicine and National Research Council. From Cancer patient to cancer survivor: Lost in translation. An American Society of Clinical Oncology and Institute of Medicine Suymposium. Washington, DC: The National Academies Press; 2006

69. Pinder MC, Duan Z, Goodwin J, et al. Congestive heart failure in olde women treated with adjuvant anthracyline chemotherapy for breast cancer. J Clin Oncol. 2007;25:3808-15.
70. Romond EH, Jeong JH, Rastogi $P$, et al. Seven-year follow-up assessment of cardiac function in NSABP B-31, a randomized trial comparing doxorubicin and cyclophosphamide followed by paclitaxel (ACP) with ACP plus trastuzumab as adjuvant therapy for patients with node-positive, human epidermal growth factor receptor 2-positive breast cancer. $\mathrm{J}$ Clin Oncol. 2012;30(31):3792-9.

71. Chavez-Macgregor M, Zhang N, Buchholz TA, et al. Trastuzumab-related cardiotoxicity among older patients with breast cancer. J Clin Oncol. 2013;31(33):4222-8.

72. Patt DA, Duan Z, Fang S, et al. Acute myeloid leukemia after adjuvant breast cancer therapy in older women: understanding the risk. J Clin Oncol. 2007;25(25):3871-6.

73. Wolff AC, Blackford AL, Visvanathan K, et al. Risk of marrow neoplasms after adjuvant breast cancer therapy: the national comprehensive cancer network experience. J Clin Oncol. 2015;33(4):340-8.

74. Schneider B, Zhao F, Wang M, et al. Neuropathy is not associated with clinical outcomes in patients receiving adjuvant taxane-containing therapy for operable breast cancer. J Clin Oncol. 2012;30(25):3051-7.

75. Smith EM, Pang H, Cirrincione C, et al. Effect of duloxetine on pain, function and QoL among patients with painful chemotherapy-induced neuropathy. JAMA. 2013:309(13):1359-67.

76. Hershman DL, Lacchetti C, Dworkin RH, et al. Prevention and management of chemotherapy-induced peripheral neuropathy-ASCO clinical practice guideline. J Clin Oncol. 2014;32(18):1941-67.

77. Bower JE, Bak K, Breitbart W, et al. Screening, assessment and management of fatigue in adult survivors of cancer: An ASCO practice guideline adaptation. J Clin Oncol. 2014;32(17):1840-50.

78. NCCN Clinical Practice Guidelines in Oncology (NCCN Guidelines) Cancer Related Fatigue. Version 1.2021- December 1, 2020.

79. Pachman DR, Barton DL, Swetz KM, et al. Troublesome symptoms in cancer survivors: fatigue, insomnia, neuropathy, and pain. J Clin Oncol. 2012:30:3687-96.

80. Azim HA, Azanbuja E, Colozza M, et al. Long-term toxic effects of adjuvant chemotherapy in breast cancer. Ann Oncol. 2011;22(9):1939-47.

81. Mann E, Smith MJ, Hellier J, et al. Cognitive behavioural treatment for women who have menopausal symptoms after breast cancer treatment (MENOS 1): a randomized controlled trial. Lancet Oncol. 2012;13:309-18.

82. Azim HA, Kroman HA, Paesmans A, et al. Prognostic impact of pregnancy after breast cancer according to estrogen receptor status: A multicenter retrospective study. J Clin Oncol. 2013;31(1).

\section{Radioterapia postoperatoria en cáncer de mama temprano}

1. Moran MS, Truong PT. Hypofractionated radiation treatment for breast cancer: The time is now. Breast J. 2020;26(1):47-54.

2. Garrefa E, Hughes-Davies L, Rusell S, et al. Definition of tumor bed boos in oncoplastic breast surgery: An understanding and approach. Clin Breast Cancer. 2020;20(4):510-5.

3. Murray Brunt A, Haviland JS, Wheatley DA, et al. Hypofractionated breas radiotherapy for 1 week versus 3 weeks (FAST-Forward): 5-year efficacy and late normal tissue effects results from a multicentre, non-inferiority, randomised, phase 3 trial. Lancet. 2020;395(10237):1613-26.

4. Yarnold J. Changes in radiotherapy fractionation-breast cancer. $\mathrm{Br} \mathrm{J}$ Radiol. 2019;92(1093):20170849.

5. Offersen B, Alsner J, Nielsen $\mathrm{H}$, et al. Hypofractionated versus standard fractionated radiotherapy in patients with early breast cancer or ductal carcinoma in situ in a randomized phase III trial: The DBCG HYPO Trial. J Clin Oncol. 2020;38(31):3615-25.

6. Brunt AM, Haviland JS, Sydenham M, et al. Ten-year results of FAST: A randomized controlled trial of 5 -fraction whole-breast radiotherapy for early breast cancer. J Clin Oncol. 2020;38(28):3261-72.

7. Vaidya JS, Bulsara M, Baum M, et al. Long term survival and local control outcomes from single dose targeted intraoperative radiotherapy during lumpectomy (TARGIT-IORT) for early breast cancer: TARGIT-A randomised clinical trial. BMJ. 2020;370:m2836.

8. Vicini FA, Cecchini RS, White JR, et al. Long-term primary results of accelerated partial breast irradiation after breast-conserving surgery for early-stage breast cancer: a randomised, phase 3 , equivalence trial. Lancet. 2019;394(10215):2155-64.

9. Whelan TJ, Julian JA, Berrang TS, et al. External beam accelerated partial breast irradiation versus whole breast irradiation after breast conserving surgery in women with ductal carcinoma in situ and node-negative breast cancer (RAPID): a randomised controlled trial. Lancet. 2019;394(10215):2165-72.

10. Goldberg M, Whelan TJ. Accelerated Partial Breast Irradiation (APBI): Where are we now? Curr Breast Cancer Rep. 2020:1-10.

11. Bhattacharya IS, Haviland JS, Kirby AM, et al. Patient-reported outcomes over 5 years after whole or partial-breast radiotherapy: Longitudinal analysis of the IMPORT LOW (CRUK/06/003) phase III randomized controlled trial. J Clin Oncol. 2019;37(4):305-17.

12. Viani GA, Arruda CV, Faustino AC, et al. Partial-breast irradiation versus hole-breast radiotherapy for early breast cancer: A systematic review and update meta-analysis. Brachytherapy. 2020;19(4):491-8. 
13. Strnad V, Krug D, Sedlmayer $F$, et al. DEGRO practical guideline for partial-breast irradiation. Strahlenther Onkol. 2020;196(9):749-63.

14. Polgár C, Major T, Takácsi-Nagy Z, et al. Breast conserving surgery followed by partial or whole breast irradiation: Twenty-year results of a phase 3 clinical study. Int J Radiat Oncol Biol Phys. 2021;109(4):998-1006.

15. Shah C, Obi E, Tom MC, Manyam BV, et al. Initial outcomes with image-guided partial breast irradiation delivered with intensity-modulated radiation therapy. Breast J. 2020;26(2):227-30.

16. Gulstene S, Raziee H. Radiation boost after adjuvant whole breast radiotherapy: Does evidence support practice for close margin and altered fractionation? Front Oncol. 2020;10:772.

17. Zheleva V, Nelson RA, Dumitra S, et al. Time to adjuvant radiotherapy in breast cancer affects survival: Implications for the American College of Surgeons Commission on Cancer Quality Metrics. Ann Surg Oncol. 2020;27(8):2614-25

18. Flores-Balcázar CH, Flores-Luna ML, Villarreal-Garza CM, et al. Provider delay in treatment initiation and its influence on survival outcomes in women with operable breast cancer. Rep Pract Oncol Radiother. 2020;25(2):271-5

19. Paluch-Shimon S, Cardoso F, Partridge AH, et al. ESO-ESMO $4^{\text {th }}$ International Consensus Guidelines for Breast Cancer in Young Women (BCY4). Ann Oncol. 2020;31(6):674-96.

20. Billena C, Wilgucki M, Flynn J, et al. 10 year breast cancer outcomes in women $<35$ years of age. Int $J$ radiat Oncol Biol Phys. 2021:109(4):1007-18.

21. Beaton L, Chan EK, Tyldesley S, et al. In the era after the European Organisation for Research and Treatment of Cancer 'Boost' Study, is the additional radiotherapy to the breast tumour bed still beneficial for young women? Clin Oncol (R Coll Radiol). 2020;32(6):373-81.

22. Tung NM, Boughey JC, Pierce LJ, et al. Management of hereditary breast cancer: American Society of Clinical Oncology, American Society for Radiation Oncology, and Society of Surgical Oncology Guideline. J Clin Oncol. 2020;38(18):2080-106.

23. Haussmann J, Budach W, Tamaskovics B, et al. Which target volume should be considered when irradiating the regional nodes in breast cancer? Results of a network-meta-analysis. Radiat Oncol. 2019;14(1).

24. Anzic M, Marinko T. Effect of adjuvant hormonal therapy on the development of pulmonary fibrosis after postoperative radiotherapy for breast cancer. J Breast Cancer. 2020;23(5):449-59.

\section{Manejo neoadyuvante}

1. Loibl S, Denkert C, von Minckwitz. Neoadjuvant treatment of breast cancer clinical and research perspective. Breast. 2015;24(Suppl 2):S73-S77.

2. Simons JM, Jacobs JG, Roijers JP, et al. Disease-free and overall survival after neoadjuvant chemotherapy in breast cancer: breast-conserving surgery compared to mastectomy in a large single-centre cohort study. Breast Cancer Res Treat. 2021;185(2):441-51.

3. Early Breast Cancer Trialists' Collaborative Group (EBCTCG). Long-term outcomes for neoadjuvant versus adjuvant chemotherapy in early breast cancer: meta-analysis of individual patient data from ten randomised trials. Lancet Oncol. 2018:19(1):27-39.

4. Donker M, Straver ME, Rutgers EJ, et al. Radioguided occult lesion localization (ROLL) in breast-conserving surgery after neoadjuvant chemotherapy. Eur J Surg Oncol. 2012;38(12):1218-24.

5. von Minckwitz G, Untch M, Nuesch E, et al. Impact of treatment characteristics on response of different breast cancer phenotypes: pooled analysis of the German neoadjuvant chemotherapy trials. Breast Cancer Res Treat. 2011;125:145-56.

6. Pease AM, Riba LA, Gruner RA, et al. Oncotype DX® recurrence score as a predictor of response to neoadjuvant chemotherapy. Ann Surg Oncol. 2019;26:366-71.

7. Cain H, Macpherson IR, Beresford M, et al. Neoadjuvant Therapy in Early Breast Cancer: Treatment considerations and common debates in practice. Clin Oncol (R Coll Radiol). 2017:29(10):642-52.

8. Schmid P, Cortes J, Pusztai L, et al.; KEYNOTE-522 Investigators. Pembrolizumab for early triple-negative breast cancer. $\mathrm{N}$ Engl J Med. 2020;382(9):810-21.

9. Mittendorf EA, Zhang $\mathrm{H}$, Barrios $\mathrm{CH}$, et al. Neoadjuvant atezolizumab in combination with sequential nab-paclitaxel and anthracycline-based chemotherapy versus placebo and chemotherapy in patients with early-stage triple-negative breast cancer (IMpassion031): a randomised, double-blind, phase 3 trial. Lancet. 2020;396(10257):1090-100.

10. Stafford A, Williams A, Edmiston K, et al. Axillary response in patients undergoing neoadjuvant endocrine treatment for node-positive breast cancer: Systematic literature review and NCDB analysis. Ann Surg Oncol. 2020;27(12):4669-77.

11. Allevi G, Strina C, Andreis D, et al. Increased pathological complete response rate after a long-term neoadjuvant letrozole treatment in postmenopausal estrogen and/or progesterone receptor-positive breast cancer. Br J Cancer. 2013;108:1587-92.
12. Barchiesi G, Mazzotta M, Krasniqi E, et al. Neoadjuvant endocrine therapy in breast cancer: Current knowledge and future perspectives. Int $\mathrm{J}$ Mol Sci. 2020;21(10):3528.

13. Scheel JR, Kim E, Partridge SC, et al: ACRIN 6657 Trial Team and I-SPY Investigators Network. MRI, clinical examination, and mammography for preoperative assessment of residual disease and pathologic complete response after neoadjuvant chemotherapy for breast cancer: ACRIN 6657 Trial. AJR Am J Roentgenol. 2018:210(6):1376-85.

14. Reig B, Heacock L, Lewin A, et al. Role of MRI to assess response to neoadjuvant therapy for breast cancer. J Magn Reson Imaging. 2020;52(6).

15. Goorts B, Dreuning KMA, Houwers JB, et al. MRI-based response patterns during neoadjuvant chemotherapy can predict pathological (complete) response in patients with breast cancer. Breast Cancer Res. 2018;20(1):34.

16. Law W, Cao X, Wright FC, et al. Adequacy of invasive and in situ breast carcinoma margins in radioactive seed and wire-guided localization lumpectomies. Breast J. 2021;27(2):134-40.

17. Petruolo O, Sevilimedu V, Montagna G, et al. How often does modern neoadjuvant chemotherapy downstage patients to breast-conserving surgery? Ann Surg Oncol. 2021;28(1):287-94

18. Montagna G, Sevilimedu V, Fornier M, et al. How effective is neoadjuvant endocrine therapy (NET) in downstaging the axilla and achieving breast-conserving surgery? Ann Surg Oncol. 2020;27(12):4702-10.

19. van Loevezijn AA, van der Noordaa MEM, van Werkhoven ED, et al. Minimally invasive complete response assessment of the breast after neoadjuvant systemic therapy for early breast cancer (MICRA trial): Interim analysis of a multicenter observational cohort study. Ann Surg Oncol. 2021:28(6):3243-53.

20. Masuda N, Lee SJ, Ohtani S, et al. Adjuvant capecitabine for breast cancer after preoperative chemotherapy. N Engl J Med. 2017;376:2147-59.

21. von Minckwitz G, Huang CS, Mano MS, et al. Trastuzumab emtansine for residual invasive HER2-positive breast cancer. N Engl J Med. 2019;380:617-28.

22. Huang Z, Zhu Li, Huang X-B, et al. Postmastectomy radiotherapy based on pathological nodal status in clinical node positive stage II-III breast cancer treated with neoadjuvant chemotherapy. Int J Radiat Oncol Biol Phys. 2020;108(4):1030-9.

23. Krug D, Lederer B, Seither F, et al. Post-mastectomy radiotherapy after neoadjuvant chemotherapy in breast cancer: A pooled retrospective analysis of three prospective randomized trials. Ann Surg Oncol. 2019;26(12):3892-901.

24. Marino L, Lancellotta V, Franco $P$, et al. Loco-regional adjuvant radiation therapy in breast cancer patients with positive axillary lymph-nodes at diagnosis (CN2) undergoing preoperative chemotherapy and with complete pathological lymph-nodes response. Development of GRADE (Grades of Recommendation, Assessment, Development and Evaluation). Recommendation by the Italian Association of Radiation therapy and Clinical Oncology (AIRO). Breast. 2021;55:119-27.

25. Belkacemi $Y$, Debbi $K$, Loganadane $G$, et al. Radiothérapie adjuvante et néoadjuvante des cancers du sein: mise au point sur les données de la littérature disponibles en 2020. Cancer Radiother. 2020;24(6-7):482-92.

26. National Cancer Institute, Radiation Therapy Oncology Group. Standard or comprehensive radiation therapy in treating patients with early- stage breast cancer previously treated with chemotherapy and surgery. Identifier: NCT01872975 [Internet]. U.S. National Library of Medicine, ClinicalTrials.gov [consultado: 2 de enero de 2021]. Disponible en: https://clinicaltrials.gov/ct2/show/NCT01872975

27. National Cancer Institute, Canadian Cancer Trials Group. Comparison of axillary lymph node dissection with axillary radiation for patients with node-positive breast cancer related with chemotherapy. Identifier: NCT01901094 [Internet]. https://clinicaltrials.gov/ct2/show/NCT01901094. U.S. National Library of Medicine, ClinicalTrials. gov [consultado: 2 de enero de 2021]. Disponible en: https://clinicaltrials.gov/ct2/show/NCT01901094

28. Shu-Liang W, Hui F, Yon-Wen S et al. Hypofractionated versus conventional fractionated postmastectomy radiotherapy for patients with high-risk breast cancer: a randomised, non-inferiority, open label, phase 3 trial. Lancet Oncol. 2019;20(3):352-60.

29. Liu L, Yang Y, Guo Q, et al. Comparing hypofractionated to conventional fractionated radiotherapy in postmastectomy breast cancer: a meta-analysis and systematic review. Radiat Oncol. 2020;15(1):17.

30. Cibor J, Georgiew F, Goyal S. A retrospective analysis on safety and effectiveness of hypofractionated postmastectomy radiotherapy. Breast J. 2020;26(2):176-81.

31. Bradley JA, Mendenhall NP. Novel radiotherapy techniques for breast cancer. Annu Rev Med. 2018;69:277-88.

32. Chacón MA, Ramos R, Rumoroso A. et al. Voluntary breath-hold reduces dose to organs at risk in radiotherapy of left-sided breast cancer. Rep Pract Oncol Radiother. 2020;25(1):104-8.

33. Haussmann J, Corradini S, Nestle-Kraemling C, et al. Recent advances in radiotherapy of breast cancer. Radiat Oncol. 2020;15(1):71.

34. Wright JL, Yom SS, Awan MJ, et al. Standardizing normal tissue contouring for radiation therapy treatment planning. An ASTRO consensus paper. Pract Radiat Oncol. 2019;9(2):65-72. 
35. Alexopoulou E, Katsila T, Tolia M, et al. An exploratory study of radiation dermatitis in breast cancer patients. Anticancer Res. 2018;38(3):1615-22.

36. Yee C, Wang K, Asthana R, et al. Radiation-induced skin toxicity in breas cancer patients: A sistematic review of randomized trials. Clin Breast Cancer. 2018;18(5):825-40.

37. Hanania AN, Mainwaring W, Ghebre YT, et al. Radiation-induced lung injury: Assessment and management. Chest. 2019;156(1):150-62.

38. Ohri N, Haffty BG. The evolution of adjuvant radiation therapy for early-stage and locally advanced breast cancer. Breast J. 2020;26(1):59-64

39. Orecchia R. Radiation therapy for inflammatory breast cancer. Eur J Surg Oncol. 2018:44(8):1148-50.

40. Ueno NT, Espinosa Fernandez JR, Cristofanilli M, et al. Internationa Consensus on the Clinical Management of Inflammatory Breast Cance from the Morgan Welch Inflammatory Breast Cancer Research Program $10^{\text {th }}$ Anniversary Conference. J Cancer. 2018;9(8):1437-47.

41. Werner EM, Eggert MC, Bohnet S, eo al. Prevalence and characteristics of pneumonitis following irradiation of breast cancer. Anticancer Res. 2019;39(11):6355-8.

\section{Tratamiento del cáncer de mama metastásico/recurrente}

1. Cardoso F, Paluch-Shimon S, Senkus E, et al. $5^{\text {th }}$ ESO-ESMO international consensus guidelines for advanced breast cancer (ABC 5). Ann Oncol. 2020;31(12):1623-49.

2. Caswell-Jin JL, Plevritis SK, Tian L, et al. Change in survival in metastatic breast cancer with treatment advances: Meta-analysis and systematic review. JNCl Cancer Spectr. 2018;2(4):pky062

3. Kobayashi K, Ito $\mathrm{Y}$, Matsumara M, et al. Impact of immunohistological subtypes on the long term prognosis of patients with metastatic breast cancer. Surg Today. 2016;46(7):821-6.

4. Frets $\mathrm{T}$, Tesch $\mathrm{H}$, Rauh J, et al. Palliative systemic therapy and overal survival of 1395 patients with advanced breast cancer - results from the prospective German TMK cohort study. Breast. 2017;34:122-30.

5. Amir E, Miller N, Geddie W, et al. Do the results of metastatic breast cancer biopsies affect patient survival outcomes? Results from a large prospective trial. Cancer Res. 2010;70(24 Suppl):abstr PD10-05.

6. Aurilio G, Disalvatore D, Pruneri G, et al. A meta-analysis of oestrogen receptor, progesterone receptor and human epidermal growth factor receptor 2 discordance between primary breast cancer and metastases. Eur J Cancer. 2014;50:277.

7. Daly MB, Pal T, Berry MP, Buys SS, Dickson P, Domchek SM, et al. Genetic/Familial High-Risk Assessment: Breast, Ovarian, and Pancreatic Version 2.2021, NCCN Clinical Practice Guidelines in Oncology. J Nat Compr Canc Netw. 2021 Jan 6;19(1):77-102.

8. Robson M, Im SA, Senkus E, et al. Olaparib for metastatic breast cancer in patients with a germline BRCA mutation. N Engl J Med. 2017;377:523.

\section{Tratamiento de acuerdo con el subtipo de cáncer de mama}

1. Li J, Huo X, Zhao F, et al. Association of cyclin-dependent kinases 4 and 6 inhibitors with survival in patients with hormone receptor-positive metastatic breast cancer: A systematic review and meta-analysis. JAMA Netw Open. 2020;3:e2020312.

2. Cardoso FS, Paluch-Shimon E, Senkus G, et al. $5^{\text {th }}$ ESO-ESMO international consensus guidelines for advanced breast cancer (ABC 5). Ann Oncol. 2020;31(12):1623-49.

3. Tripathy D, Im SA, Colleoni M, et al. Ribociclib plus endocrine therapy for premenopausal women with hormone-receptor-positive, advanced breast cancer (MONALEESA-7): a randomised phase 3 trial. Lancet Oncol. 2018;19(7):904-15.

4. Finn RS, Martin M, Rugo HS, et al. Palbociclib and letrozole in advanced breast cancer. N Engl J Med. 2016;375:1925-36.

5. Hortobagy GN, Stemmer SM, Campone M, et al. Ribociclib as first-line therapy for HR positive, advanced breast cancer. N Engl J Med. 2016;375:1738-48.

6. Goetz MP, Toi M, Campone M, et al. MONARCH 3: Abemaciclib as initial therapy for advanced breast cancer. J Clin Oncol. 2017;35(32):3638-46.

7. Johnston S, Martin M, Di Leo A, et al. MONARCH 3 final PFS: a randomized study of abemaciclib as initial therapy for advanced breast cancer. NPJ Breast Cancer. 2019;5:5.

8. Mauri D, Pavlidis N, Polyzos NP, et al. Survival with aromatase inhibitors and activators versus standard hormonal therapy in advanced breast cancer: metaanalysis. J Natl Cancer Inst. 2006;98:1285-91.

9. Robertson J, Bondarenko I, Trishkina E, et al. Fulvestrant $500 \mathrm{mg}$ versus anastrozole $1 \mathrm{mg}$ for hormone receptor-positive advanced breast cancer (FALCON): an international, randomised, double-blind phase 3 trial. Lancet. 2016;388:2997-3005.

10. Cristofanilli M, Turner NC, Bondarenko I, et al. Fulvestrant plus palbociclib versus fulvestrant plus placebo for treatment of hormone-receptor-positive, HER2-negative metastatic breast cancer that progressed on previous endocrine therapy (PALOMA-3): final analysis of the multicentre double-blind, phase 3 randomised controlled trial. Lancet Oncol. 2016;17(4):425-39.
11. Sledge GW Jr, Toi $M$, Neven $P$, et al. MONARCH 2: Abemaciclib in combination with fulvestrant in women with HR+/HER2- advanced breast cancer who had progressed while receiving endocrine therapy. J Clin Oncol. 2017;35(25):2875-84.

12. Slamon DJ, Neven $P$, Chia $S$, et al. Overall survival with ribociclib plus fulvestrant in advanced breast cancer. N Engl J Med. 2020;382(6):514-24.

13. Slamon DJ, Neven $P$, Chia $S$, et al. Phase III randomized study of ribociclib and fulvestrant in hormone receptor-positive, human epidermal growth factor receptor 2-negative advanced breast cancer: MONALEESA-3. J Clin Oncol. 2018;36(24):2465-72.

14. Piccart M, Baselga J, Noguchi S, et al. Final progression-free survival analysis of BOLERO-2: a phase III trial of everolimus for postmenopausal women with advanced breast cancer [SABCS abstract P6- 04-02]. Cancer Res. 2012;72(Suppl 3).

15. Baselga J, Campone M, Piccart M, et al. Everolimus in postmenopausal hormone receptor-positive advanced breast cancer. $\mathrm{N}$ Engl $\mathrm{J}$ Med. 2012;366:520-9.

16. Lonning PE, Bajetta E, Murray R, et al. Activity of exemestane in metastatic breast cancer after failure of nonsteroidal aromatase inhibitors: a phase II trial. J Clin Oncol. 2000;18:2234-44.

17. Chia S, Gradishar W, Mauriac L, et al. Double-blind, randomized placebo controlled trial of fulvestrant compared with exemestane after prior nonsteroidal aromatase inhibitor therapy in postmenopausal women with hormone receptor-positive, advanced breast cancer: results from EFECT. $\mathrm{J}$ Clin Oncol. 2008;26:1664-70.

18. Kornblum N, Zhao F, Manola J, et al. Randomized phase II trial of fulvestrant plus everolimus or placebo in postmenopausal women with hormone receptor-positive, human epidermal growth factor receptor 2-negative metastatic breast cancer resistant to aromatase inhibitor therapy: Results of PrE0102. J Clin Oncol. 2018;36(16):1556-63.

19. Dickler MN, Tolaney SM, Rugo HS, et al. MONARCH 1, A phase II study of abemaciclib, a CDK4 and CDK6 inhibitor, as a single agent, in patients with refractory HR+/HER2- metastatic breast cancer. Clin Cancer Res. 2017;23(17):5218-24.

20. NCCN Clinical Practice Guidelines in Oncology (NCCN Guidelines) Breast Cancer. Version 5.2021- June 28, 2021.

21. Cardoso F, Paluch-Shimon S, Senkus E, et al. $5^{\text {th }}$ ESO-ESMO International Consensus Guidelines for Advanced Breast Cancer (ABC 5). Ann Oncol. 2020;31(12):1623-49.

22. Cardoso F, Senkus E, Costa A, et al. $4^{\text {th }}$ ESO-ESMO International Consensus Guidelines for Advanced Breast Cancer (ABC 4). Ann Oncol. 2018;29(8):1634-57.

23. Johnston S, Pergram M, Press $M$, et al. Lapatinib combined with letrozole vs. letrozole alone for front line postmenopausal hormone receptor positive (HR+) metastatic breast cancer (MBC). J Clin Oncol. 2009;27:5538-46.

24. Kaufman B, Mackey JR, Clemens M, et al. Trastuzumab plus anastrozole versus anastrozole alone for the treatment of postmenopausal women with human epidermal growth factor receptor 2-positive, hormone receptor-positive metastatic breast cancer: Results from the randomized phase III TAnDEM Study. J Clin Oncol. 2009;27:5529-37.

25. Arpino G, Ferrero JM, de la Haba-Rodriguez J, et al. Abstract S3-04: primary analysis of PERTAIN: a randomized, two-arm, open-label, multicenter phase II trial assessing the efficacy and safety of pertuzumab given in combination with trastuzumab plus an aromatase inhibitor in first-line patients with HER-2-positive and hormone receptor-positive metastatic or locally advanced breast cancer. Cancer Res. 2017;77(4 Suppl):abstr S3-04

26. Johnston SRD, Hegg R, IM SA, et al. Phase III, randomized study of dual human epidermal growth factor receptor 2 (HER-2) blockade with lapatinib plus trastuzumab in combination with an aromatase inhibitor in postmenopausal women with HER-2-positive, hormone receptor- positive metastatic breast cancer: ALTERNATIVE. J Clin Oncol. 2018;36(8):741-8.

27. Giordano SH, Temin S, Kirshner JJ, et al. Systemic therapy for patients with advanced human epidermal growth factor receptor 2-positive breast cancer: American society of clinical oncology clinical practice guideline. $J$ Clin Oncol 2014;32:2078-2099. http://dx.doi. org/10.1200/ JCO.2013.54.0948

28. Swain SM, Kim SB, Cortés J, et al. Pertuzumab, trastuzumab, and docetaxel for HER-2-positive metastatic breast cancer (CLEOPATRA study): overall survival results from a randomized, double-blind, placebo-controlled, phase 3 study. Lancet Oncol. 2013;14(6):461-71.

29. Baselga J, Cortés J, Kim SB, et al. Pertuzumab plus trastuzumab plus docetaxel for metastatic breast cancer. N Engl J Med. 2012;366:109-19.

30. Marty M, Cognetti F, Maraninchi D, et al. Randomized phase II trial of the efficacy and safety of trastuzumab combined with docetaxel in patients with human epidermal growth factor receptor 2-positive metastatic breast cancer administered as first-line treatment: the M77001 study group. J Clin Oncol. 2005;23:4265-74.

31. Andersson $M$, Lidbrink $E$, Bjerre $K$, et al. Phase III randomized study comparing docetaxel plus trastuzumab with vinorelbine plus trastuzumab as first-line therapy of metastatic or locally advanced human epidermal growth factor receptor 2-positive breast cancer. The HERNATA Study. J Clin Oncol. 2011;29:264-71. 
32. Verma S, Miles D, Gianni L, et al. Trastuzumab emtansine for HER-2-positive advanced breast cancer. N Engl J Med. 2012;367(19):1783-91.

33. Urruticoechea A, Rizwanullah M, IM SA, et al. Randomized phase III tria of trastuzumab plus capecitabine with or without pertuzumab in patients with human epidermal growth factor receptor 2-positive metastatic breast cancer who experienced disease progression during or after trastuzumab-based therapy. J Clin Oncol. 2017:35:3030-8.

34. Geyer CE, Forster J, Lindquist D, et al. Lapatinib plus capecitabine for HER-2-positive advanced breast cancer. N Engl J Med. 2006;355:2733-43.

35. Blackwell KL, Burstein HJ, Storniolo AM, et al. Randomized study of lapatinib alone or in combination with trastuzumab in women with $\mathrm{Er}$ bB2-positive, trastuzumab-refractory metastatic breast cancer. J Clin Oncol. 2010;28:1124-30

36. von Minckwitz G, du Bois A, Schmidt M, et al. Trastuzumab beyond progression in human epidermal growth factor receptor 2-positive advanced breast cancer: a German breast group 26/breast internationa group 03-05 study. J Clin Oncol. 2009;27:1999-2006.

37. NCCN Clinical Practice Guidelines in Oncology (NCCN Guidelines) Breast Cancer. Version 5.2021- June 28, 2021.

38. Cardoso F, Paluch-Shimon S, Senkus E, et al. $5^{\text {th }}$ ESO-ESMO International Consensus Guidelines for Advanced Breast Cancer (ABC 5). Ann Oncol. 2020;31(12):1623-49.

39. Clinical Practice Guidelines in Oncology (NCCN guidelines). Breast Cancer version 3.2018 [Internet]. National Comprehensive Cancer Network [acceso: 12/01/2019]. Disponible en: https://jnccn.org/view/journals/ jnccn/16/11/article-p1362.xml?print

40. Cardoso F, Costa A, Senkus E, et al. $3^{\text {rd }}$ ESO-ESMO International Consensus Guidelines for Advanced Breast Cancer (ABC 3). Ann Oncol. 2017;28:16-33.

41. Partridge A, Rumble B, Carey L, et al. Chemotherapy and targeted therapy for women with human epidermal growth factor receptor 2-negative (or unknown) advanced breast cancer: American Society of Clinical Oncology clinical practice guideline. J Clin Oncol. 2014;32:1-23.

42. Robson M, Im SA, Senkus E, et al. Olaparib for metastatic breast cancer in patients with a germline BRCA mutation. N Engl J Med. 2017:377(6):523-33

43. Carrick S, Parker S, Wilcken N, et al. Single agent versus combination chemotherapy for metastatic breast cancer. Cochrane Database Syst Rev. 2005;2:CD003372.

44. Conte PF, Guarneri V, Bruzzi P, et al. Concomitant versus sequentia administration of epirubicin and paclitaxel as first-line therapy in metastatic breast carcinoma: results for the Gruppo Oncologico Nord Ovest randomized trial. Cancer. 2004:101:704-12.

45. O'Shaughnessy J, Miles D, Vukelja S, et al. Superior survival with capecitabine plus docetaxel combination therapy in anthracycline-pretreated patients with advanced breast cancer: phase III trial results. J Clin Oncol 2002;12:2812-23.

46. Albain KS, Nag SM, Calderillo-Ruiz G, et al. Gemcitabine plus paclitaxel versus paclitaxel monotherapy in patients with metastatic breast cancer and prior anthracycline treatment. J Clin Oncol. 2008:26:3950-7.

47. Blum JL, Dees EC, Chacko A, et al. Phase II trial of capecitabine and weekly paclitaxel as first-line therapy for metastatic breast cancer. J Clin Oncol. 2006:24:4384-90.

48. Chan S, Romieu G, Huober J, et al. Phase III study of gemcitabine plus docetaxel compared with capecitabine plus docetaxel for anthracycline-pretreated patients with metastatic breast cancer. J Clin Oncol. 2009;27:1753-60.

49. Soto C, Torrecillas L, Reyes S, et al. Capecitabine $(X)$ and taxanes in patients with anthracycline-pretreated metastatic breast cancer: sequential vs. combined therapy results from a MOSG randomized phase III trial. J Clin Oncol. 2006;24:570.

50. Fumoleau P, Largillier R, Clippe C, et al. Multicentre, phase II study evaluating capecitabine monotherapy in patients with anthracycline and taxane-pretreated metastatic breast cancer. Eur J Cancer. 2004;40:536-42.

51. Kaufman PA, Awada A, Twelves C, et al. A phase III, open-label, randomized, multicenter study of eribulin mesylate versus capecitabine in patients with locally advanced or metastatic breast cancer previously treated with anthracyclines and taxanes. J Clin Oncol. 2015 Feb 20;33(6):594-601.

52. Cortes J, O'Shaughnessy J, Loesch D, et al. Eribulin monotherapy versus treatment of physician's choice in patients with metastatic breast cancer (EMBRACE): a phase 3 open-label randomized study. Lancet. 2011;377:914-23

53. Cortes J, Vahdat L, Blum JL, Twelves C, Campone M, Roche H, et al. Phase II Study of the Halichondrin B Analog Eribulin Mesylate in Patients With Locally Advanced or Metastatic Breast Cancer Previously Treated With an Anthracycline, a Taxane, and Capecitabine. J Clin Onco 28:3922-3928.

54. Carrick S, Ghersi D, Wilcken N, et al. Platinum containing regimens for metastatic breastcancer.Cochrane Database SystRev. 2004:(3):CD003374.

55. Tutt A, Ellis P, Kilbum L, et al. TNT: a randomized phase III trial of carboplatin compared to docetaxel for patients with metastatic or recurrent locally advanced triple-negative or BRCA1/2 breast cancer. Cancer Res. 2015;75:9.
56. Tutt A, Tovey H, Cheang MCU, et al. Carboplatin in BRCA1/2-mutated and triple-negative breast cancer BRCAness subgroups: the TNT Trial. Nat Med. 2018;24(5):628-37.

57. Miller K, Wang M, Gralow J, et al. Paclitaxel plus bevacizumab versus paclitaxel alone for metastatic breast cancer. $N$ Engl J Med. 2007;357:2666-76

58. Miles D, Chan A, Dirix L, et al. Phase III study of bevacizumab plus docetaxel compared with placebo plus docetaxel for the first-line treatment of human epidermal growth factor receptor 2-negative metastatic breast cancer. J Clin Oncol. 2010;28:3239-47.

59. Robert NJ, Diéras V, Glaspy J, et al. RIBBON-1: randomized, double-blind, placebo-controlled, phase III trial of chemotherapy with or without bevacizumab for first-line treatment of human epidermal growth factor receptor 2-negative, locally recurrent or metastatic breast cancer. $\mathrm{J}$ Clin Oncol. 2011;29:1252-60.

60. O'Shaughnessy J, Miles D, Gray R, et al. A meta-analysis of overall survival data from three randomized trials of bevacizumab (BV) and first-line chemotherapy as treatment for patients with metastatic breast cancer (MBC). J Clin Oncol [Internet]. 2010;28(suppl 15):1005. Disponible en: https://ascopubs.org/doi/abs/10.1200/jco.2010.28.15_suppl.1005

61. Miles DW, Diéras V, Cortes $J$, et al. First-line bevacizumab in combination with chemotherapy for HER-2 negative metastatic breast cancer: pooled and subgroup analysis of data from 2447 patients. Ann Oncol. 2013;24:2773-80.

62. Rugo HS, Barry WT, Moreno-Aspitia A, et al. Randomized phase III tria of paclitaxel once per week compared with nanoparticle albumin-bound nab-paclitaxel once per week or ixabepilone with bevacizumab as first-line chemotherapy for locally recurrent or metastatic breast cancer: CALGB 40502/NCCTG N063H (Alliance). J Clin Oncol. 2015;33(21):2361-9.

63. Schmid P, Adams S, Rugo HS, et al. Atezolizumab and nab-paclitaxel in advanced triple-negative breast cancer. N Engl J Med. 2018;379(22): 2108-21.

64. Cortes J, Cescon DW, Rugo HS, et al. Pembrolizumab plus chemotherapy versus placebo plus chemotherapy for previously untreated locally recurrent inoperable or metastatic triple-negative breast cancer (KEYNOTE-355): a randomised, placebo-controlled, double-blind, phase 3 clinical trial. Lancet. 2020;396(10265):1817-28.

65. Robson ME, Tung N, Conte $\mathrm{P}$, et al. OlympiAD final overall survival and olerability results: Olaparib versus chemotherapy treatment of physician's choice in patients with a germline BRCA mutation and HER2-negative metastatic breast cancer. Ann Oncol. 2019;30(4):558-66.

66. Gennari A, Sormani M, Bruzi P, et al. A meta-analysis of chemotherapy duration in metastatic breast cancer (MBC). J Clin Oncol [Internet]. 2008;26(suppl 15):1067. Disponible en: https://ascopubs.org/doi/ abs/10.1200/jco.2008.26.15 suppl.1067

67. Gennari A, Stocker M, Puntoni M, et al. Duration of chemotherapy for metastatic breast cancer: a systematic review and meta-analysis of randomized clinical trials. J Clin Oncol. 2011;29:2144-9.

\section{Bisfosfonatos e inhibidores del ligando del receptor activador del NF-K} (RANKL) en metástasis óseas

1. Angelucci A, Alesse E. Molecular pathology of cancer. Metastasis: Suggestions for future therapy. En: Bologna M, editor. Biotargets of Cancer in Current Clinical Practice. Springer; 2012. pp. 469-515

2. Kremer R, Gagnon B, Meguerditchian AN, et al. Effect of oral bisphosphonates for osteoporosis on development of skeletal metastases in women with breast cancer: results from a pharmaco-epidemiological study. J Natl Cancer Inst. 2014;106(11).

3. Hadji P, Aapro MS, Body JJ, et al. Management of aromatase inhibitor-associated bone loss in postmenopausal women with breast cancer: practical guidance for prevention and treatment. Ann Oncol. 2011;22(12):2546-55

4. Wong MH, Stockler MR, Pavlakis N. Bisphosphonates and other bone agents for breast cancer. Cochrane Database Syst Rev. 2012;2:CD003474.

5. Lluch A, Cueva J, Ruiz-Borrego M, et al. Zoledronic acid in the treatment of metastatic breast cancer. Anticancer Drugs. 2014;25(1):1-7.

6 . Stopeck AT, Lipton A, Body JJ, et al. Denosumab compared with zoledronic acid for the treatment of bone metastases in patients with advanced breast cancer: a randomized, double-blind study. J Clin Oncol. 2010;28:5132-9

7. Barrett-Lee $\mathrm{P}$, Casbard A, Abraham J, et al. Oral ibandronic acid versus intravenous zoledronic acid in treatment of bone metastases from breast cancer: a randomized, open label, non-inferiority phase 3 trial. Lancet Oncol. 2014;15(1):114-22.

8. Amadori D, Aglietta M, Alessi B, et al. Efficacy and safety of weekly versus 4-weekly zoledronic acid for prolonged treatment of patients with bone metastases from breast cancer (ZOOM): a phase 3, open-label, randomized, non-inferiority trial. Lancet Oncol. 2013;14(7):663-70.

9. Hortobagyi N. Efficacy and safety of continued zoledronic acid every 4 weeks versus every 12 weeks in women with bone metastases from breast cancer: Results of the OPTIMIZE-2 trial. J Clin Oncol. 2014;32(15). 


\section{Papel de la cirugía en enfermedad metastásica}

1. SantaMaria CA, Gradishar Wj. Changing treatment paradigms in metastatic breast cancer: lesson learned. JAMA Oncol. 2015;1:528534.

2. Bacalbaşa N, Alexandrescu ST, Popescu I. A role for hepatic surgery in patients with liver metastatic breast cancer: review of literature. Hepat Oncol. 2015;6(19):159170.

3. Güth U, Magaton I, Huang DJ, et al. Primary and secondary distant metastatic breast cancer: Two sides of the same coin. Breast 2014; 23:26-32.

4. Sundquist M, Brudin L, Tejler G. Improved survival in metastatic breast cancer 1985-2016. Breast. 2017;31:46-50.

5. Mariani $P$, Servois $V$, de Rycke $Y$, et al. Liver metastases from breas cancer: surgical resection or not? A case-matched control study in highly selected patients. Eur J Surg Oncol. 2013;39:1377-83.

6. Pockaj BA, Wasif N, Dueck AC, et al. Metastasectomy and surgical re section of the primary tumor in patients with stage IV breast cancer. Time for a second look? Ann Surg Oncol- 2010;17:2419-26.

7. Kobayashi T, Ichiba T, Sakuyama T, et al. Possible clinical cure of metastatic breast cancer: lessons from 30 year experience with oligometastatic breast cancer patients and literature review. Breast Cancer. 2012;19:218-37.

8. Golse N, Adam R. Liver metastases from breast cancer: What role fo surgery? Indications and results. Clin Breast Cancer. 2017;17(4):256-65.

9. Mc Donald ML, Deschamps C, Ilstrup DM, et al. Pulmonary resection for metastatic breast cancer. Ann Thorac Surg. 1994;58(6):1599-602.

10. Rusch VW. Pulmonary metastasectomy: a moving target. J Thorac Oncol. 2010;5(6):S130-1.

11. Kycler W, Lasky P. Surgical approach to pulmonary metastases from breast cancer. Breast. 2012;18(1):52-7.

12. Bendell JC, Domchek SM, Burstein $\mathrm{HJ}$, et al. Central nervous system metastases in women who receive trastuzumab based therapy for metastatic breast carcinoma. Cancer. 2003;97:2972-7.

13. Takahashi $\mathrm{H}$, Isogawa M. Management of breast cancer brain metastases. Chin Clin Oncol. 2018;7(3):30.

14. Suryanarayana Deo SV, Jha D. Role of locoregional surgery in metastatic breast cancer. J Cancer Res Ther. 2013:9:181-6.

15. Early surgery or standard palliative therapy in treating patients with stage IV breast cancer [Internet]. U.S. National Library of Medicine, ClinicalTrials.gov; november 2010. Disponible en: https://clinicaltrials.gov/ct2/ show/NCT01242800

16. Khan S, Stewart A, Morrow M. Does aggressive local therapy improve survival in metastatic breast cancer? Surgery. 2002;132(4):620-7.

17. Gnerlich J, Beers C. Surgical removal of the primary tumor increases overall survival in patients with metastatic breast cancer: analysis of the 19882003 SEER data. Ann Surg. 2007;14(8):2187-94.

18. Rapiti $\mathrm{E}$, Verkooijen $\mathrm{H}$. Complete excision of primary breast tumor improves survival of patients with metastatic breast cancer at diagnosis. J Clin Oncol. 2006;24(18):2743-9.

19. Cady B, Nathan N, Michaelson J. Matched pair analyses of stage IV breast cancer with or without resection of primary breast site. Ann Surg. 2008;15(12):3384-95.

20. Ruiterkamp J, Ernst M. Surgical resection of the primary tumour is associated with improved survival in patients with distant metastatic breast cancer at diagnosis. J Surg. 2009;35(11):1146-51.

21. Nguyen D, Truong $P$, Alexander $C$, et al. Can locoregional treatment of the primary tumor improve outcomes for women with stage IV breast cancer at diagnosis? Int J Radiat Oncol Biol Phys. 2012;84(1):39-45.

22. Babiera GV, Rao R, Feng $L$, et al. Effect of primary tumor extirpation in breast cancer patients who present with stage IV disease and an intact primary tumor. Ann Surg Oncol. 2006;13(6):776-82.

23. Dominici L, Najita J, Hughes M, et al. Surgery of the primary tumor does not improve surgical in stage IV breast cancer. Breast Cancer Res Treat. 2012;129(2):459-65

24. Medina Franco H, Suarez Bobadilla YL. Role of surgery in metastatic breast cancer. Rev Invest Clin. 2012;64:81-8.

25. Soran A, Ozmen V, Ozbas S, et al. Randomized trial comparing resection of primary tumor with no surgery in stage IV breast cancer at presentation: Protocol MF0701. Ann Surg Oncol. 2018;25(11):3141-9.

26. Rajendra Badwe, et al. Locoregional treatment versus no treatment of the primary tumour in metastatic breast cancer: an open-label randomized controlled trial. Lancet Oncol. 2015;16(13):1380-8.

27. Fitzal F, Bjelic-Radisic V, Knauer M, et al. Impact of breast surgery in primary metastasized breast cancer outcomes of the prospective randomized phase III ABCSG28 POSYTIVE Trial. Ann Surg. 2019;269(6) 1163-9.

28. Tari A. King, et al. A prospective nalysis of surgery and survival in stage IV breast cancer (TBCR 013). J Clinic Oncol [Internet]. 2017;34(Suppl 15):1006.

29. Bergenfeldt M, Jensen BV, Skjoldbye B, et al. Liver resection and loca ablation of breast cancer liver metastases - A systematic review. Eur $J$ Surg Oncol. 2011;37:549-57.

\section{Papel de la radioterapia en enfermedad metastásica}

1. Soran A, Özbaş S, Doğan L, et al. Loco-regional treatment for intact primary tumor in patient with de novo metastatic breast cancer; comments and concerns of ECOG-ACRIN 2108 Trial. Eur J Breast Health. 2020;16(3):158-9

2. Pons-Tostivint E, Alouani E, Kirova $Y$, et al. Is there a role for locoregional treatment of the primary tumor in de novo metastatic breast cance in the era of tailored therapies? Evidences, unresolved questions and a practical algorithm. Crit Rev Oncol Hematol. 2020;157:103-46.

3. Marazzi F, Orlandi A, Manfrida S, et al. Diagnosis and treatment of bone metastases in breast cancer: Radiotherapy, local approach and systemic therapy in a guide for clinicians. Cancers (Basel). 2020;12(9):2390.

4. Suh JH, Kotecha R, Chao ST, et al. Current approaches to the management of brain metastases. Nat Rev Clin Oncol. 2020;17(5):279-99.

5. Tsao M, Xu W, Wong $\mathrm{R}$, et al. Whole brain radiotherapy for the treatment of newly diagnosed multiple brain metastases. Cochrane Database Syst Rev. 2018;1(1):CD003869.

6. Giuseppe ZR, Silvia C, Eleonora F, et al. Hippocampal-sparing radiotherapy and neurocognitive impairment: $A$ systematic literature review. J Cancer Res Ther. 2020;16(6):1215-22.

7. Chao ST, De Salles A, Hayashi M, et al. Stereotactic radiosurgery in the management of limited (1-4) brain metasteses: systematic review and international stereotactic radiosurgery society practice guideline. Neurosurgery. 2018;83:345-53.

8. Hughes RT, Masters AH, McTyre ER, et al. Initial SRS for patients with 5 to 15 brain metastases: results of a multi-institutional experience. Int $\mathrm{J}$ Radiat Oncol Biol Phys. 2019;104(5):1091-8.

9. Lievens Y, Guckenberger M, Gomez D, et al. Defining oligometastatic disease from a radiation oncology perspective: An ESTRO-ASTRO consensus document. Radiother Oncol. 2020;148:157-66.

10. David $S$, Tan J, Savas $P$, et al. Stereotactic ablative body radiotherapy (SABR) for bone only oligometastatic breast cancer: A prospective clinical trial. Breast. 2020;49:55-62.

11. Franzese $\mathrm{C}$, Comito $\mathrm{T}$, Viganò $\mathrm{L}$, et al. Liver metastases-directed therapy in the management of oligometastatic breast cancer. Clin Breast Cancer. 2020;20(6):480-6.

12. Kalinauskaite GG, Tinhofer II, Kufeldmm, et al. Radiosurgery and fractionated stereotactic body radiotherapy for patients with lung oligometastases. BMC Cancer. 2020;20(1):404.

13. Kessel KA, Grosser RCE, Kraus KM, et al. Stereotactic body radiotherapy (SBRT) in patients with lung metastases - prognostic factors and long-term survival using patient self-reported outcome (PRO). BMC Cancer. 2020;20(1):442.

14. Tsao MN, Barnes EA, Chow E, et al. Multiple bone metastases: what the palliative care specialist should know about the potential, limitations and practical aspects of radiation therapy. Ann Palliat Med. 2020;9(3): 1307-13

15. Hirano $\mathrm{Y}$, Konishi K, Ejima $\mathrm{Y}$. Utility of whole brain radiation therapy for leptomeningeal carcinomatosis. Int J Clin Oncol. 2020;25(7):1432-9.

\section{Evaluación y manejo de la recurrencia locorregional}

1. Tovar JR, Zandonade E, Amorim MH. Factors associated with the incidence of local recurrences of breast cancer in women who underwent conservative surgery. Int J Breast Cancer. 2014;2014:639534.

2. Priedigkeit N, Ding K, Horne W, et al. Acquired mutations and transcriptional remodeling in long-term estrogen-deprived locoregional breast cancer recurrences. Breast Cancer Res. 2021;23(1):1.

3. Wu ZY, Han HH, Kim HJ, et al. Locoregional recurrence following nipple-sparing mastectomy with immediate breast reconstruction: Patterns and prognostic significance. Eur J Surg Oncol. 2021;47(6):1309-15.

4. Yoon Cl, Ahn SG, Kim D, et al. Repeat sentinel lymph node biopsy for ipsilateral breast tumor recurrence after breast conserving surgery with sentinel lymph node biopsy: Pooled analysis using data from a systematic review and two institutions. Front Oncol. 2020;10:518-68.

5. Sávolt Á, Cserni G, Lázár G, et al. Sentinel lymph node biopsy following previous axillary surgery in recurrent breast cancer. Eur J Surg Oncol. 2019;45(10):1835-8.

6. Arthur DW, Winter KA, Kuerer HM, et al. Effectiveness of breast-conserving surgery and 3-dimensional conformal partial breast reirradiation for recurrence of breast cancer in the ipsilateral breast: The NRG Oncology/ RTOG 1014 Phase 2 Clinical Trial. JAMA Oncol. 2020;6(1):75-82.

7. Montagne L, Hannoun A, Hannoun-Levi JM. Second conservative treatment for second ipsilateral breast tumor event: A systematic review of the different re-irradiation techniques. Breast. 2020;49:274-80.

8. Fattahi S, Ahmed SK, Park SS, et al. Reirradiation for locoregional recurent breast cancer. Adv Radiat Oncol. 2020;6(1):100640.

9. Aebi S, Gelber S, Anderson SJ, et al. Chemotherapy for isolated locoregional recurrence of breast cancer (CALOR): a randomised trial. Lance Oncol. 2014:15:156-63. 
XIII. Integración de cuidados de soporte y paliativos en el manejo de pacientes con cáncer de mama avanzado

1. Hui $D$, Bruera E. Integrating palliative care into the trajectory of cancer care. Nat Rev Clin Oncol. 2016;13(3):159-71.

2. Palliative Care Definition [Internet]. Houston, TX: International Association for Hospice and Palliative Care (2018). Disponible en: https://hospicecare.com/ what-we-do/projects/consensus-based-definition-of-palliative-care/definition

3. Hui D, Bruera E. Models of integration of oncology and palliative care. Ann Palliat Med. 2015;4(3):89-98.

4. Ferrell BR, Temel JS, Temin S, et al. Integration of palliative care into standard oncology care: American Society of Clinical Oncology clinical practice guideline update. J Clin Oncol. 2017; 35:96-112.

5. Burt M, Kamal AH. Practical strategies for optimizing and integrating palliative care in cancer. Curr Oncol Rep. 2018;20:97-103.

6. Cardoso F, Senkus E, Costa A, et al. $4^{\text {th }}$ ESO-ESMO International Consensus Guidelines of Advanced Breast Cancer (ABC 4) Section XII: Supportive and palliative care. Ann Oncol. 2018; 29:1634-57.

7. Cherny NI, Paluch-Shimon S, Berner-Wygoda Y. Palliative care: needs of advanced breast cancer patients. Breast Cancer. 2018;10:231-43.

8. Levy M, Smith T, Alvarez-Perez A, et al. Palliative Care. Version 1.2016. Clinical Practice Guidelines in Oncology. J Natl Compr Canc Netw. 2016;14(1):82-113.

9. Hui D, Mori M, Watanabe SH, et al. Referral criteria for outpatient specialty palliative cancer care: an international consensus. Lancet Oncol. 2016;16:e552-559.

\section{Cáncer de mama en mujeres jóvenes}

1. Villarreal-Garza C, Platas A, Miaja M, et al. Young women with breast cancer in Mexico: Results of the pilot phase of the Joven and Fuerte prospective cohort. JCO Glob Oncol. 2020;6:395-406.

2. Villarreal-Garza C, Martinez-Cannon BA, Platas A, et al. Fertility concerns among breast cancer patients in Mexico. Breast. 2017;33:71-5.

3. Villarreal-Garza CM, Platas A, Castro-Sánchez A, et al. Sexual function and satisfaction in Mexican young women undergoing breast cancer treatment. J Clin Oncol [Internet]. 2017;35(Suppl 15):e21714. Disponible en: https://ascopubs.org/doi/10.1200/JCO.2017.35.15_suppl.e21714

4. Villarreal-Garza C, López-Martínez EA, Martínez-Cannon BA, et al. Medical and information needs among young women with breast cancer in Mexico. Eur J Cancer Care (Engl). 2019;28(4):e13040.

5. Castro-Sanchez A, Martinez-Cannon B, Platas A, et al. Suboptimal use of effective contraceptive methods in young Mexican women with breast cancer. J Glob Oncol. 2018;4:1-7.

6. Hubbeling HG, Rosenberg SM, González-Robledo MC, et al. Psychosocial needs of young breast cancer survivors in Mexico City, Mexico. PLoS One. 2018:13(5):e0197931.

7. Paluch-Shimon S, Cardoso F, Partridge AH, et al. ESO-ESMO $4^{\text {rd }}$ International Consensus Guidelines for Breast Cancer in Young Women (BCY4). Ann Oncol. 2020;31(6):674-96.

8. Cardoso F, Loibl S, Pagani O, et al. The European Society of Breast Cancer Specialists recommendations for the management of young women with breast cancer. Eur J Cancer. 2012;48(18):3355-77.

9. Botteri E, Bagnardi V, Rotmensz N, et al. Analysis of local regional recurrences in breast cancer after conservative surgery. Ann Oncol. 2010;21(4):723-8.

10. Vila J, Gandini S, Gentilini O. Overall survival according to type of surgery in young ( $\leq 40$ years) early breast cancer patients: A systematic meta-analysis comparing breast-conserving surgery versus mastectomy Breast. 2015;24(3):175-81.

11. Maishman T, Cutress RI, Hernandez A, et al. Local recurrence and breast oncological surgery in young women with breast cancer: The POSH Observational Cohort Study. Ann Surg. 2017;24(3):175-81.

12. Frandsen J, Ly D, Cannon G, et al. In the modern treatment era, is breast conservation equivalent to mastectomy in women younger than 40 years of age? A multi-institution study. Int J Radiat Oncol Biol Phys. 2015;93(5):1096-103.

13. Villarreal-Garza C, Ferrigno AS, De la Garza-Ramos C, et al. Clinical utility of genomic signatures in young breast cancer patients: a systematic review. NPJ Breast Cancer. 2020;6:46

14. Francis PA, Pagani O, Fleming GF, et al. Tailoring adjuvant endocrine therapy for premenopausal breast cancer. N Engl J Med. 2018;379(2):122-37.

15. Bellet M, Gray KP, Francis PA, et al. Twelve-month estrogen levels in premenopausal women with hormone receptor-positive breast cance receiving adjuvant triptorelin plus exemestane or tamoxifen in the suppression of ovarian function trial (SOFT): The SOFT-EST substudy. J Clin Oncol. 2016;34(14):1584-93.

16. Cardoso F, Paluch-Shimon S, Senkus E, et al. $5^{\text {th }}$ ESO-ESMO International Consensus Guidelines for Advanced Breast Cancer (ABC 5). Ann Oncol. 2020;31(12):1623-49.
17. Lambertini M, Peccatori FA, Demeestere I, et al. Fertility preservation and post-treatment pregnancies in post-pubertal cáncer patients: ESMO Clinical Practice Guidelines. Ann Oncol. 2020;31(12):1664-78.

18. Oktay $\mathrm{K}$, Harvey $\mathrm{BE}$, Partridge $\mathrm{AH}$, et al. Fertility preservation in patients with cancer: ASCO clinical practice guideline update. J Clin Oncol. 2018;36(19):1994-2001.

19. Lambertini M, Moore HCF, Leonard RCF, et al. Gonadotropin-releasing hormone agonists during chemotherapy for preservation of ovarian function and fertility in premenopausal patients with early breast cancer: A systematic review and meta-analysis of individual patient-level data. J Clin Oncol. 2018:36(19):1981-90.

20. Lambertini M, Ceppi M, Poggio F, et al. Ovarian suppression using luteinizing hormonereleasing hormone agonists during chemotherapy to preserve ovarian function and fertility of breast cancer patients: A meta-analysis of randomized studies. Ann Oncol. 2015;26(12): 2408-19.

21. Hartman EK, Eslick GD. The prognosis of women diagnosed with breast cancer before, during and after pregnancy: a meta-analysis. Breast Cancer Res Treat. 2016;160(2):347-60.

22. Blondeaux E, Perachino M, Bruzzone M, et al. Abstract GS3-09: Chances of pregnancy after breast cancer, reproductive and disease outcomes: A systematic review and meta-analysis [Internet]. Cancer Research; febrero 2021. Disponible en: https://cancerres.aacrjournals.org/content/81/4_Supplement/GS3-09

23. Lambertini M, Ameye L, Hamy AS, et al. Pregnancy after breast cancer in patients with germline BRCA mutations. J Clin Oncol. 2020;38(26): 3012-23.

24. Lambertini M, Del Mastro L, Pescio MC, et al. Cancer and fertility preservation: International recommendations from an expert meeting. BMC Med. 2016;14:1

25. Mueller BA, Simon MS, Deapen D, et al. Childbearing and survival after breast carcinoma in young women. Cancer. 2003;98(6):1131-40.

26. Pagani $O$, Ruggeri M, Manunta $S$, et al. Pregnancy after breast cancer: Are young patients willing to participate in clinical studies? Breast. 2015;24(3):201-7.

27. Ganz P, Bower JE, Partridge AH, et al. Abstract GS2-10: Targeting depressive symptoms in younger breast cancer survivors: A randomized controlled trial of mindfulness meditation and survivorship education [Internet]. Cancer Research; febrero 2021. Disponible en: https://cancerres. aacrjournals.org/content/81/4_Supplement/GS2-10

\section{Tratamiento en pacientes adultas mayores}

1. World Health Organization. World report on ageing and health [Internet]. World Health Organization; 2015 [acceso: 30/10/2018]. Disponible en: http://apps.who.int/iris/bitstream/handle/10665/186463/9789240694811 eng.pdf;jsessionid=AE9C814194CD2896734F 44934CA1E886?sequen$\mathrm{ce}=1$

2. Soto-Perez-de-Celis E, Li D, Yuan Y, et al. Functional versus chronological age: geriatric assessments to guide decision making in older patients with cancer. Lancet Oncol. 2018;19(6):e305-e316.

3. Mohile SG, Dale W, Somerfield MR, et al. Practical assessment and management of vulnerabilities in older patients receiving chemotherapy: ASCO Guideline for Geriatric Oncology. J Clin Oncol. 2018;36(22): 2326-47.

4. Kenis $\mathrm{C}$, Decoster L, van Puyvelde K, et al. Performance of two geriatric screening tools in older patients with cancer. J Clin Oncol. 2014;32(1): 19-26.

5. Loh KP, Soto-Perez-de-Celis E, Hsu T, et al. What every oncologist should know about geriatric assessment for older patients with cancer: Young International Society of Geriatric Oncology Position Paper. J Oncol Pract. 2018;14(2):85-94.

6. Ferrat $E$, Paillaud $E$, Caillet $P$, et al. Performance of four frailty classifications in older patients with cancer: Prospective Elderly Cancer Patients Cohort Study. J Clin Oncol. 2017;35(7):766-77.

7. Mohile SG, Velarde C, Hurria A, et al. Geriatric assessment-guided care processes for older adults: A Delphi Consensus of Geriatric Oncology Experts. J Natl Compr Canc Netw. 2015;13(9):1120-30.

8. Suemoto CK, Ueda P, Beltrán-Sánchez H, et al. Development and validation of a 10-year mortality prediction model: Meta-analysis of individual participant data from five cohorts of older adults in developed and developing countries. J Gerontol A Biol Sci Med Sci. 2017;72(3):410-6.

9. Magnuson A, Sedrak MS, Gross CP, et al. Development and validation of a risk tool for predicting severe toxicity in older adults receiving chemotherapy for early-stage breast cancer. J Clin Oncol. 2021;39(6): 608-18.

10. Extermann M, Boler I, Reich RR, et al. Predicting the risk of chemotherapy toxicity in older patients: the Chemotherapy Risk Assessment Scale for High-Age Patients (CRASH) score. Cancer. 2012;118(13) :3377-86. 
11. Tang V, Zhao S, Boscardin J, et al. Functional status and survival after breast cancer surgery in nursing home residents. JAMA Surg. 2018;153(12):1090-6.

12. Hughes KS, Schnaper LA, Bellon JR, et al. Lumpectomy plus tamoxifen with or without irradiation in women age 70 years or older with early breast cancer: long-term follow-up of CALGB 9343. J Clin Oncol. 2013;31(19):2382-7.

13. Kunkler $\mathrm{IH}$, Williams LJ, Jack WJ, et al. Breast-conserving surgery with or without irradiation in women aged 65 years or older with early breas cancer (PRIME II): a randomised controlled trial. Lancet Oncol. 2015;16(3):266-73.

14. Muss HB, Woolf S, Berry D, et al. Adjuvant chemotherapy in older and younger women with lymph node-positive breast cancer. JAMA 2005;293(9):1073-81.

15. Barcenas $\mathrm{CH}$, Niu J, Zhang N, et al. Risk of hospitalization according to chemotherapy regimen in early-stage breast cancer. J Clin Oncol. 2014;32(19):2010-7.

16. Hind D, Wyld L, Beverley $C B$, et al. Surgery versus primary endocrine therapy for operable primary breast cancer in elderly women (70 years plus). Cochrane Database Syst Rev. 2006(1):CD004272.

\section{Cáncer de mama en el hombre}

1. Registro Histopatológico de Neoplasias Malignas. México: Secretaría de Salud: 2008.

2. American Cancer Society. Cancer Facts and Figures 2020. Atlanta, Georgia: American Cancer Society; 2020.

3. Giordano SH. A review of the diagnosis and management of male breast cancer. Oncologist. 2005;10:471-9.

4. Fentiman IS, Fourquet A, Hortobagyi GN. Male breast cancer. Lancet. 2006;367:595-604.

5. Cardoso F, Bartlett J Slaets J. Characterization of male breast cancer: first results of the EORTC10085/TBCRC/BIG/NABCG International Male Breast Cancer Program. Ann Oncol. 2018;29:405-17.

6. Abdelwahab Y. Male breast cancer: Epidemiology and risk factors. Semin Oncol. 2017:44(4):267-72.

7. NIH Surveillance, Epidemiology, and End Results Program. Disponible en: https://seer.cancer.gov/statfacts/html/breast.html

8. Ferzoco R, Ruddy K. The epidemiology of male breast cancer. Curr Oncol Rep 2016; 18: 1.

9. Masci G, Caruso M, Caruso F, et al. Clinicopathological and immunohistochemical characteristics in male breast cancer: a retrospective case series. Oncologist 2015;20:1-7.

10. Rudlowski C. Male breast cancer. Breast Care. 2008;3(3):183-9.

11. Fentiman I, Fourquet A, Hortobagyi G. Male breast cancer. Lancet. 2006;367:595-604.

12. Liu N, Johnson KJ, Ma CX. Male breast cancer: An updated surveillance, epidemiology and end results data analysis. Clin Breast Cancer. 2018;18:e997.

13. Sousa B, Moser E, Cardoso F. An update on male breast cancer and future directions for research and treatment. Eur J Pharmacol. 2013;717(1 3):71-83.

14. Cardoso F, Senkus E. $4^{\text {th }}$ ESO-ESMO International Consensus Guidelines for Advanced Breast Cancer (ABC 4). Ann Oncol. 2018;29:1634-57.

15. Lanitis S, Rice AJ, Vaughan A. Diagnosis and management of male breast cancer. World J Surg. 2008;32:2471-6.

16. Robson M. Olaparib for metastatic breast cancer in patients with a germline BRCA mutation. N Eng J Med. 2017;377:523-33.

17. Litton JK, Rugo HS, Ettl J, et al. Talazoparib in patients with advanced breast cancer and germline BRCA mutation. $N$ Eng $J$ Med. 2018;379(8):753-63

18. Duso B, Trapani D, Marra A, et al. Pharmacological management of male breast cancer. Expert Opin Pharmacother. 2020;21(12):1493-504.

19. Schmid $P$. Atezolizumab and nab-paclitaxel in advanced triple-negative breast cancer. N Engl J Med. 2018;379:2108-21.

\section{Cáncer de mama asociado al embarazo y a la lactancia}

1. McCormick A, Peterson E. Cancer in pregnancy. Obstet Gynecol Clin North Am. 2018;45(2)187-200.

2. Shachar SS, Gallagher K, McGuire K, et al. Multidisciplinary management of breast cancer during pregnancy. Oncologist. 2017;22(3):324-34.

3. Amant $F$, Han SN, Gzirimm, et al. Management of cancer in pregnancy. Best Pract Res Clin Obstet Gynaecol. 2015;29(5):741-53.

4. Robbins J, Jeffries D, Roubidoux M, et al. Accuracy of diagnostic mammography and breast ultrasound during pregnancy and lactation. AJR Am J Roentgenol. 2011;196(3):716-22.

5. Committee Opinion No. 723: Guidelines for Diagnostic Imaging During Pregnancy and Lactation. Committee on Obstetric Practice. Obstet Gy necol. 2017;130(4):e210-e216.
6. ACR-SPR practice parameter for imaging pregnant or potentially pregnant adolescents and women with ionizing radiation. Revised 2018 (Resolution 39) [Internet]. American College of Radiology [consulta: 5 de diciembre 2018]. Disponible en: https://www.acr.org/-/media/acr/files/ practice-parameters/pregnant-pts.pdf

7. Peccatori FA, Codacci-Pisanelli G, Del Grande M, et al. Whole body MRI for systemic staging of breast cancer in pregnant women. Breast. 2017;35:177-81.

8. Nguyen CP, Goodman LH. Fetal risk in diagnostic radiology. Semin UItrasound CT MR. 2012;33(1):4-10.

9. Cordeiro CN, Gemignani ML. Breast cancer in pregnancy: Avoiding fetal harm when maternal treatment is necessary. Breast J. 2017;23(2):200-5.

10. Gropper AB, Calvillo KZ, Dominici L, et al. Sentinel lymph node biopsy in pregnant women with breast cancer. Ann Surg Oncol. 2014;21(8):2506-11.

11. Lohsiriwat V, Peccatori FA, Martella $S$, et al. Immediate breast reconstruction with expander in pregnant breast cancer patients. Breast. 2013:22(5):657-60.

12. Martin DD. Review of radiation therapy in the pregnant cancer patient. Clin Obstet Gynecol. 2011;54:591-601.

13. van Hasselt JG, van Calsteren $K$, Heyns $L$, et al. Optimizing anticance drug treatment in pregnant cancer patients: pharmacokinetic analysis of gestation-induced changes for doxorubicin, epirubicin, docetaxel and paclitaxel. Ann Oncol. 2014;25(10):2059-65.

14. Amant $F$, Loibl $S$, Neven $P$, et al. Breast cancer in pregnancy. Lancet. 2012;379:570-9

15. Peccatori FA, Lambertini M, Scarfone G, et al. Biology, staging, and treatment of breast cancer during pregnancy: Reassessing the evidences. Cancer Biol Med. 2018;15:6-13.

16. Alfasi A, Ben-Aharon I. Breast cancer during pregnancy-Current paradigms, paths to explore. Cancers. 2019:11:1669.

17. Shachar SS, Gallagher K, McGuire K, et al. Multidisciplinary management of breast cancer during pregnancy. Oncologist. 2017;22:324-34.

18. $\mathrm{Yu} \mathrm{HH}$, Cheung PS, Leung RC, et al. Current management of pregnancy-associated breast cancer. Hong Kong Med J. 2017;23(4):387-94.

19. Poggio F, Tagliamento M, Pirrone $C$, et al. Update on the management of breast cancer during pregnancy. Cancers. 2020;12:3616.

20. Amant $F$, van den Broucke $T$, Verheecke $M$, et al. International Network on Cancer, Infertility, and Pregnancy (INCIP). Pediatric outcome after maternal cancer diagnosed during pregnancy. $\mathrm{N}$ Engl $\mathrm{J}$ Med. 2015;373(19):1824-34

21. Murthy RK, Theriault RL, Barnettcm, et al. Outcomes of children exposed in utero to chemotherapy for breast cancer. Breast Cancer Res. 2014;16(6):500.

22. Cardonick E, Bhat A, Gilmandyar D, et al. Maternal and fetal outcomes of taxane chemotherapy in breast and ovarian cancer during pregnancy: case series and review of the literature. Ann Oncol. 2012;23(12):3016-23.

23. McGrath SE, Ring A. Chemotherapy for breast cancer in pregnancy: evidence and guidance for oncologists. Ther Adv Med Oncol. 2011;3(2):73-83

24. Padmagirison R, Gajiar K, Spencer C. Management of breast cancer during pregnancy. Obstet Gynecol. 2010;12:186-92.

25. Lambertini M, Peccatori FA, Azim HA Jr. Targeted agents for cancer treatment during pregnancy. Cancer Treat Rev. 2015;41(4):301-9.

26. Zagouri F, Sergentanis TN, Chrysikos D, et al. Trastuzumab administration during pregnancy: a systematic review and meta-analysis. Breast Cancer Res Treat. 2013:137(2):349-57.

27. Sekar R, Stone PR. Trastuzumab use for metastatic breast cancer in pregnancy. Obstet Gynecol. 2007;110:507-10.

28. A Study of Pregnancy and Pregnancy Outcomes in Women With Breas Cancer Treated With Trastuzumab, Pertuzumab in Combination With Trastuzumab, or Ado-Trastuzumab Emtansine (MotHER). Clinical Trial NCT00833963 [Internet]. U.S. National Library of Medicine, ClinicalTrials. gov [última actualización: 16 de mayo de 2019]. Disponible en: https:// clinicaltrials.gov/ct2/show/NCT00833963

29. $\mathrm{Yu} \mathrm{HH}$, Cheung PS, Leung RC, et al. Current management of pregnancy-associated breast cancer. Hong Kong Med J. 2017;23(4):387-94.

30. Azim HA, Santoro L, Russell-Edu W, et al. Prognosis of pregnancy-associated breast cancer: A meta-analysis of 30 studies. Cancer Treat Rev. 2012;38(7):834-42

31. Amant F, von Minckwitz G, Han NS, et al. Prognosis of women with primary breast cancer diagnosed during pregnancy: results from an international collaborative study. J Clin Oncol. 2013;31(20):2532-9.

32. Bell RJ, Fradkin P, Parathithasan N, et al. Pregnancy-associated breas cancer and pregnancy following treatment for breast cancer, in a cohort of women from Victoria, Australia, with a first diagnosis of invasive breast cancer. Breast. 2013;22:980-5.

33. Crowther CA, Doyle LW, Haslam RR, et al. Outcomes at 2 years of age after repeat doses of antenatal corticosteroids. N Engl J Med. 2007;357:1179-89.

34. Boxer LA, Bolyard AA, Kelley ML, et al. Use of granulocyte colony- stimulating factor during pregnancy in women with chronic neutropenia. Obstet Gynecol. 2015;125:197-203. 


\section{Manejo de histologías poco frecuentes}

\section{Tumor phyllodes}

1. Tse GMK, Tan PH, Lui PCW, et al. Spindle cell lesions of the breast-the pathologic differential diagnosis. Breast Cancer Res Treat. 2008;109:199-207.

2. Birch JM, Alston RD, McNally RJ, et al. Relative frequency and morphology of cancers in carriers of germline TP53 mutations. Oncogene. 2001;20(34):4621-8.

3. Rosenberger LH, Thomas SM, Nimbkar SN, et al. Germline genetic mutations in a multi-center contemporary cohort of 550 phyllodes tumors: An opportunity for expanded multi-gene panel testing. Ann Surg Oncol. 2020;27(10):3633-40

4. Ruvalcaba-Limón E, Jiménez-López J, Bautista-Piña V, et al. Phyllodes tumor of the breast: 307 treated cases, the largest Mexican experience at a single breast disease institution. Iranian J Pathology. 2016;11(4):399 408.

5. Zhou ZR, Wang CC, Sun XJ, et al. Prognostic factors in breast phyllodes tumors: a nomogram based on a retrospective cohort study of 404 patients. Cancer Med. 2018;7(4):1030-42.

6. Wang $H$, Wang $X$, Wang CF. Comparison of clinical characteristics be tween benign borderline and malignant phyllodes tumors of the breast. Asian Pac J Cancer Prev. 2014:15(24):10791-5

7. Ruvalcaba-Limón E, Bautista-Piña V, Villegas-Carlos F, et al. Phyllodes tumor of the breast. Not all are self-detected. J Xiangya Med. 2017;2:49.

8. Park HL, Kwon SH, Chang SY, et al. Long-term follow-up result of benign phyllodes tumor of the breast diagnosed and excised by ultrasound-guided vacuum-assisted breast biopsy. Breast Cancer. 2012; 15(2):224-9.

9. McCarthy E, Kavanagh J, O'Donoghue Y, et al. Phyllodes tumours of the breast: radiological presentation, management and follow-up. Br J Radiol. 2014;87:20140239.

10. Youn I, Choi SH, Moon HJ, et al. Phyllodes tumors of the breast: ultrasonographic findings and diagnostic performance of ultrasound-guided core needle biopsy. Ultrasound Med Biol. 2013;39(6):987-92.

11. Mishra SP, Tiwary SK, Mishra M, et al. Phyllodes tumor of breast: A review article. ISRN Surgery. 2013;2013:361469.

12. Komenaka IK, El-Tamer M, Pile-Spellman E, et al. Core needle biopsy as a diagnostic tool to differentiate phyllodes tumor from fibroadenoma. Arch Surg. 2003;138(9):987-90.

13. Dillon MF, Quinncm, McDermott EW, et al. Needle core biopsy in the diagnosis of phyllodes neoplasm. Surgery. 2006;140:779.

14. Lee AH, Hodi Z, Ellis IO, et al. Histological features useful in the distinction of phyllodes tumour and fibroadenoma on needle core biopsy of the breast. Histopathology. 2007;51:336.

15. WHO: Histological typing of breast tumors. Tumori. 1982;68:181-98.

16. WHO Classification of Tumours of the Breast. Lyon, France: IARC; 2012. pp. 22-3.

17. Tavassoli FA, Devilee P. Pathology and genetics of tumours of the breast and female genital organs. En: World Health Organization Classification of Tumours. Lyon, France: IARC Press; 2003. pp. 99-103

18. Mitus JW, Blecharz $P$, Jakubowicz J, et al. Phyllodes tumors of the breast. The treatment results for 340 patients from a single cancer centre. Breast. 2019;43:85-90.

19. Co M, Chen C, Tsang JY, et al. Mammary phyllodes tumour: a 15-year multicentre clinical review. J Clin Pathol. 2018;71(6):493-7.

20. Yom CK, Han W, Kim SW, et al. Reappraisal of conventional risk stratification for local recurrence based on clinical outcomes in 285 resected phyllodes tumors of the breast. Ann Surg Oncol. 2015;22:2912-8.

21. Moo TA, Alabdulkareem $\mathrm{H}$, Tam $\mathrm{A}$, et al. Association between recurrence and re-excision for close and positive margins versus observation in patients with benign phyllodes tumors. Ann Surg Oncol. 2017:24(10):3088-92

22. NCCN National Comprehensive Cancer Network. Clinical Practice Guidelines in Oncology. Breast Cancer. Version 6.2020. September 8, 2020.

23. Kapiris I, Nasiri N, A'Hern R, et al. Outcome and predictive factors of local recurrence and distant metastases following primary surgical treatment of high-grade malignant phyllodes tumours of the breast. Eur J Surg Oncol. 2001;27(8):723-30.

24. Kim YJ, Kim K. Radiation therapy for malignant phyllodes tumor of the breast: An analysis of SEER data. Breast. 2017;32:26-32.

25. Zeng $S$, Zhang $X$, Yang $D$, et al. Effects of adjuvant radiotherapy on borderline and malignant phyllodes tumors: A systematic review and meta-analysis. Mol Clin Oncol. 2015;3(3):663-71.

26. Gnerlich JL, Williams RT, Yao K, et al. Utilization of radiotherapy for malignant phyllodes tumors: analysis of the National Cancer Data Base, 1998-2009. Ann Surg Oncol. 2014;21(4):1222-30.

27. The University of Texas MD Anderson Cancer Center. Algoritm of phyllodes tumor [Internet]. University of Texas, MD Anderson Cancer Center 2019 [consulta: 8 diciembre 2020]. Disponible en: https://www.mdanderson.org/documents/for-physicians/algorithms/cancer-treatment/ca-treatment-phyllodes-web-algorithm.pdf
28. Kim YH, Kim GE, Lee JS, et al. Hormone receptors expression in phyllodes tumors of the breast. Anal Quant Cytol Histol. 2012;34(1):41-8.

29. Morales-Vásquez F, Gonzalez-Angulo AM, Broglio K, et al. Adjuvant chemotherapy with doxorubicin and dacarbazine has no effect in recurrence-free survival of malignant phyllodes tumors of the breast. Breast J. 2007;13:551.

30. Lu Y, Chen Y, Zhu L, et al. Local recurrence of benign, borderline, and malignant phyllodes tumors of the breast: A systematic review and meta-analysis. Ann Surg Oncol. 2019;26(5):1263-75.

31. Zhang Y, Kleer CG. Phyllodes tumor of the breast. histopathologic features, differential diagnosis, and molecular/genetic updates. Arch Pathol Lab Med. 2016;140:665-71.

\section{Histologías poco frecuentes en cáncer de mama}

1. World Health Organization. Breast Tumours: WHO Classification of Tumours. $5^{\text {th }}$ edition. International Agency for Research on Cancer; 2019.

2. Dabbs David J. Breast Pathology. Philadelphia, PA: Elsevier; 2012.

3. Dieci MV, Orvieto E, Dominici M, et al. Rare breast cancer subtypes: histological, molecular, and clinical peculiarities. Oncologist. 2014;19(8):805-13

4. Cadoo KA, McArdle O, O'Shea AM, et al. Management of unusual histological types of breast cancer. Oncologist. 2012;17(9):1135-45.

5. Han Y, Wang J, Xu B. Clinicopathological characteristics and prognosis of breast cancer with special histological types: A surveillance, epidemiology, and end results database analysis. Breast. 2020:54:114-20.

6. Tan PH, Ellis I, Allison K, et al. The 2019 World Health Organization classification of tumours of the breast. Histopathology. 2020;77(2):181-5.

7. Marrazzo E, Frusone F, Milana F, et al. Mucinous breast cancer: A narrative review of the literature and a retrospective tertiary single-centre analysis. Breast. 2020;49:87-92.

8. Tan PH, Tse GMK, Bay BH. Mucinous breast lesions: Diagnostic challenges. J Clin Pathol. 2008:61:11-9.

9. Di Saverio S, Gutierrez J, Avisar E. A retrospective review with long term follow up of 11,400 cases of pure mucinous breast carcinoma. Breast Cancer Res Treat. 2008;111:541-7.

10. Rosen LE, Gattuso P. Neuroendocrine tumors of the breast. Arch Pathol Lab Med. 2017;141(11):1577-81.

11. Inno A, Bogina G, Turazza M, et al. Neuroendocrine carcinoma of the breast: Current evidence and future perspectives. Oncologist. 2016;21:28-32.

12. Grabowski J, Salzstein SL, Sadler GR, et al. Intracystic papillary carcinoma: A review of 917 cases. Cancer. 2008;113:916-20.

13. Pal SK, Lau SK, Kruper L, et al. Papillary carcinoma of the breast: An overview. Breast Cancer Res Treat. 2010;122:637-45.

14. Rakha EA, Gandhi N, Climent $F$, et al. Encapsulated papillary carcinoma of the breast: An invasive tumor with excellent prognosis. Am J Surg Pathol. 2011:35:1093-103.

15. Sarnaik AA, Meade T, King J, et al. Adenoid cystic carcinoma of the breast: A review of a single institution's experience. Breast J. 2010;16:208-10.

16. Tixier $\mathrm{H}$, Picard $\mathrm{A}$, Guiu S, et al. Long-term recurrence of secretory breas carcinoma with metastatic sentinel lymph nodes. Arch Gynecol Obstet. 2011;283(Suppl 1):77-8.

17. Toss MS, Billingham K, Egbuniwe IU, et al. Breast tumours resembling the tall cell variant of thyroid papillary carcinoma: Are they part of the papillary carcinoma spectrum or a distinct entity? Pathobiology. 2019;86(2-3):83-91.

18. Foschini MP, Asioli $S$, Foreid $S$, et al. Solid papillary breast carcinomas resembling the tall cell variant of papillary thyroid neoplasms: A unique invasive tumor with indolent behavior. Am J Surg Pathol. 2017; 41(7):887-95.

19. Tanaka K, Imoto S, Wada N, et al. Invasive apocrine carcinoma of the breast: Clinicopathologic features of 57 patients. Breast J. 2008; 14:164-8.

20. Luini A, Aguilar M, Gatti G, et al. Metaplastic carcinoma of the breast, an unusual disease with worse prognosis: The experience of the European Institute of Oncology and review of the literature. Breast Cancer Res Treat. 2007;101:349-53.

21. Pezzicm, Patel-Parekh L, Cole K, et al. Characteristics and treatment of metaplastic breast cancer: Analysis of 892 cases from the National Cancer Data Base. Ann Surg Oncol. 2007;14:166-73.

22. Jung SY, Kim HY, Nam BH, et al. Worse prognosis of metaplastic breast cancer patients than other patients with triple-negative breast cancer. Breast Cancer Res Treat. 2010;120:627-37.

23. Hare F, Giri S, Patel JK, et al. A population-based analysis of outcomes for small cell carcinoma of the breast by tumor stage and the use of radiation therapy. Springerplus. 2015;4:138.

24. Zekioglu O, Erhan Y, Ciris M, et al. Invasive micropapillary carcinoma of the breast: High incidence of lymph node metastasis with extranodal extension and its immunohistochemical profile compared with invasive ductal carcinoma. Histopathology. 2004;44:18-23. 
XIX. Seguimiento posterior al tratamiento con intención curativa y en enfermedad metastásica

\section{Terapia hormonal de reemplazo}

1. Legorreta D, Montano JA, Hernández I, et al. Age at menopause, motives for consultation and symptoms reported by $49-59$ year old Mexican Women. Climateric. 2013;16(4):417-25.

2. Collaborative Group on Hormonal Factors in Breast Cancer. Breast cancer and hormone replacement therapy: collaborative reanalysis of data from 51 epidemiological studies of 52,705 women with breast cancer and 108,411 women without breast cancer. Lancet. 1997;350:1047-59.

3. Col NF, Kim JA, Chlebowski RT. Menopausal hormone therapy after breast cancer: a meta-analysis and critical appraisal of the evidence. Breast Cancer Res. 2005;7(4):R535-40.

4. Bruno D, Feeney KJ. Management of postmenopausal symptoms in breast cancer survivors. Semin Oncol. 2006;33(6):696-707.

5. Fahlealn M, Fornander $\mathrm{T}$, Johansson $\mathrm{H}$, et al. Hormone replace therapy after breast cancer: 10 year follow up of the Stockholm randomized trial. Eur J Cancer. 2013;49:52-9.

6. Kenemans P, Bundred NJ, Foidart JM, et al. Safety and efficacy of tibolone in breast-cancer patients with vasomotor symptoms: a double-blind, randomized, non-inferiority trial. Lancet Oncol. 2009;10:135-46.

7. Bregar A, Taylor K, Syuckey A. Hormone therapy in survivors of gynecological and breast cancer. Obstet Gynecol. 2014;16(4):251-8.

\section{Genética y cáncer mamario}

1. González-Santiago S, Ramón y Cajal T, Aguirre E, et al. SEOM clinical guidelines in hereditary breast and ovarian cancer (2019). Clin Trans Oncol. 2020;22:193-200.

2. Wendt $C$, Margolin S. Identifying breast cancer susceptibility genes - a review of the genetic background in familial breast cancer. Acta Oncol. 2019;58(2):135-46.

3. Kobayashi H, Ohno S, Sasaki Y, et al. Hereditary breast and ovarian cancer susceptibility genes. Oncology Reports. 2013;30:1019-29.

4. Economopoulou P, Dimitriadis G, Psyrri A. Beyond BRCA: new hereditary breast cancer susceptibility genes. Cancer Treat Rev. 2015;41:1-8.

5. Oliver J, Quezada-Urban R, Franco-Cortés CA, et al. Latin American study of hereditary breast and ovarian cancer LACAM: a genomic epidemiology approach. Front Oncol. 2019;9:1429.

6. Narod SA, Rodríguez AA. Genetic predisposition for breast cancer: BRCA1 and BRCA2 genes. Salud Pública Méx. 2011;53:420-9.

7. National Comprehensive Cancer Network. Genetic/familial high-risk assessment: Breast, ovarian and pancreatic (version 2.2021) [Internet] National Comprehensive Cancer Network. Disponible en: https://www. nccn.org/professionals/physician_gls/pdf/genetics_bop.pdf

8. LaDuca $\mathrm{H}$, Polley EC, Yussuf $\mathrm{A}$, et al. A clinical guide to hereditary cancer panel testing: evaluation of gene-specific cancer associations and sensitivity of genetic testing criteria in a cohort of 165,000 high-risk patients. Genet Med. 2020;22:407-15

9. Villarreal-Garza C, Weitzel JN, Llacuachaqui M, et al. The prevalence of BRCA1 and BRCA2 mutations among young Mexican women with triple-negative breast cancer. Breast Cancer Res Treat. 2015;150:389-94.

10. Zugazagoitia J, Pérez-Segura $P$, Manzano A, et al. Limited family structure and triple-negative breast cancer (TNBC) subtype as predictors of BRCA mutations in a genetic counseling cohort of early-onset sporadic breast cancers. Breast Cancer Res Treat. 2014;148:415-21.

11. Fragoso-Ontiveros V, Velázquez-Aragón JA, Nuñez-Martínez PM, et al. Mexican BRCA1 founder mutation: Shortening the gap in genetic assessment for hereditary breastand ovarian cancerpatients. PLoSOne. 2019;14(9):e0222709.

\section{Aspectos psicooncológicos en cáncer mamario}

1. Campbell-Enns HJ, Woodgate R. The psychosocial experiences of women with breast cancer across the lifespan: a systematic review. Psychooncology. 2017;26(11):1711-21.

2. Brandao T, Schulz MS, Matos PM. Psychological adjustment after breast cancer: A systematic review of longitudinal studies. Psychooncology. 2017;26(7):917-26.

3. Cardoso F, Loibl S, Pagani O, et al. The European Society of Breast Cancer Specialists recommendations for the management of young women with breast cancer. Eur J Cancer. 2012;18:3355-77.

4. Champion L, Wagner $\mathrm{LI}, \mathrm{O}$ Monahan $\mathrm{P}$, et al. Comparison of younger and older breast cancer survivors and age-matched controls on specific and overall quality of life domains. Cancer. 2014;120:2237-46.

5. Vázquez OG, Castillo ER, Huertas LA, et al. Guía de práctica clínica para la atención psico-oncológica del cuidador primario informal de pacientes con cáncer. Psicooncología. 2015;12(1):87-104.

6. Manne S, Kashy D, Siegel S, et al. Unsupportive partner behaviors, social cognitive and psychological outcomes in couple coping with early stage breast cancer. J Fam Psychol. 2014;28(2):214-24.
7. Galindo $\mathrm{O}$, Benjet $\mathrm{C}$, Juárez $\mathrm{F}$, et al. Propiedades psicométricas de la Escala Hospitalaria de Ansiedad y Depresión (HADS) en una población de pacientes oncológicos mexicanos. Salud Ment. 2015;38(4).

8. Galindo-Vázquez $\mathrm{O}$, Benjet $\mathrm{C}$, Cruz-Nieto $\mathrm{MH}$, et al. Psychometric properties of the Zarit Burden Interview in Mexican caregivers of cancer patients. Psychooncology. 2015;24(5):612-5.

9. Moral De la ubia, J. Estudio de validación de la escala de ajuste diádico (DAS) en población mexicana. Revista Internacional de Ciencias Sociales y Humanidades, SOCIOTAM [Internet]. 2009;XIX(1):113-138.

10. Matthews $\mathrm{H}$, Grunfeld $E A$, Turner $A$. The efficacy of interventions to improve psychosocial outcomes following surgical treatment for breast cancer: A systematic review and meta-analysis. Psychooncology. 2017;26(5):593-607.

11. Galindo-Vázquez $\mathrm{O}$, Pérez-Barrientos $\mathrm{H}$, Alvarado-Aguilar $\mathrm{S}$, et al. Efectos de la terapia cognitivo conductual en el paciente oncológico: una revisión. GAMO. 2013;12(2):108-15.

\section{Rehabilitación física de la paciente con cáncer de mama}

1. Dinas, K, Kalder M, Zepiridis L, et, al. Axillary web syndrome: Incidence, pathogenesis and management. Curr Probl Cancer. 2019;(3)1:1-4.

2. Connell $F$, Brice $G$, Jefferson $S$, et al. A new classification system for primary lymphatic displasias based no phenotype. Clin Genet. 2010;77:438-52

3. Connell F, Gordo K, Brice G, et al. The classification and diagnostic algorithm for primary lymphatic displasia: an update forma 2010 to include molecular findings. Clin Genet. 2013;84(4):303-14.

4. Paiva C, Dutra C. Prevalencia de linfedema tras tratamiento de cáncer de mama en mujeres con sobrepeso. Fisioter Pesqui. 2016;23(3):263-7.

5. Rockson S. Diagnosis and management of lymphatic vascular disease. J Am Coll Cardiol. 2008;52:799.

6. Merchant S, Chen S. Prevention and management of lymphedema after breast cancer treatment. Breast J. 2015;21(3):276-84.

7. Yélamos C, Montesinos F, Eguino A, et al. Impacto del linfedema en la calidad de vida de las mujeres con cáncer de mama. Psicooncología. 2007;4(1):143-63.

8. Foldi $\mathrm{E}$, Foldi $\mathrm{M}$, Weissleder $\mathrm{H}$. Conservative treatment of lymphoedema of the limbs. Angiology. 1985;36:171-80.

9. Morris $\mathrm{C}$, Wonders $\mathrm{K}$. Concise review on the safety of exercise on symptoms of lymphedema. World J Clin Oncol. 2015;6(4):43-4.

10. Ciucci JL. $6^{\circ}$ Consenso Latinoamericano para el tratamiento del linfedema. Guía de tratamiento. Linfología [Internet]. 2007:175-178. Disponible en: http://www.centrociucci.com.ar/descargas/6-Consenso-2017-n uevo3.pdf

11. Thomaz J, Maximo D, Rezende L. Efeito do uso do taping na redução do volume do linfedema secundário ao câncer de mama: revisão da literatura. J Vasc Bras. 2018;17(2):136-40.

12. Brown J, Winters-Stone $\mathrm{K}$, Lee J, et al. Cancer, physical activity, and exercise. Compr Physiol. 2012;2:2775-809.

\section{COVID-19 y cáncer de mama}

1. Al-Shamsi HO, Alhazzani W, Alhuraiji A, et al. A practical approach to the management of cancer patients during the novel coronavirus disease 2019 (COVID-19) pandemic: An International Collaborative Group. Oncologist. 2020;25(6):e936-e945.

2. Kawate T, Yoshida A, Sugae S, et al. Recommendations for the management of breast cancer patients during the COVID-19 pandemic from the Japan Breast Cancer Society. Breast Cancer. 2021;28:247-53.

3. Chan JJ, Sim Y, Guan S, et al. The impact of COVID-19 on and recommendations for breast cancer care: the Singapore experience. Endocr Relat Cancer. 2020;27(9):R307-R327.

4. Curigliano G, Banerjee S, Cervantes A, et al. Managing cáncer patients during the COVID-19 pandemic: an ESMO multidisciplinary expert consensus. Ann Oncol. 2020;31(10):1320-35.

5. Cortés-Meda A, Ponciano-Rodríguez G. Impacto de los determinantes sociales de la COVID-19 en Méxic. Boletín COVID-19. 2021;2(17):9-13.

6. Desai A, Sachdeva S, Parekh T, et al. COVID-19 and cancer: Lessons from a pooled meta-analysis. JCO Glob Oncol. 2020;(6):557-9.

7. Giannakoulis VG, Papoutsi E, Siempos II. Effect of cancer on clinical outcomes of patients with COVID-19: A meta-analysis of patient data. JCO Glob Oncol. 2020;6:799-808.

8. Liang W, Guan W, Chen R, et al. Cancer patients in SARS-CoV-2 infection: a nationwide analysis in China. Lancet Oncol. 2020; 21(3):335-7.

9. Kuderer NM, Choueiri TK, Shah DP, et al. Clinical impact of COVID-19 on patients with cancer (CCC19): a cohort study. Lancet. 2020; 395(10241):1907-18.

10. Belkacemi $Y$, Grellier N, Ghith S, et al. A review of the international early recommendations for departments organization and cancer management priorities during the global COVID-19 pandemic: applicability in low- and middle-income countries. Eur J Cancer. 2020;135:130-46. 
11. Sud A, Jones ME, Broggio J, et al. Collateral damage: the impact on outcomes from cancer surgery of the COVID-19 pandemic. Ann Oncol. 2020;31(8):1065-74

12. de Azambuja E, Trapani D, Loibl S, et al. ESMO Management and treatment adapted recommendations in the COVID-19 era: Breast cancer. ESMO Open. 2020;5(Suppl 3):e000793.

13. Sheng JY, Santa-Maria CA, Mangini N, et al. Management of breast cancer during the COVID-19 pandemic: A stage-and subtype-specific approach. JCO Oncol Pract. 2020;16(10):665-74.

14. Royce TJ, Sanoff HK, Rewari A. Telemedicine for cancer care in the time of COVID-19. JAMA Oncol. 2020;6(11):1698-9.

15. Marcus DM, Weathers WM, Rossi PJ. Computed tomography in radiation oncology during the coronavirus disease 2019 pandemic. Adv Radiat Oncol. 2020;5(4):757-60

16. Soran A, Gimbel M, Diego E. Breast cancer diagnosis, treatment and follow-up during covid-19 pandemic. Eur J Breast Health. 2020; 16(2):86-8.

17. Shankar A, Saini D, Roy S, et al. Cancer care delivery challenges amidst coronavirus disease-19 (COVID-19) outbreak: Specific precautions for cancer patients and cancer care providers to prevent spread. Asian Pac J Cancer Prev. 2020;21(3):569-73

18. Lee LYW, Cazier JB, Angelis V, et al. COVID-19 mortality in patients with cancer on chemotherapy or other anticancer treatments: A prospective cohort study. Lancet. 2020;395(10241):1919-26.

19. Brar G, Pinheiro LC, Shusterman M, et al. COVID-19 severity and outcomes in patients with cancer: A matched cohort study. J Clin Oncol. 2020;38(33):3914-24.

20. Song $\mathrm{C}$, Dong $\mathrm{Z}$, Gong $\mathrm{H}$, et al. An online tool for predicting the prognosis of cancer patients with SARS-CoV-2 infection: a multi-center study. $\mathrm{J}$ Cancer Res Clin Oncol. 2021;147(4):1247-57.

21. Lambertini M, Toss A, Passaro A, et al. Cancer care during the spread of coronavirus disease 2019 (COVID-19) in Italy: young oncologists' perspective. ESMO Open. 2020;5(2):e000759

22. Vordermark D. Shift in indications for radiotherapy during the COVID-19 pandemic? A review of organ-specific cancer management recommendations from multidisciplinary and surgical expert groups. Radiat Oncol. 2020;15(1):140.

23. Maldonado Magos F, Félix Leyva A Pérez Álvarez SI, et al. Guía Práctica sobre el funcionamiento de un servicio de Radioterapia durante el brote de coronavirus en México [Internet]. Mexico: Consejo Mexicano de Certificación en Radioterapia A.C., Sociedad Mexicana de Radioterapeutas. Disponible en: https://www.somera.org.mx/wp-content/uploads/2020/03/ Gui\%CC\%81a-Radioterapia-COVID-19-V1.1-1.pdf-1.pdf

24. de Azambuja E, Trapani D, Loibl S, et al. ESMO Management and treatment adapted recommendations in the COVID-19 era: Breast Cancer. ESMO Open. 2020;5(Suppl 3):e000793.

25. Nagar H, Formenti SC. Cancer and COVID-19 - potentially deleterious effects of delaying radiotherapy. Nat Rev Clin Oncol. 2020; $17(6): 332-4$

26. Braunstein LZ, Gillespie EF, Hong L, et al. Breast radiation therapy unde COVID-19 pandemic resource constraints-approaches to defer or shorten treatment from a comprehensive cancer center in the United States. Adv Radiat Oncol. 2020;5(4):582-8.

27. Coles CE, Aristei C, Bliss J, et al. International Guidelines on Radiation Therapy for Breast Cancer During the COVID-19 Pandemic. Clin Oncol (R Coll Radiol). 2020;32(5):279-81.

28. Al-Rashdan A, Roumeliotis M, Quirk S, et al. Adapting radiation therapytreatments for patients with breast cancer during the COVID-19 pandemic: Hypo-fractionation and accelerated partial breast irradiation to address World Health Organization recommendations. Adv Radiat Oncol. 2020;5(4):575-6.

29. ESMO statements for vaccination against COVID-19 in patients with cancer. COVID-19 vaccination in cancer patients: ESMO statements [Internet]. European Society for Medical Oncology; 2021. Disponible en: www. esmo.org/covid-19-vaccination

30. Dai L, Gao GF. Viral targets for vaccines against COVID-19. Nat Rev Immunol. 2021;21(2):73-82.

\section{PARTICIPANTES EN LA NOVENA REVISIÓN DEL CONSENSO}

\section{Coordinadores}

Dr. Jesús Cárdenas Sánchez

Oncólogo médico

Centro Médico de Colima

Colima, Col.
Dra. Aura A. Erazo Valle-Solís

Oncóloga médica

Centro Médico Nacional 20 de Noviembre, ISSSTE

Ciudad de México, Méx.

Dra. Claudia Arce Salinas

Oncóloga médica

Instituto Nacional de Cancerología, SS

Ciudad de México, Méx.

\section{Dr. Juan Enrique Bargalló Rocha}

Cirujano oncólogo

Instituto Nacional de Cancerología, SS

Ciudad de México, Méx.

\section{Dra. Verónica Bautista Piña}

Patóloga

Instituto de Enfermedades de la Mama, FUCAM

Ciudad de México, Méx.

Dra. Ma. Guadalupe Cervantes Sánchez

Oncóloga médica

Centro Médico Nacional 20 de Noviembre, ISSSTE

Ciudad de México, Méx.

Dra. Christian Haydeé Flores Balcázar

Radiooncóloga

Instituto Nacional de Ciencias Médicas y Nutrición

Salvador Zubirán, SS

Ciudad de México, Méx.

Dra. Ma. del Carmen Lara Tamburrino

Radióloga

Grupo CT Scanner de México

Ciudad de México, Méx.

Dra. Ana Lluch Hernández

Oncóloga médica

Hospital Clínico

Valencia, España

\section{Dr. Antonio Maffuz Aziz}

Cirujano oncólogo

Centro Médico ABC

Ciudad de México, Méx.

\section{Dr. Víctor Manuel Pérez Sánchez}

Patólogo

Instituto Nacional de Cancerología, SS

Ciudad de México, Méx.

Dra. Adela Poitevín Chacón

Radiooncóloga

Médica Sur

Ciudad de México, Méx.

\section{Dr. Efraín Salas González}

Oncólogo médico

Centro Médico Nacional de Occidente, IMSS

Guadalajara, Jal.

\section{Dr. Enrique Soto Pérez de Celis}

Oncólogo médico

Instituto Nacional de Ciencias Médicas y Nutrición Salvador Zubirán, SS

Ciudad de México, Méx.

Dra. Laura Torrecillas Torres

Oncóloga médica

Centro Médico Nacional 20 de Noviembre, ISSSTE 
Ciudad de México, Méx.

Dr. Vicente Valero Castillo

Oncólogo médico

University of Texas

M. D. Anderson Cancer Center

Houston, TX, EE.UU.

Dra. Yolanda Villaseñor Navarro

Radióloga

Instituto Nacional de Cancerología, SS

Ciudad de México, Méx.

\section{Grupo 1 - Oncología médica}

Dra. Claudia Arce Salinas (C)

Oncóloga médica

Instituto Nacional de Cancerología, SS

Ciudad de México, Méx.

Dra. Ma. Guadalupe Cervantes Sánchez (C)

Oncóloga médica

Centro Médico Nacional 20 de Noviembre, ISSSTE

Ciudad de México, Méx.

Dra. Ana Lluch Hernández (C)

Oncóloga médica

Hospital Clínico

Valencia, España

Dr. Efraín Salas González (C)

Oncólogo médico

Centro Médico Nacional de Occidente, IMSS

Guadalajara, Jal.

Dra. Laura Torrecillas Torres (C)

Oncóloga médica

Centro Médico Nacional 20 de Noviembre, ISSSTE

Ciudad de México, Méx.

Dr. Vicente Valero Castillo (C)

Oncólogo médico

University of Texas

M.D. Anderson Cancer Center

Houston, TX, EE.UU.

\section{Dr. Fernando Aldaco Sarvide}

Oncólogo médico

Centro Médico Nacional 20 de Noviembre, ISSSTE

Ciudad de México, Méx.

Dr. Alberto Alvarado Miranda

Oncólogo médico

Instituto Nacional de Cancerología, SS

Ciudad de México, Méx.

Dra. Paula Anel Cabrera Galeana

Oncóloga médica

Instituto Nacional de Cancerología, SS

Ciudad de México, Méx.

\section{Dra. Yanín Chavarri Guerra}

Oncóloga médica

Instituto Nacional de Ciencias Médicas y Nutrición

Salvador Zubirán, SS

Ciudad de México, Méx.

Dra. Mariana Chávez MacGregor

Oncóloga médica
University of Texas

M.D. Anderson Cancer Center

Houston, TX, EE.UU.

Dr. Mario Escobar Gómez

Oncólogo médico

Hospital General de México Eduardo Liceaga, SS

Ciudad de México, Méx.

Dra. Diana Flores Díaz

Oncóloga Médica

Instituto Nacional de Cancerología, SS

Ciudad de México, Méx.

Dra. Georgina Garnica Jaliffe

Oncóloga médica

Hospital General de México Eduardo Liceaga, SS

Ciudad de México, Méx.

Dr. Juan Francisco González Guerrero

Oncólogo médico y radioterapeuta

Centro Universitario contra el Cáncer, UANL

Monterrey, N. L.

Dra. Rocío Grajales Álvarez

Oncóloga médica

Hospital de Oncología, CMN Siglo XXI, IMSS

Ciudad de México, Méx.

Dra. Flavia Morales Vázquez

Oncóloga médica

Instituto de Enfermedades de la Mama, FUCAM

Ciudad de México, Méx.

Dra. Perla Pérez Pérez

Oncóloga médica

Centro Médico Nacional 20 de Noviembre, ISSSTE

Ciudad de México, Méx.

Dra. Sandy Ruiz García

Oncóloga médica

Instituto Nacional de Cancerología, SS

Ciudad de México, Méx.

Dr. Benito Sánchez Llamas

Oncólogo médico

Centro Médico Nacional de Occidente, IMSS

Guadalajara, Jal.

Dr. Ricardo Villalobos Valencia

Oncólogo médico

Centro Médico La Raza, IMSS

Ciudad de México, Méx.

Dra. Cynthia Villarreal Garza

Oncóloga médica

Centro de Cáncer de Mama, Hospital Zambrano

Hellion, Tec Salud

Monterrey, N.L.

Grupo 2 - Cirugía oncológica

Dr. Juan Enrique Bargalló Rocha (C)

Cirujano oncólogo

Instituto Nacional de Cancerología, SS

Ciudad de México, Méx.

Dr. Antonio Maffuz Aziz (C)

Cirujano oncólogo 
Centro Médico ABC

Ciudad de México, Méx.

Dra. Alethia Álvarez Cano

Cirujana oncóloga

Hospital Universitario Dr. José Eleuterio González

Monterrey, N.L.

Dr. Jaime Corona Rivera

Cirujano oncólogo

Hospital Century 2000

Guadalajara, Jal.

Dra. Ana Olivia Cortés Flores

Cirujana oncóloga

Hospital San Javier

Guadalajara, Jal.

Dr. Carlos Alberto Cortés García

Cirujano oncólogo

Hospital de Especialidades CMN Manuel Ávila Camacho, IMSS

Puebla, Pue.

Dr. Sarish del Real Ordóñez

Ginecóloga oncóloga

Centro Oncológico Región Sureste

Saltillo, Coah.

Dra. Nereida Esparza Arias

Cirujana oncóloga

Instituto Nacional de Cancerología, SS

Ciudad de México, Méx.

Dr. Jonathan Figueroa Padilla

Cirujano plástico reconstructor

Instituto Nacional de Cancerología, SS

Ciudad de México, Méx.

Dra. Sonia Ma. Flores Moreno

Cirujana oncóloga

Hospital Regional de Alta Especialidad Materno Infantil, SS

Monterrey, N.L.

\section{Dr. Sergio Carlos Hidalgo Bahena}

Cirujano oncólogo

Hospital Central Militar

Ciudad de México, Méx.

Dr. Fernando Mainero Ratchelous

Cirujano oncólogo

Hospital de Gineco-Obstetricia N.- 4, IMSS

Ciudad de México, Méx.

\section{Dr. Heriberto Medina Franco}

Cirujano oncólogo

Instituto Nacional de Ciencias Médicas y Nutrición

Salvador Zubirán, SS

Ciudad de México, Méx.

Dra. Sarina Navarro Santiesteban

Cirujana oncóloga

Hospital General Agustín O'Horan

Mérida, Yuc.

Dr. Gregorio Quintero Beuló

Cirujano oncólogo
Hospital General de México Eduardo Liceaga, SS

Ciudad de México, Méx.

Dra. Ma. Teresa Ramírez Ugalde

Cirujana oncóloga

Instituto Nacional de Cancerología, SS

Ciudad de México, Méx.

Dr. Carlos D. Robles Vidal

Cirujano oncólogo

Instituto Nacional de Cancerología, SS

Ciudad de México, Méx.

Dr. Sergio Rodríguez Cuevas

Cirujano oncólogo

Academia Mexicana de Cirugía

Ciudad de México, Méx.

Dra. Eva Ruvalcaba Limón

Ginecóloga oncóloga

Instituto de Enfermedades de la Mama, FUCAM

Ciudad de México, Méx.

Dr. Rodrigo Serrano Ortiz

Cirujano oncólogo

Centro Oncológico Estatal, ISSEMyM

Toluca, Méx.

Dr. Rafael Vázquez Romo

Cirujano oncólogo

Instituto Nacional de Cancerología, SS

Ciudad de México, Méx.

\section{Grupo 3 - Radiooncología}

Dra. Adela Poitevín Chacón (C)

Radiooncóloga

Médica Sur

Ciudad de México, Méx.

Dra. Christian Haydeé Flores Balcázar (C)

Radiooncóloga

Instituto Nacional de Ciencias Médicas y Nutrición Salvador Zubirán, SS

Ciudad de México, Méx.

Dra. Adriana Alvarado Zermeño

Radiooncóloga

Centro Médico de Occidente, IMSS

Guadalajara, Jal.

Dra. Eva Eulalia Arvizo Bencomo

Radiooncóloga

Centro Universitario Contra el Cáncer, UANL

Monterrey, N.L.

Dra. Ma. Yisel Bautista Hernández

Radiooncóloga

Hospital General de México Eduardo Liceaga, SS

Ciudad de México, Méx.

Dra. Jessica Chávez Nogueda

Radiooncóloga

Hospital de Oncología, CMN Siglo XXI, IMSS

Ciudad de México, Méx.

Dra. Dolores de la Mata Moya

Radiooncóloga 
Centro Médico ABC

Ciudad de México, Méx.

Dr. Luis Carlos Durazo Cons

Radiooncólogo

Centro Oncológico Estatal

Hermosillo, Son.

Dr. Jesús Manuel Flores Castro

Radiooncólogo

Instituto Nacional de Cancerología, SS

Ciudad de México, Méx.

Dra. Gabriela Núñez Guardado

Radiooncóloga

Centro Médico Nacional 20 de Noviembre, ISSSTE

Ciudad de México, Méx.

Dr. Daniel Rivera Sánchez

Radiooncólogo

Instituto Nacional de Cancerología, SS

Ciudad de México, Méx.

Dra. Amelia Esperanza Sarricolea Puch

Radiooncóloga

Hospital de Especialidades Ignacio García Téllez, IMSS

Mérida, Yuc.

Dra. Michelle Aline Villavicencio Queijeiro

Radiooncóloga

Centro Médico Nacional 20 de Noviembre, ISSSTE

Ciudad de México, Méx.

Dra. Jean L. Writght

Radiooncóloga

John Hopkins University

Baltimore, MD, EE.UU.

Grupo 4 - Patología

Dr. Víctor Manuel Pérez Sánchez (C)

Patólogo

Instituto Nacional de Cancerología, SS

Ciudad de México, Méx.

Dra. Verónica Bautista Piña (C)

Patóloga

Instituto de Enfermedades de la Mama, FUCAM

Ciudad de México, Méx.

Dr. Aldo Antonio Alcaraz Wong

Patólogo

Centro Médico de Occidente, IMSS

Guadalajara, Jal.

Dra. Isabel Alvarado Cabrero

Patóloga

Hospital de Oncología, CMN Siglo XXI, IMSS

Ciudad de México, Méx.

Dr. Héctor Aquiles Maldonado Martínez Patólogo

Instituto Nacional de Cancerología, SS

Ciudad de México, Méx.

Dra. Yolanda Ortíz Mancisidor

Patóloga

Hospital Regional de Xalapa, SS

Xalapa, Ver.
Dr. Jorge Rodarte Corro

Patólogo

Hospital General de Tijuana, SS

Tijuana, B.C.N.

Dr. Héctor Santiago Payán

Patólogo

Hospital Santa Fé

Ciudad de México, Méx.

Dra. Tania Pilar Álvarez Domínguez

Patóloga

Hospital General Naval de Alta Especialidad

Ciudad de México, Méx.

Dr. Pedro Damián Fons Enríquez

Patólogo

Central Estatal de Cancerología, SS

Xalapa, Ver.

Dra. Gabriela Sofía Gómez Macías

Patóloga

Centro de Cáncer de Mama, Hospital San José

Monterrey, N.L.

Dra. Mercedes Hernández González

Patóloga

Hospital General de México Eduardo Liceaga, SS

Ciudad de México, Méx.

Dr. Gerónimo Tavares Macías

Patólogo

Centro Médico de Occidente, IMSS

Guadalajara, Jal.

Dra. Graciela Velázquez Delgado

Patóloga

Centro Estatal de Atención Oncológica, SS

Morelia, Mich.

Dra. Ángela Dayana Williams Jacquez

Patóloga

Hospital Regional de Alta Especialidad de la Península de Yucatán, SS

Mérida, Yuc.

Grupo 5 - Diagnóstico por imagen

Dra. Yolanda Villaseñor Navarro (C)

Radióloga

Instituto Nacional de Cancerología, SS

Ciudad de México, Méx.

Dra. María del Carmen Lara Tamburrino (C)

Radióloga

Grupo CT Scanner de México

Ciudad de México, Méx.

Dra. Lesvia Oliva Aguilar Cortázar

Radióloga

Instituto Nacional de Cancerología, SS

Ciudad de México, Méx.

Dra. Nadia Millán Sánchez

Radióloga

Grupo CT Scanner de México

Ciudad de México, Méx.

Dra. Liliana Moreno Astudillo

Radióloga 
Instituto Nacional de Cancerología, SS

Ciudad de México, Méx.

Dra. Myrna Verónica Palma Garzón

Radióloga

Hospital Regional de Alta Especialidad, SS

Oaxaca, Oax.

Dra. Cecilia Magdalena Pavón Hernández Radióloga

Instituto Nacional de Cancerología, SS

Ciudad de México, Méx.

Dra. Martha Patricia Pérez Badillo

Radióloga

Instituto Nacional de Cancerología, SS

Ciudad de México, Méx.

\section{Grupo 6 - Misceláneos}

Dr. Enrique Soto Pérez de Celis (C)

Oncólogo médico

Instituto Nacional de Ciencias Médicas y Nutrición

Salvador Zubirán, SS

Ciudad de México, Méx.

Dr. Sergio Rodríguez Cuevas (epidemiología)

Cirujano oncólogo

Academia Mexicana de Cirugía

Ciudad de México, Méx.

M. en C. Luz del Carmen Hernández Hernández

Epidemióloga

Organización Panamericana de la Salud e INDRE

Ciudad de México, Méx.

Dr. Arturo Vega Saldaña (educación y factores de riesgo)

Ginecólogo

Centro Nacional de Equidad de Género y Salud Reproductiva, SS

Ciudad de México, Méx.

Dra. Silvia Allende Pérez (cuidados paliativos)

Paliativista

Instituto Nacional de Cancerología, SS

Ciudad de México, Méx.

Dra. Edith Monreal Carrillo

Paliativista

Instituto Nacional de Cancerología, SS

Ciudad de México, Méx.

Dra. Emma Verástegui Avilés

Paliativista

Instituto Nacional de Cancerología, SS

Ciudad de México, Méx.

Dra. Silvia Vidal Millán (genética)

Genetista

Instituto Nacional de Cancerología, SS

Ciudad de México, Méx.
Dra. Rosa Ma. Álvarez Gómez

Genetista

Instituto Nacional de Cancerología, SS

Ciudad de México, Méx.

Dra. Ma. Teresa de Jesús Cervantes Díaz

Genetista

UMAE Hospital de Oncología, CMN Siglo XXI, IMSS

Ciudad de México, Méx.

Dra. Ma. Paulina Núñez Martínez

Genetista

Instituto Nacional de Cancerología, SS

Ciudad de México, Méx.

Dra. Martha Orozco Quiyono

Genetista

Centro Médico Nacional 20 de Noviembre, ISSSTE

Ciudad de México, Méx.

Dra. Guadalupe Eugenia Paredes Rivera

Genetista

UMAE Hospital de Oncología, CMN Siglo XXI, IMSS

Ciudad de México, Méx.

Dra. Talia Wegman Ostrosky

Genetista

Instituto Nacional de Cancerología, SS

Ciudad de México, Méx.

Psic. Onc. Salvador Alvarado Aguilar (psicooncología)

Instituto Nacional de Cancerología, SS

Ciudad de México, Méx.

Dr. en Psic. Óscar Galindo Vázquez

Instituto Nacional de Cancerología, SS

Ciudad de México, Méx.

Mtra. en Psic. Edith Rojas Castillo

Instituto Nacional de Cancerología, SS

Ciudad de México, Méx.

Lic. T. F. Isabelle Aloi-Timeus Salvato (rehabilitación)

Fisioterapeuta

Centro Médico ABC

Ciudad de México, Méx.

Dra. Verónica Cedillo Compeán

Fisioterapeuta

Instituto Nacional de Cancerología, SS

Ciudad de México, Méx.

Lic. T.F. Mabelid Mabiani Céspedes

Fisioterapeuta

Fundación Salvati A.C.

Ciudad de México, Méx.

Mtra. Sofía Saba Cohen

Fisioterapeuta

Centro Médico ABC

Ciudad de México, Méx. 